


\section{Dirección Editorial:}

Consejo de Redacción:

Secretario de Edición:

Revisores en esta edición:

Webmaster GEIIC:

Dieño página web:

Maquetación:

Traducción:

Foto portada:
Rocío Bruquetas Galán y Ana Calvo Manuel

María Aguiar, Emilio Cano Ruiz, Emma García Alonso, Marisa Gómez González, Ana Laborde Marqueze, Emilio Ruiz de Arcaute Martínez, Margarita San Andrés Moya, Sandra Zetina Ocaña.

Christhiam Fiorentino Vásquez

Isabel Argerich Fernández, Maite Barrio Olano, Ana Carrasson-López de Letona, José Manuel de la Roja de la Roja, Silvia García Fernández-Villa, Sara González Cambeiro, María Isabel Herráez Martín, Juan Antonio Herráez Ferreiro, Pilar Ineba Tamarit, Domingo Marquina, María Teresa Martínez Lopéz, Silvia Montero Redondo, María Antonia Moreno Cifuentes, Anna Nualart Torroja, Guadalupe Pinar, Sonia Santos Goméz, Ana Schoebel Orbea, Gabriela Siracusano, Carmén Vega Martín.

Emma García Alonso

Pepe Nieto PEZRED

Christhiam Fiorentino Vásquez

María Aguiar

Detalle de la obra pictórica Albacín (1962), del pintor José Guerrero.

@2013, Colección del Centro José Guerrero. www.centroguerrero.org

ISSN: 1989-8568

Está publicación utiliza una licencia Creative Commons

Se permite compartir, copiar, distribuir y comunicar públicamente la obra con el reconocimiento expreso de su autoría y procedencia. No se permite un uso comercial de la obra original ni la generación de obras derivadas.

Esta revista utiliza Open Journal Systems, software libre de gestión y publicación de revistas desarrollado, soportado y libremente distribuido por el Public Knowledge Project bajo Licencia Pública General GNU.

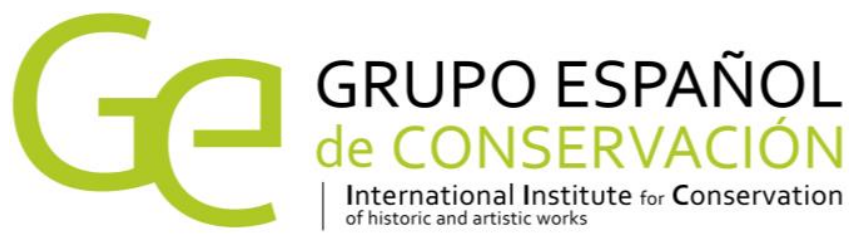

Ge-conservación no se responsabiliza de la información contenida en los artículos ni se identifica necesariamente con ellas.

๑ La propiedad intelectual de los artículos pertenece a los autores y los derechos de edición y publicación de este número son de Ge-conservación. Rogamos que en la difusión libre de los contenidos queden patentes los créditos de los autores y la procedencia.

El Grupo Español de Conservación es una asociación independiente afiliada a The International Institute for Conservation of Historic and Artistic Works, inscrita en el Registro Nacional de Asociaciones, Sección 1a, № 160.299. Sede: I.P.C.E. C/Greco, 428040 Madrid. Asociación Declarada de Utilidad Pública por Orden del Ministerio del Interior 3404/2009 (BOE 18-12-2009).

\section{Ge-conservación}

www.revista.ge-iic.com

E-mail: revista@ge-iic.org www.ge-iic.com

E-mail: administracion@ge-iic.org

Revista indexada en:

e-revist@s

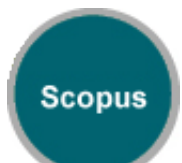

Universidad

Complutense Biblioteca Complutense

Madrid Catálogo Cisne UCM

Base de datos




\section{Editorial}

En cumplimiento de los objetivos propuestos, hemos conseguido aumentar el ritmo de nuestra publicación Ge-conservación, en 2013, con la publicación de dos números, pasando de ser anual a semestral. Hemos podido, pues, de esta manera agilizar los procesos de revisión y edición de artículos, y continuar mejorando las propuestas científicas. Con estos mismos propósitos hemos ampliado el Consejo Editorial incorporando a dos nuevos miembros, Sandra Zetina y Emilio Cano, ambos colaboradores científicos de la revista desde sus inicios. Zetina, conservadora-restauradora, desarrolla su labor investigadora en estudios técnicos de la pintura desde el Laboratorio de Diagnóstico de Obras de Arte de la Universidad Nacional Autónoma de México. Cano, también conservador-restaurador, está especializado en la conservación de metales y trabaja como investigador en el Centro Nacional de Investigaciones Metalúrgicas (CENIM).

La ampliación del Consejo Editorial coincide, sin embargo, con la marcha de uno de nuestros principales colaboradores, Christhiam Fiorentino, quien se ha estado encargando del trabajo de gestión editorial desde que se puso en marcha este proyecto. El cambio no significa un alejamiento sino un nuevo tipo de colaboración, por lo que no caben despedidas. En su lugar iniciará su andadura como nueva secretaría de edición Concepción de Frutos, a la que damos nuestra más calurosa bienvenida.

La demanda de la revista, tanto para publicar como para la descarga de artículos, ha seguido incrementándose día a día, lo que viene a confirmar su destacada posición entre los medios de difusión e investigación dedicados a la conservación del Patrimonio Cultural. Ello se traduce en una variada presencia de temas y espacios tratados, como se manifiesta en el número que ahora se publica. Entre las firmas invitadas contamos esta vez con la de Vasco Fassina, presidente de CEN/TC346, del European
No cumprimento dos objetivos propostos, conseguimos aumentar o ritmo da nossa publicação Ge-conservación, em 2103, com a edição de dois números, passando de anual a semestral. Podemos, desta maneira, agilizar os processos de revisão e edição de artigos e continuar a melhorar as propostas científicas. Com estes mesmos propósitos, ampliamos o Conselho Editorial incorporando dois novos membros, Sandra Zetina e Emílio Cano, ambos colaboradores científicos da revista, desde o seu início. Zetina, conservadorarestauradora, desenvolve a sua ação investigadora em estudos técnicos sobre pintura a partir do Laboratório de diagnóstico de Obras de Arte da Universidade Nacional Autónoma do México. Cano, também conservador-restaurador, é especialista em conservação de metais e trabalha como investigador no Centro Nacional de Investigações Metalúrgicas (CENIM).

A ampliação do Conselho Editorial coincide, no entanto, com a saída de um dos nossos principais colaboradores, Christhiam Fiorentino, que estava encarregue do trabalho de gestão editorial desde que este projeto começou. A mudança não significa um afastamento mas antes um novo tipo de colaboração, pelo que não cabem despedidas. No seu lugar, iniciará a caminhada como nova secretária de edição, Concepción de Frutos, a quem damos as nossas mais calorosas boa vindas.

A procura pela revista, tanto para publicar como para descarregar artigos, tem vindo a crescer de dia para dia, o que vem confirmar a sua destacada posição entre os meios de difusão e de investigação dedicados à conservação do Património Cultural. Ela traduz-se numa variada presença de temas e espaços tratados, como a manifestada no número que agora se publica. Entre os autores convidados contamos, desta vez, com 
Committee for Standarization, quien nos ha brindado un artículo sobre la normalización europea en el campo del Patrimonio Cultural. Asimismo, Isabel M. García Fernández, profesora de la Facultad de Bellas Artes de la Universidad Complutense de Madrid y especialista en conservación preventiva, publica la primera parte de un interesante texto sobre la historia de esta disciplina.

Como en los anteriores números, también en este ofrecemos una entrevista con una persona destacada en la conservación del patrimonio cultural desde perspectivas muy diversas. En esta ocasión se la hemos dedicado a Arsenio Sánchez Hernampérez, conservador-restaurador de la Biblioteca Nacional de Madrid, recientemente galardonado con el Premio Nacional de Restauración y Conservación de Bienes Culturales. El premio le ha sido concedido por el Ministerio de Educación, Cultura y Deporte en reconocimiento a su trayectoria en el ámbito de la conservación del patrimonio cultural, una trayectoria que, en palabras del jurado y que compartimos plenamente, ha hecho evolucionar la disciplina «hacia un nuevo paradigma científico y ético» que sirve de modelo entre profesionales de la conservación y restauración y de los archivos y bibliotecas. Aprovechamos esta oportunidad para felicitar también a los galardonados en la categoría de mejor proyecto, Juan Carlos Pérez Ferrer y Jesús Serrano Rodríguez, por la excelente calidad del trabajo de conservación realizado en el Oratorio de San Felipe Neri de Cádiz.

El resto de los artículos, sometidos a evaluación anónima por pares, abordan diferentes cuestiones directamente relacionados con la práctica y la teoría de la conservación y restauración. Desde una visión historiográfica de la Conservación del Patrimonio Cultural, como el artículo de María Dolores Ruiz de Lacanal sobre la aportación en este campo del insigne erudito andaluz del siglo XIX y principios del XX, José Gestoso y Pérez, a otros trabajos de investigación orientados a diferentes campos de especialización, como la tecnología de los Rayos $\mathrm{X}$ aplicada a las obras de gran formato (José Antonio Madrid García), la conservación preventiva en exposiciones (María del Carmen
Vasco Fassina, presidente de CEN/TC346, da European Committee for Standarization, que nos brindou com um artigo sobre a normalização europeia no campo do Património Cultural. Também, Isabel $M$. García Fernández, professora da Faculdade de Belas Artes da Universidade Complutense de Madrid e especialista em conservação preventiva, publica a primeira parte de um interessante texto sobre a história desta disciplina.

Tal como nos números anteriores, também neste oferecemos uma entrevista a uma pessoa destacada em conservação do património cultural com perspectivas muito diversas. Nesta ocasião, dedicamo-la a Arsenio Sánchez Hernampérez, conservadorrestaurador da Biblioteca Nacional de Madrid, recentemente galardoado com o Prémio Nacional de Restauración y Conservación de Bienes Culturales. O prémio foi-lhe concedido pelo Ministério da Educação, Cultura e Desporto em reconhecimento da sua trajectória no âmbito da conservação do património cultural, trajectória que, na palavras do júri e que compartilhamos plenamente, fez evoluir a disciplina «para um novo paradigma científico e ético» que serve de modelo entre os profissionais da conservação e restauro e dos arquivos e bibliotecas. Aproveitamos esta oportunidade para felicitar, também, os galardoados na categoria de melhor projeto, Juan Carlos Pérez Ferrer e Jesús Serrano Rodríguez, pela excelente qualidade de trabalho de conservação realizado no Oratório S. Filipe Néri de Cádiz.

Os restantes artigos, submetidos a avaliação anónima por pares, abordam diferentes questões diretamente relacionadas com a prática e teoria da conservação e restauro. Desde uma visão historiográfica da Conservação do Património Cultural, como o artigo de María Dolores Ruiz de Lacanal sobre o contributo neste campo do insigne e erudito andaluz do século XIX e princípios do século XX, José Gestoso y Pérez, a outros trabalhos de investigação dedicados a diferentes áreas de especialização, como a 
Bellido-Márquez), los sistemas de reintegración cromática (Ana Bailão) o la puesta a punto de metodologías para el estudio de policromías escultóricas (Beatriz Prado Campos), para terminar, finalmente, con un artículo de Blanca Flor Herrero Morán en el que reflexiona sobre la conservación del patrimonio etnográfico a través de la musealización.

Por último, se aportan algunas reseñas de publicaciones, como es habitual ya en nuestra revista. tecnologia de raios-x aplicada a obras de grande formato (José Antonio Madrid García), a conservação preventiva em exposições (María Carmen Bellido-Márquez), os sistemas de reintegração cromática (Ana Bailão), ou a proposta de metodologias para o estudo de policromias escultóricas (Beatriz Prado Campos), para, finalmente, terminar com um artigo de Blanca Flor Herrero Morán, em que reflete sobre a conservação do património etnográfico através da musealização.

Por último, apresentam-se algumas recensões de publicações, como já é habitual na nossa revista.

Ana Calvo y Rocío Bruquetas

Directoras de Ge-conservación 


\section{Índice}

Firmas invitadas y entrevista

Páginas

The activity of CEN TC 346-Conservation of Cultural Heritage

Vasco Fassina

Historia de la conservación preventiva. Parte I

Isabel M. García Fernández

Por Rocío Bruquetas Galán y Charo Fernández

\section{Artículos}

José Gestoso y Pérez.Teoría y Praxis de la Conservación

$M^{a}$ Dolores Ruiz de Lacanal

Método para el estudio de los motivos polícromos

Beatriz Prado Campos

Conservación preventiva y temperatura de superficie en obras pictóricas en exposición

María del Carmen Bellido-Márquez

Use of telemetry X-ray techniques in large-size pictorial works

Jose Antonio Madrid Garcia

O sistema das nove cores na reintegração cromática de bens culturais Ana Bailão

La conservación del patrimonio etnográfico a través de la musealización

Blanca Flor Herrero Morán

\section{Reseñas de publicaciones}

Scientific Research on Ancient Asian Metallurgy. Proceedings of the Fifth Forbes Symposium at the

Freer Gallery of Art

Reseña de Marisa Gómez González

El Retablo de la Coronación de la Virgen. Parroquia de la Asunción de Errentería

Reseña de Marisa Gómez González

Blue Pigments. 5000 years of Art and Industry

Reseña de Rocío Bruquetas Galán 
Firmas Invitadas y Entrevista 


\title{
The activity of CEN TC 346-Conservation of Cultural Heritage
}

\author{
Vasco Fassina
}

\begin{abstract}
A specific European standardisation activity in the field of conservation of cultural heritage is essential to acquire a common unified scientific approach to the problems relevant to the preservation and conservation of the cultural property. The scope of CEN TC 346 is to establish standards in the field of the processes, practices, methodologies and documentation of conservation of tangible cultural heritage to support its preservation, protection and maintenance and to enhance its significance. This includes standardisation on the characterisation of deterioration processes and environmental conditions for cultural heritage and the products and technologies used for the planning and execution of conservation, restoration, repair and maintenance. Up to now sixteen EN standards were published according to a matrixbased method in which three main topics have been developed. First is dealing with general guidelines and methodology. Second topic is regarding Evaluation of methods and products for conservation works. The work was focused on a general draft "Surface protection for porous inorganic materials-laboratory test methods for the evaluation of the performance of water repellent products". The evaluation is based on the measurements of different parameters appropriate to assess the performance of the product using standardized and reproducible methods. Third topic is regarding Indoor/outdoor climate-Specifications and measurement. The purpose of the work was to develop standards and recommendations relating specifically to the climate and its influence on the preservation of heritage. Standards developed will assist professionals involved in environmental diagnostics and in the investigation and control of the climate for preventive conservation and maintenance. The assistance includes the choice of methodologies and instruments and the interpretation of results.
\end{abstract}

Key Word: Cultural Heritage \& Standardization, Terminology.

\section{La actividad del CEN TC 346-Conservación del Patrimonio Cultural}

Resumen: Es esencial una actividad específica de normalización europea en el campo de la conservación del patrimonio cultural para adquirir un enfoque científico unificado y común de los problemas relacionados con la preservación y conservación de los bienes culturales. El fin del CEN TC 346 es establecer normas en el campo de los procesos, prácticas, metodologías y documentación de la conservación del patrimonio cultural tangible para apoyar su conservación, protección y mantenimiento y realzar su significado. Esto incluye la estandarización de la caracterización de los procesos de deterioro y las condiciones ambientales del patrimonio cultural y los productos y tecnologías que se utilizan para la planificación y ejecución de su conservación, restauración, reparación y mantenimiento. Hasta ahora se han publicado dieciséis normas EN de acuerdo con un método basado en una matriz, en la que se han desarrollado tres temas principales. El primero se refiere a las directrices generales y la metodología. Elsegundo tema aborda la Evaluación de métodos y productos para conservación de las obras. El trabajo se centró en un un esbozo general, "Protección de la superficie de materiales inorgánicos porosos - tests de laboratorio para la evalucación de la eficacia de los productos repelentes al agua". La evaluación está basada en mediciones de diferentes parámetros apropiados para verificar la eficiencia del producto mediante métodos normalizados y reproducibles. El tercer tema trata sobre las condiciones ambientales interior/ exterior-Especificaciones y medición. El propósito del trabajo fue desarrollar normas y recomendaciones relacionadas específicamente con el clima y su influencia en la conservación del patrimonio. Las normas desarrolladas auxiliarán a profesionales responsables del diagnóstico ambiental y en la investigación y el control del clima para la conservación preventiva y el mantenimiento. El apoyo incluye una selección de metodologías e instrumentos y la interpretación de los resultados.

Palabra Clave: Patrimonio Cultural y Normalización, Terminología. 


\section{A atividade do CEN TC 346-Conservação do Património Cultural}

Resumo: É essencial uma ação específica de estandardização europeia na área da conservação do património cultural para conseguir uma abordagem científica comum e unificada dos problemas relevantes da preservação e conservação desse património. O objetivo do CEN TC 346 é estabelecer standards nos processos, práticas, metodologias e na documentação da conservação do património cultural tangível, de modo a garantir a sua preservação, proteção, manutenção e a realçar o seu significado. Isto inclui a estandardização da caracterização dos processos de deterioração e das condições ambientais para o património cultural e dos produtos e tecnologias usados no planeamento e na execução das ações de conservação, restauro, reparação e de manutenção. Até agora, 16 NE normas foram publicadas de acordo com um método baseado numa matriz, na qual, três grandes tópicos foram desenvolvidos. O primeiro referese a diretrizes e metodologias gerais. O segundo tópico aborda a Avaliação de métodos e produtos usados em operações de conservação. O trabalho esteve focado num esboço geral, "Proteção da superfície de materiais inorgânicos porosos - testes laboratoriais para a avaliação da eficácia dos produtos repelentes á água". A avaliação é baseada em medições de diferentes parâmetros apropriados para verificar a eficiência do produto segundo métodos standard e reprodutíveis. O terceiro tópico abrange, Condições ambientais de interior e de exterior - Especificações e medições. O objetivo do trabalho é desenvolver standards e recomendações relacionadas, especificamente, com as condições ambientais e a sua influência na preservação do património. As normas desenvolvidas irão auxiliar os profissionais responsáveis pelo diagnóstico ambiental, pela investigação e pelo controle do clima em conservação preventiva e em manutenção. $\mathrm{O}$ apoio inclui a seleção de metodologias, de instrumentos e a interpretação de resultados.

Palavras-chave: Património Cultural \& Terminologia estandardizada.

\section{Introduction}

The foremost aim of European standardization is to facilitate the exchange of goods and services through the elimination of technical barriers to trade.

The use of standards by industry and the social and economic partners is always voluntary; however, European standards are sometimes related to European legislation (Directives), and conformity to such standards may constitute a presumption of conformity to the legal requirements of the Directives.

CEN (European Committee for Standardization) is responsible for the planning, development and adoption of European standards. It is a legal association, the members of which are the National Standards Bodies (NSBs) of thirty European countries and seven Associates (organizations representing social and economic interests at European level), supported by a CEN Management Center based in Brussels. It is the European counterpart of ISO (International Organization for Standardization) with which it has a standing protocol (the Vienna Agreement) to facilitate technical co-operation. The principal deliverable of CEN is the European standard (EN), which must be published by each of NSBs as an identical national standard, with any per-existing national standards in conflict being withdrawn.

Standard is a document available to the public, drawn up with the cooperation and consensus or general approval of all interested parties affected by it, based on the consolidated results of science, technology and experience, aimed at the promotion of optimum community benefits and approved by a recognized standardizing body on the national, regional, or international level for repeated or continuous application, with which compliance is not mandatory. 
CEN and its Technical Committees are also able to offer the Technical Specification (CEN/TS) and the Technical Report (CEN/TR) as solutions to market needs.

\section{Need for EU standards}

A specific European standardization activity in the field of conservation of cultural heritage is essential to acquire a common unified scientific approach to the problems relevant to the preservation and conservation of the cultural property.

A scientific approach is essential for the conservation of the cultural heritage, as a preliminary basis that will ensure effective planning of ordinary and extraordinary maintenance works, as well to assure their efficacy and durability.

Only thanks to a sound scientific knowledge of the materials constituting the cultural property, of its environmental and conservation conditions, these conservation/restoration works can be successfully carried out.

Unfortunately the great experience developed in this field by the different European countries, for the time being can not constitute a common background because there are too many differences not only in the methods of analysis, but also in the terminology used.

Moreover, this common approach and the use of standardized methodologies and procedures would promote the exchange of information, would avoid the risk of duplication and foster synergy between the European experts and specialists involved in the preservation activity.

In 2001 UNI, the Italian Standard Body presented a request to CEN to create a new TC (Technical Committee) dealing with the conservation of cultural property.

\section{Business environment of CEN TC 346}

The standardization activities proposed by the CEN/TC 346 are strictly related with the decisions taken by the European Council relevant to the development of cultural programmes and to the conservation and safeguarding of cultural heritage, encouraging the co-operation at European and International level:

"The Community cultural programmes aim to encourage co-operation between Member States and third countries for the improvement of the knowledge and dissemination of European culture and history, as well as in the conservation and safeguarding of cultural heritage and artistic and literary creation (Document Reference: COM (98) 239; Document Date: 1998-04-27)".

"The Treaty on European Union introduced a specific legal base for culture bringing cultural activities into the field of Community activities and policies. Article 128, paragraph 4, states that "the Community shall take cultural aspects into account in its action under other provisions of this Treaty". The present document contains the first report on the consideration of cultural aspects in Community actions under this Article 128, paragraph 4 (Document Reference: COM(96) 160; Document Date:1996-04-17)".

"Article 128 of the Treaty identifies Cultural Heritage as a priority field of action (includes both movable and immovable heritage) through conservation and safeguarding of Cultural Heritage of European significance taking Cultural Heritage into account in regional development and job creation; tourism 
and environment; research (Community Action Plan in the Field of Cultural Heritage. Council Decision O.J. 94/C 235/01). (European Spatial Development Perspective, 10 May 1999, 2002-12-20 Page 7".

There are also the Recommendations contained in the STOA (Scientific and Technological Options Assessment) Report "Technological requirements for solutions in the conservation and protection of historic monuments and archaeological remains", which was prepared for the European Parliament, Directorate-General for Research, October 2001. Section 4 recommends the urgent need for a "European Panel on the application of science to Cultural Heritage", to provide vision, guidance and guidelines for 'best practice' at a European level, such as scientifically-based protocols for validating conservation work on monuments and archaeological remains".

Between 1986 and 2007 the European Commission spent more than 120 million Euros to improve the scientific knowledge in conservation of Cultural Heritage and at the end of 2006 a new cultural heritage research programme was launched within the 7th Framework Programme. The number of European Universities, Research and Governmental Institutions contributing basic and innovative research has increased exponentially in these two decades.

With the aim of reinforcing knowledge and decision processes regarding cultural heritage, research programmes that improve intervention methods have been funded in many European countries. When relevant, it is important that this information is used as a contribution for the preparation of European standards.

\section{Scope of CEN TC 346}

The main objective of CEN/TC 346 is drafting European standards which will help conservation professionals in their conservation and restoration work. It will also ensure that European experts can exchange information on test and analysis methods for the conservation of cultural heritage. This standardization activity will harmonize and unify methodologies in the European area. The initial scope of CEN/TC 346, as approved in 2002, was the standardization in the field of definitions and terminology, methods of testing and analysis, to support the characterization of materials and deterioration processes of movable and immovable heritage, and the products and technologies used for the planning and execution of their conservation, restoration, repair and maintenance.

In particular, the standardization activity on the conservation of Cultural Heritage deals with: terminology relevant to movable and immovable cultural property, and to the conservation of the cultural property and of the material constituting the cultural property themselves, so that a common European terminology can be created;

-guidelines for a methodological approach to the knowledge of the cultural property and of the materials constituting the cultural property, of the deterioration processes, and of conditions of optimum long-term conservation/preservation work;

-test and analysis methods for the diagnosis and for the characterization of the cultural property and of their state of conservation with regards to outdoor and indoor environmental parameters;

-test and analysis methods (in laboratory and in-situ) for the evaluation of the performance of the products and methodologies to be used in the conservation work (ordinary and/or extraordinary maintenance); 
-test and analysis methods for the evaluation of conservation conditions of indoor Cultural Heritage. In particular, standardization on transportation and packaging methods, shall take in due accounts the needs and problems related to itinerant exhibitions and exchanges of works of art, in the permanent presentation conditions in museums, galleries, libraries and archives, in temporary exhibit galleries, in stores and in transport packaging.

This standardization activity will be a useful and valuable occasion to compare, for specific items, different results coming from various European institutions or laboratories. To realize the above work programme five working groups were established as reported in fig. 1.

\section{Benefits expected from the work of CEN TC 346}

Standardization in the field of conservation of cultural property will:

-improve methodology, protocols, guidelines to allow implementations of better practices or define equipment for preservation and conservation;

-improve the efficiency and pertinence of the diagnosis with a subsequent better management of funding for the conservation/restoration works and therefore increasing the number of conservation projects and spin-off economic benefits/opportunities for new investment, and consequent job creation;

-give precise and appropriate indication on the kind of diagnosis studies to be performed, promoting in this way conservation works on an increasing number of artifacts;

-increase longevity and reduce maintenance costs of conservation works, therefore reducing costs in the on a long-term range because conservation operations will be needed less frequently over time spaced out;

-facilitate professional mobility and international trade and increase the employment opportunities especially for young conservators, restorers, technicians etc...

-facilitate the exchanges between interested parties in Europe, respecting cultural identities, through the use of a common vocabulary;

\section{Users of the standards}

This standardization is addressed to all parties concerned with the individual subjects covered by the standards including public and government bodies (e.g. Ministry of Culture and Education, Government Agencies); public national and international non-government organizations-NO (e.g. ICCROM, ICOMOS, IIC, ICOM); regional provincial local administrations; restoration schools; ecclesiastical bodies/organizations; stakeholders; public and private analysis laboratories; restoration companies; professionals in the field of conservation and exhibitions planning; distributors and manufacturers of materials used in restoration; companies specializing in the preparation and organization of exhibitions; transportation and packaging companies; lighting installation companies, air conditioning and heating installation companies, informatics and advanced technology companies; cultural institutions and users of cultural heritage: museums, galleries, libraries, archives; architecture and surveyors; peer groups such as architects, custodians, archaeologists, engineers, planners, conservators-restorers, craftsmen, conservation scientists, energy advisers, transport and insurance companies 


\section{Updating of CEN TC 346 activity}

The focus of all the CEN/TC 346 standards is on the tangible cultural heritage. However, every cultural thing has intangible aspects. Conservation of the tangible, when properly carried out, respects the intangible.

The activity was initially developed according to a "matrix-based method" which is a theoretical approach perfect in establishing the most urgent standards.

Up to now seventeen EN standards were published according to a matrix-based method in which three main topics have been developed.

First is dealing with general guideline, terminology and characterization of materials constituting cultural property. The following four drafts were published

-EN 15898:2011-Main general terms and definitions. This document defines the main general terms used in the field of conservation of cultural property with particular attention to those terms which have wide use or significance.

It provides terms and their definitions for a set of general concepts which are widely used by those working in the field of conservation of tangible cultural heritage. Its purpose is to bring greater understanding and encourage collaboration amongst those who have responsibility for or an interest in cultural heritage. The need for such agreement and clarification in the use of conservation words has become increasingly recognized in recent years. The definition of the terms here will also help to ensure consistent use of words and concepts within the other CEN/TC 346 conservation standards which define only those terms specific to each individual standard.

The definitions of four terms presented in the draft ('conservation', 'preventive conservation', 'remedial conservation', 'restoration') were developed in parallel with those of ICOM-CC and so have considerable commonality, but they are not identical.

The arrangement of terms reflects the ways in which most heritage professionals approach the conservation of cultural heritage. At its root is consideration of what is to be conserved, its significance and its condition.

Terms and definitions are grouped according to the following clauses:

- Cultural heritage terms

- Condition terms

- Conservation terms

- Preventive conservation terms

- Remedial conservation terms

- Planning and documentation terms

-EN 16095:2012- Condition recording for movable heritage. This standard sets out the purpose and context of condition recording for movable cultural heritage and a framework for a condition report. It specifies the status of a condition report and its essential contents. This standard applies 
to all kinds of movable cultural heritage, whether individual objects or whole collections. It can also be used for immovable features in buildings or monuments.

The purpose of making a condition report is to record the condition of cultural heritage following an inspection and assessment. The contents of a condition report can provide not only technical data but also knowledge and understanding about an object or collection, information produced by monitoring its change over time and information that will assist with future planning. Changes in the condition of cultural heritage may diminish its significance and reduce its potential benefits to present and future generations.

Condition reports on cultural heritage are performed by experienced professionals who have received specific training in this activity, particularly conservator-restorers. The quality and usefulness of a condition report depends upon the knowledge and skill of its author or authors. Sound knowledge of the materials comprising the cultural heritage, of the processes that led to their creation and deterioration, and experience in examining such cultural heritage are all required to draft a competent condition report. The author of a report should be aware of the limitations of his/her own knowledge and expertise, and appreciate the risks of going beyond these.

-EN 16096:2012- Condition survey and report of built cultural heritage. This Standard gives guidelines for a condition survey of built cultural heritage. It states how the condition of the built cultural heritage should be registered, examined, documented and reported on. It encompasses evaluation of the condition of a building or other structure mainly by visual observation, together when necessary - with simple measurements. The relevant data and documentation on the built cultural heritage should be collected and included in the report. This standard can be applied to all built cultural heritage such as buildings, ruins, bridges and other standing structures. It comprises both protected and other historic buildings in general. Archaeological sites and cultural landscapes are not dealt with in this standard.

This standard does not specify how to carry out a diagnosis of the built cultural heritage. For listed/protected immovable heritage specific national rules for expert documentation and works may apply: This standard may be applied to:

a) identify maintenance measures and the need for further investigation and diagnostics of damage;

b) defining procurement needs and the requirement for detailed specification;

c) providing a unified method to obtain comparative data, when carrying out a condition survey for a group of buildings or a region.

-EN 16085:2012- Methodology for sampling from materials of cultural property-general rules. This standard provides a methodology and criteria for sampling cultural property materials for their scientific investigation. It covers, for example, how to characterize the material(s), assess the condition, determine the deterioration causes and/or mechanism(s) and decide on and/or evaluate the conservation treatment(s). Apart from sampling, this document also provides requirements for documentation, and handling of sample(s). This standard does not deal with the decision making process for taking a sample nor how the sample is to be used. Sampling requires people with manual skill and knowledge of the cultural property. 
This is a general standard for sampling of materials constituting cultural property in order to characterize them during all stages of conservation. The sampling procedure depends on the type and condition of the material to be sampled, the specific case under study and the type of investigation chosen. Sampling is invasive and invariably causes damage, however small. It should only be undertaken if there is strong justification for it and in the closest consultation with those having responsibility for the object and those who will be studying the samples. The consultation should consider whether the same information could be obtained by non-invasive methods.

Second topic is regarding evaluation of methods and products for conservation works. The work was focused on a general draft

pr En 16581 "Surface protection for porous inorganic materials-laboratory test methods for the evaluation of the performance of water repellent products". This standard specifies the methodology for laboratory evaluation of the performance of water repellent products on porous inorganic materials. It is based on the measurement of several parameters which assess the performance of the product using standard test methods before and after aging.

The main goal of a water repellent is to reduce the penetration of liquid water and soluble substances into porous materials by changing its surface properties through capillary action. A water repellent product when applied to the surface of a material decreases its surface tension and prevents wetting of the surface.

Many deterioration mechanisms result from the presence of water and therefore the reduction of water absorption may positively influence the preservation of porous inorganic materials.

A water repellent should fulfill the following requirements:

- to reduce the absorption of liquid water in the material,

- to minimize change of water vapour permeability,

- to minimize change in colour and gloss of the substrate,

- to produce no harmful by-products after the application,

- to have a good chemical stability.

Water repellent products should be applied on the surface of heritage objects only after they have been tested on representative samples of porous inorganic materials in the laboratory. This standard for the evaluation of water repellent treatments is based on the measurement of appropriate parameters to assess the performance of the product using standardized and reproducible test methods.

In order to evaluate the durability and in service performance of a water repellent product applied on the substrate, aging tests representing the environment in which the porous inorganic material is located must be carried out.

The following six standards applied to porous inorganic materials either untreated or subjected to any treatment or aging have been already published:

-EN 15801:2010 - Determination of water absorption by capillarity

-EN 15802:2010 - Determination of static contact angle 
-EN 15803:2010-Determination of water vapour permeability $(\delta p)$

-EN 15886:2010-Colour measurement of surfaces

-EN 16302:2013 - Measurement of water absorption by pipe method

-EN 16322:2013 - Determination of drying properties.

-EN 15801:2010. This standard specifies a method for determining the water absorption by capillarity. The water absorption experiment provides information about the material's transport properties for liquid water. The draft is based on the process of water capillary rise to calculate the water absorption coefficient (AC) and to determine the amount of water absorbed (Qi) at different time. Capillarity measurements are carried out on untreated specimens and repeated after treatments and/or ageing of treated material on the same specimen and measuring the amount of absorbed water at the same time intervals.

-EN 15803: 2010. This standard specifies a method for determining the water vapour permeability (WVP). It measures the amount of water vapour passing through the specimen over time in static conditions. A flux of water vapour through the specimen occurs when the partial pressure of water vapour differs between the two opposite surfaces of the specimen.

-EN 15802:2010. This standard specifies a method for the measurement of the static contact angle of a water drop deposited on the tested surface. The draft is used to assess the degree of water-repellency of a surface. Determination of static contact angle is carried out on untreated specimens and repeated after treatments and/or aging of treated material on the same specimens. The contact angle $\theta$ of a liquid on a surface is used to estimate the wetting properties of the material by calculating its solid-liquid-vapour surface tension.

-EN 15886:2010. This standard describes a test method to measure the surface colour of porous inorganic materials, and their possible chromatic changes. No reference to the appearance of glossy surfaces is described. The measurement of the surface colour of a specimen is performed on untreated specimens and repeated after treatments and/or aging of treated material on the same specimens. When the number of readings has been determined, the measuring points for the after treatment colour measurement shall be localized by reference coordinates in order to ensure precise repetition of the measurement. A grid delimiting the measurement field may be useful for this purpose, depending on specimen size.

-EN 16302:2013. This standard specifies a method to measure the amount and rate at which water is absorbed through the test surface that is in contact with water. Measurements are carried out on untreated specimens and the measurements repeated after treatment and/or aging of treated material on the same specimens. The test is performed by measuring the volume of water absorbed through a defined surface under low pressure and within a specified time. This test can be performed in situ or in the laboratory and can be used to measure vertical and horizontal water transport. Penetration of driving rain into wall surfaces results in horizontal transport. Under actual conditions, the rate of rain penetration depends on prevailing wind conditions as well as on the composition and condition of the exposed surfaces.

-EN 16322:2013. This standard specifies a method for the determination of the drying behaviour of porous inorganic materials. The drying properties of materials can be calculated from a curve that indicates the weight loss of the mass of water inside the sample, as a function of time, during a drying experiment. Usually the drying of specimens saturated with water consists of two phases. 
The first drying phase is characterized by transport of liquid water to the surface followed by evaporation. The surface remains wet allowing evaporation at a constant rate, as water moves to the surface fast enough to compensate for the losses due to evaporation. The evaporation at the surface is determined to a large extent by the test boundary conditions. These are temperature, relative humidity and the flow velocity of the ambient air. The slope of the drying curve during the first drying phase therefore reflects these conditions. The second drying phase starts when the amount of water brought to the surface becomes too small to keep the surface wetted and the rate of evaporation decreases. Transport of liquid water to the surface is no longer possible and only the less efficient vapour diffusion mechanism remains available.

Some materials, e.g. adobe or sandstones containing clay, do not dry in this typical two-phase drying curve. For example, in the case of material treated with water repellent, the first drying phase does not exist.

Third topic is regarding Indoor/outdoor climate-Specifications and measurement. The purpose of the work was to develop standards and recommendations relating specifically to the climate and its influence on the preservation of heritage. Standards developed will assist professionals involved in environmental diagnostics and in the investigation and control of the climate for preventive conservation and maintenance. The assistance includes the choice of methodologies and instruments and the interpretation of results.

The following six standards, intended for use in the study of environments for cultural property. have been already published:

EN 15757:2010. Specifications for temperature and relative humidity to limit climate-induced mechanical damage in organic hygroscopic materials. This standard is a guide to specifying the control of temperature and relative humidity levels to limit climate-induced physical damage of organic hygroscopic materials, in indoor environments of museums, galleries, storage areas, archives, libraries, churches and modern or historic buildings. This class of objects comprises wooden items and structural elements such as floors, doors, panelling and roof timbers, paintings, books, organs, textiles, objects made of bone, ivory or leather. Objects can consist of several hygroscopic materials and different kinds of materials can share one space. They are vulnerable to changes and fluctuations in ambient $\mathrm{RH}$ that produce changes in equilibrium moisture content (EMC) in the materials as they absorb and release moisture to adapt to the continually changing environmental conditions. The variations in EMC produce dimensional changes of the materials which may lead to high levels of stress and physical damage as fracture and deformation. Given the extreme complexity of the response of materials constituting cultural properties to variations of temperature and $\mathrm{RH}$, this standard proposes a methodology for arriving at general specifications to limit climate-induced physical damage of organic hygroscopic materials.

-EN 15758:2010. Procedures and instruments for measuring temperatures of the air and the surfaces of objects. This guidance recommends the procedures for measuring temperatures of the air and the surfaces of cultural property in indoor and outdoor environments as well as specifies the minimum characteristics of instruments for such measurements. The document contains recommendations for accurate measurements which ensure at the same time the safety of objects and is addressed to any people in charge of environmental diagnostic, conservation, restoration or maintenance of buildings, collections, or single objects. The temperature of the air and the temperature of the object surfaces constitute important aspects of that environment. Temperature can have a profound effect on the preservation of objects. Physical characteristics of materials 
change as they absorb or release heat. Objects expand and contract as the temperature changes, become rigid and brittle if the temperature falls below the glass transition temperature, or are mechanically damaged by the melting and freezing of water in the outdoor environment. The rates of some important chemical reactions, such as the degradation of cellulose (paper, textiles) increase with rising temperature. Temperature influences the activity of fungi and insects responsible for the bio deterioration of organic materials. Temperature may affect some minerals and masonry crystallization. Temperature has also an important indirect effect: a rise in temperature causes lowering of the relative humidity, which results in drying moisture absorbing materials like wood, paper or leather. Such drying may lead to shrinkage and embrittlement.

-EN 15759-1:2012. Indoor climate - Part 1: Guidelines for heating churches, chapels and other places of worship. The objective of this draft is to provide guidelines for the selection of heating strategies and heating systems in churches, chapels and other places of worship such as mosques and synagogues, in order to prevent damage to cultural property while at the same time creating an indoor climate that allows for a sustainable use of these buildings. It applies to most kinds of places of worship regardless of size and construction. This standard applies not only to the introduction of new heating systems but also to the replacement of old ones.

This standard applies to buildings that are part of cultural heritage or that house cultural heritage objects. The standard deals with indoor climate conditions, heating strategies and technical solutions for their implementation but not with the technical equipment itself. Churches, chapels and other places of worship such as mosques and synagogues (referred collectively in the text of this standard as "places of worship") are an important part of the European cultural heritage. The buildings and their interiors, containing cultural heritage objects, are documents of our heritage that society agrees need to be preserved for present and future generations. The indoor climate is a critical factor in conserving the fabric of buildings and the objects they house. An inappropriate indoor climate may result in material damage.

This standard is motivated by the need to reflect the special characteristics of places of worship, conditions which are not addressed in standards for the heating of other kinds of buildings. The defining characteristics of these buildings are their construction (often early building techniques); the fact that they were not designed as living or working spaces; their intermittent use; and the vulnerability of their surface decoration and contents.

-EN 16242:2012- Procedures and instruments for measuring humidity in the air and moisture exchanges between air and cultural property. This standard gives guidance and specifies procedures and instruments for the measurement of relative humidity $(R H)$ in air in outdoor or indoor environments. It indicates how RH can be directly measured or how it can be calculated from air temperature, wet-bulb temperature and dew-point temperature. This standard contains recommendations for accurate measurements of ambient conditions and moisture exchanges between air and cultural heritage objects. It is addressed to anyone in charge of environmental diagnosis, conservation or maintenance of buildings, collections or single objects.

Humidity plays a key role in the conservation of cultural heritage because most materials and/or deterioration mechanisms are directly or indirectly affected by humidity levels or changes. This standard is a guide intended to assist in providing an acceptable environment to cultural heritage objects. Humidity in air, expressed in a number of ways, is an important aspect of that environment. 
Therefore, the control of levels and variability of humidity reduces the risk of deterioration and is an important preventive measure, minimizing the need for future conservation interventions.

-EN 16141:2013- Guidelines for management of environmental conditions-Open storage facilities: definitions and characteristics of collection centers dedicated to the preservation and management of cultural heritage. This standard defines the characteristics of specific areas dedicated to the preservation, storage, management of, and access to collections. It lists the considerations that should be taken into account to achieve optimum storage and accessibility. The importance of preserving and transmitting cultural heritage under the best conditions is imperative for all, but first and foremost for cultural heritage institutions. They have the responsibility of preserving, presenting and developing spaces dedicated to the public or reserved for the collections. Stored collections have traditionally been inaccessible to the public but increasingly there is an expectation that collections should be accessible even when not on display, either for the general viewing public or for controlled research and collection management activities. To meet this demand, dedicated facilities are being constructed that allow access and research. These "Open Storage Facilities" or "Collection Centers" place new demands on cultural heritage institutions and this guidance document is intended to assist institutions by describing common best practice in the design and function of such facilities.

-TS-16163:2013-Guidelines and procedures for choosing appropriate lighting for indoor exhibitions. This Technical Specification defines the procedures as well as the means to implement adequate lighting, with regard to the conservation policy. It takes visual, exhibition and conservation aspects into account and it also discusses the implications of the lighting design on the safeguarding of cultural property. This Technical Specification gives recommendations on values of minimum and maximum illumination levels. It aims to provide a tool for setting up a common European policy and a guide to help curators, conservators and project managers to assess the correct lighting that can assure the safeguarding of the exhibits. This Technical Specification covers lighting for heritage objects on exhibition in both public and private sites and does not consider lighting in other cultural heritage contexts such as open-air collections, etc.

Lighting is needed for many specific functions in museums and other cultural heritage buildings, for example, for research, conservation and permanent or temporary exhibitions. Enough light is needed to see well but this may present a challenge when what is being viewed will deteriorate in the presence of light. Where cultural heritage is judged to be worth preserving for future generations the controlled use of light has to be considered. Indeed, light is an environmental factor, which is a threat to many objects. Alone or in combination with other environmental factors (temperature, humidity, pollution, etc.) light causes fading, discoloration and embrittlement of a wide range of materials. This damage is cumulative and irreversible: no conservation treatment can restore change of colour or loss in strength of materials damaged by light. Therefore, the challenge of museum exhibition lighting is to find an appropriate compromise between the long term preservation of the exhibit and the needs of visitors to view them within a suitable exhibition design.

Regarding the work of WG5 which has the role to prepare standards on methods of transportation and packing of cultural heritage outside institutions especially for exhibitions the following standard was delivered.

EN 15946:2011 - Packing principles for transport. This standard specifies the packing process for objects considered by the owner/custodian as ready to be moved. This standard provides 
recommendations (the word should is used) and lists requirements (the word shall is used) for safe and secure packing of cultural property for transport. It is intended for individuals or organizations involved in the preservation of cultural property in order to reduce the risk of damage.

The standard proposes a common terminology and procedures for packing. The appropriate range of knowledge, skills and competencies is required by every party involved with packing cultural property for transport.

Seven relevant documents are at a final stage and will be published in 2014:

-prEN 16581:2014-Surface protection for porous inorganic materials-Laboratory test methods for the evaluation of the performance of water repellent products.

-pr En 16572:2014-Glossary of technical terms concerning mortars for masonry, renders and plasters used in cultural heritage.

-pr En 16455:2014-Determination of soluble salts in natural stone and related materials used in cultural heritage.

-pr En 16515:2014-Guidelines to characterize natural stone used in cultural heritage.

-pr En 15999-1:2014- Guidelines for management of environmental conditions-Recommendations for showcases used for exhibition and preservation of cultural heritage-Part I General requirements.

-pr En 16682:2014-Guide to the measurements of moisture content in materials constituting movable and immovable cultural heritage.

-pr En 16648:2014-Conservation of cultural heritage-Transport methods

\section{Objectives of CEN TC 346 as revised in the new Business Plan approved in Venice in 2012}

The work programme in force since 2004 was a matrix-based approach which has a theoretical approach perfect in establishing the most urgent standards. However, this method does not include the "feasibility". The Matrix can fail whenever no interested volunteers having the required experience are found; as opposed, it is successful whenever it optimized existing technical and human resources. In the new Business Plan it was decided to change the title from Cultural Property into Cultural Heritage and to prepare standards on a need-based approach. It was also specified the scope as following:

"standards will be established in the fields of the processes, practices, methodologies and documentation of conservation of tangible cultural heritage to support its preservation, protection, and maintenance and to enhance its significance. This includes standardization on the characterization of deterioration processes and environmental conditions for cultural heritage, and the products and technologies used for the planning and execution of its conservation, restoration, repair and maintenance."

Moreover some general principles were introduced:

"The relevance of the proposals to the work of CEN/TC 346, considering the problems or difficulties that are intended to be solved, the impacts and benefits of the standards and the urgency of their development. 
- The availability of the necessary resources, i.e.: technical resources (the subject is sufficiently developed in Europe); human resources (specific experts are available) and funding (necessary funding to be invested by the interested parties).

- The appropriate Working Groups exist or can be created, in order that each standard is developed by the appropriate specialists.

In order to prevent any overlapping with other TC or ISO committee particular attention will be paid to existing European standards or draft standards being prepared by other CEN/TCs or ISO/TCs. In these cases, the proposers are required to:

"a) State how the proposed work may relate to or impact on existing work, especially CEN deliverables;

b) List relevant existing documents;

c) Explain how the work differs from apparently similar work"

In accordance with the objective of the revised BP the working structure in five WGs established in 2004 is changed as reported in fig. 2 to cover the objectives 2012-2015 described in the new BP.

\section{Cooperation with European and International organizations}

CEN/TC 346 is open to liaisons with any other European and International cultural and professional organizations dedicated to the conservation of cultural heritage that may provide a positive contribution to standardization activity.

Many International organizations have asked to establish liaison to contribute to the standardization process offering their expertise.

In 2007 a liaison with ICOM-CC, International Council of Museums Conservation Committee, was established. ICOM was created in 1946 and is a non-governmental organization (NGO) maintaining formal relations with UNESCO and having a consultative status with the United Nations' Economic and Social Council. ICOM has 116 National Committees and 30 International Committees. ICOMCC, created in 1968, is the largest of the International Committees with almost 1600 members worldwide. ICOM with over 22,000 members is the international organization of museums and museum professionals committed to the conservation, continuation and communication to society of the world's natural and cultural heritage. Through collaboration with CEN/TC 346, ICOM offers his expertise in the full range of museum-related cultural heritage conservation activities and hopes to benefit from the important work on standardization that CEN is doing. Main goal would be to help disseminate the results of the CEN/TC 346 to its international membership. In 2008 a liaison with IIC, International Institute for Conservation, was established. Since 1950 IIC has promoted the knowledge, methods and working standards needed to protect and preserve historic and artistic works throughout the world. IIC members belong to an international community of professionals who aim to provide the highest possible level of care for the world's cultural heritage. IIC serves as a forum for communication among professionals with responsibility for the preservation of cultural heritage. It promotes professional excellence and public awareness through its awards and scholarships. IIC is an independent international organization supported by around 2300 individuals and 440 institutional members in 65 countries. The council of IIC has decided on collaboration with the CEN TC 346 project, since it fits well with its interest in setting standards in conservation. Liaison status will ensure that, via his representative, to be kept fully 
informed on progress with this important work, and that it can keep his members fully informed. It looks forward to promoting the approved standards to his membership and beyond.

In 2009 a liaison with E.C.C.O., European Confederation of Conservator-Restorers Organizations, was established. ECCO has been established in 1991 seeking to develop and promote, on a practical, scientific and cultural level, the profession of Conservator-Restorer of Cultural Property, representing, through their professional associations, more than 5.000 members throughout Europe from 16 countries within the European Union (EU) and the European Free Trade Association (EFTA). E.C.C.O.'s main objectives is to guarantee the safeguarding of cultural heritage through the promotion of a high level of training for the Conservator-Restorer and the work toward legal recognition of professional status. In relation with all these activities the Committee of E.C.C.O. has decided to seek collaboration with the CEN/TC 346 project, since it fits well with its interest in setting standards in conservation. In the same year one more liaison was established with UIA-The International Union of Architects which was founded in Lausanne (Switzerland) on 28th June 1948, to unite the architects of the world without regard to nationality, race, religion, or architectural doctrine, and to federate their national organizations. From the 27 delegations present at the founding assembly, the UIA has grown to encompass the key professional organizations of architects in 124 countries and territories, and now represents, through these organizations, more than 1,300,000 architects worldwide. Over time, the UIA has become an accomplished nongovernmental organization, an incomparable professional network of architects that reaches all continents.

In 2010 a liaison with ICOMOS -The International Council on Monuments and Sites was established. ICOMOS was founded in 1965 at Warsaw (Poland) one year after the signature of the International Charter on the Conservation and restoration of monuments and sites, known as the "Venice Charter". ICOMOS is an association of over 10,000 cultural heritage professionals present in over 100 countries throughout the world, working for the conservation and protection of monuments and sites-the only global non-government organization of its kind. It benefits from the crossdisciplinary exchange of its members-architects, archaeologists, art historian, engineers, historians, planners, who foster improved heritage conservation standards and techniques for all forms of cultural properties; buildings, historic towns, cultural landscapes. Archaeological sites, etc. ICOMOS is officially recognized as an advisory body to UNESCO, actively contributing to the World Heritage Committee and taking part of the implementation of the World heritage Convention. It also runs 28 specialized International Scientific Committees on a variety of subjects.

In 2010 one more liaison was established with IFLA-International Federation of Library Associations and Institutions - Preservation and Conservation Section" IFLA was founded in 1927 has set up 48 sections of which one established in 1984 dealing with Preservation and Conservation of library collections. The IFLA Section for Preservation and Conservation consists of a standing committee with 20 members elected for four years, with an option to sit for another four-year period. The members come from many different countries from all over the world. IFLA considers that a liaison status in the CEN TC 346 "Conservation of Cultural Property" would give the opportunity to more closely follow the work done in the development of standards for the protection of cultural property and would be able to follow CEN TC 346 results and further disseminate them through IFLA yearly meetings and conferences.

A close co-operation was established with COST actions. COST is for European Cooperation in Science and technology. The following two COST actions respectively for environment and wood per-standardisations were involved: 
-COST D D42 Chemical interactions between Cultural Artifacts and Indoor Environment (EnviArt) 2006-2010.

-COST IE0601 - Wood Science for Conservation of Cultural Heritage (WoodCultHer), 2008-2012.

\section{Crucial points influencing the current and future development}

One of the major risks in the development of standardization activity in the field of conservation of cultural heritage is the problem of finding funding and planning budgets to finance the activity of the relevant experts involved in the work. Most of the experts involved in the conservation field work for SMEs or small specialist departments in academic institutions / quasi-government agencies where securing funding for new projects is difficult and always needs to be agreed and budgeted well in advance. The fact that resources are limited across Europe makes it essential that there is prioritization of Work Items and standards to insure the more important ones are completed. According to a "Matrix-based method" the most urgent standards can be established, but if no interested volunteers having the required experience were found the matrix failed; as opposed, it was successful whenever it optimized existing technical and human resources.

A second possibility is the "Marked-based method" which should work if the market will take in charge the working and traveling costs. However, if the "market" gains from standardization but does not pay for it, it is deprived of any link with the standardization activity. If experts work in the absence of any financial support they have no any reason to follow the market. In Europe some Countries might have resources to support standardization activity and in such a case the National Standards Body can impose priorities. In the case experts are neither paid for their activity nor reimbursed for their traveling expenses, a crucial factor is to find volunteers that are expert in the selected topics.

A third possibility is "feasibility, i.e. a compromise between requests (i.e. Matrix) and potentials" or "exploitation and optimization of the existing capabilities" in terms of technical and human resources, i.e. number and type of experts.

Although at the European level there is a great interest in this kind of activity, there is often a lack of contact between the experts and the National Standards Bodies. In particular, in some cases there is no specific national active mirror committee or group which can deal with the work of standardization on conservation of cultural heritage. It is important to consult as widely as possible through National Mirror Groups, who should discuss how to contact the relevant people; e.g. through their professional national bodies, register of experts.

In conclusion analyzing the different situation in each European country we find that only few governmental institutions allocated financial resources to support standardization and what we need is the financial support of national governmental institutions. 


\section{CEN TC 346 Conservation of cultural heritage}

WG1-General guidelines and terminology with the responsibility for the drafting of standards on terminology dealing with movable and immovable cultural heritage and guidelines on conservation planning

WG2-Materials constituting cultural property with the responsibility to define tests and analyses methods for the characterization of the materials and for the evaluation of the state of conservation/preservation of materials

WG3-Evaluation of methods and products for conservation works with the responsibility of drafting documents on criteria to select methods and/or products and working conditions in relation to the conservation/restoration, maintenance and preventive conservation work

WG 4 - Environment with the responsibility for the drafting of guidelines for the control of environmental variables, and of standards on the measurement of indoor and outdoor environmental conditions, and on cultural property environment interaction

WG 5 - Transportation and packing method with the responsibility for the drafting of standards on methods of packing and transportation of cultural heritage outside the institutions

\section{CEN TC 346 Conservation of cultural heritage}

WG1-General guidelines and terminology with the responsibility for the drafting of standards on terminology dealing with movable and immovable cultural heritage and guidelines on conservation planning

WG2-Materials constituting cultural property with the responsibility to define tests and analyses methods for the characterization of the materials and for the evaluation of the state of conservation/preservation of materials

WG3-Evaluation of methods and products for conservation works with the responsibility of drafting documents on criteria to select methods and/or products and working conditions in relation to the conservation/restoration, maintenance and preventive conservation work

WG 4 - Environment with the responsibility for the drafting of guidelines for the control of environmental variables, and of standards on the measurement of indoor and outdoor environmental conditions, and on cultural property environment interaction

WG 5 - Transportation and packing method with the responsibility for the drafting of standards on methods of packing and transportation of cultural heritage outside the institutions 


\section{CEN TC 346 Conservation of cultural heritage}

WG1-General methodologies and terminology (Italy - Mr. Appolonia)

WG2-Characterisation and analysis of porous inorganic materials constituting cultural property (from Greece to United Kingdom: Mr. Yates)

WG 3 - Evaluation of methods and products for conservation works on porous inorganic materials constituting cultural heritage (Italy - Mr. Fassina)

WG4-Protection of collections (Denmark-Mr. Stub Johnsen)

WG5- Packing and transport (France - Ms. De Wallens)

WG6- Exhibition lighting of cultural heritage-JWG between TC 346 \&TC 169 (Italy - Mr. Camuffo)

WG7-Specifying and measuring Indoor/outdoor climate (Italy-Mr. Camuffo)

WG8- Energy efficiency of historic buildings (Norway-Mrs. Boro )

WG9- Waterlogged wood (Italy-Mr. Fioravanti)

WG 10-Historic timber structures (Italy-Mr. Macchioni)

WG11-Conservation process (Germany-Mr. Goetz) Scope: description of the successive steps of the conservation of cultural heritage, taking into account the variety of cultural heritage and situations and the terminology in EN 15898:2011

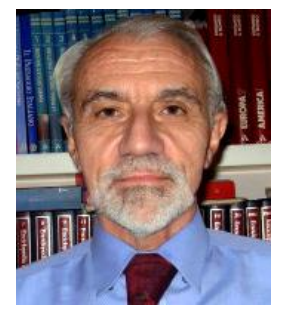

\section{Vasco Fassina}

vasco.fassina@gmail.com

Ministry of Italian Cultural Heritage-Superintendence of Fine Arts of Veneto-Venice-Chairman CEN/TC346Conservation of Cultural Heritage

From 1975 to 2012 he served the Italian Ministry of Cultural Heritage for 25 years as Director of the Scientific Laboratory of Venice Superintendence and successively for 12 years he had the responsibility for the Veneto Superintendence to co-ordinate and promote interdisciplinary investigation projects at worksites and to develop new treatment proposals. The activity was mainly dealing with conservation of building stone and wall paintings materials.

He was involved for 25 years in International Training Programme for conservation of cultural heritage as teacher, coordinator and director of the biennial International Stone Conservation Course of UNESCOICCROM held in Venice. 
Teaching activities at International level as Visiting Professor: in the Sino-Italy cooperation Project "Training in the Restoration and Conservation of the Chinese Cultural Heritage" through the support of the Chinese Institute of Cultural Property (CNICP) of Beijing, in 2004 and 2007, in the International Course of University School of Monument Conservation in Rhodos, Crete, Ravello, for the Faculty of Architecture in Rosario (Argentina) and Salvador de Bahia (Brazil).

In 2004 he was appointed Chairman of CEN/TC 346 The European Committee for the standardization in the field of Conservation of Cultural Heritage. In 2007-2008 he was appointed by the General Direction for Cooperation and Development of the Italian Foreign Affairs Ministry to evaluate the feasibility study for the establishment of Longmen Stone Relics Conservation Center and of Dazu Stone Monuments Conservation Center respectively located in the Middle and in the South West of China.

For four years (2008-2012) was appointed as Chair of the Scientific Committee of the 12th International Congress on Deterioration and Conservation of Stone, held in New York the last October 2012.

For four years (2006-2010) was appointed as Chair of WG3 Guidelines on harmonization and standardization in COST (European Cooperation in Science and Technology) D42 Chemical Interactions between artifacts and indoor environment.

In 2012 he has been appointed as Chairman of the national standardization commission for Cultural Heritage.

Actually is teaching chemistry applied to conservation and diagnostics techniques for investigation and conservation at Italian Universities and Academy of Fine Arts in Milano, Bologna, Napoli, Verona.

Artículo enviado el 23/10/2013 


\title{
Historia de la conservación preventiva*. Parte I
}

\author{
Isabel M. García Fernández
}

Resumen: El nacimiento de la conservación preventiva no está muy claro, aunque se puede decir que se encuentra íntimamente ligado a la producción de bienes patrimoniales y el deseo del ser humano de que estos perduren. No obstante, va a ser en el siglo XIX cuando se asienten las bases de la conservación y restauración, $y$ en el siglo $X X$, cuando se desarrollen los conceptos científicos y de aplicación en el ámbito de los museos. En esta primera parte tratamos la historia de la conservación preventiva desde sus orígenes hasta 1990, destacando los hitos importantes acaecidos antes y después de la Segunda Guerra Mundial.

Palabras clave: conservación preventiva, agentes de deterioro, control medioambiental.

\section{História da conservação preventiva. Parte I}

Resumo: O nascimento da conservação preventiva não é muito claro, mas pode dizer-se que está intimamente ligado à produção de bens patrimoniais e ao desejo humano de que estes perdurem. No entanto, é no século XIX que ficam assentes as bases da conservação e restauro e é no século XX que se desenvolvem os conceitos científicos e da aplicação ao contexto dos museus. Nesta primeira parte tratamos da história da conservação preventiva desde as suas origens até 1990, destacando os principais marcos que ocorreram antes e depois da Segunda Guerra Mundial.

Palavras-chave: conservação preventiva, agentes de deterioração, controle ambiental.

\section{History of preventive conservation. Part I}

\begin{abstract}
The origin of preventive conservation is not well defined, although it can be stated that is directly related to the production of works of art and to the human desire to preserve them. However, it is in the $19^{\text {th }}$ century that the conservation and restoration principles were established and it is in the $20^{\text {th }}$ century that the scientific concepts were developed, altogether with its application to the museum context. In the first part it is presented the history of preventive conservation since its origins until 1990, highlighting the important events occurred before and after the Second World War.
\end{abstract}

Keywords: preventive conservation, deterioration agents, environmental control.

\section{Introducción}

Desde hace varias décadas hemos estado asistiendo a un cambio de mentalidad que se ha traducido en un nuevo uso de las colecciones que han pasado a formar parte activa de la cultura, lo que a su vez ha propiciado una nueva actitud hacia la preservación del Patrimonio Cultural. Una prueba de este cambio es la aparición de la llamada "Conservación Preventiva" que tiene que ver con la consecución del equilibrio entre el uso y disfrute del patrimonio y su conservación.

El nacimiento de esta disciplina no está muy claro. El término apareció en la década de 1950 y su desarrollo y aplicación parece que fueron impulsados por la comunidad de conservadoresrestauradores anglosajones, quienes recogiendo y ahondando sobre importantes trabajos, algunos publicados a principios del siglo XX, pero sobre todo en la década de 1930, empezaron a identificar los agentes de deterioro que afectaban a las colecciones en museos y a comprender los procesos a los que daban lugar, entendiendo a su vez que su control era la medida principal a tomar para 
asegurar la supervivencia de los objetos y obras de arte albergados en museos y otras instituciones culturales. También tuvo mucho que ver el interés creciente que existía hacia el estudio de la cultura material y la revalorización de colecciones distintas a las estrictamente artísticas, como por ejemplo, las colecciones científicas, las de arqueología, etnología e historia natural.

La conservación preventiva se asoció fundamentalmente a la institución del museo, entendiendo que una las funciones primordiales contemplada en todas las definiciones es la de la conservación y preservación de los objetos que allí se albergan y que forman parte del patrimonio cultural del país, y otra igualmente importante, es la puesta en valor de ese patrimonio, concepto utilizado en la actualidad de forma generalizada para hacer referencia a los planes de enriquecimiento, promoción y valorización del patrimonio cultural, que son requisitos esenciales vinculados a la protección y conservación de museos. La promoción y difusión se lleva a cabo principalmente a través de la exposición, es esta última la que está generando más publicaciones asociadas a los estándares y aplicación de medidas de conservación preventiva.

A los museos, desde el comienzo de su existencia se les ha considerado como protectores del Patrimonio, siendo la creencia general que los objetos y obras de arte se iban a conservar para siempre dentro de estas instituciones. Así, según el ICOM (2006:1):

"Los museos son los responsables del patrimonio natural y cultural, material e inmaterial. La primera obligación de los órganos rectores y de todos los interesados por la orientación estratégica y la supervisión de los museos es proteger y promover ese patrimonio, así como los recursos humanos, físicos y financieros disponibles a tal efecto."

Sin embargo, en un alto porcentaje, los esfuerzos encaminados a la supervivencia de los objetos en los museos han sido limitados, en parte debido a la poca información que existía sobre los procesos de deterioro y la aplicación de los medios de control. En la actualidad se aboga por un cambio de mentalidad que conlleve hacer de la conservación preventiva un elemento esencial en el funcionamiento de los museos formando e implicando a todos los agentes relacionados con las colecciones. Además la conservación preventiva ha traspasado los muros del museo para ocuparse de otras instituciones patrimoniales, incluyendo monumentos, sitios históricos, yacimientos arqueológicos y parajes naturales manteniendo los mismos principios, aunque variando los procedimientos o medidas de control.

Este cambio de mentalidad se está produciendo de manera paulatina, para entender cuál es el proceso destacamos una serie de hitos importantes que tienen que ver con el desarrollo de los campos de la conservación y la restauración y su desarrollo con otras funciones del museo, como es la exposición. La exposición ha sido siempre un lugar de encuentros problemáticos, que han ido surgiendo a la par que se han ido ampliando horizontes y poniendo de relieve que la preservación del patrimonio es algo muy complejo. Los desencuentros se producen a medida que la ciencia y la tecnología avanzan exigiendo la adquisición de nuevos conocimientos, la adaptación a nuevas situaciones y la aplicación de nuevas técnicas. En definitiva, se requiere de los profesionales un reciclaje continuo y una apertura de miras que algunos se niegan a aceptar porque choca en muchas ocasiones con el peso de la tradición. 


\section{Origen de la conservación preventiva y su desarrollo hasta la Segunda Guerra Mundial}

La historia de la conservación preventiva está indisolublemente unida a la historia de la conservación y la restauración, así como a la producción de bienes patrimoniales y el deseo de mecenas y artistas de que sus obras perduren para la posteridad. Desde que los arquitectos y urbanistas se preocuparon del diseño de las ciudades, sus edificios, su orientación, los sistemas de construcción, elección de materiales, adopción de medidas para el control de clima dentro de los inmuebles (ventilación y calefacción) ha existido una preocupación por la conservación. No obstante, a pesar de las medidas preventivas tomadas para conservar los inmuebles y el patrimonio histórico-artístico que albergaban, en el siglo XIX se impuso la restauración y las intervenciones en los bienes culturales fueron muy extendidas; todo ello en contra de las doctrinas de John Ruskin y sus seguidores, ya que para estos, tal y como recoge González-Varas (1999: 193), la antigüedad de la obra de arte, la vetustez acumulada en las piedras del monumento, pasa a erigirse en un valor sustancial de la obra de arte, en venerable signo de su autenticidad. Recordemos que John Ruskin lideró la doctrina de la "no intervención" formulada a mediados del siglo XIX en Inglaterra, su teoría de la conservación la encontramos en su libro Las siete lámparas de la arquitectura, en concreto en los aforismos XVIII, XIX y XX de "La Lámpara de la Memoria" que actuó como revulsivo a los excesos y falsificaciones de la "restauración estilística" que se difundió por toda Europa durante la segunda mitad del siglo XIX gracias a la personalidad del arquitecto francés Viollet-le-Duc. No obstante, Ruskin ya apuntaba algunos de los principios esenciales de la conservación preventiva y también de lo que luego se ha denominado la conservación curativa que en este caso está asociada a la consolidación de edificios:

"Cuidad de vuestros monumentos y no tendréis necesidad de restaurarlos. Una hoja de plomo puesta a tiempo sobre un techo, la oportuna limpieza de algún trozo o detritus de madera que obstruye un conducto, podrá salvar de la ruina muros y cubierta. Vigilad con ojo atento un edificio, conservadlo lo mejor posible con todos vuestros medios, salvadlo de cualquiera que sea la causa de disgregación." (Véase González-Varas, 1999: 205).

En ese siglo se dieron dos hechos fundamentales asociados estrechamente a la conservación preventiva y el control del clima: uno, la instalación de sistemas de calefacción en muchas viviendas y edificios públicos que, como en la actualidad, utilizaban radiadores que funcionaban con agua caliente conducida mediante tuberías desde una caldera (esta alimentada con carbón); y otro, la introducción de lámparas de gas para la iluminación. Estos dos factores, además de los altos niveles de contaminación asociados a la revolución industrial, propiciaron la aparición de una serie de problemas de conservación que no habían existido en siglos anteriores y que tendrán su solución durante el siglo siguiente.

En el siglo XX científicos y restauradores se van a enfrentar a estos problemas y otros nuevos que irán surgiendo poco a poco, además se van a ir concretando las características de esta disciplina a la que siempre se ha unido una vertiente práctica; un ejemplo de ello es la iniciativa del Museo de Bellas Artes de Boston que en 1905 quiso establecer unos parámetros climáticos para la conservación de sus colecciones: mantener una HR del 50\% y una temperatura de 50-60 ०F (10-15,6 $\left.{ }^{\circ} \mathrm{C}\right)$, según recoge Pamela Hatchfield (2011: 42), su nuevo edificio inaugurado en 1908 fue el primero en introducir un sistema de control de la humedad y otro de "lavado del aire" para eliminar contaminantes. McCabe dirá en 1931 refiriéndose a esta experiencia, que después de dos años de estar funcionando, se demostró que "la humedad que mejor se adaptaba a las pinturas de caballete y otras obras de arte variaba entre el 55 y el 60\%", aunque no se proporcionó ninguna información sobre experiencias o estudios que avalaran esta información; a pesar de ello dicha 
afirmación tuvo mucha influencia en el establecimiento de valores medioambientales en museos. Los valores de temperatura, como ha apuntado Hatchfield, eran más bajos que los actuales y estaban condicionados por la capacidad de los sistemas de calefacción. Hatchfield también apunta que Stuart Cramer, pionero de estos sistemas, fue el fabricante de telas que en 1905 quiso mejorar la manipulación del algodón en su fabricación añadiendo humedad al aire, acuñando entonces el término "aire acondicionado", sistema que luego se generalizará para muchos usos y edificios, incluidos los museos.

Por otra parte, Friedrich Rathgen, director del Laboratorio de los Museos Reales de Berlín, escribió en 1905 un manual dirigido a los conservadores de museos, traducido al inglés como The Preservation of Antiquities. A Handbook for Curators [La preservación de antigüedades. Un manual para conservadores]. Este libro fue muy importante para la época, ya que aparte de hacer accesibles los tratamientos de conservación de objetos en museos, en él se planteaban acciones de conservación preventiva recogidas en la sección denominada "el cuidado de las antigüedades después del tratamiento de preservación"; de este modo, comenzaba diciendo que "además de la protección contra el polvo que proporcionan las vitrinas de cristal, es importante proteger a los objetos de la acción de la luz solar directa, especialmente durante los meses de verano", los objetos tampoco debían colocarse cerca de aparatos de calefacción. Planteaba que, aunque no existían estudios publicados sobre la acción de la luz, sí se había evidenciado que esta afectaba tanto a objetos orgánicos como a inorgánicos, por lo que era "aconsejable proteger todas las antigüedades de cualquier forma de iluminación durante el tiempo que no fueran expuestas al público". Incidía en que las vitrinas eran un buen sistema de conservación, ya que también impedían que los visitantes tocasen los objetos; por último, denunciaba la utilización de cartelas de cartón unidas a los objetos con alambre de hierro por el deterioro que puede causar su oxidación en los materiales con los que entra en contacto.

En la década de 1930, antes de la Segunda Guerra Mundial, ya aparecen estudios importantes relacionados con las condiciones medioambientales en los museos que tendrán gran influencia en los trabajos posteriores y en el desarrollo del campo de la conservación preventiva. Podemos destacar aquí los trabajos de autores como P. Coremans, director del Instituto Real del Patrimonio Artístico de Bruselas; G. Rosenberg, conservador del Museo Nacional de Copenhague; J. Maclntyre, ingeniero en la HM Office of Works en Londres, o F. I. G. Rawlins, asesor científico de la Galería Nacional de Londres, que plantean cuestiones clave relativas a esta disciplina sobre todo relacionadas con recomendaciones de niveles de humedad relativa óptimos y sistemas de humidificación. Así, Rosenberg en su conocido artículo "Antiquities and Humidity" de 1930, considerado el tratado más extenso de la época sobre clima en museos con colecciones variadas, recomienda valores de humedad relativa (HR) entre 45 y $65 \%$ para colecciones mixtas de antigüedades cuyos materiales constitutivos son de naturaleza orgánica. Por otra parte, hay que destacar las investigaciones en la Galería Nacional de Londres en pinturas sobre tabla que ponían de relieve los efectos de la HR y sus fluctuaciones. Recordemos que en 1934 se instaló el primer sistema de aire acondicionado en museos de Europa, concretamente en la Orangery del Hampton Court Palace, donde los cartones de Andrea Mantegna se estaban deteriorando de manera evidente por las variaciones de HR y temperatura. En Estados Unidos, como hemos mencionado anteriormente, ya se habían documentado intentos de controlar los parámetros medioambientales utilizando sistemas de aire acondicionado desde los primeros años del siglo XX. El desarrollo de esta tecnología no se extendió a otros países de manera inmediata debido a la Segunda Guerra Mundial y sus consecuencias en Europa. Por el contrario, como apuntan Edhardt et alii (2007:12) a principios de los 40 existían alrededor de doce museos e instituciones en Estados Unidos con estos 
sistemas de control medioambiental, incluyendo los Archivos Nacionales y la Biblioteca del Congreso.

Dos años más tarde, P. Coremans planteaba que los experimentos que se habían llevado a cabo en varios lugares parecían mostrar que la temperatura y la humedad óptimas estaban muy cercanas a los $15^{\circ} \mathrm{C}$ y $60 \%$ de HR. Estos datos sobre el medio ambiente "óptimo" fueron los dominantes en Europa durante las décadas de 1930 y 1940, aunque los experimentos de los que hablaba Coremans no se especificaban con rigor.

Asimismo, en esa época, no hay que olvidar el papel de la Oficina Internacional de Museos (OIM) perteneciente a la Sociedad de Naciones y creada por la decisión de la Comisión Internacional para la Cooperación Intelectual en 1926; en su revista Mouseion publicada desde 1927 hasta 1946 ya se recogieron algunos trabajos relacionados con la conservación preventiva. Publicó aproximadamente cuarenta y seis artículos durante quince años que versaban sobre la protección de sitios y monumentos, aunque estaban más enfocados a la restauración que a la conservación. A finales de la década de 1930 aparecen artículos sobre la protección de los monumentos y obras de arte en tiempos de guerra y dejó de publicarse durante cinco años debido a la Segunda Guerra Mundial. La Oficina Internacional de Museos cesó en sus funciones en 1946 cuando se creó la Organización de Naciones Unidas y el Consejo Internacional de Museos (ICOM). El ICOM está asociado a la UNESCO y publica desde 1948 la revista Museum (más tarde pasó a denominarse Museum International), que ha sido y sigue siendo muy influyente por su amplia divulgación de temas de museología y museografía, entre los que la conservación y restauración han tenido lugar destacado.

En 1930, la OIM organiza la Conferencia Internacional para el Estudio de los Métodos Científicos Aplicados al Examen y la Conservación de las Obras de Arte en Roma, allí el término de conservación se independiza del de restauración. Un año más tarde se produce otro hecho significativo, la celebración de la Conferencia de Expertos para la Protección y Conservación de Monumentos de Arte y de Historia del 21 al 30 de octubre en Atenas, que auspicia la famosa Carta de Atenas sobre la conservación del patrimonio arquitectónico. Este texto se redacta como conclusión a la conferencia y se considera el primer documento internacional que plantea principios y normas generales para la conservación y restauración de monumentos. En 1934 auspicia la conferencia sobre arquitectura y acondicionamiento de los museos de arte, celebrada en Madrid, en la que se evidencia la correlación de las cuestiones museográficas con la conservación preventiva; los planteamientos allí expuestos se consideran imprescindibles en el desarrollo de la disciplina. Los resultados de la conferencia se publicaron en dos volúmenes con el título de Muséographie. Architecture et aménagement des musées d'art. Destacable también es el estudio llevado a cabo en 1936 que resultó en el borrador de la Convención para la Protección de Edificios Históricos y Obras de Arte en tiempos de Guerra presentado en la Asamblea General del Consejo de la Liga de Naciones en 1938.

La Segunda Guerra Mundial y las consecuencias terribles para la población y el patrimonio, también fueron un detonante para la toma de decisiones en el campo de la conservación que van a tener una influencia fundamental sobre los principios en los que se asienta la plenamente desarrollada disciplina de la conservación preventiva de los años noventa. Decisiones como el traslado de las colecciones del Museo Británico para ponerlas a salvo de los bombardeos; estas fueron divididas para su custodia en varias localizaciones, entre ellas, la Biblioteca Nacional de Gales, sita en Aberystwyth. En este lugar se construyó un túnel a prueba de bombas en la roca debajo del edificio de la biblioteca y se invitó al museo a compartir el espacio; este se considera el 
experimento más temprano en el uso de aire acondicionado en un almacén subterráneo. En agosto de 1939 llegaron procedentes del Museo Británico cientos de toneladas de libros, manuscritos, grabados y dibujos. Otros objetos y obras de arte se trasladaron a unas canteras sitas también en Gales que presentaban unas condiciones medioambientales estables con valores del $60 \%$ de HR y $15{ }^{\circ} \mathrm{C}$ de temperatura. Las obras de la Galería Nacional de Londres también fueron a Gales, distribuyéndose en varias localidades, entre ellas, dependencias de la Universidad de Gales del Norte en Bangor, la Biblioteca Nacional en Aberystwyth y los castillos de Caernarvon y Penrhyn. Se pensó mandar las obras a Canadá, algo que inquietaba al director del Museo Kenneth Clark, pero el mismo Winston Churchill vetó la idea dirigiéndose a Clark de la siguiente manera: "escóndelas en cuevas y sótanos, pero ningún cuadro debe dejar la isla".

Por seguridad se decidió más tarde reunirlas en un mismo lugar y se eligió una mina de pizarra en Manod que se acondicionó para servir de almacén; se agrandó el acceso para permitir la entrada de los cuadros grandes y se construyeron pequeñas habitaciones por medio de muros de ladrillo creando espacios más controlados para proteger las obras de las variaciones de humedad y temperatura. En el verano de 1941 se reunieron todas las obras allí y durante los años que duró su estancia las condiciones permanecieron estables, aunque la humedad ambiental era alta. Las obras no sufrieron ningún daño, y esta circunstancia obligó a replantearse las acciones a tomar una que vez regresaran otra vez al museo en Londres. Así, Rawlins en 1942 expresó su deseo de reproducir estas condiciones en las salas de exposiciones diseñando equipamientos para ello. Las condiciones serían diferentes, según recoge Erhardt et alii (2007:12); se hicieron estudios que analizaban el comportamiento de la madera en las salas de la Galería Nacional de Londres y, teniendo en cuenta los resultados y las condiciones climáticas de Londres, se establecieron los estándares del museo y se trabajó para evitar las fluctuaciones.

Otro de los problemas al que debían enfrentarse los encargados de la conservación de las colecciones fue el control de contaminantes en una ciudad tan polucionada como Londres; desde que comenzara la revolución industrial los niveles de contaminantes procedentes de la combustión del carbón eran muy altos y peligrosos para la población y la conservación del patrimonio; no solo se emitían gases nocivos, sino que también existían altas concentraciones de partículas dañinas como el hollín, a este problema no se hallará fácil solución. Recordemos que una década más tarde de la propuesta de Rawlins, el 4 de diciembre de 1952, tuvo lugar en Londres la Great Smog (la gran niebla) que duró cinco días y causó miles de muertos. Se ha documentado que en las salas de Galería Nacional de Londres se registraban dos terceras partes de los contaminantes medidos en el exterior, el nivel era muy alto debido a la combustión del carbón. En 1956 la ley denominada Clear Air Act intentará mejorar la situación con una serie de medidas, entre las que entraba, el control de las fuentes de energía domésticas incluyendo zonas sin humo, además de revisiones a las industrias para reducir las emisiones de partículas.

En relación a las consecuencias de la guerra, prácticamente toda Europa hubo de enfrentarse a la tarea de proteger su patrimonio; podemos destacar la labor de Istituto Centrale del Restauro (ICR) en Roma, creado en 1939, que organizó un Consejo Técnico responsable de verificar la sostenibilidad de las condiciones medioambientales durante la guerra. En España se vivió una Guerra Civil que también tuvo un impacto muy negativo en la vida de los españoles y en su patrimonio histórico-artístico. Con el fin de protegerlo se creó en Madrid en 1936 la Junta de Protección del Tesoro Artístico y luego otras juntas delegadas que llevaron a cabo las acciones más diversas para poner a salvo el patrimonio tanto in situ como en lugares acondicionados para ello. Ya en los últimos meses del conflicto se creó un Comité Internacional para el Salvamento de los Tesoros de Arte Españoles, formado por directores y conservadores de museos respaldados por la 
Sociedad de Naciones, que hizo posible su evacuación hasta Ginebra, la entrega a la Sociedad de Naciones y su posterior traspaso al nuevo gobierno establecido en España en 1939. Entre las publicaciones e iniciativas que documentan este hecho destacamos la del Museo Nacional del Prado y el Instituto del Patrimonio Histórico Español (actual Instituto del Patrimonio Cultural de España), que presentaron en las salas del Museo del Prado la exposición Arte Protegido. Memoria de la Junta del Tesoro Artístico durante la Guerra Civil en junio de 2003. La exposición mostró imágenes inéditas del Fichero de la Junta del Tesoro Artístico de Madrid, que conserva el IPCE, y cómo estas sirvieron de instrumento indispensable para la catalogación de las obras de arte y para la documentación de procesos preventivos y de restauración.

\section{Desde el final de la Segunda Guerra Mundial hasta la década de 1990}

Después de la Segunda Guerra Mundial, en 1950, se funda el International Institute for the Conservation of Museum Objects [Instituto Internacional para la Conservación de los Objetos en Museos], luego se cambió su nombre a International Institute for the Conservation of Historic and Artistic Works (IIC) [Instituto Internacional para la Conservación de Bienes Históricos y Artísticos] con sede en Londres, dos años más tarde se publicaba su revista Studies in Conservation que se ha convertido en un referente fundamental en el campo de la conservación y la restauración, así como los congresos internacionales que organiza. Esta revista es heredera de los Technical Studies in the Field of Fine Arts publicada de 1932 a 1942 por el Museo Fogg de Arte perteneciente a la Universidad de Harvard.

Otro hecho importante de esta década es que en 1956 Harold J. Plenderleith, conservador del laboratorio científico del Museo Británico de Londres, que también fue director del "Rome Centre" o Centro de Roma (1959-1969) después conocido como ICCROM, publicó el libro The Conservation of Antiquities and Works of Art, que como Philip Ward destacó años más tarde (1986): "La importancia de este volumen radica en su contenido diagnóstico: fue la primera explicación sistemática de los mecanismos de deterioro, que continúa siendo la base de la conservación. También demostró la posibilidad práctica de la prevención y, junto con los conocimientos aportados por la ciencia de los materiales a las técnicas tradicionales de la restauración, dio forma a la nueva disciplina de la conservación".

Por último, también al final de la década de 1950, la UNESCO a través de su división de Patrimonio Cultural contribuyó al campo de la conservación y restauración, así gracias a su apoyo en 1959 nace el International Centre for the Study of the Preservation and Restoration of Cultural Property (ICCROM) [Centro Internacional para el estudio de la Preservación y Restauración de los Bienes Culturales en Roma], institución de referencia en el ámbito de la conservación a nivel mundial que coordina proyectos internacionales y ofrece formación especializada. Muchos de los proyectos y cursos llevados a cabo desde finales de los años ochenta tienen que ver específicamente con la conservación preventiva.

Por otra parte, en 1955 se documenta una iniciativa fundamental llevada a cabo por el ICOM, esta organización mandó unos cuestionarios a museos de todo el mundo con el fin de conocer los niveles medioambientales de estas instituciones y las medidas de control aplicadas; respondieron 64 museos de 11 países. Este material fue estudiado por el Doctor R. Sneyers en colaboración con R. Organ y F. I. G. Rawlins, y confeccionaron un informe; este trabajo preliminar fue la base del número monográfico de la revista Museum dedicado a la "Climatología y Conservación en Museos" (vol. XIII, 4) de 1960. La edición de esta publicación fue encargada a dos de las figuras más 
importantes en el campo de la restauración en esa época: el citado H. J. Plenderleith y Paul Philippot, los textos estaban dirigidos a los profesionales de los museos y en ellos se exponían de manera sencilla la composición de la atmósfera y su influencia en procesos de deterioro.

En los distintos artículos se dio mucha importancia al estudio y control de las condiciones medioambientales en museos: temperatura y sobre todo humedad relativa, planteando que la humedad era sin lugar a dudas el agente principal de deterioro, exponían lo dañinas que podían ser las fluctuaciones y la necesidad de reducir las variaciones estacionales. Los autores presentaron diferentes situaciones climáticas y dieron información práctica sobre los instrumentos de medición y equipos de control. Se hablaba de conservación y aunque no se hacía referencia a conservación preventiva explícitamente, sí que hay un nuevo intento de diferenciar la conservación y la restauración. En esta línea Paul Coremans en 1965 hablaba de conservación asociándola a la parte científica y objetiva destinada a conservar la integridad de los materiales, teniendo en cuenta la evidencia histórica y cultural, mientras que identificaba como restauración a la parte que se corresponde con la sensibilidad artística desde lo humanístico combinada con la habilidad manual y técnica que tiene como propósito reintegrar la imagen o forma original del objeto; todo ello está recogido en el artículo "The training of restorers" que forma parte de la publicación del ICOM Problems of Conservation in Museums [Problemas de Conservación en Museos] de 1969.

En esta década de 1960, paralelamente al desarrollo de la conservación, se constata la evidencia de la evolución del papel del restaurador que se va convirtiendo en un especialista en el arte de la restauración y en un técnico en la ciencia de la conservación. Según el propio Coremans, es el pilar de "un equipo de investigadores formados en campos muy diferentes, aunque no contradictorios como la historia, la historia del arte, la arqueología, la física y la química". Esto, aun siendo deseable, se producía en contadas ocasiones, ya que la formación de los restauradores variaba mucho según los países. En 1962 se crea el Instituto Central de Conservación y Restauración de Obras y Objetos de Arte, Arqueología y Etnología (ICCROA) en España, como apunta Rocío Bruquetas (2009:38):

El ICCROA había surgido ante una doble necesidad: dotar al país de un organismo que pudiera atender a la conservación y restauración de las obras con las garantías científicas y técnicas debidas, y formar técnicos a los que poder encomendar esta tarea. La UNESCO a través de un informe realizado por Paul Coremans, intervino en esta primera etapa proporcionando pautas para su organización con el mismo enfoque con que se crearon grandes centros como el Institut Royal du Patrimoine Artistique (IRPA) de Bruselas o el Istituto Centrale per il Restauro (ICR).

En 1965 se fundó en Varsovia (Polonia) el ICOMOS-Consejo Internacional de Monumentos y Sitios Histórico-Artísticos, tras la elaboración de la Carta Internacional sobre la Conservación y Restauración de los Monumentos y los Sitios Histórico-Artísticos, conocida como Carta de Venecia. EI ICOMOS es la única organización internacional no gubernamental que tiene como cometido "promover la teoría, la metodología y la tecnología aplicada a la conservación, protección, realce y apreciación de los monumentos, los conjuntos y los referidos sitios" -según definición recogida en su web-. Esta organización es consejera de la UNESCO con la que colabora en la elaboración de la Lista del Patrimonio Mundial y en el seguimiento de los bienes inscritos en la misma.

En la década de 1970 destaca el papel de la UNESCO, que denuncia los problema de conservación del patrimonio a nivel mundial; así se constató en la Convención para la Protección del Patrimonio Mundial, Cultural y Natural de 1972, que decía que el patrimonio cultural y el natural estaban "cada vez más amenazados de destrucción, no solo por las causas tradicionales de deterioro, sino 
también por la evolución de la vida social y económica que las agrava con fenómenos de alteración o de destrucción aún más temibles" y que "es indispensable adoptar para ello nuevas disposiciones convencionales que establezcan un sistema eficaz de protección colectiva del patrimonio cultural y natural de valor excepcional organizada de una manera permanente, y según métodos científicos y modernos"; para ello entre otras cuestiones en el artículo 5 de la convención se establecía la necesidad de "facilitar la creación o el desenvolvimiento de centros nacionales o regionales de formación en materia de protección, conservación y revalorización del patrimonio cultural y natural y estimular la investigación científica en este campo". Son los centros de conservación nacionales o territoriales y también los laboratorios de restauración de los grandes museos, además de las asociaciones como las mencionadas del IIC, ICOM, ICOMOS e ICCROM, los que van a liderar el desarrollo de la disciplina de la conservación preventiva enfatizando la cohesión de la profesión y la multidisciplinariedad de la misma. Hay que destacar el papel del Comité para la Conservación del ICOM que celebra sus encuentros trienales desde 1984 y que en los años noventa creó un grupo específico de Conservación Preventiva, concretamente se constituyó después de la 11 Reunión Trienal celebrada en Edimburgo del 1 al 6 de septiembre de 1996. También a las instituciones citadas se unirá el Getty Conservation Institute [Instituto de Conservación del Getty] en Estados Unidos, que se ha consolidado como uno de los líderes en este campo.

Sin dejar la década de 1970 hay que hablar de la Carta Italiana del Restauro de 1972; documento normativo muy importante elaborado por el Ministerio de Instrucción Pública italiano, que teniendo en cuenta las opiniones del Consejo Superior de Antigüedades y Bellas Artes, recoge y expone las normas y criterios de intervención sobre los bienes culturales; en concreto en el artículo 4 se definen los términos de conservación preventiva (denominándola salvaguardia) y restauración:

"Se entiende por salvaguardia cualquier medida conservadora que no implique la intervención directa sobre la obra; se entiende por restauración cualquier intervención encaminada a mantener vigente, a facilitar la lectura y transmitir íntegramente al futuro las obras de arte y los objetos definidos en los artículos precedentes."

Esta carta, que tuvo mucha repercusión en el campo de la restauración, se amplía en 1987, donde se dan detalles más precisos sobre intervención aunque no ahonda en la disciplina de la conservación preventiva.

En 1978, en la Recomendación sobre la Protección de los Bienes Culturales Muebles de la UNESCO se anticipa uno de los conceptos que hoy se baraja como imprescindible en las políticas de protección del patrimonio, nos referimos a "prevención de los riesgos" que significa: "El conjunto de las medidas para salvaguardar los bienes culturales muebles contra todos los riesgos a que pueden verse expuestos, incluidos los riesgos originados por conflictos armados, motines y otros desórdenes públicos en el marco de una protección global". Plantea dentro de los principios generales que:

"Los bienes culturales muebles están expuestos al riesgo de deterioro como resultado de las malas condiciones de su almacenamiento, exposición, transporte y medio ambiente (iluminación, temperatura e higrometría desfavorables, contaminación atmosférica), condiciones que a la larga pueden repercutir más gravemente que si se tratara de daños accidentales o de vandalismo ocasional. En consecuencia, debería procurarse obtener unas condiciones ambientales que fueran convenientes con objeto de garantizar la seguridad material de dichos bienes culturales. Los especialistas responsables deberían incluir en los 
inventarios informaciones relativas al estado material de los objetos y recomendaciones aconsejando las necesarias condiciones ambientales."

La recomendación no ha perdido su vigencia, los principios generales y las medidas propuestas donde se dan una serie de pautas tanto para museos, instituciones similares como para colecciones privadas con el objetivo de atenuar los riesgos antes descritos- las suscribimos plenamente por su actualidad y destacamos que entre estas últimas está:

"Estimular a los museos y a las instituciones similares a reforzar la prevención de los riesgos mediante un sistema global de medidas y dispositivos prácticos de seguridad; y asegurar a todos los bienes culturales muebles condiciones de almacenamiento, exposición y transporte que los protejan contra todas las formas de deterioro y de destrucción, en especial el calor, la luz, la humedad, la contaminación y contra los diferentes agentes químicos y biológicos, las vibraciones, los golpes."

En esta recomendación queda claro que la responsabilidad de la conservación del patrimonio mueble recae fundamentalmente en los gobiernos: "los Estados Miembros deberían tomar todas las disposiciones necesarias para la apropiada protección de los bienes culturales muebles en los museos e instituciones similares", pero a su vez los museos son los responsables de aplicar las medidas necesarias; además el documento detalla cuáles son los agentes de deterioro que afectan a este patrimonio que se recogerán en los planes de conservación preventiva de finales de los años ochenta y principios de los años noventa. Por último, en el punto 17 habla de otra cuestión esencial que es la toma de conciencia del valor de los bienes culturales y de la necesidad de protegerlos; para ello hay que utilizar "todos los recursos posibles de educación e información".

Para ayudar a los museos en esta tarea, en 1978 se publica el libro probablemente más importante en conservación preventiva: The Museum Environment, escrito por Garry Thomson, asesor científico de la Galería Nacional de Londres de 1960 a 1985 [figura 1]. Como explicaba en el prólogo a la primera edición:

"Este libro tiene un propósito doble, y por eso lo dividimos en dos partes. La primera pretende constituir un libro de texto paras conservadores de museos preocupados por los efectos de la luz, la humedad, la contaminación del aire sobre los objetos, así como la manera de reducirlos al máximo. Los conocimientos científicos necesarios para esta primera parte son mínimos. En cuanto a la segunda, va dirigido a quienes trabajan en el campo de la investigación en conservación y resume informaciones hasta entonces dispersas o de acceso difícil. Para esta segunda parte es necesaria cierta familiaridad con los conceptos científicos generales."

La conservación preventiva estaba basada en evidencias científicas, aparte de las recogidas por la experiencia de todos aquellos encargados en la conservación del patrimonio, y Thomson mantenía que "el objetivo principal de la ciencia en museos era la prevención del deterioro", planteó que controlar las condiciones medioambientales puede minimizar el daño a los objetos y ralentizar su deterioro. 


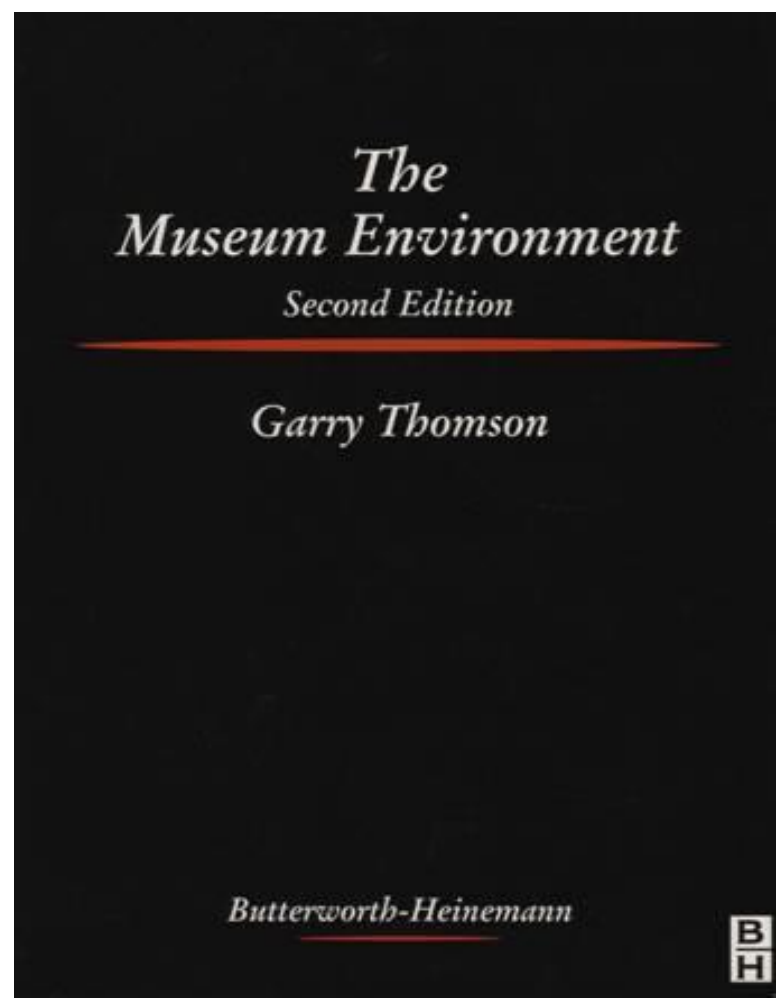

Figura 1. Portada del libro de Garry Thomson 2a edición 1986

El libro de Thomson se ocupa principalmente de los agentes medioambientales: la luz, la humedad y su relación con la temperatura y la contaminación, explicando cuáles son las características de estos agentes, los daños y efectos sobre los materiales, los aparatos de medición y los medios de control. Thomson quería crear un marco general de conocimiento sobre los agentes citados con el que se pudieran resolver problemas particulares, teniendo en cuenta el contexto de las diferentes condiciones climáticas y los requisitos de cada objeto; este marco, por otra parte, estaría sujeto a revisión teniendo en cuenta los cambios y nuevas aportaciones que pudieran surgir en el campo de la conservación. En la segunda edición en 1986 reconoce que la publicación del libro fue muy oportuna, desde entonces el interés por la conservación preventiva había crecido de manera significativa y habían aparecido muchos estudios, desde los más elementales y prácticos accesibles a todo el mundo, hasta los más avanzados desarrollados por instituciones como el Instituto Canadiense de Conservación y su Departamento de Medioambiente y Deterioro que iban destinados a los profesionales de los museos y el patrimonio. Thomson habla de la aparición del libro The National Trust Manual of Housekeeping de 1984, en el cual se proponían medidas prácticas para la conservación de todo tipo de objetos que se pudieran encontrar en casas históricas, y estaba concebido como un manual básico. Este libro luego se amplió considerablemente, y la última edición de 2011, que se llamó The National Trust Manual of Housekeeping. Care and conservation of collections in historic houses, consta de 928 páginas y en ellas se exponen además de técnicas de restauración para toda clase de objetos históricos, las medidas de conservación preventiva para estas colecciones y edificios de importante valor patrimonial, además se explica la manera de compatibilizar la conservación, la exposición de las colecciones históricas y su acceso público. 
La difusión del libro de Thomson fue muy grande, ya que recogía y sistematizaba los datos conocidos y se actualizaban con las investigaciones llevadas a cabo principalmente en la Galería Nacional de Londres. Y algo muy importante, se establecían estándares para el control de los agentes de deterioro en las salas y almacenes de los museos, algo que demandaban los conservadores de estas instituciones.

También es interesante destacar la publicación del número monográfico de la revista Museum en 1982 titulado La conservación: un desafío a la profesión en el que se destaca el artículo de Philip Ward "La conservación: el porvenir del pasado" que marcó un hito en la consolidación de las disciplinas de la conservación y la conservación preventiva; en él dice que:

Todo lo que realmente conocemos sobre nosotros mismos y sobre nuestro mundo proviene del pasado. Y todo lo que conocemos verdaderamente del pasado es aquella parte que ha sobrevivido bajo la forma de objetos materiales. Solamente una pequeña fracción de nuestra historia está consignada de manera escrita, y esta está sujeta a los errores de interpretación humanos. Solo los especímenes materiales de la historia natural y humana son indispensables, ya que son la materia prima de la historia, los hechos innegables, la verdad sobre el pasado. La conservación es el medio a través del cual preservamos. Es un acto de fe en el futuro.

Además, añadía que "la principal tarea de un museo es preservar aquellos objetos del pasado que están a su cargo para las generaciones pasadas y futuras". En este artículo expuso su famoso decálogo que resumía los contenidos y técnicas asociados a la conservación y avanzó en el terreno de la conservación preventiva, disciplina que aborda en su libro La conservación del patrimonio: carrera contrarreloj, publicado en 1986 por el Getty Conservation Institute (GCI) y el ICOM [figura 2].

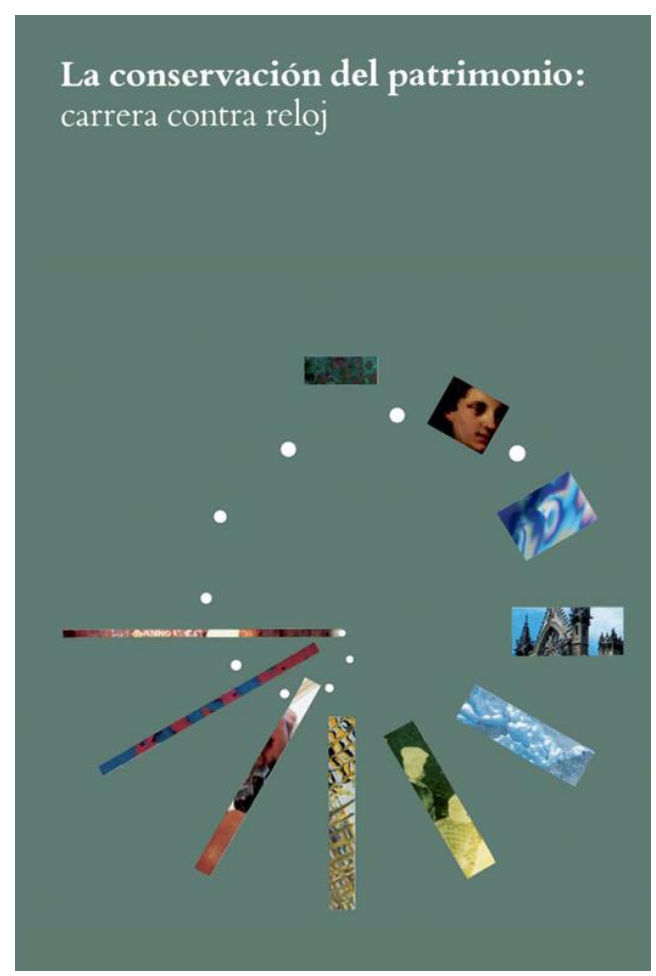

Figura 2. Portada del libro de Philip Ward, 2ª edición, 1992. 
La importancia de este libro radicaba en su objetivo de introducir el tema de la conservación del patrimonio cultural a los museólogos, teniendo un enfoque intencionadamente generalista; su objetivo era explicar el papel de la conservación en el museo y destacaba que la conservación es simplemente la aplicación del sentido común. Gran parte del contenido de este libro sigue siendo aún hoy en día relevante, como dice Timothy P. Whalen, director del GCl; sin embargo, "debe mencionarse que esta publicación representa un momento determinado en el tiempo y que muchos aspectos del enfoque de la conservación que sta presenta han cambiado desde su publicación", sobre todo porque el campo de la conservación se ha ido especializando para abarcar la conservación preventiva, la conservación curativa y la restauración; no obstante, el mérito de Ward estriba en intentar explicar de manera sencilla los retos de la conservación y llegar a todo aquel que tiene relación con este campo poniendo de relieve su interdisciplinariedad.

Sin dejar la década de 1980, destacamos una institución fundamental, que ya hemos mencionado, el GCl creado en 1985 y ahora ubicado en el Centro Getty de Los Ángeles, Estados Unidos. El GCl es una entidad sin ánimo de lucro que trabaja a nivel internacional en el avance de la conservación aplicada a través de la investigación, educación, trabajo de campo y difusión del conocimiento; cuenta con laboratorios científicos y oficinas para la administración de proyectos e investigaciones, además del centro de información sobre conservación. Aunque de reciente creación, el GCl es uno de los centros de conservación más importantes que se ha posicionado como entidad de referencia a nivel mundial al desarrollar proyectos novedosos gracias a su destacado apoyo técnico $y$ financiero.

En los años ochenta también hay que referirnos a dos publicaciones fundamentales en la aplicación de la conservación preventiva -además de la que mencionara Thomson en la segunda edición de su libro-, estamos hablando de Manual of Curatorship: A Guide to Museum Practice editado por John M. A Thompson en 1984, y Conservation and Exhibition: Packing, transport, storage and environmental considerations, escrito por Nathan Stolow y publicado por primera vez en 1986. Hay que recordar que en 1979 N. Stolow ya había publicado Conservation standards for works of art in transit and on exhibition, que fue editado por la UNESCO y ha sido un referente fundamental en el establecimiento de estándares y prácticas asociadas a la exposición. Los libros de Thompson y Stolow están concebidos como manuales prácticos, el primero abarca todo lo relativo al funcionamiento de un museo en el que entra la conservación de las colecciones, por ello se dedican capítulos a la conservación y la documentación, el control y medición del medio ambiente, la conservación y el almacén de diferentes tipos de colecciones: sistemas de almacenamiento, exposición y manipulación; además del control de plagas y los planes de emergencia. El segundo libro se dedica a un aspecto fundamental en la vida de los museos, que es la exposición; hemos de tener en cuenta que la conservación y la exposición han estado íntimamente relacionadas desde los orígenes del museo y es en este ámbito donde se producen los mayores problemas asociados con daños o deterioros de objetos, muchos de ellos provocados por el desconocimiento de los procesos que comprende un proyecto de exposición, esta obra fundamental expone estos problemas y da soluciones prácticas para que los profesionales puedan actuar en consecuencia. Se incluyen capítulos sobre los principios generales en los que se basa la conservación y desarrolla todo lo que tiene que ver con el proceso de exposición y su relación con la conservación preventiva: procedimientos de examen y confección de informes, manipulación, almacenamiento, embalaje de objetos patrimoniales, diseño y construcción de contenedores apropiados, monitorización de cajas de embalaje en itinerancia, modos de transporte, equipamiento y control en salas de exposición, seguros y directrices contra vandalismo, fuego y emergencias y otros agentes de deterioro. 
A partir de la década de 1990 la conservación preventiva ha conocido un desarrollo espectacular de sus teorías y técnicas, dando lugar a un gran número de investigaciones y a un fecundo intercambio de experiencias entre profesionales, aunque todavía queda mucho campo por recorrer en cuanto a su aplicación.

*Texto basado en un capítulo del libro Conservación preventiva de bienes culturales, publicado por Alianza Editorial, en Madrid, 2013.

\section{Bibliografía}

ARGERICH, Isabel y ARA, Judith (eds.) (2003): Arte Protegido. Memoria de la Junta del Tesoro Artístico durante la Guerra Civil, Madrid: Instituto del Patrimonio Cultural de España y Museo Nacional del Prado. Ministerio de Cultura. $1^{\text {a }}$ ed. 2003 (ed. Corregida 2009).

BRUQUETAS, Rocío (2009): "La restauración en España. Teorías del pasado, visiones del presente". En el IV Congreso del GEIIC. La Restauración en el siglo XXI. Función, estética, imagen, Cáceres: Universidad de Extremadura, 37-53.

Consejo Internacional de Museos (ICOM) (2006): Código de Deontología para los Museos. París: ICOM.

COREMANS, Paul (1969): "The Training of Restorers". En Problems of Conservation in Museums/ Problèmes de conservation dans les musées. Travaux et Publications de I'ICOM 8, París: Editions Eyrolles, 7-32.

ERHARDT, David, TUMOSA, CHARLES S, y MECKLENBURG, Marion F. (2007): "Applying Science to the Question of Museun Climate" en Tim Padfield y Karen Borchersen (eds.) Museum Microclimates, Copenhague: National Museum of Denmmark, 11-18.

GONZÁLEZ-VARAS, Ignacio (1999): Conservación de Bienes Culturales. Teoría, historia, principios y normas. Madrid: Manuales de Arte Cátedra.

HATCHFIELD, Pamela (2011): "Crack Warp Shrink Flake. New Look at Conservation Standards", Museum, January/February, 40-55.

PLENDERLEITH, Harold J. (1956): The Conservation of Antiquities and Works of Art, Londres: Oxford University Press.

PLENDERLEITH, Harold J. y PHILIPPOT, Paul (1960): "Climatology and Conservation in Museums", Museum, 13, 242-289.

RATHGEN, Friedrich (1905): The Preservation of Antiquities. A Handbook for Curators, Cambridge: University Press.

ROSENBERG, G. (1933): “Antiquities and humidity”, Museums Journal, 33, December, 307-350.

RUSKIN, John (1988): Las siete lámparas de la arquitectura. Barcelona: Alta Fulla.

SANDWITH, Hermione y STAINTON, Sheila (1984): The National Trust Manual of Housekeeping: A Practical Guide to the Conservation of Old Houses and Their Contents, Harmondsworth: The Penguin Books with the National Trust.

STOLOW, Nathan (1979): Conservation Standards for Works of Art in Transit and on Exhibition, Museums and monuments series, 17, París: UNESCO.

-(1986): Conservation and Exhibitions: Packing, Transport, Storage and Environmental Considerations, Stoneham, Mass: Butterworths Publishers.

THOMPSON, John M.A. (ed.) (1984): Manual of Curatorship: A Guide to Museum Practice Oxford: ButterworthHeineman. $2^{\mathrm{a}}$ ed. 1992.

THOMSON, Garry (1978): The Museum Environment, Londres: Butterworths. 
UNESCO (1972): Convención sobre la Protección del Patrimonio Mundial, Cultural y Natural adoptada en Paris el 16 de noviembre.

-(1978): Recomendación sobre la Protección de los Bienes Culturales Muebles, París, 28 de noviembre.

WARD, Philip (1982): “La conservación: el porvenir del pasado”, Museum, XXXIV, 1, 6-9.

-(1986): La conservación del patrimonio: Carrera contrarreloj. Marina del Rey: The Getty Conservation Institute. $2^{\mathrm{a}}$ ed. 1992.

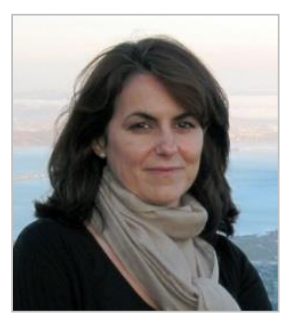

\section{Isabel M. García Fernández}

museoig@ucm.es

Isabel M. García Fernández es profesora titular de la Universidad Complutense de Madrid. Imparte docencia en la Facultad de Bellas Artes en el Departamento de Pintura y Restauración, en el Grado y Máster de Conservación y Restauración del Patrimonio Cultural. Pertenece al grupo de investigación 930420 Técnicas de Documentación, Conservación y Restauración del Patrimonio, validado por la ANEP y la UCM. Doctora en Geografía e Historia por la UCM, se especializó en museología y museografía (M.A. en San Francisco State University) y conservación preventiva (Beca de investigación en el Canadian Conservation Institute), disciplina que fue objeto de su tesis doctoral y de varios trabajos de investigación y publicaciones.

Artículo enviado el 25/10/2013 


\title{
Ge-conservación
}

Conservação | Conservation

\section{De Sarajevo a los brioches de María Antonieta. Conversaciones con Arsenio Sánchez Hernampérez}

\author{
Por Rocío Bruquetas y Charo Fernández
}

El Premio Nacional de Restauración y Conservación de Bienes Culturales ha sido otorgado este año de 2013 a Arsenio Sánchez Hernampérez, conservador-restaurador de la Biblioteca Nacional de España, en reconocimiento a una trayectoria que, en palabras del jurado, ha hecho evolucionar la disciplina «hacia un nuevo paradigma científico y ético que sirve de modelo entre profesionales de la conservación y restauración así como de archivos y bibliotecas». Arsenio representa, en efecto, esa evolución profesional experimentada por muchos restauradores desde los últimos 30 años, que han ido completando su formación convencional en las escuelas de restauración con estudios universitarios. Pero en su caso, además, ha incorporado para beneficio de toda nuestra comunidad profesional, un admirable recorrido intelectual y una vocación por trasmitir sus conocimientos que quedan

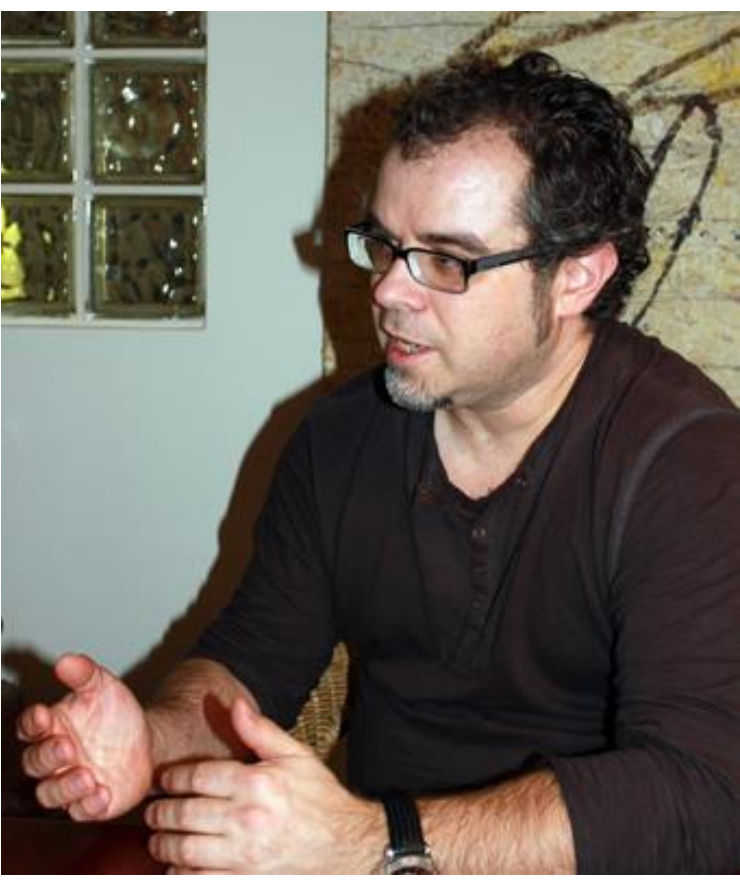

Arsenio Sánchez Hernanpérez plasmados en su amplísima producción escrita, en su labor docente desarrollada en numerosas escuelas y universidades y en sus contribuciones científicas a congresos y simposios.

Arsenio Sánchez inició sus estudios en la especialidad de Conservación y Restauración del Documento Gráfico en la Escuela de Artes Aplicadas y Oficios Artísticos de Madrid, Sección de Artes al Libro, especialidad que culminaría en 1998 con su diplomatura en la Escuela Superior de Conservación y Restauración de Bienes Culturales de Madrid. Unos años antes, en 1993, se había licenciado en Geografía e Historia, con la especialidad de Prehistoria y Etnología. Desde 1988, año en que se graduó en la Escuela de Artes Aplicadas, comenzó su andadura como restaurador de libros y documentos, primero en el Instituto del Patrimonio Histórico Español (actual IPCE), después en el Museo Nacional del Pueblo Español y por último en la Biblioteca Nacional, donde trabaja con carácter fijo desde mayo de 1992. Pero su curriculum vitae tiene otro capítulo importante en la labor docente, desde su participación como profesor de la Escuela Universitaria de Biblioteconomía y Documentación de la Universidad San Pablo CEU de Madrid, a sus numerosísimas colaboraciones en master universitarios (UCM, Autónoma de Madrid y Carlos III entre otras), cursos nacionales y seminarios internacionales, con los que ha viajado a diferentes países de Iberoamérica para impartir cursos y conferencias sobre preservación de patrimonio documental. En la Biblioteca Nacional ha comisariados dos exposiciones: la primera en 2012, La química de los libros: Ciencia y 
conservación del patrimonio documental, y la segunda, entre marzo y mayo de 2013, Piel Sobre Tabla: encuadernaciones mudéjares de la Biblioteca Nacional, en colaboración con Antonio Carpallo Bautista.

Por último, queremos destacar uno de los trabajos a los que él se siente ligado de una manera especial, el proyecto internacional para la "Dotación e instalación de los talleres de Restauración y Encuadernación de la Biblioteca Universitaria de Bosnia Herzegovina en Sarajevo, un proyecto que coordinó desde la ONG Paz Ahora entre agosto de 1999 y octubre de 2001, subvencionado por la AECID. Con este tema, clave en su trayectoria, comenzamos la entrevista.

\section{Entrevista}

Pregunta: La magnitud del desastre patrimonial y la tragedia humana que pudiste conocer de primera mano en la capital bosnia tras la guerra ¿ha marcado tu visión de lo que debe ser la conservación del Patrimonio Cultural?

Arsenio Sánchez: Este proyecto me obsesionaba desde que vi la destrucción de la Biblioteca, casi en directo, en los noticiarios televisivos del 25 de agosto de 1992. El conflicto bosnio había estallado meses antes y ya se empezaba a hablar de limpieza étnica y de memoricidio. La guerra, de carácter nacionalista, pretendía imponer una cultura sobre otras. Sí, hubo destrucciones con intereses estratégicos y económicos claros, pero con la destrucción de los censos de población del siglo XIX, de Vijecnica -sede de la biblioteca- o de las mezquitas de Foca, se trataba de destruir el patrimonio del enemigo, las culturas "extrañas", los símbolos, la composición multiétnica de Yugoslavia y todo lo que ello representaba. En 1998, Julian García, Villalobos, que preparaba un proyecto para la O.N.C.E. en Mostar, contactó conmigo y me ofreció la posibilidad de trabajar en la Biblioteca. Algunos meses después ya me había documentado, e incluso había empezado a estudiar el fenómeno del memoricidio como parte de los proyectos genocidas en sistemas totalitarios y creía estar

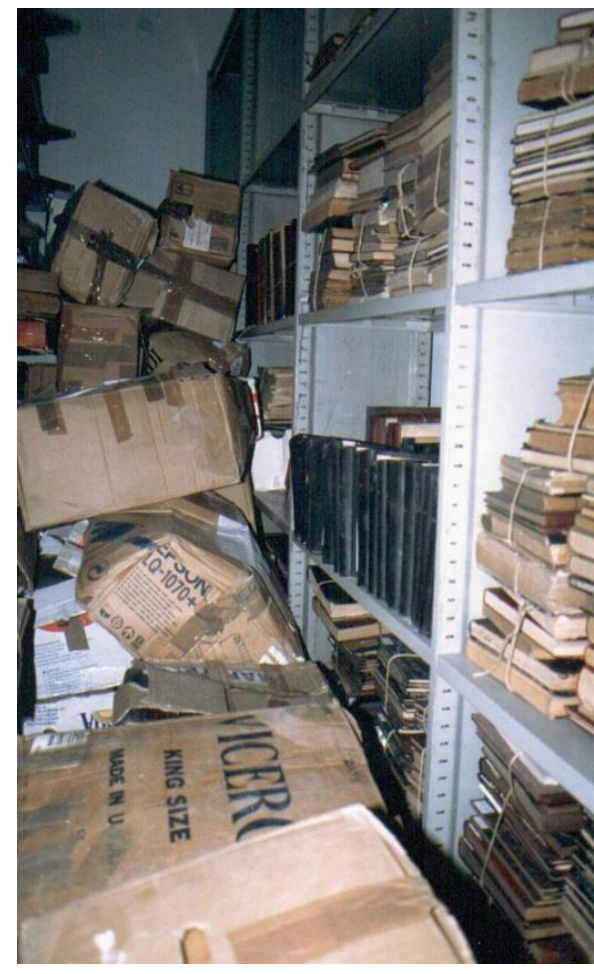

Parte del material bibliográfico recuperado después de la destrucción espera ser procesado en los nuevos depósitos de la BNUBH en Sarajevo. (O)2013. Arsenio Sánchez. preparado para verlo de primera mano. Sin embargo, la realidad fue mucho más dura de lo que había imaginado. En junio de 1999 hice mi primer viaje. Para salir del aeropuerto de Sarajevo hay que atravesar el barrio de Dobrinja uno de los frentes más duros de la guerra. La destrucción allí era especialmente brutal: casas enteras destruidas con armas cortas, huellas del impacto de obuses en muros y en el propio aeropuerto y, algo que me impactó especialmente, los destrozos de la metralla. A pesar de los niños jugando en la calle, la sensación era angustiosa, y, lo peor es que ese sentimiento no paraba de crecer cada día. Así, de pronto empecé a preguntarme qué hacía yo allí, un restaurador de bienes culturales que no paraba de hablar de reconstruir una biblioteca cuando la gente malvivía en casas con paredes y techos de plástico. Empecé a sentir vergüenza y una sensación terrible de ridículo: yo venía a restaurar 
manuscritos cuando las mujeres de Sbrenica aún lloraban a sus muertos o en Sarajevo había colas de gente esperando horas para recibir una ración de comida. Dos años después, cuando terminamos el proyecto, me di cuenta que tal vez no me había equivocado tanto y que la cooperación podía contribuir a salvar los símbolos que permiten vivir a la gente en sociedad y a sentirse personas.

P.: Son sus señas de identidad y verlas reconstruidas es un alivio para ellos. Es la forma en la que nosotros como restauradores podemos contribuir a mejorar la sociedad, porque es lo que sabemos hacer. Tú llevas participando desde hace años con bomberos del Grupo Español de Ciudades Patrimonio de la Humanidad. Cuéntanos algo de esta experiencia.

A.S.: Se trata de una iniciativa de los principales parques de bomberos de las ciudades declaradas por UNESCO Patrimonio de la Humanidad en España. Hay representantes de Cuenca, Santiago de Compostela, Toledo, Ávila, Ibiza o Córdoba entre otras. Muy concienciados con la importancia del patrimonio de sus localidades, empezaron a trabajar solos sobre cómo actuar en caso de desastre en los lugares patrimoniales. Apenas tenían información y por ello solicitaron ayuda al Ministerio de Cultura y otros organismos como el Museo Guggenheim de Bilbao, la Biblioteca Nacional de España, el Instituto de Patrimonio Cultural Español o el Cuerpo de Bomberos de Colonia. Está siendo una experiencia modélica, pues los conservadores podemos trabajar con todo el conocimiento de los expertos en situaciones catastróficas $y$, a la vez, ellos se benefician de las informaciones técnicas que restauradores, facultativos de museos, archivos y bibliotecas. Hemos realizado grandes simulacros en Segovia, Toledo o Tenerife y, a la vez, estamos colaborando con otros países en proyectos europeos -HeriProt- o formando a bomberos de Valparaíso o de La Habana.

P.: Representas una de las voces críticas más atinadas dentro de nuestra profesión. Tu interés por desmitificar aflora siempre en tus escritos, no hay más que ver algunos títulos de tu bibliografía. En uno de ellos, publicado en el año 96, "Paradigmas conceptuales de conservación", ya hablabas sobre cuestiones que hoy podemos seguir planteándonos con la misma actualidad, como la inadecuación de las políticas de conservación del Patrimonio, o el mito de la objetividad en la restauración y la restauración científica.

A.S.: Ahora pienso que son trabajos de juventud, que pecan de ingenuos, y me sonrojo al releerlos, pero estoy orgulloso de ellos. Empecé a pensar la profesión desde un punto de vista crítico. Siempre me ha gustado ser un iconoclasta y desmontar los mitos a los que nos aferramos. Por ejemplo, algo que comentaba en ese artículo era el proceso de nacimiento de la restauración científica -que yo llamaba ortodoxa por ser reconocida como buena por la comunidad de restauradores-, algo que se ha santificado durante muchos años y que se ha consagrado como la entrada en la mayoría de edad de la conservación de bienes culturales. Con ello, el debate ideológico -y aún el técnico-, parece haberse diluido. Hoy en día hablamos de resultados aportados por las técnicas instrumentales en el análisis de los materiales, pero ya no hablamos de procedimientos manuales ni de la maravillosa carga artesanal del restaurador antiguo. Se ha perdido la parte más simbólica en pos de ese cientifismo cuyo reflejo es una abrumadora cantidad de publicaciones basadas en análisis instrumentales pero muy pocas que describen técnicas o procesos de restauración. Mi impresión es que los restauradores de Patrimonio Histórico nos encontramos hoy encorsetados entre la obligación de restaurar obras del pasado, resultado de un proceso generalmente artesano $-\mathrm{y}$ por tanto eminentemente subjetivo- y la pretendida objetividad del trabajo "científico". Pero un trabajo científico no es solo "mirar por un canuto", como decía en tono iconoclasta Ortega y Gasset de Ramón y Cajal: lo importante no es el 
microscopio, sino el señor que está detrás de él y la interpretación que hace de lo que observa. En ese sentido los restauradores hemos dejado de interpretar porque nos resulta más fácil confiarlo todo a las máquinas. Nunca negaré que conocer los procesos químicos o cómo funcionan los materiales es fundamental para el restaurador, pero de ahí a que sea el objeto de la Restauración... tal vez hemos confundido el método con el objetivo

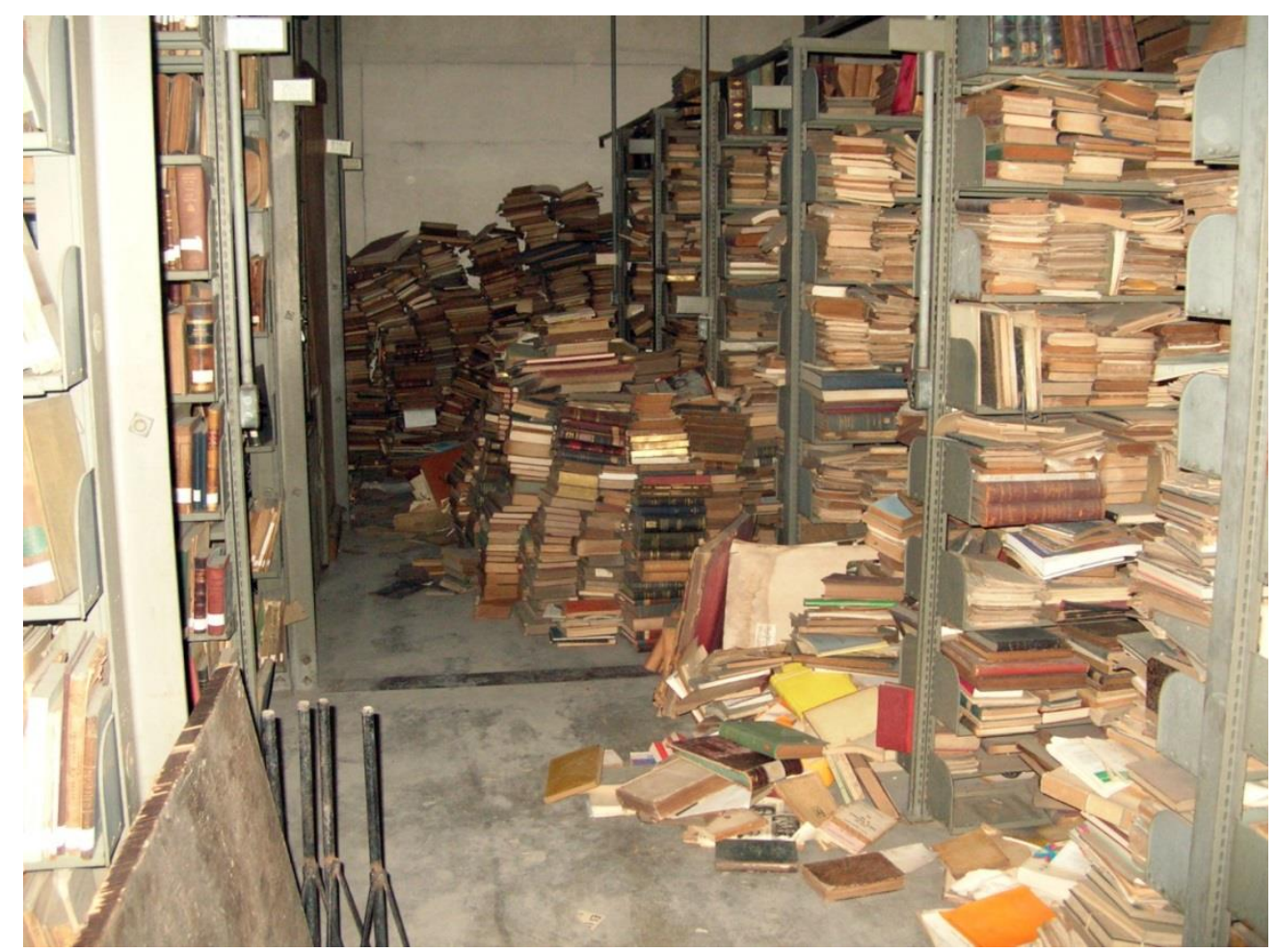

El gran desafío de la conservación en situaciones calamitosas. @2013, Arsenio Sánchez.

P.: Más bien menospreciamos ese tipo de trabajos, los consideramos signo de inmadurez. Pero recientemente el ICCROM ha distribuido una encuesta para conocer el acceso real de los restauradores a resultados de investigaciones científicas aplicadas a la restauración, y la valoración de este colectivo sobre su utilidad en sus prácticas. ¿No encuentras que hay una distancia enorme entre lo que se investiga y nuestra práctica real?

A. S.: En parte, la investigación es así. El problema es que nos encontramos todavía con muchos vacíos de información o que no siempre llega con la velocidad que quisiéramos. Por ejemplo, la desacidificación masiva del papel comenzó a estudiarse a principios de los 70 y la Biblioteca del Congreso ha empezado a utilizarla a escala industrial después de 20 años de experimentación. Ahora estamos trabajando en un proyecto del Instituto de Investigaciones Agrarias (INIA) en el que participa la Biblioteca Nacional de España para desarrollar bacterias generadoras de celulosa cristalina, de gran calidad, para refuerzo de las fibras de papel. Se han hecho grandes avances, pero quizá pasen años hasta que se puedan aplicar. Pero no siempre es así: un ejemplo de investigadora que tiene muy claro cuál es su profesión y que nunca pierde de vista las necesidades de la práctica real de la conservación es Nieves Valentín. Sus publicaciones siempre tienen una utilidad real. Cuando empezó a investigar con atmósferas inertes se ridiculizaron sus aportaciones, pero hoy son estándares internacionales en desinsectación de bienes culturales. 
P: Sin embargo, el desafío actual no reside tanto en los avances tecnológicos, sino en saber mirar a nuestro alrededor, abordar la conservación del Patrimonio desde el reconocimiento de su significado para la sociedad, sus valores culturales, en lo que entran a juego otro tipo de análisis, sociológicos, antropológicos, económicos...

A.S.: Sí, hay que analizar la carga cultural de lleva cada objeto. ¿Quién es propietario de la obra de arte? Un colectivo determinado. Pienso que la imagen del Patrimonio como tótem de la civilización no es buena porque aleja al ciudadano de la cultura y restringe su acceso a las élites. El ciudadano tiene que sentir que el Patrimonio forma parte de su vida y que puede acercarse a los grandes tesoros patrimoniales porque el Estado garantiza ese acceso. Debemos entender que el patrimonio no es algo propio de élites sino objetos reales que forman parte de nuestra vida cotidiana: en los momentos en los que Bach estaba componiendo el preludio de la primera Suite para violonchelo tal vez se estaba ahorcando a un pobre infeliz en una plaza de Cöthen. Ambos acontecimientos son parte de la vida misma y debemos aceptar que el mundo está lleno de contradicciones. Creo que uno de los problemas que hemos tenido los restauradores es que transmitimos esa idea equivocada del pasado a través de nuestro trabajo. Yo escribí hace muchos años que las restauraciones que se realizaban intentando estrechar los lazos que unían la obra con la sociedad no tenían por qué ser ilícitos, aunque chocaran con nuestros criterios de intervención. La gente de Borja está orgullosa porque desde hace dos años su localidad se hizo famosa por una desafortunada intervención restauradora. Hoy los habitantes de la ciudad están mucho más unidos a su Ecce Homo que lo había estado hasta entonces. Desde nuestro conocimiento académico y formal de restauradores eso nos choca, nos disgusta, pero hemos de admitir que nunca habría saltado a la fama con una intervención ortodoxa.

P.: Es indudable que ya es un icono para mucha gente, ha trascendido de ser una simple restauración burda a un hecho cultural, nos guste o no.

A.S.: No llega a restauración burda, como mucho, grotesca. Nosotros, en cambio, no hemos logrado conectar con los ciudadanos de igual modo. Parece que en ese lamentable caso, la acción de los medios de comunicación y la necesidad de dar "espectáculo" hace que trascienda no como un esperpento irrepetible sino como un hecho cultural relevante. A mí me gustaría que mis trabajos de restauración pasaran a formar parte del equipaje cultural de los ciudadanos, que se identificaran con las obras tratadas y que se apropiaran de sus valores, pero lo veo muy difícil.

P.: También podemos encontrar en las ciencias sociales otro tipo de herramientas que nos facilite información para nuestros múltiples interrogantes, como, por ejemplo, parámetros de evaluación para medir los riesgos y la calidad de los tratamientos.

A.S.: Efectivamente, la respuesta no es única ni simple y cualquier solución en conservación requiere análisis complejos. Por ejemplo, la importancia de un libro ¿cómo se valora? ¿Está en la portada o en el bloque de texto? Pues depende de a quien preguntemos. Para el estudioso estará el bloque de texto, pero para el bibliotecario, probablemente en la portada... ¿Qué es lo que tenemos que medir para cuantificar la pérdida del valor de un libro? ¿Una hoja, un colofón, la función de la encuadernación? Al final medimos de forma subjetiva, que es una de mis obsesiones: la subjetividad del restaurador.

P.: Pero la subjetividad no tiene por qué ser mala, lo importante es la actitud crítica y argumentada del restaurador. 
A.S.: No, ¡si yo la defiendo! El restaurador tiene que ser subjetivo al tomar decisiones, y aceptar que las está tomando. ¿Miramos por un canuto y ya está? Seguimos necesitando ese instrumento que permita diferenciarnos de los malos artesanos o de la señora del Ecce Homo de Borja. La diferencia está en la forma de pensar los problemas y las soluciones. Todos queremos pensar en términos absolutos, nos gustaría que nos dijeran "este manuscrito, en estas condiciones de HR y T va a desaparecer en 35 ó 40 años", pero la realidad nos ha demostrado que no es así de sencillo. Nuestros códices han estado en condiciones lamentables durante siglos, han pasado guerras y, sin embargo han llegado hasta aquí.

P.: Esa idea es un arma de doble filo, una justificación para la administración o los tutelares de que no hay que hacer nada...

A.S.: En absoluto, el Estado debe mimar su patrimonio porque es delicado y tiene grandes necesidades. Miro con envidia el desarrollo de la conservación en las instituciones documentales inglesas, holandesas o norteamericanas, pero su situación no es casual: las administraciones de aquellos países consideran sus bibliotecas y archivos como joyas culturales a las que deben alimentar y proteger. Algo que no me cuadra del caso español es por qué se conceden presupuestos generosos a los grandes museos y se abandonan a los grandes archivos y bibliotecas. La explicación puede estar en esa idea de la sociedad española de que las bibliotecas y archivos son lugares grises a los que van personas muy aburridas. Ello nos lleva a su desaparición o en el mejor de los casos, a la estrangulación económica. Tenemos importantes instituciones documentales al borde del colapso por la falta de medios, personal e instalaciones adecuadas. Creo que el problema es de base, y de una educación que no valora el patrimonio cultural en términos de desarrollo sino sólo como fuente de ingresos, la conservación no será una exigencia de la sociedad, sólo un reclamo turístico.

P.: Cómo va a prosperar que el Estado se haga cargo de la conservación del patrimonio, cuando además en estos tiempos se está negando a los ciudadanos servicios y necesidades básicas como la vivienda, la sanidad, la educación... Tenemos que buscar otras vías. Un ejemplo admirable de participación de los ciudadanos en la salvaguarda y conservación de su patrimonio cultural y paisajístico es el National Trust de Reino Unido, ¿cómo interesar a los ciudadanos por la Conservación de su Patrimonio Cultural?

A.S.: Tiene que ver con el papel que el patrimonio juega para el ciudadano. Esa es otra diferencia del patrimonio bibliográfico respecto a otros. Éste es un patrimonio accesible, que se usa, se toca y se manipula, y esa debería ser una de nuestras ventajas, aunque desgraciadamente se ha convertido en todo lo contrario, pues ha llevado a su trivialización. Debemos convencer de su valor y de la importancia de cuidarlo y enriquecerlo.

P.: Eso te ha llevado en muchas ocasiones a plantearte otros criterios de restauración.

A.S.: Una de las ideas clásicas más incompatibles con la conservación del patrimonio documental es que el restaurador tiene que llevar la obra a su estado original. Ello no nos sirve a los restauradores de documentos: la obra tiene una vida, ha sido transmitida de propietario a propietario y cada uno ha ido aportando variaciones, anotaciones, mutilaciones, cambios de encuadernación..., todo esto nos habla de cómo se ha ido transmitiendo ese conocimiento, y a su vez el deterioro ha ido añadiendo información al objeto. Por tanto, cuando restauramos patrimonio documental tenemos que intentar compatibilizar las necesidades de conservación del ejemplar con toda la información que enriquece al ejemplar. Por ejemplo, al fijar la liturgia católica 
en el concilio de Trento, se establecieron los cantos para cada la época del año. Los mismos cantorales se van a usar durante siglos y las manipulaciones y deterioros te indican de cómo se han utilizado. En cada biblioteca te encuentras particularidades. Sin embargo, una práctica de restauración muy común en el pasado fue eliminar todas las huellas de uso. ¿Debemos eliminar esa información?

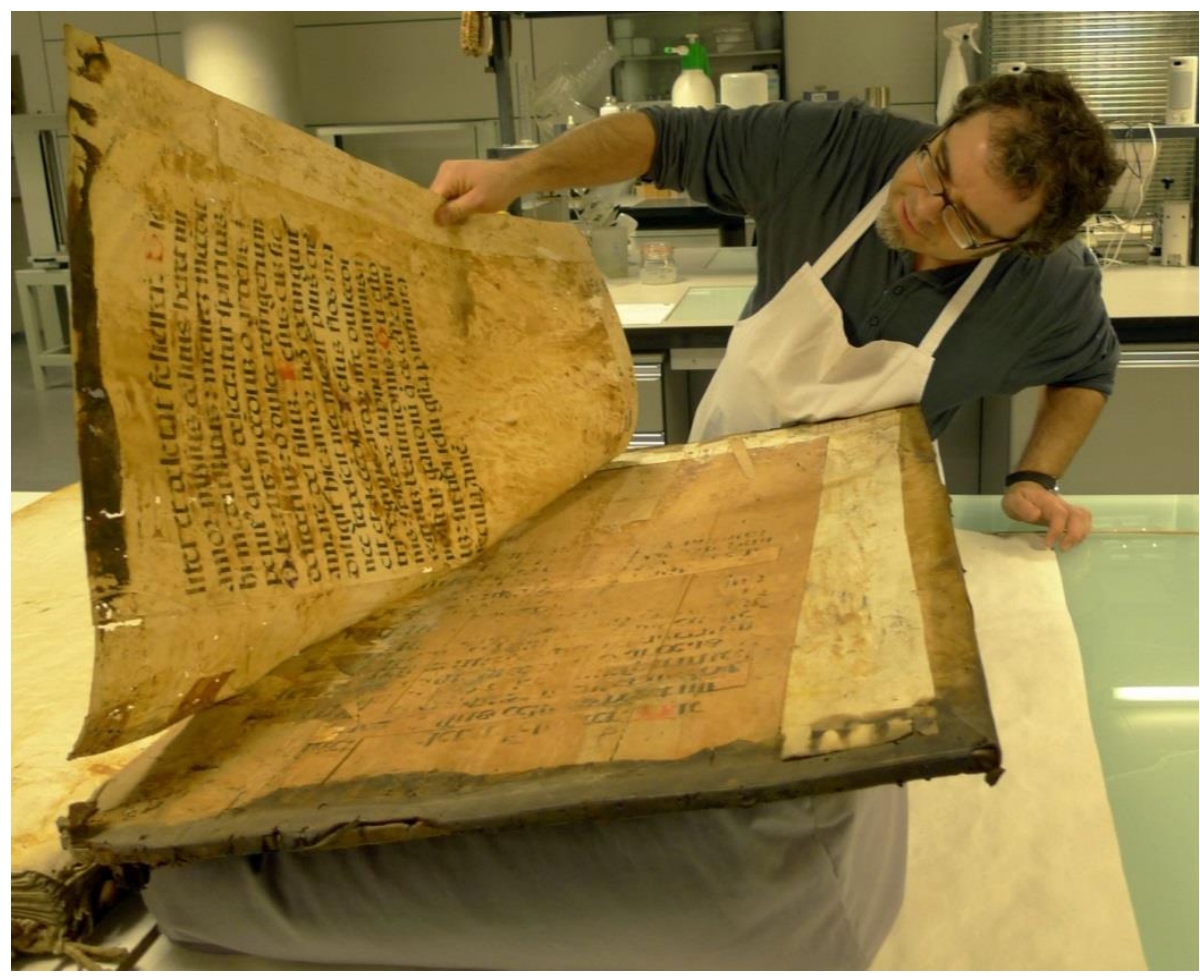

“¿Es posible un criterio universal de restauración? Tal vez, el único criterio de intervención universal sea la búsqueda 'introspectiva', el análisis de la propia personalidad del objeto, lo que es y lo que representa".

P.: Nuestra labor como restauradores se dirige al objeto físico que supone el libro. Nos interesaría saber lo que opinas sobre las bibliotecas del futuro, lo bueno y lo malo que pueden traer.

A.S.: Las bibliotecas están en un momento de crisis importantísimo. Desde los años 70 hubo que redefinir su papel en la sociedad y empezaron a ofrecer nuevos servicios a los usuarios, servicios que eran gratuitos. Pero a partir de los años 90 se comenzó a cuestionar la gratuidad del acceso a esa información y se estableció la obligación de pagar derechos de autor, lo cual me parece casi tan trágico como el hecho de que haya que pagar para entrar en un museo. El caso es que ahora mismo, con las nuevas tecnologías de la información, es mucho más fácil acceder a los contenidos de las bibliotecas y podemos leer la primera edición del Quijote en un Ipad a la vez que hacemos spinning en un gimnasio. Es un proceso que viene de lejos, en concreto desde los años 80 del siglo XX, cuando comienza la era del terror al papel ácido y las bibliotecas se lanzan a reproducir todo lo que creen que van a perder entes del siglo XXI. Actualmente, las bibliotecas digitales han sustituido a las bibliotecas tradicionales gracias a la mayor calidad $y$, sobre todo a la facilidad de acceso. Hoy es posible universalizar el acceso a la información, lo que supone uno de los mayores avances de la sociedad contemporánea, un proceso tan importante como la revolución industrial en el siglo XIX. Pero no todo es luz. En esa carrera de las instituciones hacia la reproducción de los contenidos se 
corre el riesgo de realizarse sin un análisis de lo que tienen que ofrecer esas bibliotecas digitales y, por tanto, de malgastar los recursos económicos: la Biblioteca Nacional no será mejor biblioteca digital por el hecho de ofrecer millones de páginas, sino porque sus páginas reproducen fielmente aquello que la han convertido en una de las diez bibliotecas más importantes del mundo: un extraordinario conjunto bibliográfico que representa fielmente qué es España y que ha aportado a la cultura universal. Esto en ocasiones se ha olvidado y la falta de coordinación entre las bibliotecas españolas ha llevado a que puedes encontrar en la red el mismo periódico en cuatro versiones digitales distintas. Es decir, el ciudadano ¡ha pagado cuatro veces por lo mismo! Eso es trágico si pensamos en déficit de los recursos que tienen las bibliotecas y archivos hoy día. Se están gastando en unas políticas que yo no dudo que sean bienintencionadas, pero no deja de ser, cuando menos superfluo.

P.: Cuando la gente ve esos almacenes atestados de libros y legajos piensa que la digitalización es la solución.

A.S.: Se tiende a pensar que el archivo digital sustituye al documento material, que lo digital no ocupa tanto espacio como el libro físico y, por tanto, cuesta menos conservarlo. Sin embargo, conservar la documentación digital es infinitamente más costoso que la conservación material de libros. La biblioteca del Congreso de EEUU calculó a principios de los 90 que el coste de preservación de un libro de 700 páginas en una caja era de 7 dólares, y que su conservación en formato digital de preservación y alta calidad tenía un coste aproximado de 3500 dólares en 100 años. La regla es sencilla: hay unos costes de digitalización -entre los que no vamos a incluir los costes de preservación del documento original, ni siquiera los de restauración del documento después de haber sido digitalizado, que eso es otro asunto-, y generas un archivo. Pero el coste de la digitalización no acaba ahí, el archivo tiene una permanencia limitada que es necesario actualizar mediante cambios de soporte, de formato o incluso emulando cuando los lenguajes quedan obsoletos. Por otra parte, a medida que se ingresan archivos en los servidores de la Biblioteca, es necesario, actualizar los equipos que deben gestionar archivos muy pesados a gran velocidad con cientos de demandas simultáneas, lo que exige sistemas informáticos cada vez más complejos y costosos. ¿Cuándo cuesta un sistema que gestiona 600 Tbs en línea? Es incalculable, conlleva gastos de mantenimiento de equipos, del personal que los manipula, la propia sala donde se conservan los equipos, la sustitución de componentes obsoletos. Y además, las bibliotecas tienen que ofrecer también otros servicios de información, como el acceso al catálogo, a bases de datos de pago o incluso a exposiciones virtuales y otras actividades. Nos hemos dejado arrastrar por los cantos de sirena de la digitalización y no hemos calculado los riesgos: dependencia de las empresas de software, crecimiento ilimitado del coste de la preservación digital y, como efecto derivado, la desaparición de la conservación material.

P.: Pero desde nuestro punto de vista ¿Qué significa esto? ¿Es que ya no necesitaremos las colecciones materiales de las bibliotecas?

A.S.: No, todo lo contrario. En un comercio, al comprar pagas con una tarjeta de plástico, haces uso de dinero virtual, que no ves, pero ese dinero debe existir en la caja fuerte de tu banco para que se autorice la transacción. En cierta medida, las bibliotecas y archivos son la caja fuerte de la información. Los libros físicos se guardarán en las bibliotecas mientras que la gente hará uso virtual de sus contenidos. Y tener una buena colección indicará la riqueza de tu banco.

P.: Con toda esta fiebre por la digitalización ¿se dedican menos recursos a la conservación documental? 
A.S.: Desgraciadamente si o, al menos, en el caso español. Nos estamos relajando en la conservación material del patrimonio documental y creo actualmente estamos peor que en el siglo pasado. Pero esto no es un problema universal. Las bibliotecas líderes en digitalización y recursos electrónicos son anglosajonas. Ellas imponen el modo en que se debe digitalizar, pero también las condiciones de conservación material porque han transitado previamente por el camino de la conservación material, aplicando métodos y criterios modernos durante mucho tiempo. En nuestro país, en cambio, hemos pasado de no hacer nada a intentar digitalizar todo y nos hemos saltado todo el proceso de entender qué es la conservación. El problema es que probablemente recurriremos a la conservación material cuando empecemos a ver las carencias de la información digital.

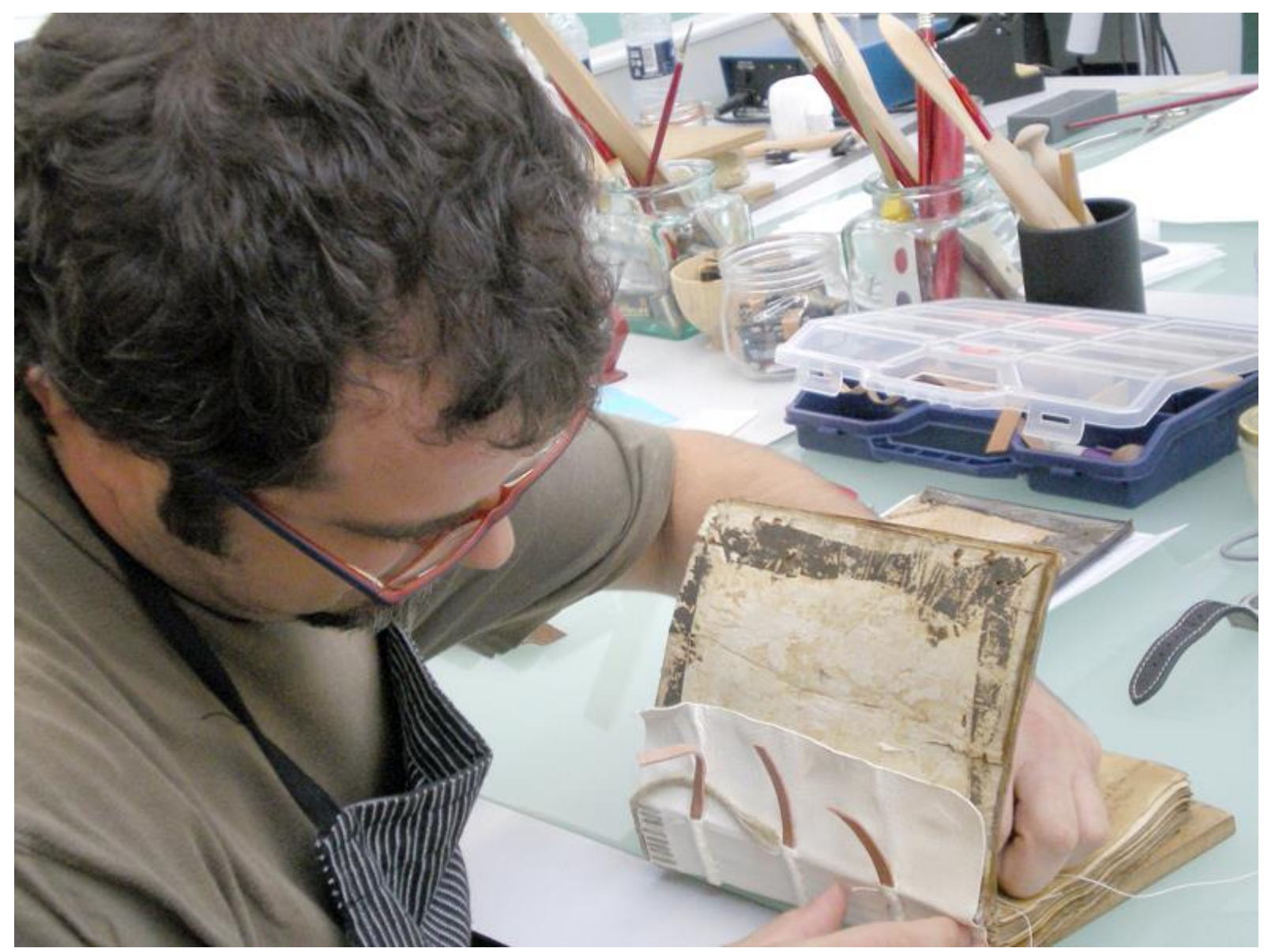

Costura del manuscrito original del Poema de Mio Cid. En su restauración se modificaron algunos elementos de la encuadernación del siglo XVI para mejorar su funcionamiento, aunque conservando el aspecto general.

P.: Hay que pensar que Estados Unidos tiene un acervo histórico y documental más corto.

A.S.: Eso no es cierto. Estados Unidos tiene el mayor patrimonio bibliográfico y documental del planeta, sólo se le acerca Reino Unido. En cualquier caso, ojalá tuviéramos en España los 200 últimos años de nuestra historia conservados de la misma manera. Nuestro país es uno de los líderes mundiales en la destrucción de su patrimonio. Los dos últimos siglos han sido terribles: lo 
hemos vandalizado, abandonado, expoliado, exportado ilegalmente, lo hemos destruido, y no contentos con ello, nos hemos vanagloriado de hacerlo. $Y$ no hablemos de situaciones en las que se entremezclan intereses económicos: los años 60 y 70, con el desarrollismo y la especulación inmobiliaria fueron tan catastróficos para el patrimonio arqueológico y arquitectónico como la Guerra Civil o la pobreza secular.

P.: Nos gustaría que hablemos de una cuestión que también afecta, y muy directamente, a la conservación del Patrimonio Cultural: la situación profesional y laboral de los restauradores. Estamos instalados en una precariedad que no es solo consecuencia de la crisis actual sino que viene de hace tiempo, a lo que se suma una falta general de reconocimiento y una aceptación resignada por nuestra parte de que la función del restaurador se reduce a la mera ejecución ¿Acaso no estamos preparados para dialogar en pie de igualdad con otras profesiones afines a la nuestra en el campo del Patrimonio? ¿Qué opinas sobre todo esto?

A.S.: No ayuda mucho la precaria situación laboral de los restauradores del Ministerio y de otras administraciones, donde los departamentos de restauración carecen de una dirección técnica o están dirigidos por el cuerpo de facultativos. La excusa es que somos técnicos y, por tanto, nuestro perfil se ajusta mejor al de contratados laborales. Ello produce una colisión de funciones entre los facultativos y los restauradores-conservadores y una rivalidad permanente entre ambos colectivos. Efectivamente, son dos parcelas complementarias, pero no podemos obviar grandes diferencias funcionales. A nadie se le ocurriría poner al frente de un departamento de Antigüedades Egipcias y de Próximo Oriente a un funcionario del Cuerpo de Gestión. ¿Por qué algunas instituciones como el Museo del Prado o el Reina Sofía sí han puesto al frente de sus departamentos de restauración a restauradores y el propio Ministerio de Educación Cultura y Deporte no lo admite en las demás instituciones? Si es bueno para instituciones punteras ¿por qué no es bueno para las demás? Es un misterio que se me escapa, pero está limitando increíblemente el desarrollo de una conservación moderna y eficiente en nuestro país.

P.: No ha habido voluntad política desde la administración por cambiar eso, han pasado muchos años desde que se puso en evidencia esa contradicción en nuestro medio profesional y se ha hecho muy poco para solucionarlo.

A.S.: Todo lo contrario, la tendencia es reducir su papel en la toma de decisiones. Cuando yo aprobé mi oposición tenía un nivel asimilado económicamente a titulado superior. El famoso Convenio Único en la Administración General del Estado se supone que habilitaba a los contratados laborales para dirigir departamentos de conservación, pero desde el año 98 no se ha creado ninguna jefatura entre los laborales dentro del convenio. Tampoco se han dotado económicamente los complementos específicos para los restauradores. En realidad fue el inicio de la decadencia de los restauradores en la Administración General del Estado. No obstante, existe una salida y pasa por que el Ministerio recurra a una figura poco conocida, el Cuerpo Técnico de Gestión, un grupo de funcionarios A1 que desarrollan funciones fuera de las habituales de ese grupo. Dado que sólo hay restauradores en el Ministerio de Educación, Cultura y Deportes, sería factible la creación de Cuerpo Técnico de Gestión de Conservadores-Restauradores de Patrimonio $y$ funciones de $\mathrm{A} 1$.

P.: Excepto los ejemplos que has mencionado, no hay en la administración central otros cargos de responsabilidad en conservación y restauración que estén ocupados por restauradores en calidad de su profesión como tal, ciertamente algunos tienen estudios en restauración, pero los méritos que les han llevado a conseguir esa plaza no son los de restaurador si no los de conservador de 
museos. Esto quiere decir que el restaurador encuentra su techo en la función práctica de su trabajo.

A.S.: Por eso se entiende que los restauradores estemos frustrados. A mí me gustaría pensar que tengo una carrera profesional en la Administración o, al menos en la institución para la que he trabajado más de 20 años. Si a veces he pensado en tirar la toalla y dedicarme a la enseñanza de Historia y Geografía en un Instituto de Secundaria ha sido al ver qué la inexistencia de promoción profesional en el ámbito de la restauración.

P.: Un reconocimiento que no sea de palabra solo...

A.S.: En una ocasión, un alto cargo del Ministerio de Cultura espetó a los investigadores del IPCE "ustedes no son personal investigador, son contratados laborales del Ministerio de Cultura". Esa frase es muy cruel, pero expresa una realidad. Nosotros no podemos aportar más porque nuestras instituciones están limitadas por las relaciones de puestos de trabajo y el Estatuto de la Función Pública. Pero no quiero que esto se confunda. Los restauradores somos profesionales bien reconocidos en general, lo que falta es una clasificación funcional que permita desarrollar la profesión dentro del ámbito de la administración. No sólo por una cuestión de modernidad, es que el patrimonio cultural lo necesita. Ello explica que los restauradores andemos tan...

\section{P.: ...tan desfondados...}

A.S.: Lo peor es que la situación, aparentemente, no va a mejorar. La tendencia actual es externalizar los servicios de restauración y a que las plazas de restauradores se vayan amortizando a medida que se vayan produciendo jubilaciones. Serán los facultativos de archivos, bibliotecas y museos en su calidad de responsables de los servicios quienes decidan en qué piezas se va a trabajar, quiénes y cómo. Y esto es un problema para la conservación del Patrimonio, porque nos lleva directamente al ámbito privado, donde la situación es también dificilísima y excelentes profesionales malviven para ganar concursos a la baja. Ya no se negocia la calidad de los proyectos, sino el precio que se va a pagar por ello. En el patrimonio documental la situación es aún peor: las instituciones no suelen tener servicios de restauración. Las bibliotecas de fondo antiguo con taller de restauración en España no deben ser más de diez, tal vez cinco. En el caso de los archivos, las instituciones con laboratorios 
bien montados probablemente sean alguno más, unos 15 ó 20, aunque algunos llevan años instalados sin que nadie haya trabajado jamás en ellos.

P.: Tener un departamento de restauración es un servicio caro, pero qué me dices del futuro, que es la Conservación Preventiva, y el presente para muchos países. ¿Cuántos instituciones dedicadas a la custodia del patrimonio en España tienen un departamento ad hoc para gestionar la Conservación Preventiva? En conservación de patrimonio documental habéis sido los primeros iniciadores en este tipo de prácticas ¿Cuál es la realidad actual de la Conservación Preventiva?

A.S.: La Conservación Preventiva surge como idea en los años 80 cuando se empieza a centrar la atención en las causas del deterioro documental y en su relación causa-efecto. Al principio se intenta desarrollar un enfoque que, a mi modo de ver, se centra especialmente en los números ya que entiende que el deterioro se puede controlar conociendo los procesos físico-químicos que lo causan. Como anécdota, en 1972 se publicó un artículo que trataba sobre la relación entre la temperatura de almacenamiento y el deterioro del papel en el que, basándose en ecuaciones termodinámicas, el autor concluía que cada $7^{\circ} \mathrm{C}$ se reducía a la mitad la esperanza de vida del papel. Incluía un cuadro que se convirtió en un clásico en el que los archiveros y bibliotecario -y también los restauradores- calculábamos cuantos años de vida le quedaban a un libro o un periódico según la temperatura a la que lo guardábamos.

Esa idea simplifica mucho la enorme complejidad que se da en los procesos físico-químicos relacionados con la temperatura, la humedad y la entalpía de alteración o energía que necesitan los materiales para deteriorarse. Claro, estamos en una sociedad un poco perezosa y, al final, lo que hacemos es simplificar $y$, trabajando en el control de humedad y la temperatura, creíamos que podríamos llegar a conservación prácticamente eterna. Eso nos lleva al falso silogismo de que unas condiciones de humedad y temperatura muy precisas nos garantizan la conservación a largo plazo. Esto no es del todo correcto porque no todos los materiales son iguales ni tienen la misma resistencia ante la humedad y la temperatura. Un mismo documento puede tener distintos materiales que pueden no reaccionar igual. Sin embargo, todos estos años hemos intentado sistemáticamente reducir la conservación preventiva al control de la humedad y la temperatura, de los contaminantes atmosféricos, las radiaciones electromagnéticas y la luz. Después fuimos ampliando a otros campos como el control de plagas y la gestión de desastres. Y así aparece el concepto de la gestión de riesgos en conservación preventiva, que nos ha llevado a una disciplina enormemente compleja para la que deben desarrollarse aún nuevos sistemas de análisis e interpretación.

P.: Esto nos lleva a uno de los últimos campos desarrollados por la Conservación Preventiva, la gestión de riesgos, en el que tú has trabajado ampliamente.

A.S.: Ahora mismo es uno de los campos más interesantes. Uno de sus iniciadores, el canadiense Robert R. Waller, se planteó un acercamiento a la gestión de riesgos valorando los elementos de deterioro, el volumen de daños en las colecciones y la frecuencia con la que los agentes afectaban en el material. Este enfoque fue después muy trabajado por el Instituto Canadiense de Conservación y en especial por Stefan Michalski que analizando qué elementos generaban deterioro, cuál era su impacto en los objetos y la pérdida de valor de la colección por el deterioro de esos objetos podría determinar una conservación preventiva y paliativa más adecuada a las necesidades de la colección. Para ello es necesario establecer una serie de ecuaciones bastante trabajosas aunque no demasiado complicadas. Esta forma de entender el deterioro me parece muy interesante porque sitúa en diferentes escenarios y facilita enormemente la toma de decisiones. En 
colecciones homogéneas permite establecer cuáles son los puntos en los que falla nuestro sistema de Conservación Preventiva. Por ejemplo, el uso de cajas acidas produce un deterioro químico en el papel, pero en una caja de archivo podemos meter hasta un volumen de hojas de $10 \mathrm{~cm}$ de grueso que, además, pueden ir guardadas en varias carpetillas; la cantidad de ácido que se trasmite desde la caja al interior viene filtrado por los documentos que están en contacto con la caja y por las carpetillas, con lo cual, la terrible agresión que trasmitirían las cajas se ve mitigada en parte por los documentos contiguos al cartón y en parte por las barreras que suponen los contenedores. Si tenemos en cuenta que un archivo se mide por kilómetros de estanterías -la Biblioteca Nacional tiene más de 400 km-; al hacer el ejercicio de gestión de riesgos veremos que las cajas ácidas generan daño a menos de una millonésima parte del fondo. Frente a ello, en los últimos 5 años se han hecho en la Biblioteca unas 60.000 cajas a medida necesarias para proteger de la manipulación y deterioro otros tantos volúmenes. Si pensamos que el coste de restauración medio sería de unos $200 €$, hemos evitado gastos por valor de $12.000 .000 €$ frente a una inversión realizada de unos $450.000 €$.

El problema es que la gestión de riesgos puede darnos buen resultado para colecciones homogéneas, pero cuando tenemos colecciones muy dispares, con valores muy diferentes el cálculo se vuelve muy complejo y farragoso.

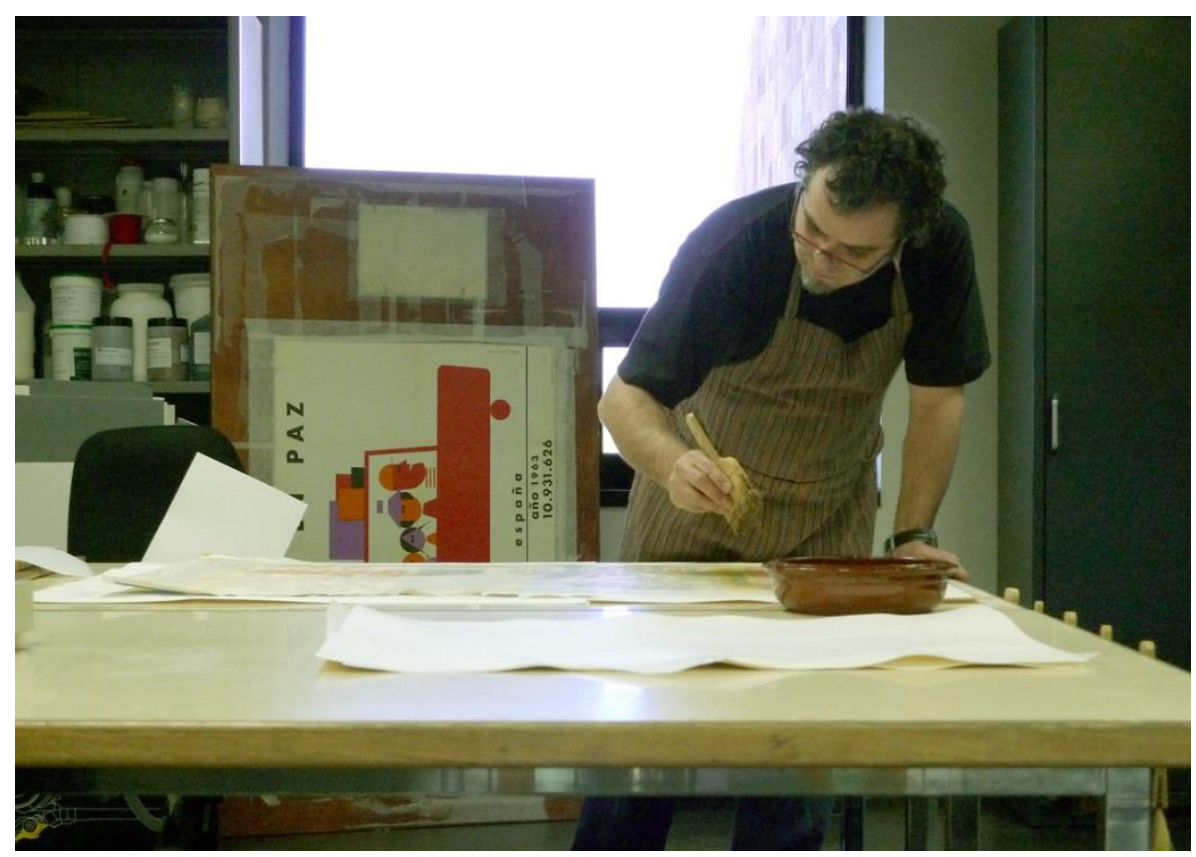

Analizando diferentes procesos de limpieza por capilaridad en el taller de la BNE en Alcalá de Henares.

P.: Una cosa es el sentido común y otra la instrumentación del sentido común. En ese sentido se entienden los diez agentes de deterioro defendidos por el ICC, que es una referencia indispensable en conservación preventiva.

A.S.: Me parece fascinante el método de conservación preventiva planteado por el Instituto Canadiense y sus diez fenómenos de alteración, aunque creo que en algunos casos se podrían reducir. Es un instrumento de trabajo poderosísimo, porque estructura y elimina el ruido que nos 
lleva a la dispersión en la conservación. Actualmente estoy trabajando en su adecuación a los archivos y bibliotecas y trato de delimitar los escenarios, pues el método se concibió para trabajar en museos. Lo interesante es que no todos los agentes están en los mismos escenarios y sólo debemos centrarnos en los que se encuentran presentes. Además el ICC fue más allá, porque aporta una solución basada en cinco pasos: identificar, bloquear, detectar, corregir, tratar, que, aunque también son discutibles, dan una guía excelente para elaborar planes de conservación por fases.

P.: Hace falta poner número a los resultados, quien toma las decisiones pide cifras.

A.S.: Sí, es necesaria la métrica de la conservación.

P.: Pero siempre chocamos con los intereses políticos, la falta de visibilidad de los resultados es un impedimento.

A.S.: Eso son riesgos de carácter externo que no puedes dominar: no puedo controlar que el político me haga caso, pero sí puedo plantear acciones más efectivas en términos de colección o la forma en la que comunico mis necesidades al responsable político. Creo firmemente en la conservación preventiva, mi experiencia me ha hecho percibir que la gente sí es consciente de su importancia. Mi primer paseo por los depósitos de la Biblioteca Nacional hace 22 años, fue una experiencia imborrable al ver las condiciones en las que se encontraban. Nada se parecía a lo que había estudiado. Pero la realidad es tozuda y hay que tener en cuenta que se trata de una institución longeva que lleva 300 años funcionando y que en todo ese tiempo no había existido conservación preventiva. Parar en seco una tradición secular y mejorar inmediatamente aplicando principios de conservación preventiva sería iluso, pues solo en el depósito general hay cerca de 6 millones de volúmenes y no es posible dar conservación a toda esa cantidad de libros en poco tiempo. Pero sí es cierto que en los últimos años se han dado grandes pasos: se ha creado un nuevo depósito en Alcalá de Henares que absorbe de manera ordenada el crecimiento del fondo, se han sustituido los sistemas de iluminación tradicional por dispositivos automáticos, se ha instalado un sistema de extinción y detección de incendios y los depósitos están limpios. Además se está desarrollando un plan de conservación de libros únicos y deteriorados que nos permite conocer el estado de los documentos más amenazados y se está encajando una media de 5.000 volúmenes al año. La realidad es que el cambio ha sido bastante notable y debemos seguir trabajando en esa línea, asumiendo nuestras dificultades y buscando alternativas viables.

P.: El trabajo es complicado y más teniendo en cuenta que no existen departamentos específicos de Conservación Preventiva. Dentro de empresas que se dedican a otros sectores profesionales hay departamentos que se dedican a la gestión de los riesgos laborales, en Patrimonio en cambio no existe esa lógica. Tú lo haces pero compatibilizándolo con la restauración, las investigaciones, las publicaciones y la docencia...

A.S.: Bueno, hay mucho que aprender y afortunadamente estoy en un sitio privilegiado. En cuanto a los departamentos de conservación preventiva, en la actualidad son una utopía en nuestro país. Hay pocos planes de formación, pero la administración no absorbe a los técnicos que se han formado. Pero en Iberoamérica, por ejemplo, el sistema de gestión de riesgos se ha desarrollado bastante hasta el punto que, en Ecuador, el gobierno declaró una emergencia nacional basándose en un estudio de riesgos de su Patrimonio Cultural. Esto es muy bueno porque la declaración de emergencia nacional implica que los recursos del estado se ponen al servicio de los gestores del patrimonio. 
Uno de los problemas de la conservación preventiva es lo abstracto de su aplicación. Los cinco pasos del ICC son lentos y es posible lograr resultados más rápidamente mediante la aplicación del método de las cinco " $\mathrm{S}$ ", un método de trabajo desarrollado en una de las factorías japonesas de Toyota para generar espacios de trabajo productivos. Se basa en 5 principios básicos que son ordenación, disciplina, orden, limpieza y normalización de las cuatro anteriores. Estoy trabajando con este método para ofrecer una aplicación sencilla de la conservación preventiva en archivos y bibliotecas. La idea me la dio Juan José Prieto, un experto en seguridad en bibliotecas. Muchas veces pensamos que el Patrimonio es algo diferente de la realidad cotidiana, pero los archivos, bibliotecas y museos no dejan de ser espacios de trabajo y la limpieza y el orden son dos puntos fundamentales. No podemos pretender ir hacia la CP si no hay limpieza ni que no haya accidentes si no hay ordenación del espacio. Son líneas de trabajo que van surgiendo a medida que se van clarificando los campos en los que tenemos que trabajar: Los trabajos del ICC y el sistema de las $5 \mathrm{~s}$ crean un tándem extraordinario con magníficas posibilidades de aplicación.

P.: ¿La Conservación Preventiva es la respuesta a la conservación del patrimonio documental, esa "tortuga difícil de alcanzar", como decías en alguno de tus artículos?

A.S.: En los años 70 y 80, con las inundaciones de Florencia y el comienzo del "terror acido" se empezó a ver que el papel se deteriora a una velocidad enorme, esto despierta una disyuntiva entre lo que hay que salvar y lo que no. No podemos restaurarlo y conservarlo todo. La respuesta son los planes de Conservación Preventiva, la creación de documentos que generen directrices con las que se debe trabajar, protocolos de trabajo, recomendaciones de conservación para cada tipo de material, y el control de los riesgos que generan el deterioro. Para mí Conservación Preventiva no es solo lo ortodoxo, lo oficial, si me permitís el término. Muchas veces estamos pensando en cajas de conservación para un archivo en el que las estanterías están deformadas o los documentos en el suelo. De ahí viene la paradoja de María Antonieta que proponía en uno de mis artículos. Dicen que en los momentos previos a la Revolución Francesa, una de las revueltas por la carestía del pan llegó hasta las puertas de Versalles. Maria Antonieta, preocupada por la algarabía preguntó el motivo de tal desorden y un ministro le comentó "Protestan porque no pueden comer pan", a lo que ella contestó, "si no pueden comer pan, que coman brioches". Ese es para mí el objetivo al que debemos llegar en conservación preventiva, dejar de recomendar brioches a quienes no pueden comprar pan...

\section{Bibliografía destacada}

\section{Libros:}

Desastres en Archivos: Como planificarlos. Gijón: Trea. 2011.183 págs.

Políticas de conservación en bibliotecas. Madrid: Arco Libros. 1999. (Instrumenta bibliológica).

Capítulos de libros y artículos:

"Documentos en exposiciones: Control de su deterioro", en Exponer documentos: Diseño y producción de muestras documentales, editado por Luis Hernández Olivera. Salamanca: ACAL, 2010, págs. 153-182.

"Después del Infierno: Reconstrucción y tareas pendientes", en Biblioteca en Guerra editado por Blanca Calvo Alonso-Cortés, Madrid; Biblioteca Nacional, 2005, págs. 389-406.

"Libri sine asseribus. Criterios de intervención en las estructuras de encuadernación flexible de los siglos XIV y $\mathrm{XV}^{\prime \prime}$. En Criterios de Intervención en la Restauración de Libros y Documentos. Pamplona: Archivo General de Navarra, 2008, págs. 179-190. 
Los soportes tradicionales y tecnológicos: Conservación y protección, métodos y medios, en Vencer al Tiempo: Conservación e instalación de los documentos municipales: Actas XVI Jornadas de Archivos Municipales, Consejería de Cultura y deportes de la Comunidad de Madrid/Ayuntamiento de Alcobendas/Grupo de Archiveros Municipales de Madrid, 2006, pág. 239-260.

"El códice Breviario de Amor y el concepto de mínima intervención en la restauración de documentos", en Roig Picazo, Pilar et.al. (eds.), 16th Internacional Meeting on Heritage Conservation Preprints of the papers to the Valencia Congreso, Valencia: Universidad Politécnica de Valencia, 2006, págs. 89-104.

"Paradigmas conceptuales en conservación", en CON•TACTO, Revista del Laboratorio de Restauración del Archivo General de la Nación, Colombia, 1996, nº especial 4-5, págs. 3-18.

\section{Exposiciones:}

"Piel Sobre Tabla: encuadernaciones mudéjares de la Biblioteca Nacional de España". Exposición realizada en la Biblioteca Nacional de España. Marzo-Mayo de 1013.

Exposición virtual en:

http://www.bne.es/es/Actividades/Exposiciones/Exposiciones/exposiciones2013/encmudejares.html?pagina=0

Catálogo en pdf interactivo disponible on line en:

http://www.bne.es/media/Micrositios/Guias/encuadmudejares/EncuadernacionesMudejares.pdf

"La química de los libros: Ciencia y conservación del patrimonio documental". Exposición realizada en el Museo de la Biblioteca Nacional de España. Noviembre-Enero de 1012. Catálogo disponible on line en: http://www.bne.es/es/Actividades/Exposiciones/Exposiciones/Exposiciones2011/QuimicaLibros.html?pagina=1

\section{Rocío Bruquetas Galán}

Instituto del Patrimonio Cultural de España. Secretaría de Estado de Cultura rocio.bruquetas@mcu.es

\section{Charo Fernández \\ ROA ESTUDIO S.C. \\ chafechafe33@hotmail.com}

Artículo enviado el 02/12/2013 
Artículos 


\title{
José Gestoso y Pérez. Teoría y Praxis de la Conservación
}

\author{
Ma Dolores Ruiz de Lacanal Ruiz-Mateos
}

\begin{abstract}
Resumen: El objetivo de este artículo es hacer una reflexión sobre las aportaciones que José Gestoso y Pérez (1852-1917) realiza a la teoría y la praxis de la conservación. Persona de gran prestigio y mérito, desarrolló su labor profesional en Sevilla a mediados del siglo XIX y principios del siglo XX y ha sido objeto de numerosas investigaciones.

Tras la lectura de los estudios, que le resaltan como un referente claro de la cultura sevillana en sus múltiples manifestaciones, (Historia y crítica del Arte, Arqueología, Archivística, etc.), este artículo concentra la atención en sus propios textos, para descubrir que constituyen un conjunto coherente y estructurado de conocimientos teóricos y prácticos, aportan unos objetivos definidos y una metodología con recursos y estrategias, que son claros antecedentes de nuestros actuales "planes" de conservación.
\end{abstract}

Palabras claves: José Gestoso y Pérez, Conservación, Restauración, Teoría, Historia, Museo, Archivística, Patrimonio Cultural, siglo XIX y XX.

\section{José Gestoso y Perez. Teoria e prática da conservação}

Resumo: O objetivo deste artigo é refletir sobre as contribuições que José Gestoso y Pérez (1852-1917) proporcionou à teoria e à prática da conservação. Pessoa de grande prestígio e mérito, desenvolveu a sua carreira profissional em Sevilha, em meados do século XIX e início do século XX e tem sido objeto de inúmeras investigações.

Após a leitura dos estudos, que o destacam como uma referência clara da cultura sevilhana nas suas múltiplas manifestações (História e Crítica de Arte, Arqueologia, Arquivística, etc), este artigo foca a sua atenção nos seus próprios escritos, para descobrir que constituem um conjunto coerente e estruturado de conhecimentos teóricos e práticos, com uns objetivos definidos e uma metodología com recursos e estratégias, que são claros antecedentes dos nossos atuais "planos" de conservação.

Palavras-chave: José Gestoso y Pérez, Conservação, Restauro, Teoria, História, Museu, Arquivística, Património Cultural, séculos XIX e XX.

\section{José Gestoso y Perez. Theory and praxis of conservation}

Abstract: The aim of this paper is to reflect upon the contributions made by José Gestoso y Pérez (18521917) to the theory and praxis of the Conservation.

As a highly recognized and meritorious person, he developed his professional career in Seville in the middle of the nineteenth century and beginning of the twentieth century, and he has been the focus of many researches.

After reading the studies, that highlighted him as an evident reference of sevillian culture on its multiple expressions (History and Art Critic, Archeology, Archivist, etc.), this paper focus its attention on his own writings, to reveal that they constitute a coherent and structured foundation of practical and theoretical knowledge, with well-established objectives and a methodology with resources and strategies, which, clearly form, the precursors of our Conservation plans.

Keywords: José Gestoso y Pérez, Conservation, Restoration, Theory, History, Museum, Archive, Cultural Heritage, 19 and 20 centuries. 
"Tal es la magia de las bibliotecas: todo reposa como perlas y corales en el fondo de los estantes, pero nada muere jamás por completo, todo está a la espera de ser reconocido, releído un día para un nuevo valor uso".

Aby Warburg (Didi_Hubermann, 2009: 465).

\section{Introducción}

José Gestoso y Pérez, una de las personalidades más destacadas de la cultura sevillana de su tiempo, estuvo muy vinculado a las principales instituciones del momento. Entre ellas, al Museo de Bellas Artes, al que dedicó parte de tu trabajo y esfuerzo (López Rodríguez 2010: 288).

Para el museo redactó un primer catálogo de 1897 y otro posterior editado en 1912, de gran rigor y contenido científico. Miembro de la Comisión a la que se le encomendó la ubicación de las salas del museo, fue responsable de su museografía y su benefactor, ya que años después a su fallecimiento, su viuda, María Daguerre, donaría la colección del reconocido arqueólogo e historiador, formándose la Sala Gestoso, con objetos de arte, cerámica antigua y moderna, armas, azulejos y pinturas que le habían pertenecido. A esta colección pertenece el retrato de 1914 mostrado en el artículo, donde Gonzalo Bilbao, gran pintor y amigo, le retrata con el traje de ceremonia como académico.

Fue Académico Correspondiente de las Reales Academias Española, de San Fernando y de la Historia, Académico Secretario de Bellas Artes de Sevilla, Preeminente de la de Buenas Letras y Oficial de Instrucción Pública de Francia. Vinculado a la Academia de Bellas Artes, institución que tuvo a lo largo del siglo XIX la competencia en protección de los monumentos, formó parte también de la Comisión de Monumentos Históricos y Artísticos y ejerció su trabajo como archivero del Archivo Municipal de Sevilla (V.V.A.A. 2012: 25, 729; V.V.A.A. 1991:57).

Conservador del Museo de Arqueología de Sevilla, estuvo fuertemente vinculado a numerosos monumentos sevillanos, particularmente a la Catedral, cuya colección estudió, describió, catalogó y divulgó (López Rodríguez 2010: 131).
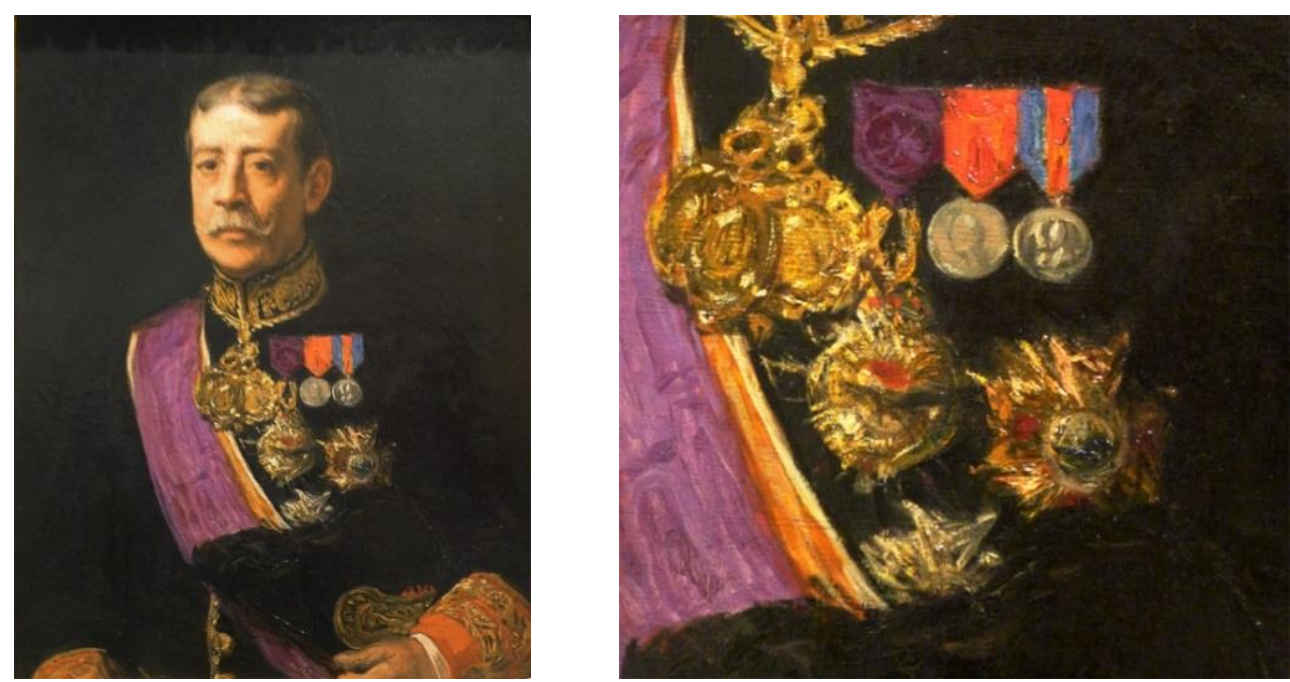

Figuras 1 y 2: Retrato de José Gestoso realizado por Gonzalo de Bilbao y detalle. Colección Museo de Bellas Artes de Sevilla. Fotografía realizada en la exposición de 2013. 


\section{La valoración de la obra de José Gestoso y Pérez}

Reconocido y valorado por un gran número de historiadores, críticos y arqueólogos, que se encargaron de resaltar su trabajo como dibujante, bibliófilo, arqueólogo, literato, ceramista, decorador, asesor de diversos procesos de restauración, archivero, coleccionista, mecenas y crítico del arte, el erudito sevillano, como prolífico escritor, con más de un centenar de trabajos publicados es una referencia indispensable en múltiples trabajos de Historia del Arte, Arqueología o Archivística. El estudio de su obra ha sido constante. Baste recordar el homenaje póstumo realizado por José Hernández Díaz (1946), que resaltaba su labor en la crítica del arte, las apreciaciones de Álvaro Recio Mir (2008), centradas en su concepto artístico, o el trabajo de Antonio José Albardonedo Freire (2010) valorando sus aportaciones a la historiografía del arte; a las que se sumarían entre otras, la mirada de José Beltrán Fortes (2002) a través de la Arqueología, o la de José Ramón López Rodríguez (2010), bajo el prisma de la historia de los museos de Andalucía; las investigaciones de Alfonso Pleguezuelo Hernández (1995) atentas especialmente al estudio del coleccionismo y el mecenazgo, y más concretamente al campo de la cerámica, y a Pedro Gómez Ramos, con su visión general que abunda en el papel que ocupa en la propia historia de Sevilla y su provincia. Todos contribuyeron a trazar su personalidad, guardar su memoria y retener para el recuerdo la enorme e interesante tarea que llevó a cabo a lo largo de su vida.

Sin embargo, sus publicaciones y sus documentos no se agotan y permiten ser valorados de nuevo, ahora bajo un nuevo valor, la disciplina de la Conservación. Sorprende descubrir que existe en su obra un cuerpo coherente y estructurado de conocimientos y saberes, teóricos y prácticos, unidos bajo la Conservación.

Ciertamente, la Conservación como disciplina se ha consolidado recientemente, por lo que resulta aún más sorprendente la aportación, que se anticipa a la configuración de la disciplina moderna. Además es bajo ésta, como sus aportaciones a los diferentes campos de la cultura, adquieren la forma de metodología aglutinadora y pionera. Es decir, en Gestoso encontramos un conjunto de reflexiones teóricas que articulan un conocimiento abstracto, que aplica a los ejemplos y casos. En estas prácticas o estrategias, hemos podido encontrar algo más que fragmentos sueltos, los antecedentes de la propia metodología científica de nuestros actuales planes de conservación.

¿Pero qué entendió José Gestoso y Pérez por conservación?

Las palabras que fueron grabadas en el Panteón de llustres Sevillanos recogen esta estrecha relación entre vida y conservación:

"José Gestoso y Pérez gastó su vida en la defensa de los intereses históricos y artísticos de esta ciudad; procurando solícito la conservación de sus tradiciones y monumentos".

Su concepto de conservación parece algo profundo y emocional, un sentimiento que surge ante el rechazo de la destrucción misma. Una experiencia emocional que registra y reacciona frente al paso del tiempo, la destrucción y el olvido. Esa "sensibilidad" se plasma en un doble sentido, en sus reflexiones y en sus prácticas.

Antes de pasar a ellas se puede observar con claridad esa sensibilidad, concretamente en su libro Apuntes del Natural. Leyendas y artículos (Sevilla, 1872), en el que, con un claro tono becqueriano, describe con estas palabras las ruinas del Monasterio de San Isidoro del Campo de Sevilla: 
"El claustro abandonado y sombrío, con sus oscuros sillares corroídos con sus destrozadas pilastras cubiertas por el musgo, con su extenso patio alfombrado de amapolas y jaramagos. ¿Qué conseguiría yo censurando la incuria de unos y la indiferencia de los demás?... La destrucción ha fijado en el monasterio su asiento, el tiempo poco a poco lo va desmoronando y quizás en plazo no lejano veremos al arado abrir sus surcos sobre el sepulcro de Guzmán el Bueno" (Gestoso y Pérez 1879: 26).
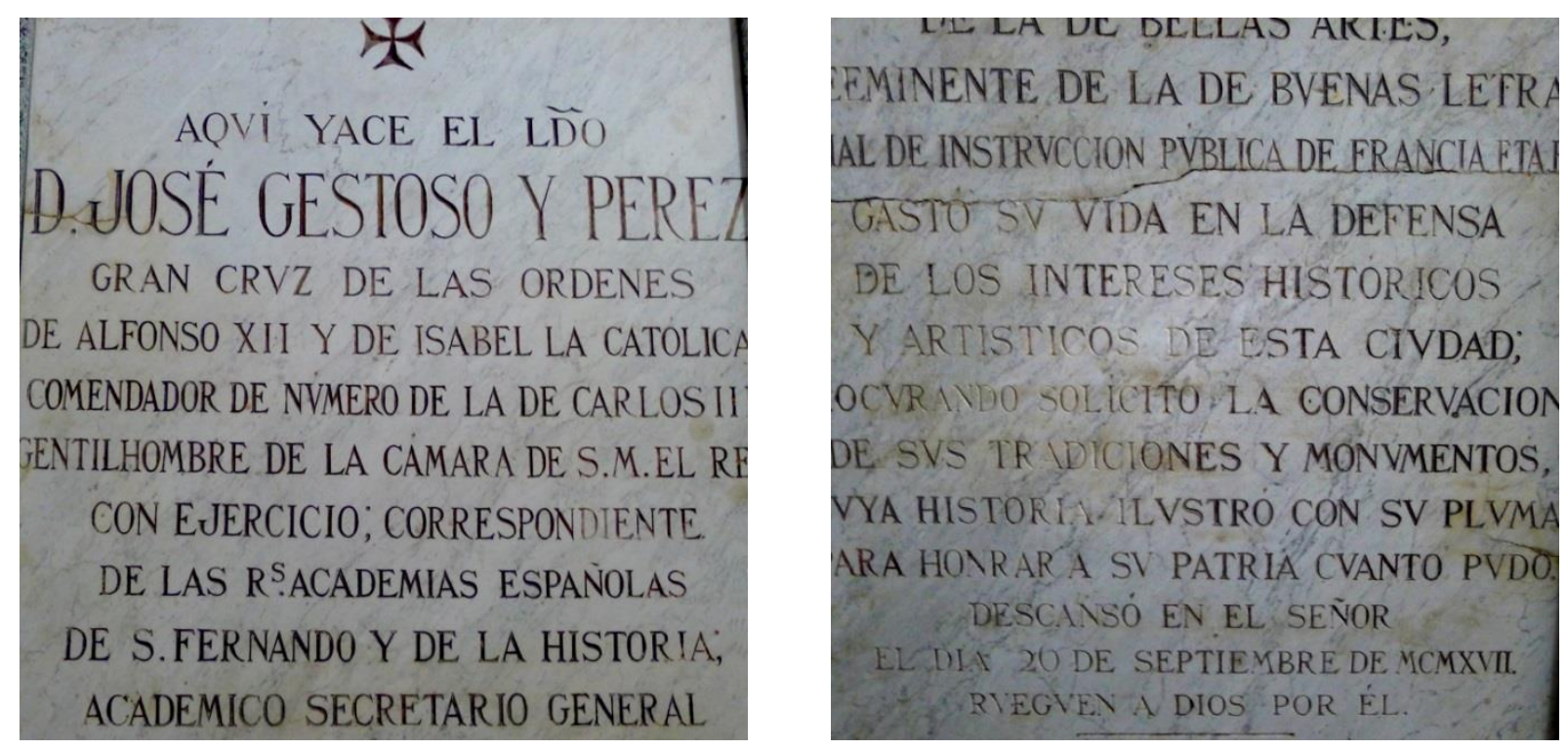

Figuras 3 y 4: Panteón de llustres Sevillanos. Cripta de la Iglesia de la Anunciación. Universidad de Sevilla. Detalles.

\section{La teoría de la Conservación.}

Sustentado en esa sensibilidad, la piedra angular de la conservación, José Gestoso manifiesta claramente cuáles son los objetivos de esta:

- "Salvar del olvido las antiguas memorias de sucesos y cosas que yacen en los archivos y bibliotecas",

- "Llamar la atención pública acerca del abandono en el que algunas yacen",

- "Preocuparse por la pérdida de los testimonios vivos de nuestra cultura pasada",

- "Evitar la desaparición de monumentos, la pérdida de las huellas y pruebas de la memoria" (Gestoso 1872: 8).

En cuanto a la teoría, se pueden apreciar diferentes ideas, conceptos y reflexiones.

Podemos estructurar estas apreciaciones en varios apartados:

- Concepto de monumento.

- Sus reflexiones sobre el concepto de valor e interés.

- Sus reflexiones teóricas sobre el legado material e inmaterial y el valor histórico. 


\subsection{Concepto de monumento}

José Gestoso y Pérez mostró un interés muy amplio hacia las manifestaciones culturales que comprendían desde la conservación de una bandera a un barro vidriado, desde una escultura, a un convento, desde un libro a un documento. De los libros de coro pasó a las pinturas y azulejos polícromos y de estos a los edificios, a los sepulcros y al mobiliario. Hay autores que han visto en esta apertura, y con razón, un anuncio de lo que será el concepto de patrimonio cultural.

Efectivamente, es precisamente en esa apertura donde se observa la evolución de los conceptos antiguos a los nuevos, es decir, del interés por las curiosidades y los monumentos (título que Gestoso y Pérez mantiene en uno de sus libros) hacia otros valores, como son los etnográficos, científicos y técnicos, además de los ya consolidados valores monumentales y arqueológicos. Por ejemplo, de su extensa bibliografía recogemos algunas citas que muestran su preocupación por los libros del Coro de la Catedral de Sevilla (Gestoso y Pérez, 1884:11); por las pinturas de la Casa de Pilato (Gestoso y Pérez, 1884:237), los azulejos polícromos de la Casa del Duque de Alba o la Casa de los Pinelos (Gestoso y Pérez, 1884:139, 143) o bien apela a la conservación de edificios, como el aludido Monasterio de San Isidoro del Campo (Gestoso y Pérez, 1883). Esa renovación de estos conceptos es evidente y ha sido apreciada por otros investigadores, por ejemplo por Adolfo Rodríguez Jurado (1918: 33).

\subsection{Reflexiones sobre su concepto de valor e interés}

Una apreciación nueva es el cambio del sistema de valoración, de uno tradicional a otro más moderno, de uno personal a otro de interés social. Es importante señalar que sustenta el valor en la estima que despierta en los ciudadanos, comprendiendo que son éstos al fin los que hacen posible su trasmisión y conservación. Gestoso se mueve hacia la conservación de interés social. Apela a la competencia municipal y a las autoridades, a las instituciones públicas, prefigurando con ello la gestión del patrimonio del mundo moderno.

\subsection{Sus reflexiones teóricas sobre el legado material e inmaterial y su valor histórico}

La conservación para Gestoso tiene además un fundamento. No responde a criterios más o menos personales, antes bien, descansa en lo que él llama "la verdad histórica". Un nexo invisible une los documentos con el legado material, haciendo imprescindible la relación entre las propias instituciones y los monumentos. Su trabajo en archivos, bibliotecas y museos le permite trazar un puente de conexión entre el legado material y su propio valor histórico. El valor histórico, custodiado en los legajos, en los estratos arqueológicos, en los libros o en los monumentos es otro de los pilares de la conservación.

\section{La práctica de la conservación}

Pero sobre todo, Gestoso articula un plan. La práctica de la conservación es el conjunto de estrategias que hacen posible la transmisión del legado. Y para ello, Gestoso sigue una metodología, cuyo primer paso es la investigación y la búsqueda de documentación en las fuentes archivísticas; le sigue la clasificación -incluida la peritación e informes sobre atribuciones inciertas o falsedades-, para continuar con la exposición, la restauración -si fuera necesaria-y la difusión. 
En éste proceso se puede observar el método científico, un plan aplicado a la propia conservación, como una verdadera aportación pionera.

Hasta aquí se había mostrado a José Gestoso y Pérez en sus distintas facetas, en sus relaciones con las distintas disciplinas. Ahora, bajo la luz de la conservación, se observa claramente su metodología, que comienza con la investigación y continúa con la exposición o apertura a la sociedad, para enlazar con la educación y la difusión.

\subsection{La investigación y búsqueda de documentación}

Es el aspecto más estudiado de la obra de José Gestoso y Pérez. Concretamente fue José Hernández Díaz quién recopiló sus trabajos e hizo hincapié en su perfil de investigador y crítico de arte. Sin embargo, se debe llamar la atención sobre estos estudios guiados por su afán de conservación. Por ejemplo, el que realizó sobre Juan de Valdés Leal (Gestoso y Pérez 1890), donde recoge todo tipo de consultas en los archivos; o los de la vida y obra de Pedro Millán y Pedro de Campaña, con la publicación de datos biográficos, contratos y otros documentos (Gestoso y Pérez, 1899-1908), en donde son frecuentes sus comentarios sobre el estado de conservación y los problemas que conlleva el mantenimiento y cuidado de las obras estudiadas. La búsqueda de la documentación se completa con la clasificación y valoración artística, cuyo resultado será su diccionario de artistas sevillanos (Gestoso y Pérez 1899-1908).

El método de Gestoso se basaba en tomar algunos casos como ejemplo de su metodología. Por ejemplo en algunos monumentos de la provincia de Cádiz, como el Castillo de Luna y la Parroquia Nuestra Señora de la O de Rota (Gestoso y Pérez 1911), o la descripción del Convento de Regla de Chipiona (Gestoso y Pérez 1894), con agudas valoraciones que aún hoy resultan imprescindibles.

\subsection{Catalogaciones, inventarios y guía}

Para Gestoso, lo importante no son los bienes, sino Sevilla, no son los recursos o las riquezas, sino los valores significativos de la ciudad. También en esto parece adelantarse a su tiempo. Su concepto de conservación no queda encerrado en "los objetos o curiosidades", sino que está ligado al de "ciudad". Sevilla para Gestoso es una ciudad compuesta por monumentos y curiosidades que hay que catalogar. Sus bienes muebles e inmuebles requieren de una herramienta eficaz que los describa y los proteja frente a su desaparición. Esa herramienta son los inventarios y los catálogos. Realiza por un lado el catálogo de las pinturas y esculturas del Museo Provincial de Sevilla, y por otro, el catálogo de bienes muebles e inmuebles de la ciudad a partir del propio territorio, construyendo una guía (Gestoso y Pérez 1884). Otros trabajos suyos muy conocidos son el catálogo de bienes muebles de la Catedral o el estudio exhaustivo de su Sacristía y sus bienes muebles (Gestoso y Pérez 1892).

\subsection{Las exposiciones}

Gestoso desarrolla también una amplia labor como comisario de exposiciones, concediendo a la difusión una gran importancia metodológica. Exponer es mostrar al público, es decir, es una de las estrategias fundamentales de la conservación, orientada a la difusión, a la pedagogía y al disfrute. Es un ejemplo claro de hombre ilustrado que vuelve la mirada hacia la sociedad, uniendo la conservación con la ilustración, la pedagogía y la difusión. 
Entre las exposiciones en las que participó cabe destacar las realizadas en Sevilla de "Pintura retrospectiva" (1896), "Bordados" (1898) y "Retratos antiguos" (1910), así como muchas otras de diferentes temas en Madrid (1882), Barcelona (1891, 1892, 1893, 1907, 1910 y 1911), Múnich (1883) y Chicago (1893).

\subsection{La restauración}

La palabra "restauración" tiene para José Gestoso y Pérez un doble sentido: restauración como intervención y restauración como restablecimiento de la memoria perdida. Este es el caso de la restauración de la Cabeza del Rey $D$. Pedro en la que, según sus palabras, "se restaura la memoria del monarca" (Gestoso y Pérez 1985: 7-8)

Fue un teórico y un técnico de la restauración. En primer lugar por sus numerosas alusiones a restauraciones históricas y en segundo por los trabajos que él mismo llevó a cabo. Como historiador de las restauraciones, nos dio a conocer la importancia que tuvo el taller de restauración de la Catedral de Sevilla, que ocupaba la Sala de Descanso y de Rentas. Por ejemplo, así describe una limpieza que se había llevado a cabo en una tabla con la Purísima Concepción de Murillo, de la Sala Capitular con estas palabras:

"Este cuadro se limpió en 1882 sin tocarle en lo más mínimo con los pinceles, y en tal concepto acaso sea el único de los que ejecutó aquel soberano ingenio que se conserva sin repinte ni barnices" (Gestoso y Pérez 1884: 110).

En algunos casos hace una defensa del original:

"Restauraciones que hicieron perder en los originales su valor artístico como el que se refiere a unas estatuas del monumento de Semana Santa" (Gestoso y Pérez 1884:112).

En otros aporta su opinión sobre la restauración, como en el caso de la intervención de una pintura de la Iglesia de San Julián, del pintor Juan Sánchez de Castro:

“El tiempo, la ambición de poderoso magnate por adquirir valiosas joyas y más que nada la ignorancia, el más duro de todos los azotes de nuestras glorias artísticas, han hecho desaparecer las obras del eximio Patriarca (...) si bien lamentando el deplorable estado, pues que por ambos lados de su tercio inferior se encontró bárbaramente aserrada". Y continúa señalando que mejor no se restaure: "lo cual, afortunadamente, no se ha hecho, y creemos que no se debe intentar nunca, si tenemos en cuenta su deplorable estado, pues daría lugar a fantásticos repintes, nunca admisibles" (Gestoso y Pérez 1885: 25).

Se podría señalar una lista o registro de restauradores citados por Gestoso, pero baste recordar a D. Antonio Torrado y D. Rafael Romero Barros en Córdoba, en relación a San Elías y la Virgen de los Plateros de Córdoba, restaurada en 1795 (Gestoso y Pérez 1884: 31).

Como vicepresidente de la Comisión Provincial de Monumentos Históricos y Artísticos, tomó parte activa en numerosas restauraciones llevadas a cabo en edificios emblemáticos, como la Catedral, el Alcázar o la Torre del Oro. Uno de los casos más notables es la restauración del Pendón de la ciudad, que suscitó una cierta polémica ante la decisión del Ayuntamiento de sacar en procesión el original, restaurado por el propio Gestoso. Resulta interesante el efecto que produjo sobre la opinión pública y los medios de comunicación. El pendón quedó finalmente expuesto en el Archivo Municipal y no se volvió a sacar en procesión. 
Otra restauración interesante fue la del León del Alcázar o la polémica defensa de las Murallas de Sevilla.

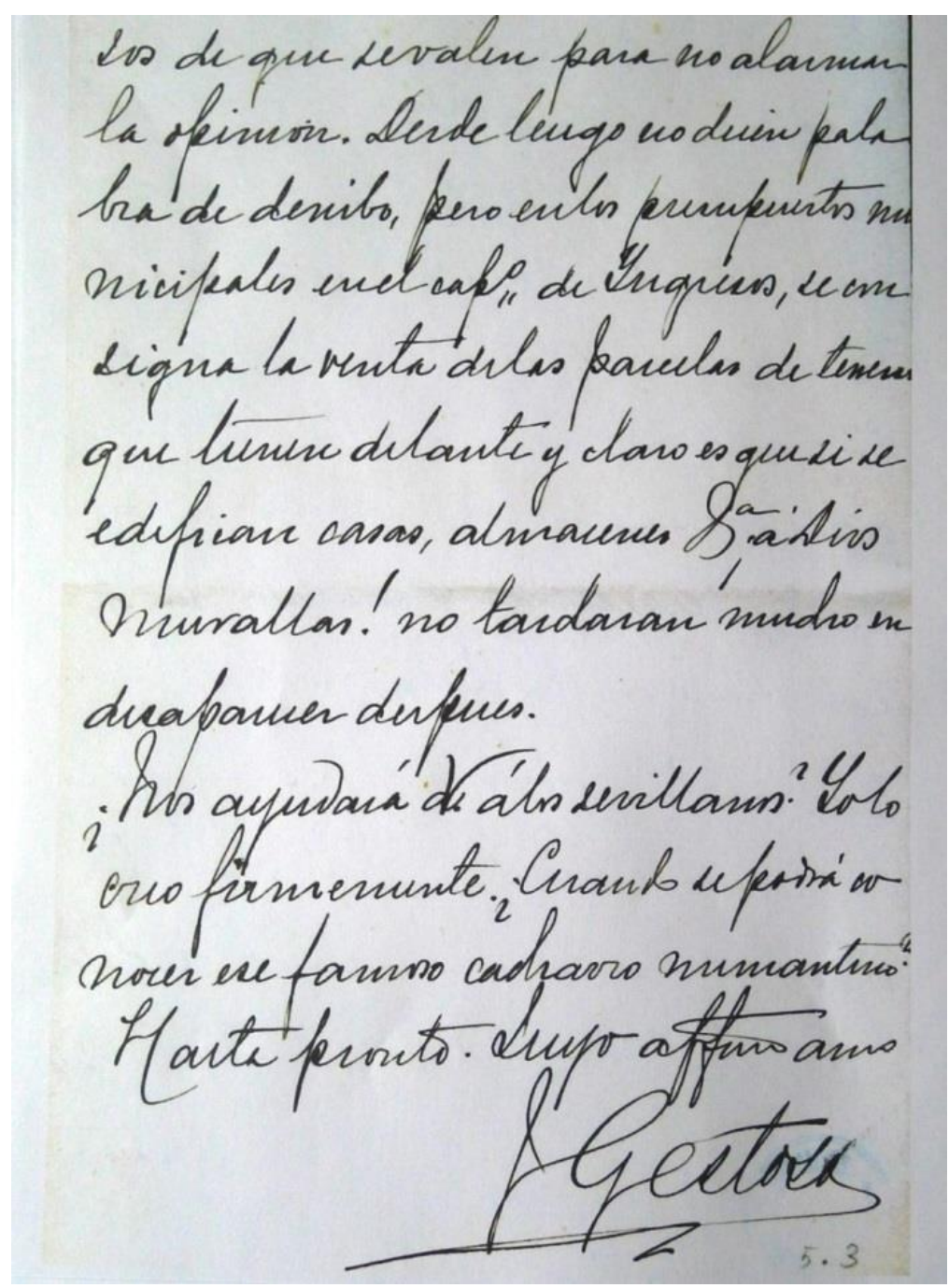

Figuras 5: Imagen de documentos del Archivo Histórico de Andalucía. Carta de José Gestoso y Pérez a J.R. Mélida sobre la conservación de las Murallas de Sevilla. Archivo Histórico de Andalucía. (A.G. A. Misceláneo, 4834.5.3)

Baste reseñar en esta visión general de su contribución como teórico y crítico de la restauración de monumentos su libro "Sevilla monumental y artística", en el que ofrece amplias referencias al estado de conservación de numerosas torres, conventos, parroquias o palacios y otros monumentos sevillanos. Sus alusiones a la acción del tiempo sobre los monumentos son constantes. Son curiosos sus comentarios llamando la atención sobre algunos elementos como, por ejemplo, una piedra romana de mármol en la Torre de Santa Lucía:

“(...) de la incuria de las autoridades para atender a la conservación de los edificios que son el más importante ornamento de esta histórica ciudad, al consentir que se vaya la ruina posesionando de éste, apreciable por tantos títulos y permanezca en poder de un 
particular que en uso de su derecho, podrá derribarlo cuando a bien tenga" (Gestoso y Pérez 1889:136).

En definitiva, Gestoso, hace un cuerpo teórico y crítico sobre Conservación a la par que sobre Historia del Arte (Recio Mir 2008-2009).

Defensor de lo original y buscador del "esplendor prístino" (Gestoso y Pérez 1889: 136, 139), se pronuncia a favor de la eliminación de añadidos barrocos (Gestoso y Pérez 1889: 216) y de la limpieza de la cal de las paredes de muchas iglesias sevillanas (Gestoso y Pérez 1889: 228). También reclama una conservación cuidadosa y por manos peritas. Son muchos los casos donde Ilama la atención en este sentido, por el ejemplo, en la puerta mudéjar del siglo XIV de la Catedral de Sevilla, para la que pide que "procuren su limpieza, siempre que ésta se encomiende a persona perita" (Gestoso y Pérez 1884:102).

\subsection{La difusión}

En cuanto a la difusión, Gestoso y Pérez recurre frecuentemente a la prensa y a los medios de comunicación, otorgándoles el papel de intermediarios entre el patrimonio y los ciudadanos. Su plan incluye la difusión y la información a los ciudadanos sobre la situación del estado de conservación en el que se encuentra el patrimonio. Así se recoge en esta frase:

"A lo largo de su vida, Gestoso se convirtió en un guerrero contra los muchos desmanes, sobre todo arquitectónicos, producidos en su tiempo, dando a conocer, sobre todo a través de sus colaboraciones en prensa, las razones auténticas que enmascaraban las destrucciones, ocultaciones o desnaturalizaciones de obras históricas y artísticas" (Fernández Gómez 2002:165).

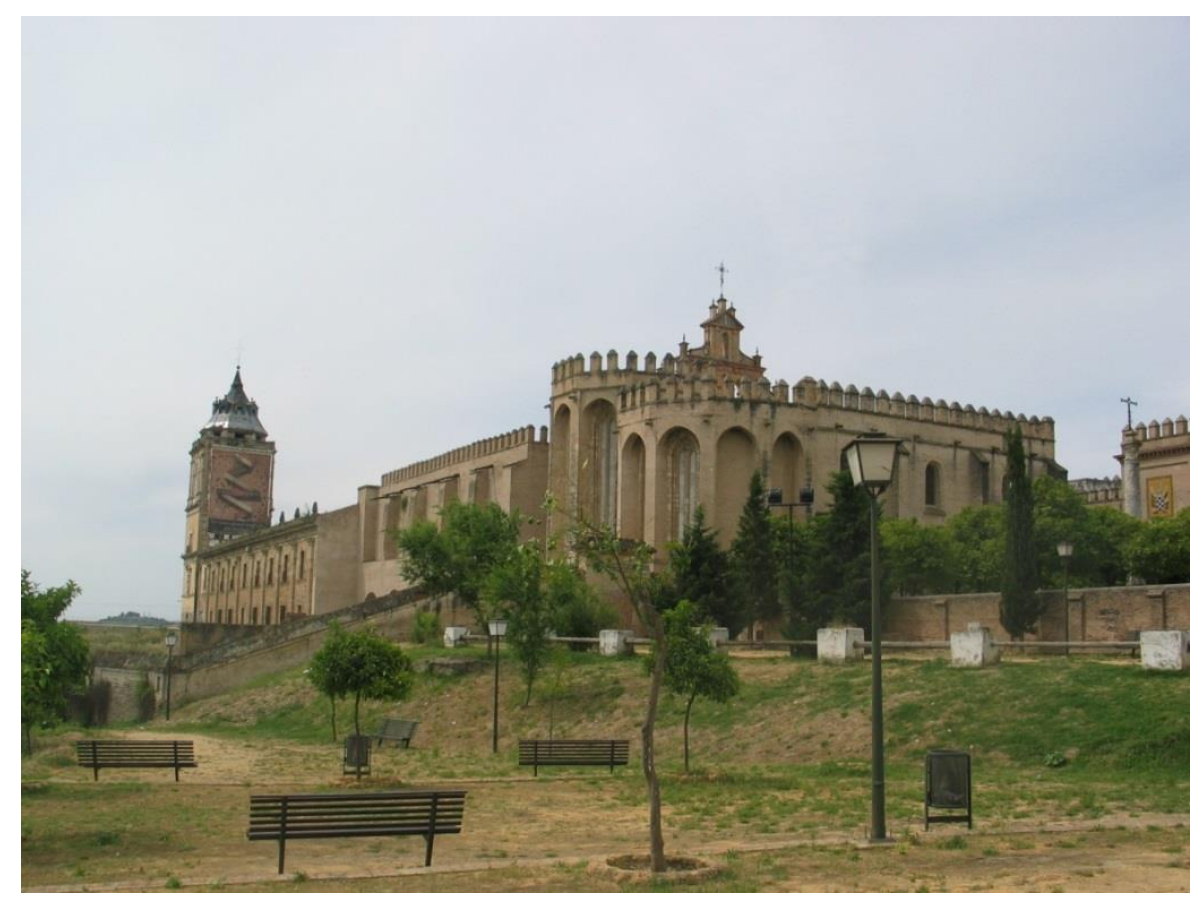

Figura 6: Monasterio San Isidoro del Campo (Sevilla) tras su recuperación en 1992. 


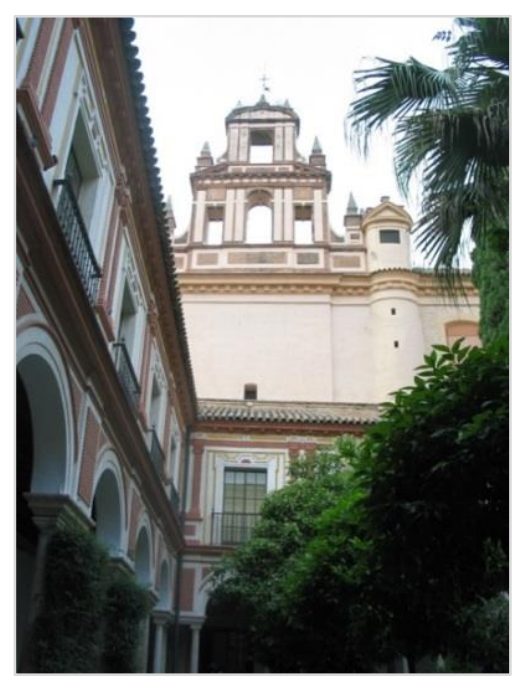

Figura 7: Museo de Bellas Artes de Sevilla. Claustro Grande.

\section{Conclusiones:}

En la actualidad, a la valoración de la fructífera labor de José Gestoso se suma el reconocimiento a sus importantes contribuciones a la Conservación y Restauración como profesional del patrimonio, por los siguientes motivos:

- Por su concepto de conservación, entendido como teoría y práctica.

- Por su manera de articular y organizar la teoría y la práctica, haciéndolas caminar juntas y confluir hacia un objetivo común y único: la conservación.

- Porque entiende por "monumento" un conjunto variado de manifestaciones culturales, en un sentido amplio y diverso que se anticipa en el concepto moderno de bien cultural y patrimonio histórico.

- Por su comprensión del museo como una institución moderna, no como un lugar, sino como un conjunto de bienes organizados, clasificados y abierto al público.

- Por ampliar la conservación y restauración del ámbito del museo a la propia ciudad, y entender que son sus monumentos y sus bienes los que guardan el registro de la memoria.

En cuanto a la aplicación o praxis, también ha quedado clara su metodología, es decir, el conjunto de recursos y estrategias que son los antecedentes de nuestros "planes" de conservación:

- Investigación: Por entender que una de las estrategias para la conservación es la investigación y el estudio. Por comprender que la conservación comienza con la labor de catalogación e inventario, que permite conocer, identificar y clasificar los diferentes bienes de la cultura y del arte, trabajo complejo que configura un eslabón fundamental en la cadena de tutela y protección.

- Exposición: Por defender que la conservación debe dirigirse a la exposición pública. Por su capacidad para organizar exposiciones como estrategias de difusión, entendidas como medios de conservación, en cuanto que acerca un legado cultural a los ciudadanos. 
- Restauración: Por la importancia que tiene en su trabajo la restauración, tanto en un sentido teórico como práctico, tanto dirigida a los bienes muebles como a los inmuebles. También por apelar a la profesionalización de la restauración. Concibe la restauración como una intervención que requiere de peritos, capaces de abordarla con acierto. Apunta que es una operación compleja y crítica, en cuanto que existe una mala praxis o una buena praxis.

- Difusión: Por la importancia que da a los medios de comunicación, y por recurrir a la prensa como elemento de comunicación con la ciudadanía.

\section{Bibliografía}

ALBARDONEDO FREIRE, A. J. (2010). "Precursores del Laboratorio de Arte: Don José Gestoso y sus trabajos patrocinados por el Ayuntamiento de Sevilla". En Estudios de Historia del Arte. Centenario del Laboratorio de Arte (1907-2007), Sevilla: Vicerrectorado de Relaciones Institucionales y Dpto. de $\mathrm{H}^{\mathrm{a}}$ del Arte de la Universidad de Sevilla, Vol. 2, pp. 45-62.

BELTRÁN FORTES, J. (2002). "Descubrimientos arqueológicos en el anfiteatro de Itálica en 1914", Revista de Arqueología, (11), pp. 5-375.

DIDI_HUBERMAN, G. (2009). La imagen superviviente, Historia del arte y tiempo de los fantasmas según Ady Warburg, Madrid: Ed. Abada.

FERNÁNDEZ GÓMEZ, M. (2002-2005). Diccionario de ateneístas de Sevilla, Sevilla: Ateneo de Sevilla, Vol. I.

GESTOSO Y PÉREZ, J. (1883). Apuntes del Natural. Leyendas y artículos. Sevilla, Establecimiento tipográfico de Gironés y Orduña, (Ed. Sevilla, 2001).

-(1884). Pedro Millán. Ensayo biográfico-crítico del escultor sevillano de este nombre, Sevilla: Imprenta de D. Rafael Tarascó.

-(1884). Guía artística de Sevilla. Historia y descripción de los principales monumentos religiosos y civiles, Sevilla: Establecimiento tipográfico de El Orden, (Ed. 2008).

-(1885). Curiosidades antiguas sevillanas. Estudios arqueológicos. Sevilla: Oficina periódico Universal.

-(1889). Sevilla Monumental y Artística. Historia y descripción de todos los edificios notables, religiosos y civiles, que existen actualmente en esta ciudad y noticias de preciosidades artísticas y arqueológicas que en ellos se conservan, Sevilla (Ed. 1984).

-(1890). Biografía del pintor sevillano Juan de Valdés y Leal y estudio de sus obras, Sevilla: Oficina tipográfica de Juan P. Gironés.

-(1892). Historia y descripción de la Sacristía Mayor de la Catedral de Sevilla y de las preciosidades artísticas que en ella se custodian. Sevilla: Imprenta de la Revista de Tribunales.

-(1894). Recuerdos del Monasterio de Nuestra Señora de Regla, Sevilla: Imp. de E. Rasco.

-(1896). Catálogo de las obras que forman la Exposición retrospectiva de la pintura sevillana celebrada en esta ciudad, Sevilla: Tip. de la Región.

-(1899-1908). Ensayo de un diccionario de los artífices que florecieron en Sevilla desde el siglo XIII al XVIII inclusive, Sevilla, "Andalucía moderna", 3 v.

- (1910). Catálogo de la Exposición de Retratos Antiguos celebrada en Sevilla en Abril de MCMX, Madrid: Oficina Tipográfica de Blanco y Negro.

-(1911). Apuntes histórico-descriptivos de la Iglesia y del Castillo de la Villa de Rota, Boletín de la Comisión de Monumentos de la Provincia de Cádiz, t.ll, núm.16, pp. 105-134.

-(1912). Catálogo de Pinturas y Esculturas del Museo Provincial de Sevilla, Madrid: Ed. Lacoste. 
GÓMEZ RAMOS, P. (1975). Catálogo de los tomos manuscritos (papeles varios) del Fondo documental José Gestoso existente en la Biblioteca Capitular Colombina de Sevilla, Memoria de Licenciatura, Universidad de Sevilla.

HERNÁNDEZ DíAZ, J. (1946). Gestoso, investigador y crítico de arte, en Boletín de la Real Academia Sevillana de Buenas Letras, número 72, enero-marzo, pp. 41-49.

LÓPEZ RODRÍGUEZ, J.R. (2010). Historia de los Museos de Andalucía (1500-2000), Sevilla: Universidad de Sevilla.

PLEGUEZUELO HERNÁNDEZ, A. (1995). José Gestoso y la recuperación de la cerámica sevillana (1855-1908). En: Renacimientos: la Cerámica Española en Tiempos de Ruiz de Luna. Ed. Cuenca, pp. 72-89.

RECIO MIR, A. (2009). "El sepulcro neogótico del Cardenal Cienfuegos en la Catedral de Sevilla y la crítica de Gestoso a su "concepto artístico". Laboratorio de Arte, 21 (2008-2009), pp. 219-239.

RODRÍGUEZ JURADO, A. (1918). “Homenaje rendido a la memoria del excelentísimo señor D. José Gestoso y Pérez", en Hernández Díaz, J. (1967): Sevilla: Museo Provincial de Bellas Artes, Madrid: Ministerio de Educación y Ciencia.

RUIZ DE LACANAL RUIZ-MATEOS, M.D. (1994): Conservadores y Restauradores en la Historia de la Conservación y Restauración de Bienes Culturales, Sevilla: Editorial Olimpia.

V.V.A.A. (2011-2012). Gonzalo Bilbao. Fondos del Museo de Bellas Artes de Sevilla. Sevilla: Junta de Andalucía, Consejería de Cultura.

V.V.A.A. (1991). Museo de Bellas Artes, Sevilla: Ediciones Gever.

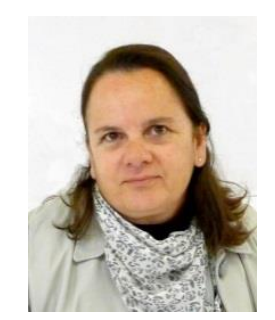

Ma Dolores Ruiz de Lacanal Ruiz-Mateos

mdrmus@us.es

María Dolores Ruiz de Lacanal Ruiz-Mateos es Doctora en Bellas Artes e Historia del Arte y Master en Arquitectura y Patrimonio. Su vida profesional se desarrolla en la Facultad de Bellas Artes de la Universidad de Sevilla, donde imparte la asignatura Teoría e Historia de la Conservación y Restauración de Bienes Culturales y comparte su tiempo entre la investigación y la docencia.

Especialista en esta materia, su primer trabajo se centró en el estudio y evolución de la Conservación y Restauración de los Bienes Culturales en España a través de los profesionales, conservadores y restauradores como protagonistas.

Esta línea de investigación está siendo continuada por el grupo de investigación y desarrollo tecnológico "S.O.S. Patrimonio", que presta un servicio a la sociedad en el ámbito de la conservación y restauración y cuyas actividades comprende desde investigaciones (tesis doctorales, catalogaciones e inventarios, etc.) a trabajos de conservación preventiva y restauración, además de desarrollar proyectos educativos y de difusión.

Entre sus publicaciones destacan: Conservadores y Restauradores en la Historia de la Conservación y Restauración de Bienes Culturales. Estudio del perfil y de la formación (1992), El conservador - restaurador de bienes culturales. Historia de la profesión (1999).

Artículo enviado el 23/08/2012

Artículo aceptado el 13/11/2013 


\title{
Método para el estudio de los motivos polícromos
}

\section{Beatriz Prado Campos}

\begin{abstract}
Resumen: Este artículo expone y propone un método de estudio no invasivo para el análisis de los motivos polícromos de las indumentarias de las esculturas policromadas. El método no afecta a la integridad física de la obra, es accesible ya que no requiere de un material específico o costoso, y está al alcance de un amplio grupo de profesionales. A partir de la implementación sistemática de la ficha de motivos polícromos, se obtendrá la información necesaria para determinar conclusiones relacionadas con los motivos decorativos, su técnica de ejecución y los tejidos polícromos (fondos) sobre los que se asientan. Finalmente, se ha aplicado el método descrito sobre un conjunto de 135 esculturas procedentes de Antequera (Málaga), confirmando la viabilidad del método de trabajo expuesto.
\end{abstract}

Palabras clave: motivos polícromos, método de estudio, ficha de motivos polícromos, técnicas polícromas, indumentaria y escultura.

\section{Método para o estudo de motivos polícromos}

Resumo: Este artigo expõe e propõe um método de estudo não-invasivo para a análise dos motivos polícromos dos trajes em esculturas policromadas. O método não afecta a integridade física da obra, é acessível, uma vez que não requere equipamento específico ou dispendioso e está disponível a um vasto grupo de profissionais. A partir da implementação sistemática de uma ficha de motivos polícromos, obter-seá a informação necessária para chegar a conclusões relacionadas com essas decorações, a sua técnica de execução e com os tecidos polícromos (fundos) sobre os quais assentam. Por fim, foi aplicado o método descrito a um conjunto de 135 esculturas provenientes de Antequera (Málaga), confirmando a viabilidade do sistema de trabalho exposto.

Palavras-chave: motivos polícromos, método de estudo, ficha de motivos polícromos, técnicas polícromas, indumentária e escultura.

\section{Method for studying polychrome patterns}

\begin{abstract}
This article exposes and proposes a non-invasive method for the analysis of the polychrome patterns on painted sculpture costumes. This method does not affect the physical integrity of the artwork, it is accessible (as it does not require specific or expensive equipment) and it is available to a wide group of professionals. Through the systematic implementation of a record sheet on polychrome patterns, indispensable information will be obtained in order to reach conclusions about the polychrome motives, their techniques of execution and the backgrounds upon which they are applied on. Finally, the method described was experimented on a set of 135 sculptures from Antequera (Málaga), confirming the feasibility of the method of work outlined.
\end{abstract}

Keywords: polychrome patterns, method of work, polychrome patterns record sheet, polychrome techniques, costume and sculpture. 


\section{Introducción}

La escultura en madera policromada de forma individualizada, como dentro un contexto iconográfico-retablístico, supone una de las manifestaciones del arte español por excelencia (Echeverría 1992: 4). La policromía por sí misma, tiene la capacidad de dotar de realismo a la talla, acercándola al pueblo y haciendo comprensible y directo su mensaje contribuyendo con ello a la funcionalidad testimonial de la obra. Cabe pensar que bajo estas circunstancias, la policromía sea objeto de numerosos estudios y análisis, pero nada más lejos de la realidad, a pesar de los esfuerzos por parte de profesionales del área de conservación-restauración.

A menudo observamos cómo su conocimiento y estudio queda relegado a un segundo plano, primando el análisis volumétrico de la obra. Esta circunstancia se agrava por los múltiples aspectos que se deben tener en cuenta (Fernández Pardo 2005: 53) a la hora de abordarla (datación, autoría, repolicromías, anacronismo entre talla-policromía, entre otras). Todos ellos son objeto de distintas disciplinas (Bruquetas, Carrasón y Gómez Espinosa 2003: 25) -difícilmente aunables en una sola persona, haciendo que llevar a cabo un riguroso estudio resulte extremadamente complejo.

En este artículo se expone un método de trabajo y conocimiento de los motivos polícromos de la escultura en madera dorada y policromada relacionado con su contexto (indumentaria que reviste la obra). El estudio propuesto es una forma de aproximación no invasiva para el bien, su estudio, conocimiento, valoración técnica que posteriormente permite extraer conclusiones, tanto a nivel de detalle de las policromías de una obra, como de un conjunto de piezas que tengan un nexo común. Al mismo tiempo resulta accesible y útil a un amplio campo de profesionales de distintas disciplinas con conocimientos sobre técnicas polícromas.

La viabilidad del método de trabajo queda manifiesta después de haberse aplicado con éxito sobre un conjunto de 135 esculturas exentas en madera dorada y policromada procedente de Antequera (Málaga), con una cronología entre los siglos XV al XVIII. Si bien, predominan las policromías de influencia ornamental barroca frente a las góticas o renacentistas en este ámbito geográfico.

\section{Objetivo y originalidad del método}

El objetivo principal planteado consiste en establecer y mostrar una metodología de trabajo para el conocimiento, documentación y extracción de conclusiones sobre las decoraciones polícromas de la escultura en madera dorada y policromada de cualquier ámbito geográfico o cronología. Esta aportación va destinada a todos aquellos investigadores o profesionales interesados en la documentación exhaustiva de las indumentarias polícromas en la escultura.

Como planteamiento metodológico, e influenciado por el volumen de piezas propuestas y estudiadas, y las circunstancias que las acontecen, se ha planteado como requisito fundamental, establecer un método de estudio directo y no invasivo de la obra. Basado en su análisis visual y toma de datos fotográfica, sin necesidad de acudir a costosos métodos de caracterización y estudio de materiales (Gómez González et al. 2002: 227-236), difícilmente abordables cuando se trata de estudiar un amplio número de piezas, o bien, por la imposibilidad de obtener los permisos necesarios o la accesibilidad a la obra para la extracción de las muestras. Este permite documentar los motivos decorativos polícromos y su contexto desde cierta distancia, contribuyendo activamente en la democratización y divulgación del propio método. 
Si la metodología en sí misma no presenta la clave de la originalidad del trabajo, puesto que sigue los preceptos de cualquier investigación científica, su interés y novedad reside en el objeto enfocado -escultura exenta policromada- y el tratamiento que de él se lleva a cabo.

En otras palabras, la originalidad reside en plantear un desarrollo metodológico de estudio sistemático, enfocado en la escultura exenta en madera dorada y policromada, concretada en el análisis de los motivos decorativos y su contexto (relacionando la ornamentación con la vestimenta sobre la que se aplica y la iconografía del personaje representado), frente al estudio de las decoraciones de la pintura sobre tabla (Santos Gómez 2005; López Zamora 2007), especialmente si éstas pertenecen a un ámbito museístico. Se priorizan las indumentarias polícromas frente a las carnaciones, más frecuentemente desarrolladas (Gañán Medina 1999).

La clave de esta propuesta es la presentación de un método económico y sencillo, pensado para aquellas esculturas integradas en los discursos iconográfico-retablístico que decoran nuestros inmuebles religiosos, denostadas y olvidadas en gran medida por no pertenecer a una elite artística. Muchos de ellos están abocadas a la exclusión en ambiciosos estudios, por no existir los medios suficientes, o la bondad de incluirlas en planes específicos de conservación que derivan en restauraciones de retablos como medio de conocimiento de las especificidades de esta tipología de obras.

Para obtener una aplicación efectiva del método y unas conclusiones fiables, veraces y concluyentes, había que seguir una trayectoria sistemática que tratara la información de cada obra con la misma rigurosidad e iguales parámetros. Este aspecto se ha concretado en la elaboración una ficha de motivos polícromos. Ésta ha sido creada como un instrumento con capacidad para, a un solo golpe de vista, contener la máxima información acerca de los motivos polícromos de la indumentaria de una obra, y su contextualización en el conjunto polícromo. Dicha información se relaciona con la vestimenta que decora -túnica o manto y determina si constituye el motivo decorativo, o si por el contrario, es la decoración de fondo sobre la que se asienta-. Además de contextualizarla de forma sencilla, aporta información sobre los datos generales de la escultura.

La aplicación de esta metodología a un conjunto de esculturas de un mismo autor, época, escuela o ámbito geográfico, permite obtener conclusiones novedosas acerca de los motivos decorativos, técnicas de ejecución, efectos pictóricos y utillaje empleado en la creación artística de las indumentarias polícromas de las esculturas. En muchos casos, se establecen unos patrones de ejecución que pueden servir en un futuro para autentificar y aportar nuevas autorías, aportando luz a este campo de estudio hasta ahora poco desarrollado de forma sistemática.

\section{Antecedentes}

Desde hace relativamente poco tiempo, se han llevado a cabo estudios centrados en las policromías de las esculturas. Se han creado grupos de trabajo formado por profesionales del sector de la conservación-restauración, vinculados con instituciones de reconocido prestigio del sector patrimonial como: Instituto Andaluz de Patrimonio Histórico, The Getty Conservation Institute, Institut Royal du Patrimoine Artistique, Instituto de Patrimonio Histórico Español, Grupo de Conservación del International Council of Musseum, entre otros.

Los grupos de trabajo que han contribuido al conocimiento del tema con la publicación de sus conclusiones son: el Grupo ICOM-CC de Sculpture, Polychromy and Architectural Decoration, del International Council of Museums (Preprints), y el proyecto de investigación europeo para el estudio 
de la escultura policromada dentro del Proyecto de Investigación del Programa Raphael de la Unión Europea (Proyecto Policromía).

Destacan las aportaciones al tema por parte de autores españoles, que han sido pioneros en la materia, abordando el estudio de la policromía de la escultura en madera policromada o pintura sobre tabla desde la perspectiva histórica, material y/o técnica principalmente. Algunos de ellos son: Pedro Echevarría Goñi, Rosaura García Ramos, Emilio Ruiz de Arcaute Martínez, Ma José González López, Rocío Bruquetas Galán, Enriqueta González Martínez, Fernando R. Bartolomé García, Domingo Sánchez Mesa, Ainhoa Rodríguez López, Teresa Gómez Espinosa, Agnes Le Gac, Ana Carrasón López de Letona, Consuelo Dalmau Moliner, Eva López Zamora, Sonia Santos Gómez, entre otros.

En general, desde la óptica de historiadores del arte ha predominado un enfoque histórico, dándole mayor relevancia a aspectos puramente relacionados con su historia material, iconográfica y documental, como así lo atestiguan los numerosos ensayos existentes. Sin embargo, cuando la policromía es abordada por especialistas de las Bellas Artes en general, y en particular por Conservadores-Restauradores, el enfoque se dirige hacia aspectos relacionados con las técnicas de dorado y las capas de preparación específicamente, pasando someramente por el análisis en profundidad de las técnicas decorativas o los efectos pictóricos que ofrecen. Otros estudios, se centran en aspectos materiales, haciendo especial relevancia en los materiales presentes mediante su identificación y posterior caracterización por medio de análisis científicos, o tecnológicos desarrollando aspectos constructivos y determinando el proceso de ejecución. Cuando el objetivo se basa específicamente en la ornamentación, predominan los estudios de pintura sobre tabla en detrimento de la policromía de las esculturas.

Pero, si hay un momento oportuno e inmejorables condiciones para documentar y estudiar los motivos decorativos, y por ende, la policromía de una escultura, esa situación se plantea durante la restauración de un retablo. Ella trae consigo el acceso directo a la obra, permitiendo su manipulación y la observación de y observar detalles que a cierta distancia se pierden, la habitual caracterización de materiales constructivos y técnicas artísticas que normalmente se realizan. Todo ello contribuye a conocer muchos datos que de otra forma no serían tan certeros, o simplemente inapreciables. Por esto resulta indispensable conocer los casos publicados acerca de las intervenciones de restauración de retablos, como: Retablo Mayor de la Catedral de Sevilla, Retablo Mayor de la Catedral de Tudela, Retablo Mayor de la Iglesia Parroquial de Albolote (Granada), Retablo y sarga de San Eutropio de El Espinar, Retablo de Santa Bárbara de la Catedral de Málaga, Retablo de Santa Ana de Sevilla, Retablo de la Catedral Vieja de Salamanca, Metodología para la intervención del Retablo de la Capilla Real de Granada y de la Iglesia de San Luis de los Franceses de Sevilla, entre otros.

\section{Aplicación del método de trabajo}

El método de estudio aplicado a la escultura exenta en madera dorada y policromada debe ser planteado sobre un objetivo concreto, es decir, obras con un elemento en común. Por ejemplo: pertenecer a un mismo retablo o inmueble, ser atribuidas a un mismo autor o cronología, o bien, hallarse en un ámbito geográfico concreto, como es el caso expuesto.

Para cualquiera de estos planteamientos, el punto de partida se inicia con el denominado reconocimiento del terreno, concretándose en la determinación del volumen de obras que se 
incluirán, la accesibilidad de las mismas y la viabilidad del estudio. La próspera ciudad de Antequera cuenta en la actualidad con un total de 23 inmuebles religiosos en activo, contenedores de 135 esculturas exentas en madera dorada y policromada. Las obras incluidas en el estudio son aquellas que han podido inspeccionarse durante el proceso de trabajo de campo, quedando fuera de él aquellas a las que no ha sido posible el acceso.

El siguiente paso a seguir, es la solicitud de los permisos necesarios para llevar a cabo la documentación in situ de las obras. Este punto no reviste mayor dificultad, puesto que el método planteado no implica la manipulación directa de las obras, y por lo tanto predispone positivamente a cooperar a los custodios de dichos bienes muebles. Los inmuebles incluidos en la praxis son gestionados en su mayoría por órdenes o agrupaciones religiosas, dos de ellos en cambio, son gestionados directamente por la corporación municipal. A este respecto, cabe destacar que el consistorio de Antequera destaca por el interés que manifiesta en la conservación y restauración de los bienes muebles e inmuebles del municipio, contribuyendo activamente con un taller de restauración municipal.

Uno de los momentos claves para el desarrollo del estudio lo constituye la toma de documentación fotográfica in situ, de las obras en sí mismas, de sus detalles polícromos y del entorno (retablo e inmueble) que las rodea e integra. Las 135 esculturas antequeranas fueron documentadas realizando un barrido fotográfico de las mismas en su correspondiente ubicación, tomando en la medida de lo posible macrofotografías de los detalles relacionados con la ejecución de la policromía. In situ, también se anotan referencias en cuanto a la ubicación dentro del inmueble, situación en el retablo, dimensiones aproximadas, posibles repolicromías o distribución de repintes, estado de conservación, y cualquier otro dato significativo que pueda aportar luz al estudio posterior.

Tras obtener los documentos gráficos de cada obra, necesarios para su estudio y contextualización, se vuelcan a soporte informático. El criterio para su agrupación y clasificación se estableció partiendo de lo más general (inmuebles) a lo más particular (primero, retablos y finalmente por obras). Al contar con 23 inmuebles, 80 retablos y 135 esculturas, muchas de ellas con idéntica iconografía o nombre, se añadió a cada obra un código de referencia alfanumérico como medida identificativa.

Trabajo de Campo

$>$ Obras con un elemento en común.

$>$ Reconocimiento del terreno

> Solicitud de permisos

$>$ Documentación fotográfica in situ

$>$ Volcado de datos a soporte informático

> Aplicación de código de referencia

\section{Trabajo de Investigación}

$>$ Implementación de las fichas de motivos polícromos

> Criterio seleccionado de orden de clasificación

> Análisis de datos

$>$ Conclusiones 
Un aspecto fundamental para la identificación de las obras lo constituye llevar a cabo un estudio a nivel histórico-artístico, acudiendo a la documentación bibliográfica existente. Este punto es transversal a todo el desarrollo de la propuesta metodológica, puesto que cuanto más detalles se conocen de una obra, nuevos descubrimientos o reinterpretaciones de la información se incorporan a las hipótesis preestablecidas.

Hasta el momento, el desarrollo del proceso metodológico está centrado en la fase: trabajo de campo, centrado en la obtención, recopilación y clasificación de datos. A partir de este punto, se ahonda en el objeto de la cuestión: el estudio de los motivos polícromos y su contexto directo, la base o fondo sobre el que se asientan, y los aspectos técnicos desarrollados en su ejecución. Para ello, resulta fundamental contar con un instrumento de captación de datos como es la Ficha de Motivos Polícromos, diseñada especialmente, por y para esta tipología de obras, y centrada fundamentalmente en las decoraciones polícromas de estilo barroco, por ser éstas el objeto práctico de este método.

La viabilidad de la Ficha de Motivos Polícromos como instrumento de obtención de información estándar, ha sido demostrada al implementarla con los datos conseguidos de las 135 esculturas exentas propuestas.

La implementación de los descriptores propuestos en la fichas de motivos polícromos exige la clasificación, selección y tratamiento infográfico de las imágenes más representativas tomadas de la documentación fotográfica obtenida in situ de cada escultura. Ello exige estudiar pormenorizadamente toda la documentación existente de cada obra, y mediante la selección de los parámetros propuestos para la cumplimentación de cada epígrafe, se alcanza a caracterizar los rasgos generales y particulares tanto de los motivos decorativos polícromos como las decoraciones de los fondos sobre los que se asientan.

Finalmente, a pesar de la voluminosa cantidad de información y documentos fotográficos e infográficos generados durante todo el proceso de trabajo de campo e investigación, el volumen principal de estudio queda reducido a un total de 135 fichas, una por cada una de las esculturas. Es obvio decir que este volumen de información resulta mucho más cómodo y factible para la obtención de conclusiones veraces y sistemáticas, tanto a nivel particular como general, acerca de las características polícromas de las indumentarias que visten las esculturas de este ámbito geográfico y cronológico, o de cualquier otro al que se aplique.

Al avanzar en la búsqueda de conclusiones y ahondando en los datos obtenidos, se hace necesario establecer un orden de clasificación de las 135 fichas. El criterio seleccionado de orden de clasificación, sin lugar a dudas debe estar relacionado directamente con el tema objeto de estudio: los motivos polícromos y sus técnicas de ejecución.

Tras varios ensayos de orden de clasificación, se puso de manifiesto que el verdadero nexo de unión estilístico entre una obra u otra, viene determinado por las técnicas de ejecución que hayan sido empleadas en la creación de sus motivos decorativos. Frente a este aspecto, presentan menor semejanza estilística aquellas obras realizadas con una misma gama cromática, técnica de ejecución para la decoración de los fondos, o la propia naturaleza (refiriéndose a la capacidad de pertenecer a una especie u otra) del motivo decorativo. Así por ejemplo, si varias indumentarias están decoradas con motivos florales, o un mismo color de fondo para el tejido policromado, no asegura su analogía estilística. Mientras que si los motivos decorativos son ejecutados con 
idénticas técnicas, independientemente de lo que representen, ofrecerán una mayor afinidad estilística.
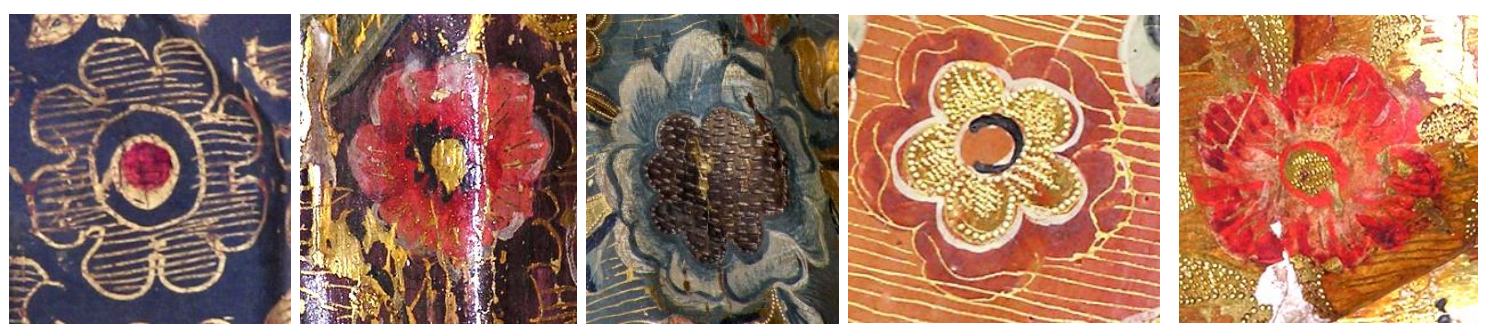

Todos estos motivos florales presentan una morfología muy similar; las semejanzas y diferencias entre ellos vienen determinadas por las técnicas y recursos plásticos utilizados en la ejecución de los mismos.

Finalmente, y en gran medida gracias al orden planteado y descrito para las fichas obtenidas, se pueden extraer todo tipo de conclusiones relacionándolas con cualquiera de los descriptores implementados, siendo este, el último eslabón de la cadena de investigación, de las policromías de un determinado ámbito.

\section{Ficha de Motivos Polícromos}

Como se ha manifestado anteriormente en la descripción de la aplicación del método, una de las claves del éxito en la extracción de conclusiones acerca de las características polícromas de la escultura antequerana está fundamentada en la utilización de la Ficha de Motivos Polícromos.

El diseño de la Ficha de Motivos Polícromos es determinante para el buen desarrollo del método, debía cumplir una serie de exigencias que facilitaran tras su implementación, la extracción de conclusiones veraces y contrastadas acerca del tema de estudio. Las exigencias requeridas y cumplidas han sido las siguientes:

- Incluir todos los datos relevantes a nivel general y específico de la escultura, y sus motivos polícromos en un solo documento, permitiendo en un golpe de vista toda la información.

- Mostrar las similitudes o divergencias técnicas y/o plásticas entre las distintas vestimentas que atavían a los distintos personajes iconográficos representados.

- Información concisa, amplia y exhaustiva acerca de la naturaleza, distribución, traspaso del dibujo y técnicas de ejecución de los motivos polícromos y su contexto más directo (fondo o tejido sobre el que se asientan los motivos decorativos y sus características formales).

- Uniformidad de contenidos y su tratamiento, para ello se establecen unos descriptores de estudio constantes a implementar.

- Crear una plantilla estándar (Ficha de Motivos Polícromos) que mantuviera el mismo formato sin variaciones dimensionales al implementar la información específica de cada escultura. Para ello se optó por trabajar con un software tipo Corel Draw 12. 


\section{Descripción formal de la Ficha de Motivos Polícromos}

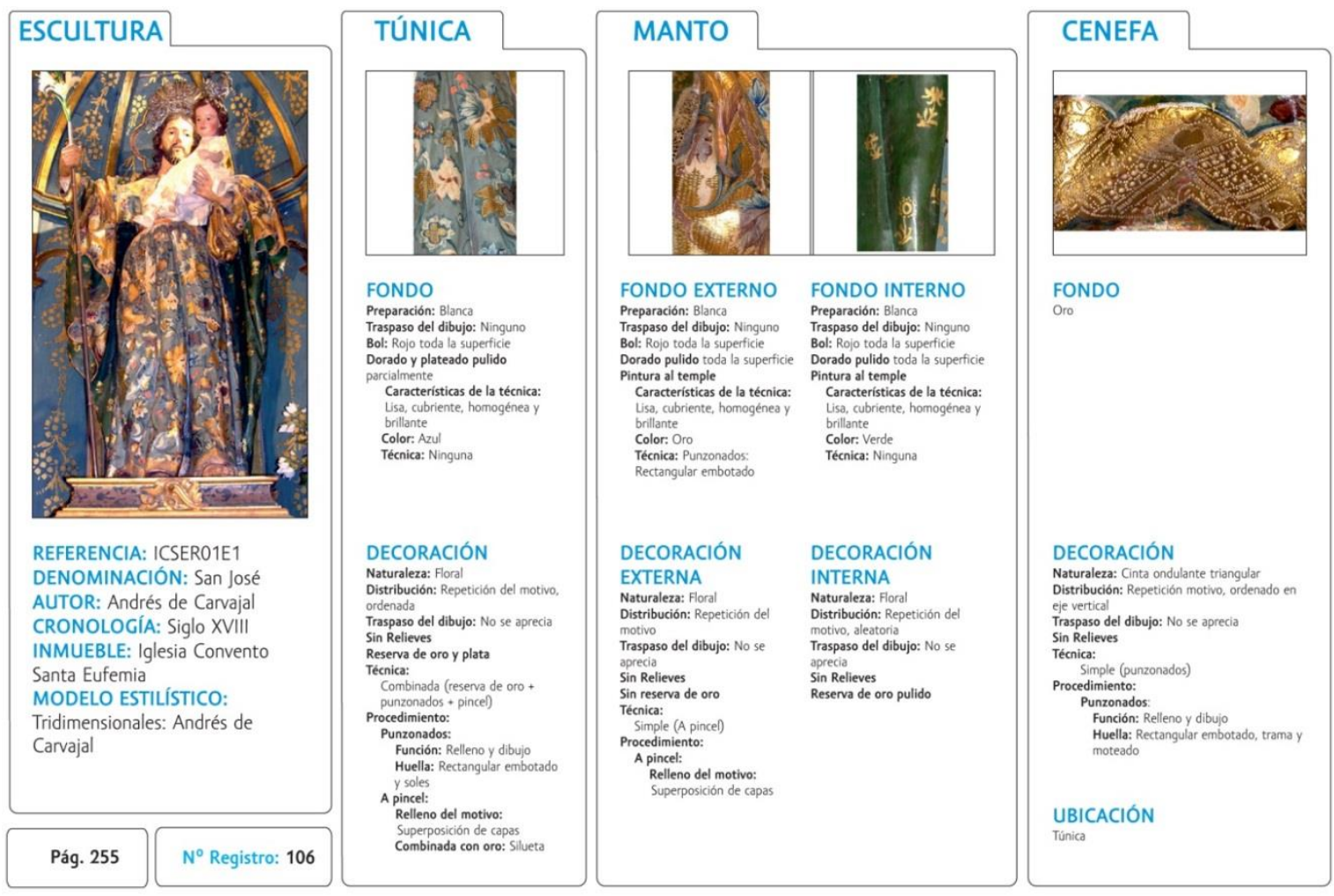

Ficha de Motivos Polícromos

La Ficha de Motivos Polícromos se presenta con una estructura homogénea y uniforme en formato apaisado. Dispuesta en cuatro columnas verticales remarcadas a modo de clasificadores con cajetín, en donde se inserta el título del tema principal (escultura, túnica, manto y cenefa).

En cada una de las columnas el espacio se divide en dos áreas fundamentales de lectura de información; fotografía acorde al tema de alusión y descriptores estándar de información. Dichos descriptores son uniformes y constantes en la Ficha de Motivos Polícromos, si ellos fueran modificados de una escultura a otra no existiría la posibilidad de estudiar y extraer conclusiones veraces sobre un grupo de policromías y sus motivos decorativos.

En la primera columna Escultura aparecen una serie de descriptores; "accesorios" para la documentación formal de la policromía, pero necesarios cuando se aplica este sistema metodológico de estudio sobre un conjunto de obras amplio y variado con el fin de extraer conclusiones sobre el mismo. Los parámetros referidos son los siguientes: referencia; clave que se asigna a cada escultura y la relaciona directamente con el inmueble y retablo en el que se ubica, Pág., establece un índice de páginas que se ordenan en función del $N^{\circ}$ de registro; este último es un número que se asigna en función del orden que se establece para clasificar las fichas obtenidas respecto a un conjunto de obras analizadas. El criterio de clasificación seleccionado y aplicado a las obras tomadas como muestra de la eficacia del método se basa en ordenarlas en función de la/s técnica/s que se emplean en la ejecución de los motivos que decoran la indumentaria de las esculturas. 
En las columnas túnica, manto y cenefa, se puede apreciar que la información se ha dividido en dos apartados claramente diferenciados: fondos y decoración. En el área Decoración se incluyen todos los datos relacionados con los motivos polícromos en sí mismos y las características de las técnicas de ejecución empleadas, mientras que en el área denominada Fondo, los motivos decorativos se contextualizan describiendo la base sobre la que se asientan.
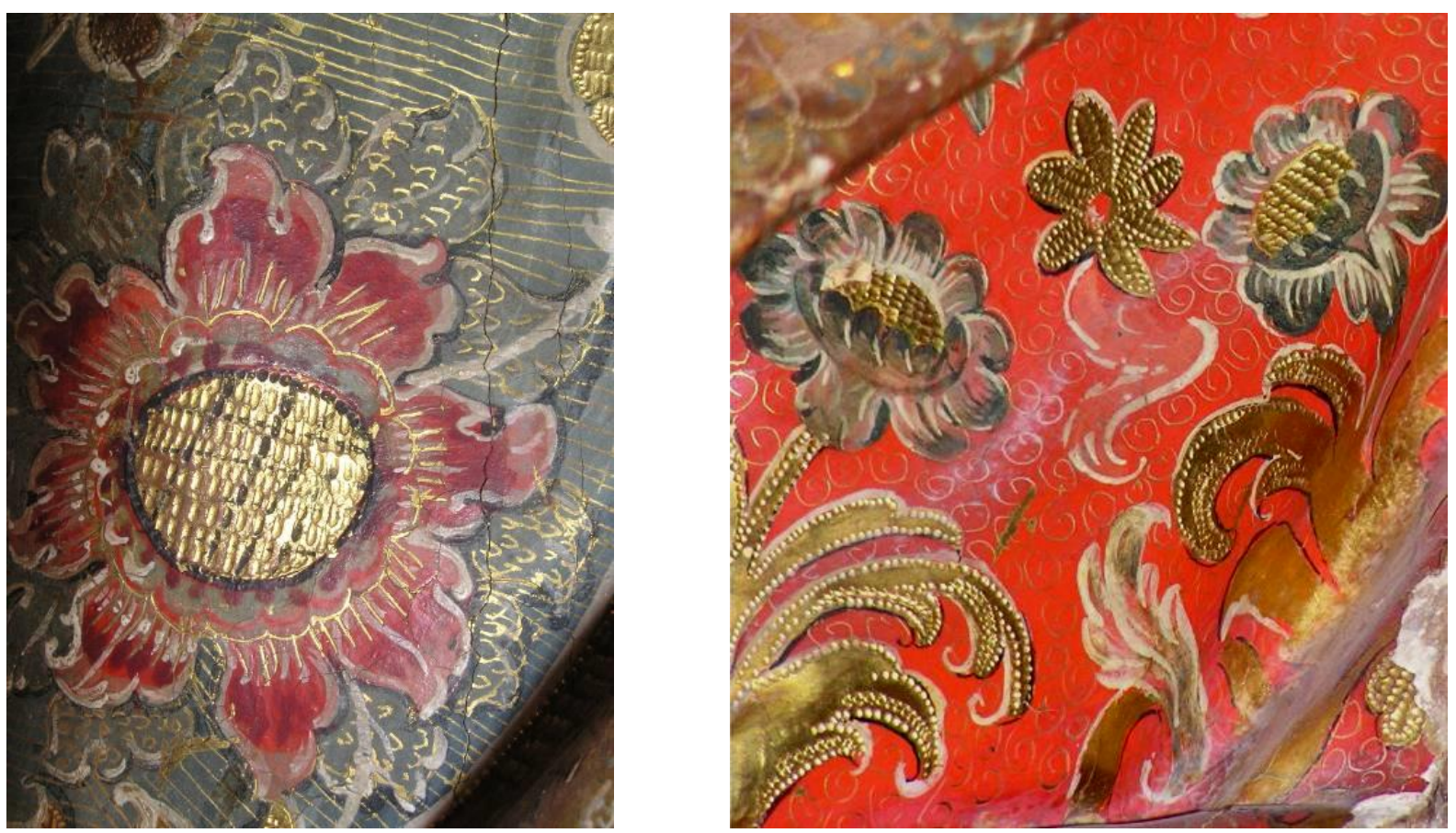

Los motivos decorativos o decoración de naturaleza floral se asientan sobre sendos fondos azul (izquierda) y rojo (derecha), esgrafiados con huellas en forma de rayados horizontales (izquierda) y roleos (derecha).

La columna manto incluye dos subapartados distribuidos verticalmente que tienen una correspondencia directa con la parte externa (anverso) y la parte interna (reverso) de los mantos o capas a los que hacen referencia. En la columna cenefa se incluye un tercer apartado en la zona inferior denominado ubicación para identificar claramente a que parte de la indumentaria pertenece, túnica y/o manto. Los datos propios de las cenefas se han planteado en una columna independiente y no como anexo inferior de las columnas túnica o manto, para propiciar la gestión del espacio, debido a la disposición arbitraria de las cenefas en las distintas vestimentas.

\section{Claves para el uso e implementación de datos en la Ficha de Motivos Polícromos}

Como anteriormente se ha especificado, los descriptores estándares de información son uniformes y constantes en todas las Ficha de Motivos Polícromos de cada una de las posibles esculturas a analizar. Sin embargo, los parámetros establecidos para su implementación, se han creado de acuerdo al conjunto de policromías analizadas como ejemplo de demostración del método no invasivo de estudio de motivos policromos6. En el presente estudio la autora se ha propuesto examinar los motivos polícromos de las indumentarias de la escultura exenta en madera dorada y policromada en Antequera (Málaga). Por ello, los posibles parámetros expuestos para cada uno de los descriptores incluidos en la ficha se adaptan a estas obras. 
Aunque la variedad de parámetros que se presenta es amplia, no hay que perder de vista que se han ajustado a las características polícromas de un área concreta. Y por tanto, no se debe considerar como un trabajo finalizado y cerrado, sino aceptarlo como una primera aproximación en la que se establecen las bases para futuras ampliaciones y nuevas aportaciones. Esto no haría más que constatar lo que ya es conocido, que la riqueza polícroma y técnica de la escultura policromada es amplísima y variada.

Los parámetros específicos de las técnicas artísticas se han nombrado atendiendo a la morfología o expresión artística que plantean, dejando al margen otro tipo de terminología basada en los conocimientos de contratos de obra u otros documentos históricos. Esta decisión viene en parte determinada ante la imposibilidad de contrastar esa terminología con documentación específica del área de Antequera. Por otro lado, se ha considerado más acertado emplear una terminología acorde a los efectos plásticos que persiguen estas técnicas o la forma que dejan impresa sobre la pintura.

A continuación, se ofrecen las claves para la implementación de cada uno de los descriptores estándar:

\section{Escultura}

- Referencia: código de registro o referencia asignado a cada obra.

- Denominación: título de la Escultura.

- Autor: creador del bien, en su defecto en aquellos casos en los que no se tenga constancia del artista, se pondrá el taller, escuela o círculo artístico al que pertenece si se conociera.

- Cronología: fecha de ejecución o contexto histórico.

- Inmueble: denominación del Inmueble en el que se encuentra.

- Modelo Estilístico': grupo estilístico al que pertenecen este tipo de policromías.

\section{Túnica, Manto (externo e interno) y Cenefa}

- Fondo²:

- Preparación: blanca o coloreada.

- Traspaso del dibujo: incisión en húmedo "U" o incisión en seco "V".

- Bol: rojo, anaranjado o amarillo. Parcial o en toda la superficie.

- Sin dorar, dorado pulido/bruñido, dorado mate o plateado pulido/bruñido.

- Características de la técnica: lisa o rugosa; cubriente o no cubriente; homogénea o desigual; brillante o mate.

- Color: blanco, amarillo, naranja, rosa, rojo, pardo claro, pardo oscuro, celeste, azul, violeta, morado, verde claro, verde oscuro, gris, negro, oro y plata (Tono de base uniforme).

\section{- Técnica:}

- Punzonado3: rectangular embotado ${ }^{4}$, rectangular, cuadrado, trama, flor, ojeteado, moteado y soles. 
- Esgrafiados: rayado horizontal, oblicuo o vertical (discontinuo), ojeteado, escamado, moteado, moaré, zig-zag y roleos.

- Corladuras: sin motivos o con motivos

- Decoración ${ }^{5:}$

- Naturaleza $a^{6}$ floral, vegetal, línea recta, red cuadrada simple, red cuadrada compuesta, estrellas, armiño o concha. Mixta simple (floral + vegetal), (estrellas + epigrafía), (floral + red cuadrada) o (floral + guirnalda). Mixta compuesta (floral + vegetal + corazones), (floral + vegetal + red diagonal), (floral + vegetal + lazos) o (floral + vegetal + humana).

- Distribución: repetición del motivo, aleatorio u ordenado. Ordenado: en eje vertical u horizontal, en sentido vertical u horizontal y en cuadrícula.

- Traspaso del dibujo: incisión en húmedo "U" o incisión en seco "V".

- Sin relieves o Con relieves.

- Sin dorar, dorado pulido, dorado mate o plateado pulido/bruñido.

- Técnica: simple (reserva de oro $^{7}$, punzonados, a pincel, esgrafiados o corlados) o combinada (reserva de oro + punzonados), (reserva de oro + pincel), (reserva de oro + esgrafiados), (dorado mate+ pincel), (reserva de oro + punzonados + pincel), (reserva de oro + punzonados + esgrafiados), (reserva de oro + punzonados + pincel+ esgrafiados), (reserva de oro + punzonados + pincel + corladuras).

○ Procedimiento:

- Punzonados:

- Función: relleno o dibujo (silueta o interior).

- Huella: rectangular embotado, rectangular, cuadrado, trama, flor, ojeteado, moteado y soles.

- A pincel:

- Relleno de color: tinta plana + silueta, tinta plana + luz/sombra, superposición de capas y degradación de color.

- Combinada con oro: Silueta o contorno del motivo, luz/sombra o sombra proyectada.

- Esgrafiados:

- Función: relleno o dibujo (silueta o interior).

- Huella: rayado horizontal, oblicuo o vertical (discontinuo), ojeteado, escamado, moteado, moaré, zig-zag, roleos, trazo fino o trazo grueso.

- Corladuras: sin motivos o con motivos.

El epígrafe Naturaleza del apartado Decoración cuando se refiere a las características de las Cenefas, presenta una diferencia sustancial respecto a sus homónimos túnicas y mantos, presentando una nomenclatura específica adaptada a los tipos de cenefas, como reflejo del análisis extraído de las obras estudiadas. Se especifican a continuación: 


\section{- Decoración (Cenefas)}

- Naturaleza: floral, cintas de follaje/zarcillo, flor de lis, cintas en zig-zag simples (flor), piedras preciosas, cintas lobuladas, sarta de perlas, cintas en zig-zag simples o triples (lis/palmeta), cintas en zig-zag polilobuladas (palmetas), cintas ondulantes triangulares (palmetas), cintas ondulantes con lazo, cintas ondulantes con elipses, cinta geométrica con rombos y círculos, o sin motivos.
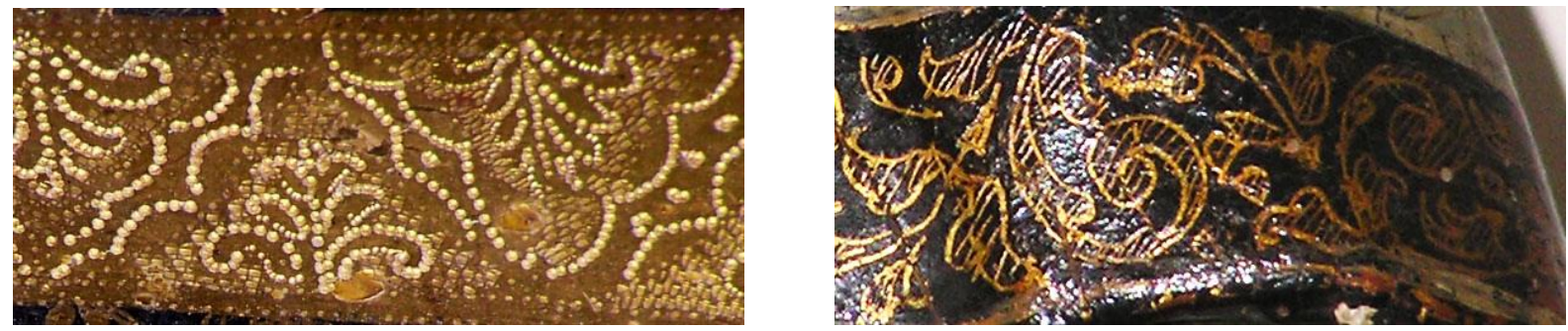

Detalle de las cenefas que rematan algunas indumentarias de las esculturas de Antequera.

\section{Resultados}

Como se ha apuntado anteriormente, todo el discurso procesual metodológico culmina con la obtención de las conclusiones, basadas fundamentalmente en los resultados (parámetros) obtenidos en cada uno de los descriptores de las fichas y su estudio comparativo.

Una de las primeras conclusiones obtenidas, extrapolable a otras piezas, es la semejanza que muestran aquellas policromías que utilizan las mismas técnicas artísticas en la ejecución de los motivos decorativos, independientemente de las empleadas para decorar los fondos sobre los que se asientan. Al agrupar y ordenar las obras antequeranas en relación con este aspecto, se han clasificado en torno a cinco grupos o modelos estilísticos, guardando todos ellos unas características comunes y relacionadas con las técnicas de ejecución empleadas en sus decoraciones polícromas.

Estos modelos estilísticos evolucionan desde policromías "monocromáticas" de aspecto plano, con indumentarias de color uniforme sin motivos decorativos, ciñéndose éstos a la ornamentación de las cenefas, entroncando así con la tradición más sobria del Concilio de Trento. Pasando a observar otras policromías, también de aspecto plano pero más sofisticado, denominadas "bidimensionales". En éstas, la técnica de ejecución empleada en las ornamentaciones tanto de los fondos como de los motivos decorativos son los esgrafiados, dificultando la diferencia entre el motivo y su fondo al quedar ambos en un mismo plano. Este tipo de policromías entronca con la tradición polícroma gótica como así lo atestigua la datación de las propias esculturas. Las más prolijas en Antequera, son aquellas policromías denominadas "tridimensionales". Se caracterizan por emplear todo tipo de técnicas y recursos plásticos en la ejecución de los motivos decorativos, en la incesante búsqueda de volumen, movimiento y en definitiva, realismo en la imitación de los tejidos históricos. En ellas, el motivo y el fondo se perciben en dos planos diferenciados en aras de la tridimensionalidad deseada. Las tres principales técnicas; punzonados, a pincel y esgrafiados, son utilizadas y combinadas en la creación de los motivos decorativos derivando en sofisticados y complejos diseños de naturaleza, generalmente floral y vegetal. 
Finalmente, configuran parte de estos cinco modelos estilísticos polícromos las obras atribuidas a los antequeranos Andrés de Carvajal (1709-1779) y la Familia de los Márquez; Diego Márquez y Vega (1724-1791) y su hijo Miguel Márquez García (1767-1826). En cada uno de ellos, entre sus obras se aprecian similitudes estilísticas relacionadas con los diseños, ejecución y distribución de los motivos decorativos. La gama cromática empleada, así como la combinación de las técnicas y recursos plásticos hacen que sus obras les caractericen y tengan nombre propio a pesar de formar parte del estilo polícromo barroco antequerano. Las pautas que se han establecido en el estudio de sus policromías, confiamos contribuyan en el futuro a identificar nuevas adjudicaciones.

Todo ello, favorece poner de manifiesto la existencia de un foco artístico antequerano, que gozó de reconocimiento en su momento histórico. Si bien, no logra alcanzar la consideración de escuela, como los focos artísticos de Granada o Sevilla, sí supone, un reconocimiento de una identidad propia en la que destacan las figuras de Andrés de Carvajal y la familia de los Márquez.

Técnicamente, la policromía de la escultura antequerana sigue la estratificación en capas tradicional, compuesta por: aparejo, bol, lámina de oro pulida, capa de color de fondo (azul, blanco o rojo son los más utilizados), decorados a base de esgrafiados con huellas de rayados horizontales (rajados). Las corladuras, como se viene apuntando en otros estudios (Echeverría 2002: 170), se relega a los interiores de los mantos y envés de las mangas.

Los motivos decorativos son utilizados para ornamentar las indumentarias, siendo de forma generalizada de naturaleza floral y vegetal, en donde abundan los rameados como elementos secundarios distribuidores de la composición. Para crearlos, los artistas recurren fundamentalmente a la utilización de punzonados combinados con retoques a pincel y reservas de oro o plata.

Uno de los aspectos más significativos y originales de este estudio, lo representa el hecho de haber elevado a las cenefas de las túnicas y mantos a la misma categoría de estudio que éstos. Mediante el análisis de las mismas, se ha determinado que no son intrínsecas a las túnicas o mantos, si no que se emplean en cierto modo, arbitrariamente. Se ha profundizado en el análisis de la naturaleza o diseño de los motivos decorativos que representan, llegando a clasificarlos según los parámetros señalados en el apartado decoración referido a cenefas, en la fichas de motivos polícromos. Los motivos predominantes en las decoraciones de las cenefas son las cintas de follaje o zarcillo, siguiéndoles las cintas en zig-zag simples y triples.

En definitiva, este método contribuye al estudio y análisis de las policromías y motivos decorativos de las indumentarias de las esculturas, incluyendo las cenefas que rematan las túnicas y mantos. Contextualizando y estableciendo relaciones entre los distintos elementos que componen y crean una policromía, yendo un paso más allá, al permitir establecer unas directrices acerca de un área de estudio con algún parámetro común.

\section{Notas}

[1] Este apartado se aclarará en las conclusiones del artículo. Se han establecido cinco grupos: monocromáticas, bidimensionales, tridimensionales, Andrés de Carvajal y Familia de los Márquez

[2] Los fondos constituyen una capa de color decorada o no, sobre la que resaltan los adornos, dibujos o motivos decorativos, situándose en un segundo plano.

[3] Método mecánico que imprime la huella del punzón mediante presión o percusión sobre una superficie polícroma, generalmente metálica pulida. 
[4] La huella impresa presenta forma rectangular con las esquinas ligeramente curvas.

[5] Se ha elegido el término decoración como sinónimo de motivo decorativo por ser más genérico y global, ya que las policromías en muchas ocasiones incluyen más de un tipo de motivo.

[6] La naturaleza de la decoración es entendida como la cualidad de pertenecer a una especie, genero o clase.

[6] Sólo parte de la superficie dorada o plateada pulida resulta visible, constituyendo el motivo decorativo en sí mismo o parte de él.

\section{Bibliografía:}

BARTOLOMÉ GARCÍA, F. (1997). "Pintura y policromía de los siglos XVII y XVIII en Orduña. El maestro pintor Juan Antonio de Jáuregui", Revista Ondare, 16: 143-166.

BRUQUETAS, R., CARRASÓN, A. y GÓMEZ ESPINOSA, T. (2003). "Los Retablos. Conocer y Conservar", Bienes Culturales, 2: 13-42.

BRUQUETAS GALÁN, R. (2004). "Los tableros de pincel. Técnicas y materiales", 2a ed. Madrid: Grupo Español de IIC.

CARRASÓN LÓPEZ DE LETONA, A., et al. (2002). "Las técnicas de dorado en los siglos XVII y XVIII en España." En Congresso Internacional Policromía. A escultura policromada religiosa dos séculos XVII e XVIII: Estudo comparativo das técnicas, alterações e conservação em Portugal, Espanha e Bélgica. Lisboa: Instituto Português de Conservação e restauro, 189-196.

DE LA FUENTE RODRÍGUEZ, L. A. (1998). “Corladura o 'meccha'. Evolución técnico-histórica”. Kermes, 31:42-56.

ECHEVARRIA GOÑI, P. L. (1990). La policromía del renacimiento en Navarra. Pamplona: Gobierno de Navarra.

ECHEVARRIA GOÑI, P. L. (1992). "Policromía renacentista y barroca." Cuadernos de Arte Español, 48: 31.

ECHEVARRIA GOÑI, P. L. (2002). "Evolución de la policromía en los siglos del Barroco. Fases ocultas, revestimientos, labores y motivos." En Congresso Internacional Policromía. A escultura policromada religiosa dos séculos XVII e XVIII: Estudo comparativo das técnicas, alterações e conservação em Portugal, Espanha e Bélgica. Lisboa: Instituto Português de Conservação e Restauro, 167-176.

FERNANDEZ PARDO, F. et al. (2005). La escultura en la ruta Jacobea: Arnao de Bruselas. Retablo Mayor de la Imperial Iglesia de Palacio. Logroño: Diócesis de Calahorra y la Calzada-Logroño.

GAÑÁN MEDINA, C. (1999). Técnicas y Evolución de la Imaginería Polícroma Sevillana. Sevilla: Universidad de Sevilla.

GARCÍA RAMOS, R. y RUIZ DE ARCAUTE, E. (1996). "Aproximación al brocado aplicado en España. Desarrollo y extensión." En XI Congreso de Conservación y Restauración de Bienes Culturales, Castellón: Grupo Español del IIC y Diputació de Castelló, 747-756.

GARCÍA RAMOS, R. y RUIZ DE ARCAUTE, E. (1997). "Aportaciones al estudio de correspondencias de policromías. Criterios y técnicas." Revista Kermes, 29: 7-12.

GÓMEZ ESPINOSA, T. (2004). "La policromía de los retablos. Estilos y Evolución”. 2ª ed. Madrid: Grupo Español de IIC.

GÓMEZ GONZÁLEZ, M., et al. (2002). "Estudio Analítico de la Policromía Castellana del Siglo XVII". En Congresso Internacional Policromía. A escultura policromada religiosa dos séculos XVII e XVIII: Estudo comparativo das técnicas, alterações e conservação em Portugal, Espanha e Bélgica. Lisboa: Instituto Português de Conservação e Restauro, 227-236. 
GONZÁLEZ LÓPEZ, M. J. (2004). “Una propuesta de ficha para la creación de una base de datos de retablos en madera policromada." En Séptimo Congreso Internacional de Rehabilitación del Patrimonio Arquitectónico y Edificación. Lanzarote: Centro Internacional para la Conservación del Patrimonio, 78-83.

LOPEZ ZAMORA, E. (2007). Estudio de los materiales y procedimientos del dorado a través de las fuentes literarias antiguas: Aplicación en las decoraciones de pinturas castellanas sobre tabla, Tesis Doctoral, Madrid: Universidad Complutense de Madrid.

LÓPEZ ZAMORA, E. y DALMAU MOLINER, C. (2006). "Estudio y clasificación de los motivos grabados en las superficies doradas de pinturas sobre madera. Propuesta de ficha de recogida de datos." En XV Congreso de Conservación y Restauración de Bienes Culturales. Murcia: Consejería de Educación y Cultura, Dirección General de Cultura, 191-202.

PRADO CAMPOS, B. (2005). Puesta a punto de una metodología de conocimiento y estudio de los motivos decorativos de la escultura exenta en madera policromada de los siglos XV al XVIII en cuatro iglesias de Antequera, Málaga: clasificación, estudio y técnica de ejecución. Inédito.

PRADO CAMPOS, B. (2011). Estudio comparativo de la policromía aplicada a la escultura exenta en madera de los siglos XV al XVIII en Antequera, Málaga: motivos ornamentales y técnicas de ejecución. Tesis Doctorla. Sevilla: Universidad de Sevilla.

SANTOS GÓMEZ, S. (2005). Las preparaciones de yeso en la pintura sobre tabla de la escuela española. Tesis Doctoral. Madrid: Universidad Complutense de Madrid.

SERUYA, A. I. (dir.) (2002). Actas do Congresso Internacional Policromía. A escultura policromada religiosa dos séculos XVII e XVIII: Estudo comparativo das técnicas, alterações e conservação em Portugal, Espanha e Bélgica: Lisboa, 29, 30 e 31 de outubro de 2002. Lisboa: Instituto Português de Conservação e Restauro.

SANCHEZ-MESA MARTÍN, D. (1971). Técnica de la escultura policromada granadina. Granada: Universidad de Granada.

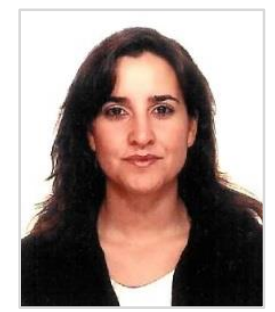

\section{Dra. Beatriz Prado Campos}

beatrizpradocampos@gmail.com

Doctora en Bellas Artes por la Universidad de Sevilla (2011). Conservadora-Restauradora licenciada en la Universidad de Granada. Su tesis doctoral se tituló Estudio comparativo de la policromía aplicada a la escultura exenta en madera de los siglos XV al XVIII en Antequera, Málaga: motivos ornamentales y técnicas de ejecución. Pertenece desde 2011 al Proyecto I+D+I: "Excavación, Estudio Histórico y Conservación de la tumba 33 de la necrópolis de Qubbet El-Hawa (Asúan, Egipto)" HAR2009-08600/HIST de la Universidad de Jaén. Actualmente, es docente en la Universidad de Sevilla en el Grado en Conservación y Restauración, e imparte las asignaturas de "Técnica y Ornamento: la Policromía Barroca e Imaginería Ligera" en el Máster en Escultura Barroca Española: desde los siglos de oro a la sociedad de la información y las redes sociales, de la Universidad Internacional de Andalucía. Gran parte de su desarrollo profesional como conservadora-restauradora está vinculado al Instituto Andaluz de Patrimonio Histórico (Sevilla), colaborando en Proyectos como El Salvador y la Iglesia de Santa Ana (Retablo Mayor) en Sevilla, recientemente, el Proyecto de la Sala de los Reyes de la Alhambra de Granada y Conservación de la Iglesia del Santo Cristo de la Salud de Málaga, además de colaborar con otras instituciones, empresas privadas y proyectos particulares.

Artículo enviado el 31/01/2013

Artículo aceptado el 28/10/2013 


\title{
Conservación preventiva y temperatura de superficie en obras pictóricas en exposición
}

\author{
María del Carmen Bellido-Márquez
}

\begin{abstract}
Resumen: Las condiciones medioambientales en que se encuentran las obras de arte son un factor que determina su conservación. Optimizar estos parámetros beneficia la conservación de las mismas. El Centro José Guerrero (Granada) cuenta con una colección permanente (gráfica y pictórica) del pintor José Guerrero, sobre la que se ha realizado el estudio que nos ocupa. El edifico no ofrece una temperatura similar en sus espacios expositivos, ni la temperatura de superficie de los cuadros en exposición es homogénea en toda su extensión, lo que se ha podido comprobar mediante técnicas analíticas de temperatura de superficie, que han reflejado con claridad las condiciones reales de temperatura de las obras, que también resultan ser diferentes a las mediciones térmicas globales del ambiente de las salas, con las consiguientes alteraciones físicas y químicas que este fenómeno puede originar en los materiales de los trabajos artísticos. Debido a ello, este hecho debe ser valorado, con la intención de evitarlo o minimizarlo convenientemente.
\end{abstract}

Palabras clave: Conservación preventiva, temperatura de superficie, condiciones ambientales, arte contemporáneo, museo, exposición, pintura.

\section{Conservação preventiva e temperatura de superfície em obras pictóricas em exposição}

Resumo: As condições ambientais em que se encontram as obras de arte são um factor que determina a sua conservação. Optimizar estes parâmetros beneficia a conservação das mesmas. O Centro José Guerrero (Granada) possui uma coleção permanente (gráfica e pictórica) deste pintor, sobre a qual foi realizado o presente estudo. $O$ edificio não oferece uma temperatura similar em todos os seus espaços expositivos nem a temperatura da superfície das pinturas em exposição é homogénea em toda a sua extensão. Isto foi demonstrado mediante técnicas analíticas de temperatura da superfície que indicaram, com clareza, as condições reais de temperatura nas obras, que para além disso, eram diferentes das medições térmicas globais do ambiente nas salas, com as consequentes alterações físico-químicas que este fenómeno pode originar nos materiais dos trabalhos artísticos. Esta é a razão pela qual este facto deve ser avaliado, com o objectivo de evitar ou minimizar, convenientemente.

Palavras-chave: conservação preventiva, temperatura de superfície, condições ambientais, arte contemporânea, museu, exposição, pintura.

\section{Preventive conservation and surface temperature of exposed paintings}

\begin{abstract}
The environmental conditions surrounding artworks are a determining factor in their conservation. Optimization of such parameters benefits their conservation. The museum Centro José Guerrero (Granada) has a permanent collection of works from this painter (drawings and paintings), upon which this study was performed. The building does not offer a similar temperature throughout its exhibition spaces and the surface temperature of the paintings on display is not regular on their full extension. This has been demonstrated by surface temperature analysis, which clearly reflected the real conditions of artwork temperature, which are also different from the global room temperature measurements. Such fact can originate physical and chemical alterations at the artwork materials. For this reason, this phenomenon should be assessed, in order to avoid or minimize it, conveniently.
\end{abstract}

Keywords: Preventive conservation, surface temperature, environment conditions, contemporary art, museum, exhibition, painting. 


\section{Introducción y objetivos}

El Centro José Guerrero es un organismo de titularidad pública, situado en la ciudad de Granada, que posee una importante colección permanente, formada por obras del artista granadino José Guerrero.

El edificio del Centro presenta planta irregular y muros exteriores de carga construidos en piedra, que están abiertos por series de ventanas arqueadas. El Centro se articula en cuatro niveles arquitectónicos superpuestos. Cada uno de ellos alberga una sala de exposiciones y todas coinciden en la parte central de la construcción, unas sobre otras. Las paredes de las salas están provistas de aislante y revestidas de mortero de construcción. El diseño horizontal de los espacios expositivos se ve favorecido por la disposición de elementos arquitectónicos de comunicación y movimiento (ascensor y varios tramos de escaleras), que generan una distribución secuencial y discursiva en el recorrido de las exposiciones. Así, queda establecido un orden por el que el espacio deviene en un lugar dinámico que guía al visitante y lo inserta en un discurso lineal, acorde con un modelo de museo actual y contemporáneo.

El inmueble cuenta con un sistema de climatización centralizado, formado por un aparato de la marca CIAT (empresa CIATESA), diseñado para controlar la temperatura, la humedad relativa y la pureza del aire, presentando mal funcionamiento, pues con él no se consigue controlar y unificar la temperatura y la humedad en todo el edificio, sino que se advierten diferencias al respecto en sus salas de exposiciones. Esto se ha podido comprobar mediante mediciones puntuales hechas con un termohigrómetro manual. El sistema de control ambiental debería funcionar adecuadamente, según la normativa referente a la conservación de bienes culturales (Baglioni y Losada, 2000) y la opinión de profesionales especialistas (Herráez y Rodríguez, 1989).

El proyecto de iluminación del Centro compatibiliza luz natural (en pasillos, recibidor de entrada, hueco de escalera y sala cuarta de exposiciones) con artificial (pasillos y salas de exposiciones). El sistema de iluminación artificial, está formado por focos direccionales, colocados en el techo de forma equidistante, que originan "baños de pared". Sus lámparas son halógenas, de la marca OSRAM. Se denominan Halolux Ceram Eco. Su potencia es de 100 Watios (W). La vida de estas lámparas se estima en 2.000 horas de uso, manteniendo sus cualidades inalterables. Su flujo luminoso es de 1.800 lumes $(\mathrm{Im})$ de intensidad. La temperatura de color es de $2.900^{\circ}$ Kelvin (K). Su rendimiento de color es del $100 \%$, lo que permite una reproducción de los colores sin distorsión. Además, los focos poseen filtros de rayos ultravioletas.

La distancia media de los focos de iluminación a los paneles expositivos o a los cuadros en exposición se ha obtenido considerando un foco de luz del techo, instalado sobre un observador de $170 \mathrm{~cm}$ de altura, colocado frente al panel o la pintura elegida, donde incide la luz del foco con una inclinación $45^{\circ}$ sobre un punto que está situado a la altura de los ojos del observador. Con estos parámetros la distancia media de los focos de luz a los paneles expositivos o a las pinturas es $210 \mathrm{~cm}$, aproximadamente.

Por otro lado, la colección permanente del Centro está formada por sesenta obras del artista José Guerrero. Cuarenta de ellas están hechas al óleo sobre lienzo y veinte en técnicas mixtas sobre papel (Guerrero, 2000). Las obras se exponen de forma rotativa, variando de ubicación cada dos o tres meses, según la programación museística. 

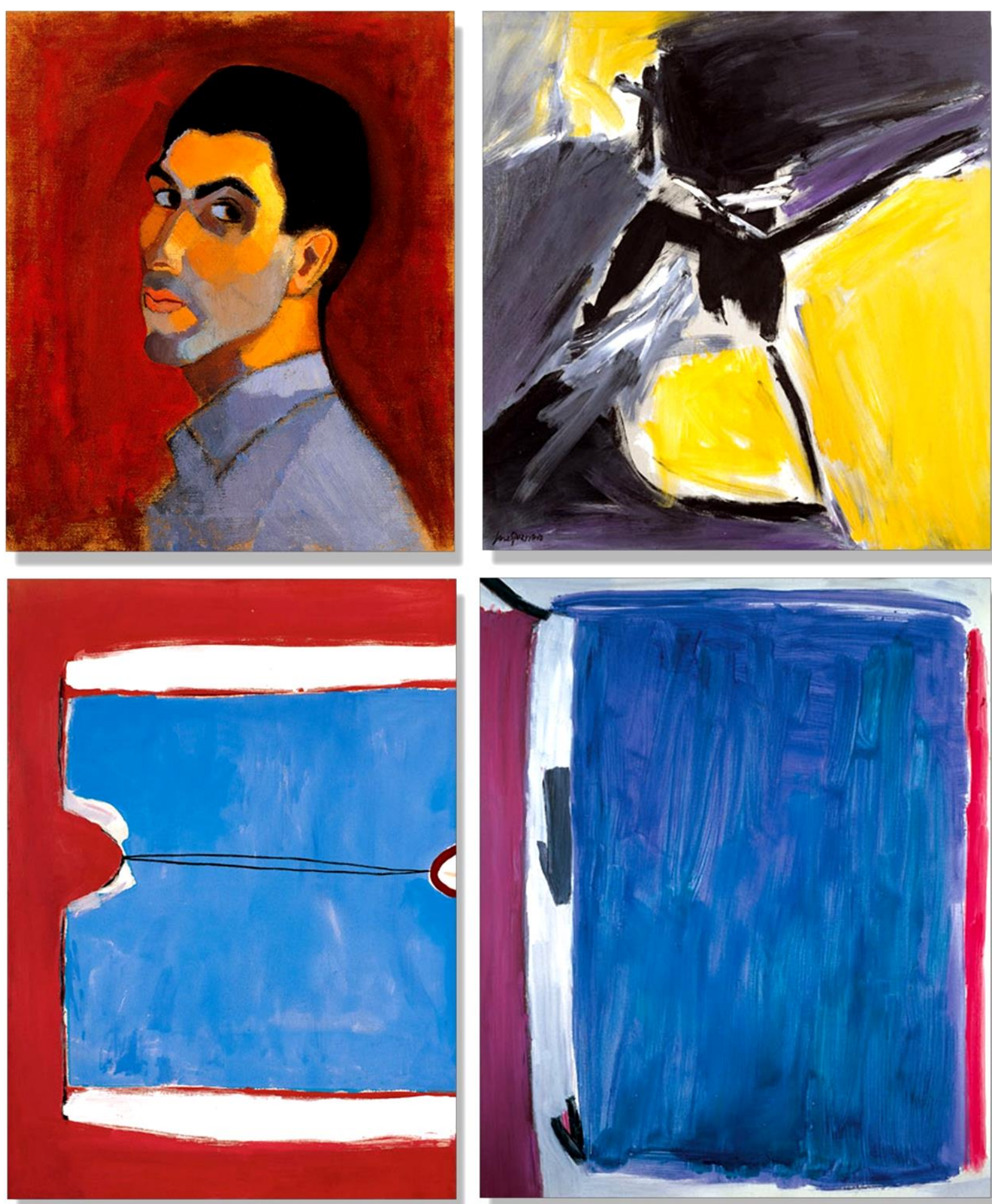

Figura 1: Obras de José Guerrero seleccionadas como material de estudio de esta investigación para realizar los ensayos técnicos de temperatura de superficie. De izquierda a derecha y de arriba abajo se encuentran las obras: Autorretrato (1950), Albacín (1962), Lateral (1974) y Azul añil (1989). @Centro José Guerrero. 
El objetivo general de este estudio es ampliar la información actual sobre la conservación de las obras de arte contemporáneo y aportar datos que ayuden a la resolución de los problemas que plantea (Llamas, 2011), (Herráez y Rodríguez, 1991).

Más concretamente, los objetivos específicos propuestos para este trabajo han sido conocer con exactitud cuáles son las condiciones reales de temperatura de superficie en las obras de la colección durante su exposición en las salas del Centro, y si éstas se ajustan a las recomendaciones de los especialistas en este campo (Guichen y Tapol 1998), comprobando si las temperaturas de superficie de las pinturas se mantienen homogéneas y si difieren o no de las temperaturas ambientales que se registran en las salas. De igual manera, se quiere conocer cuál es la temperatura ambiental media de cada sala y en cuál de ellas el gradiente diferencial de temperatura de superficie de los cuadros es más destacable.

Disponer de los datos indicados supondrá un factor a tener en cuenta en el control de los parámetros medio-ambientales del Centro, lo que ayudará a mejorar los criterios a seguir en la conservación preventiva de las obras (Bellido, 2011), dado que éstas requieren condiciones específicas y adecuadas de conservación preventiva (Calvo, 2002).

\section{Desarrollo metodológico}

Los materiales objeto de este estudio han sido obras pictóricas originales de la colección José Guerrero (Granada) [figura 1], durante su estado de exposición al público. Se han tomado las temperaturas de superficie de las pinturas en exposición y también las temperaturas ambientales de las salas en las que se encontraban expuestas. Cada una de las obras estudiadas ha sido seleccionada por haber estado expuesta en una sala diferente del Centro en el momento de hacer las mediociones del estudio. Todo ello ha supuesto contar con ejemplos prácticos sobre las condiciones térmicas que registran las obras en exhibición en cada sala del edificio.

Todas las mediciones se hicieron sin afluencia alguna de visitantes en el Centro, en días de cierre del museo al público y siempre comenzando a primera hora de la mañana (10:00 h.), estando las obras colgadas de las paredes expositivas de las diferentes salas.

El Termohigrómetro Digital Testo 625 ha sido el instrumento utilizado para la medición de la humedad relativa y la temperatura ambiental de las salas de exposiciones en que se exponían los cuadros a analizar, parámetros que han sido medidos segundos antes de iniciar los registros de las temperaturas de superficie de las obras, en cada ocasión. Este instrumento incluye sonda de humedad integrada, pila y protocolo de calibración. Al encender el termohigrómetro se debe esperar unos segundos antes de realizar mediciones, hasta que comience a funcionar. Sus características principales son: visualización de temperatura y humedad relativa, punto de rocío, valores máximo/mínimo, tecla Hold para retener lecturas, pantalla luminosa y desconexión automática.

El instrumental para obtener las mediciones de temperatura de superficie sobre las obras seleccionadas ha sido un Termómetro de Emisividad Infrarroja Ryatek Inc, Raynger PM 2EM [figura 2]. Este dispositivo es un termómetro digital portátil de superficie sin contacto, que cuenta con puntero láser y detector de rayos infrarrojos. Las características principales de este termómetro son: rango de medición de temperatura de $-18^{\circ}$ a $870^{\circ} \mathrm{C}$, emisividad de 0,10 a 1 (máxima que emite un cuerpo negro), respuesta espectral de 8 a 14 micrones, precisión de $\pm 1 \%$ de lectura de dígito y reproducibilidad de $\pm 0,5 \%$. 


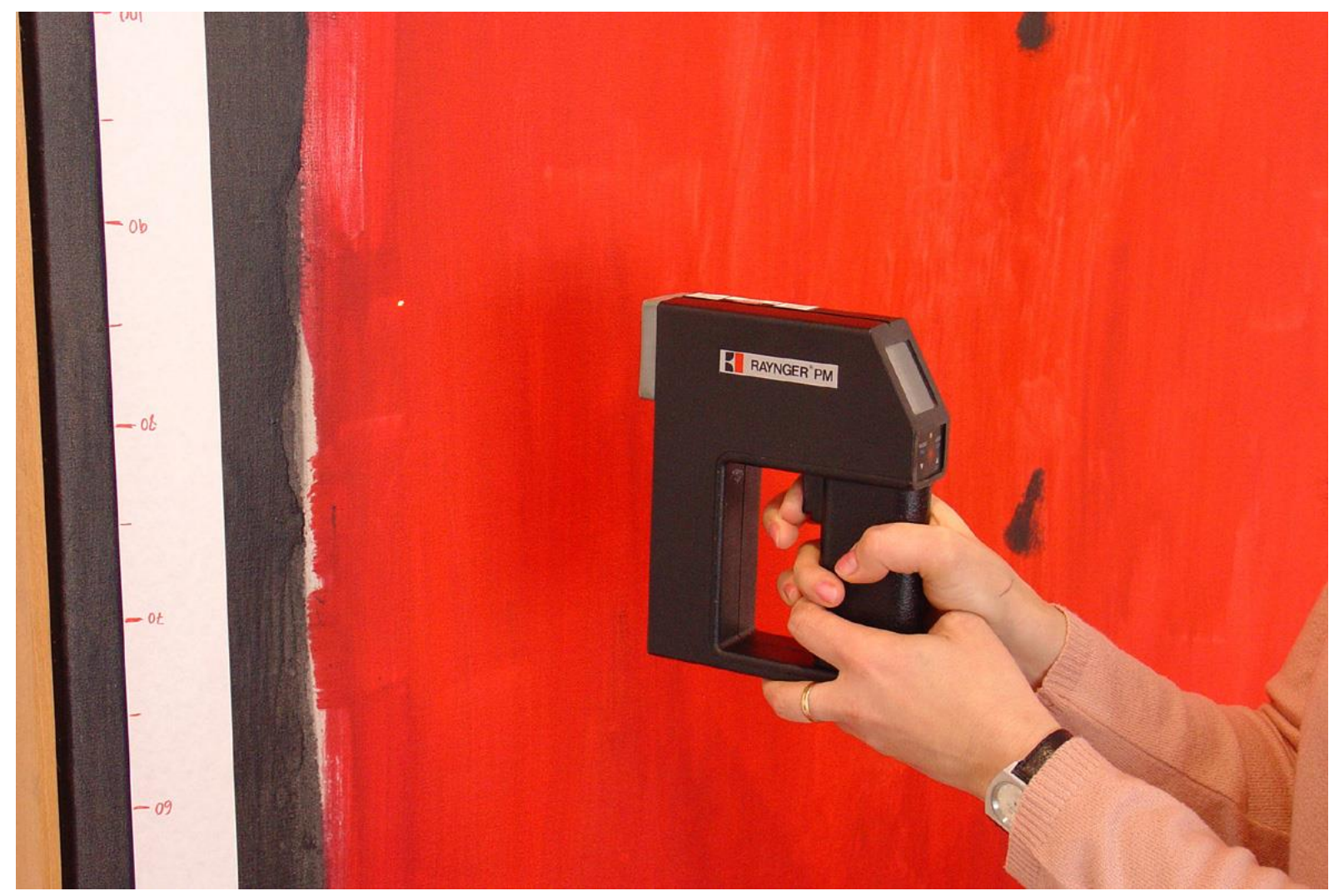

Figura 2: Realización de mediciones de temperatura de superficie sobre una obra de José Guerrero con el Termómetro Portátil Láser de Emisividad Infrarroja Ryatek Inc (Raynger PM 2EM). (María Carmen Bellido-Márquez.

El Termómetro de Emisividad Infrarroja [figura 2] usado permite hacer las mediciones de superficie a distancia, de manera puntual y rápida, registrando la emisividad infrarroja de un punto perteneciente a un cuerpo seleccionado, resultando éstas totalmente inocuas para las obras. El termómetro tiene un detector de radiación infrarroja que capta la cantidad de energía infrarroja que emite el objeto, la cual se traduce en señal eléctrica y queda expresada numéricamente. El instrumento compensa la cantidad de energía infrarroja captada con la temperatura ambiental, para evitar errores de medición.

Previamente a las mediciones de temperatura de superficie, se han realizado mapas de las obras, para ayudar a definir y localizar cada muestra. Los mapas se han obtenido a partir de imágenes escaneadas de los cuadros a medir. La superficie de cada mapa se ha dividido en cuadrículas de lados regulares y medidas proporcionales a lo que en las obras reales han sido $10 \mathrm{~cm}$. En los puntos de intersección de las líneas se ubicaron las mediciones, para ello se han numerado estos puntos con la intención de denominar y situar las diferentes muestras [figura 3].

Para obtener las mediciones de temperatura sobre la superficie de los cuadros, también se han dividido éstas últimas en cuadrículas regulares de $10 \mathrm{~cm}$ reales de lado y en las intercesiones de las líneas resultantes se han tomado los registros, haciendo coincidir la localización de cada muestra tomada con su referente en el mapa; en él se han anotado los datos de temperatura obtenidos. Así, el trabajo ha resultado organizado y controlado [figura 3,4]. 


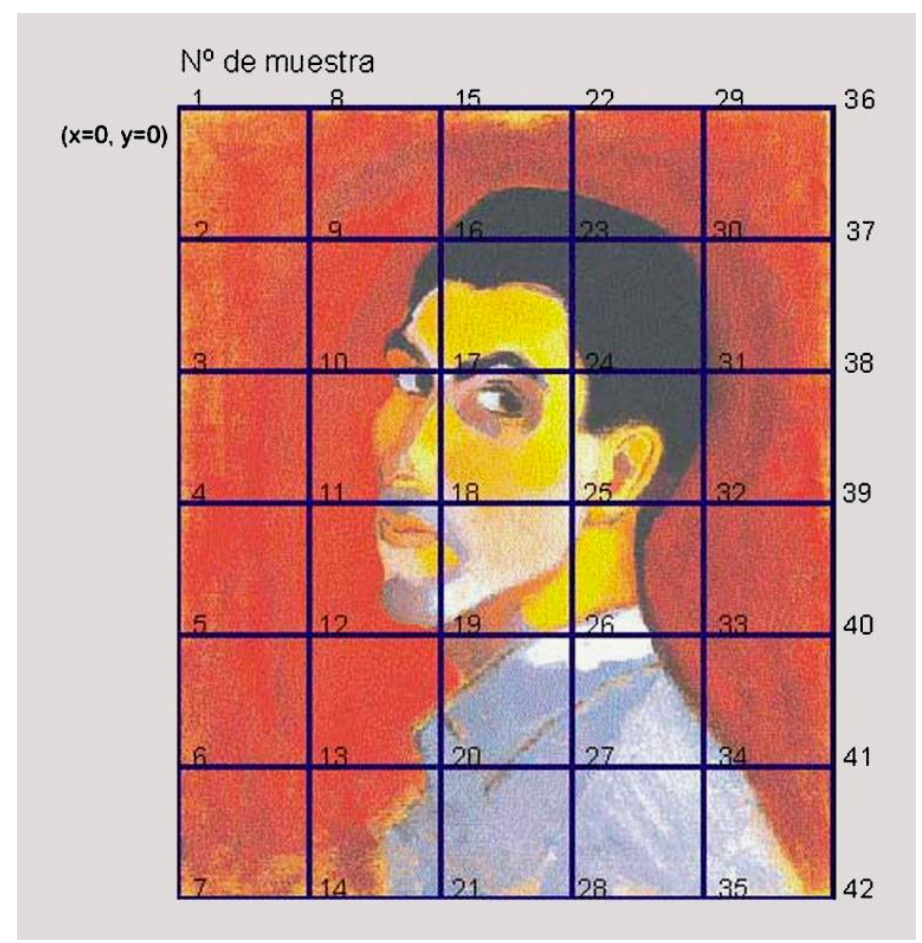

Figura 3: Mapa de trabajo de la obra Autorretrato con la numeración de cada muestra y su localización en la superficie pictórica a medir. @María Carmen Bellido-Márquez.

Para dividir las superficies de los cuados se han usado cintas métricas de tela, confeccionadas para este trabajo, con la finalidad de evitar las posibles erosiones que otro tipo de material más rígido o erosivo pudiera provocar en las superficies pictóricas [figura 4].

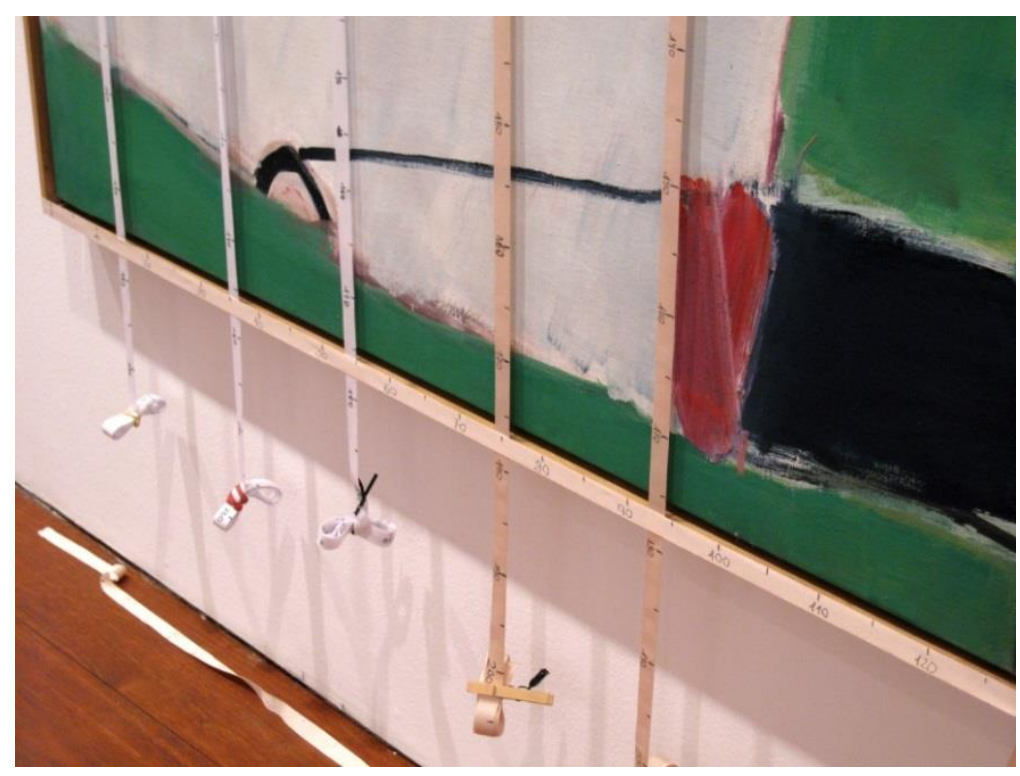

Figura 4: Detalle de la colocación de cintas métricas sobre la obra Litoral durante la toma de muestras, para establecer la localización espacial de los puntos a medir, formando una red superficial cuadriculada. oMaría Carmen Bellido-Márquez. 
Realizadas las mediciones, se han elaborado mapas de isotermas a partir de los datos recogidos. En ello, las temperaturas de superficie se han distribuido en grupos, según escala diferencial de $0,5^{\circ} \mathrm{C}$, y cada grupo de temperaturas ha quedado representado con un color y una letra determinados. De este modo, figuran en los diagramas diversas áreas de colores que corresponden a los diferentes grupos de temperaturas obtenidos, cuyos valores no difieren más de $0,5^{\circ} \mathrm{C}$. entre los muestras de un mismo grupo.

\section{Resultados y discusión}

\section{Autorretrato, 1950. Planta baja.}

La imagen [figura 5] muestra la representación gráfica de los valores procedentes de las mediciones de temperatura de superficie registradas en la obra de José Guerrero Autorretrato (1950). El ensayo se realizó en 2009. La pintura estaba expuesta en la sala primera, planta baja del Centro. Se tomaron 42 datos de temperatura sobre la superficie total del cuadro $(65,5 \times 51 \mathrm{~cm})$. Previamente, se registró la temperatura ambiental $\left(\mathrm{T}^{\mathrm{a}}=22,4^{\circ} \mathrm{C}\right)$ y la humedad relativa $(\mathrm{Hr}=33,9 \%)$ de la sala de exposiciones en que se exponía la obra.
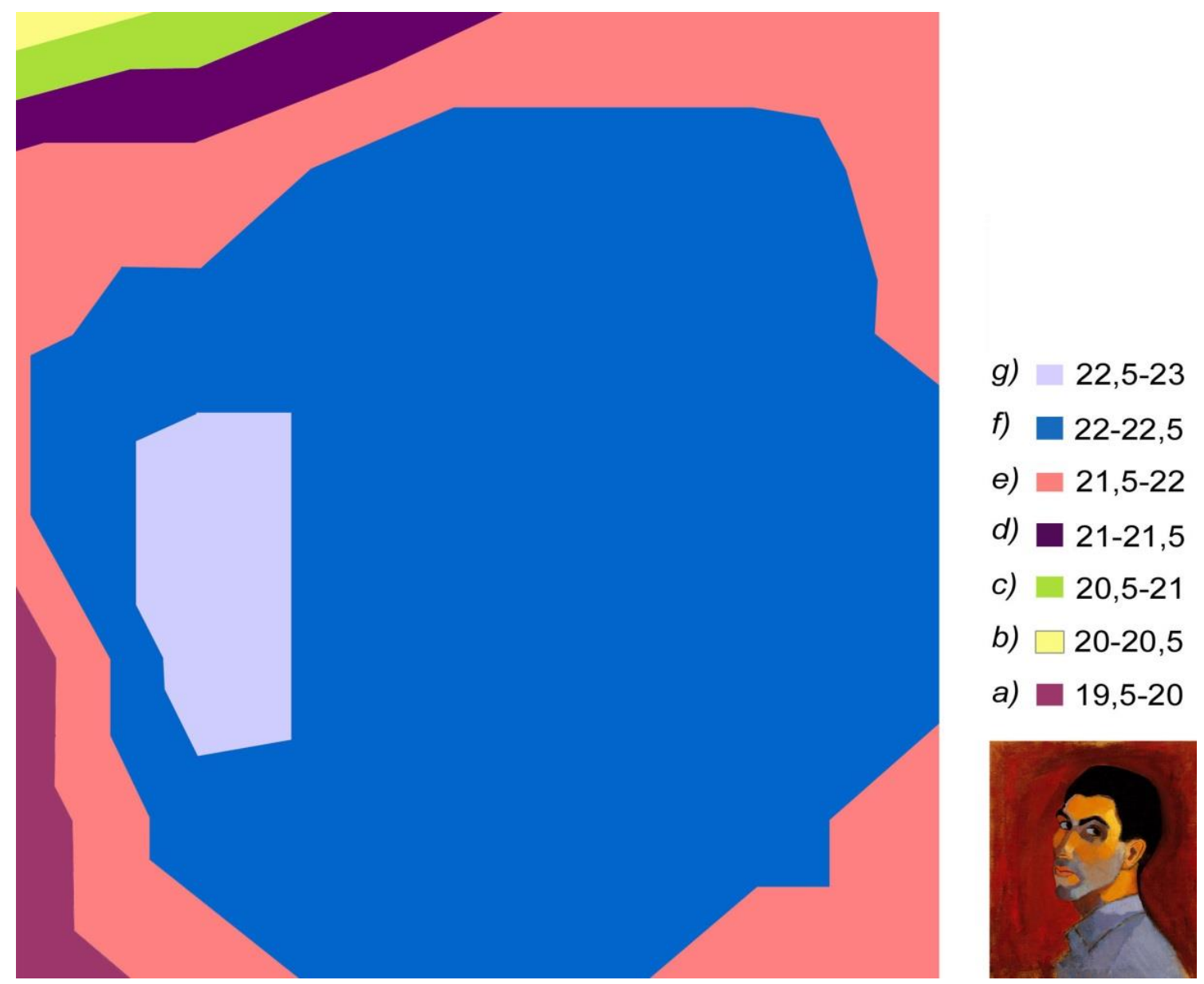

Figura 5: Diagrama de isotermas correspondiente al cuadro Autorretrato, 1950. La escala gráfica (colores y letras) representa variaciones de $0,5^{\circ} \mathrm{C}$. La imagen inferior derecha representa la pintura original. oMaría Carmen Bellido-Márquez. 
En la parte izquierda del gráfico [figura 5] se observan los valores térmicos más variables, que muestran todo el gradiente térmico de la obra. El ángulo inferior izquierdo presenta temperaturas comprendidas entre $19,5^{\circ}-20^{\circ} \mathrm{C}$ (área a, violeta). En el ángulo superior izquierdo de la imagen las temperaturas alcanzan $20^{\circ}-20,5^{\circ} \mathrm{C}$ (área b, beig) y en la mitad izquierda se sitúan las máximas con $22,5^{\circ}-23^{\circ} \mathrm{C}$ (área g, azul celeste). El lado derecho del gráfico muestra valores más uniformes que los anteriores, comprendidos entre $21,5^{\circ} \mathrm{C}$ (área e, salmón) y $22,5^{\circ} \mathrm{C}$ (área f, cian).

Se presenta [figura 5] una distribución térmica en sentido concéntrico, que asciende de fuera hacía dentro. El máximo valor térmico está comprendido entre $22,5^{\circ}-23^{\circ} \mathrm{C}$ (área g, azul celeste). Rodeando el área $\mathrm{g}$, con menor temperatura, está la zona más extensa, formada por el área f (cian), con valores establecidos entre $22^{\circ}-22,5^{\circ} \mathrm{C}$. El área de color salmón (área e) se coloca bordeando la anterior, con valores comprendidos entre $21,5^{\circ}-22^{\circ} \mathrm{C}$, que se encuentran también en los ángulos superior e inferior derechos del diagrama.

Existe una mayor diferencia térmica en la mitad izquierda del gráfico [figura 5] que en la derecha. Las zonas de máxima variabilidad corresponden al cuadrante superior izquierdo, en el que se registran las temperaturas más extremas, frente a las zonas más estables que están en los cuadrantes superior e inferior derechos, con temperaturas muy similares entre sí.

Como resumen, se ha observado en el diagrama de isotermas de la obra Autorretrato [figura 5], situada en la sala de la planta baja, que los valores globales térmicos de superficie del cuadro estuvieron comprendidos entre $19,5^{\circ} \mathrm{C}$ y $23^{\circ} \mathrm{C}$, presentando un gradiente total de $3,5^{\circ} \mathrm{C}$ en toda la superficie, aunque la mayor parte del mismo registró temperaturas establecidas entre $21,5^{\circ} \mathrm{C}$ y $22,5^{\circ} \mathrm{C}$ (áreas e y f), con un gradiente de $1^{\circ} \mathrm{C}$ de diferencia, excepto en su zona lateral izquierda.

\section{Lateral, 1974. Planta 1a}

La imagen [figura 6] muestra la representación gráfica de los datos obtenidos a partir de las mediciones de la temperatura de superficie, registrados en la obra de José Guerrero Lateral (1974). Se tomaron en 2009 y se realizaron un total de 285 mediciones sobre la superficie total del cuadro $(183 \times 135 \mathrm{~cm})$. La pintura estaba expuesta en la sala segunda del Centro (planta primera). Previamente se registraron la humedad relativa $(\mathrm{Hr}=37,7 \%)$ y la temperatura ambiental $\left(\mathrm{Ta}=24,8^{\circ}\right.$ C) de la sala en que estaba la obra.

En el gráfico [figura 6] la temperatura del cuadrante superior izquierdo presenta valores comprendidos, mayoritariamente, entre $26,5^{\circ}-27,5^{\circ} \mathrm{C}$, representados por las áreas c (beig) y d (cian). En el cuadrante inferior derecho se encuentran temperaturas comprendidas entre $25,5^{\circ}-27^{\circ}$ C en las áreas a (azul celeste), b (violeta) y c (beig).

En el diagrama de isotermas [figura 6] los valores máximos, representados en el área d (cian), se localizan dispersos en varias zonas del cuadrante superior izquierdo, mientras los valores mínimos, representados por el área a (azul celeste), están situados en el cuadrante inferior derecho.

La mayor parte de las zonas [figura 6] muestran temperaturas comprendidas entre $26^{\circ} \mathrm{C}$ y $27^{\circ} \mathrm{C}$, con un gradiente térmico de sólo $1^{\circ} \mathrm{C}$, representadas con las áreas b (violeta) y c (beig). Predomina mayoritariamente el área c, que corresponde a valores entre $26,5^{\circ}-27^{\circ} \mathrm{C}$. 


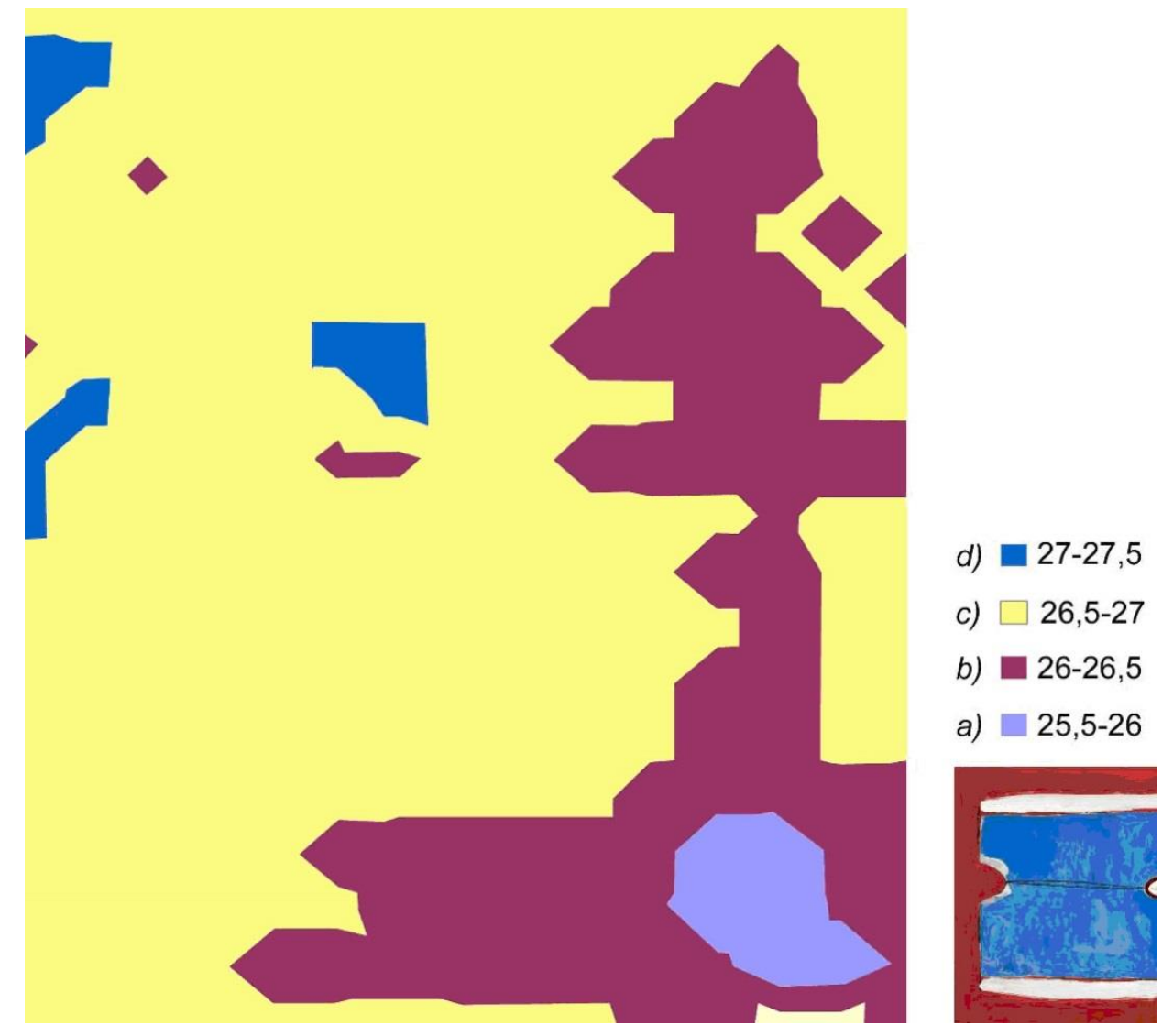

Figura 6: Diagrama de isotermas correspondiente al cuadro Lateral, 1974. La escala gráfica (colores y letras) representa variaciones de $0,5^{\circ} \mathrm{C}$. La imagen inferior derecha representa la pintura original. oMaría Carmen Bellido-Márquez.

El gráfico [figura 6] presenta una variación térmica de temperaturas superiores en el lado izquierdo e inferiores en el derecho. En el primer caso se encuentran, globalmente, valores entre $26^{\circ} \mathrm{C}$ y $27,5^{\circ}$ $C$, en las áreas b (violeta), $c$ (beig) y d (cian) y en el segundo las temperaturas oscilan entre $25,5^{\circ} \mathrm{C}$ y $27^{\circ} \mathrm{C}$, estando representadas con las áreas a (azul celeste), b (violeta) y c (beig)).

Resumiendo, el diagrama de isotermas del cuadro Lateral [figura 6], situado en la sala de la planta primera [figura 6] presentó valores térmicos de superficie comprendidos entre $25,5^{\circ} \mathrm{C}$ y $27,5^{\circ} \mathrm{C}$, con un gradiente de $2^{\circ} \mathrm{C}$ en toda la superficie. La temperatura fue descendente de izquierda a derecha de la obra, siendo el descenso más acusado en dirección diagonal, desde el ángulo superior izquierdo al ángulo inferior derecho de la misma.

\section{Albaicín, 1962. Planta 2a}

La imagen [figura 7] muestra la representación gráfica de los valores obtenidos a partir de las mediciones de temperatura de superficie, registradas en la obra de José Guerrero Albaicín (1962). Fueron realizadas en 2009, cuando la pintura estaba expuesta en la sala tercera del Centro (planta segunda). Previamente, se registraron la humedad relativa $(\mathrm{Hr}=38,9 \%)$ y la temperatura ambiental $\left(\mathrm{T}^{\mathrm{a}}=24,4^{\circ} \mathrm{C}\right)$ de la sala. Se tomaron 342 datos de temperatura de superficie, abarcando la totalidad de la extensión de la pintura $(178 \times 168 \mathrm{~cm})$. 


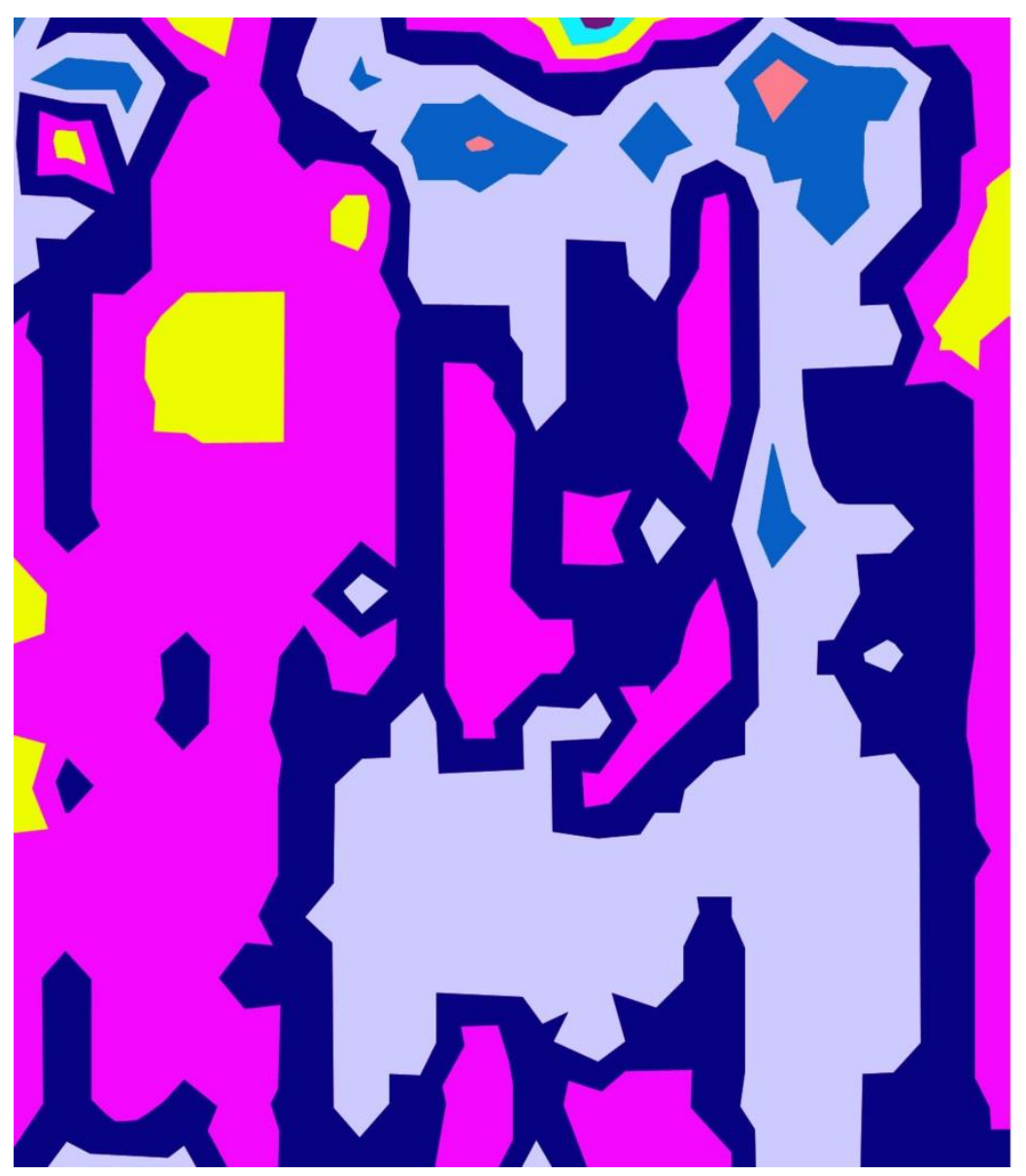
h) $\square 29,5-30$
g) $\square 29-29,5$
f) $\quad 28,5-29$
e) $\square 28-28,5$
d) $27,5-28$
c) $\square 27-27,5$
b) $\square 26,5-27$
a) $26-26,5$

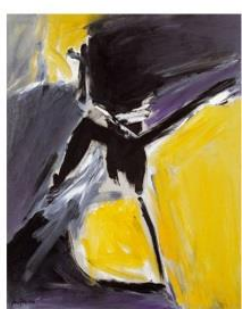

Figura 7: Diagrama de isotermas correspondiente al cuadro Albaicín, 1962. La escala gráfica (colores y letras) representa variaciones de $0,5^{\circ} \mathrm{C}$. La imagen inferior derecha representa la pintura original.

cMaría Carmen Bellido-Márquez.

En la mitad superior del diagrama [figura 7] se encuentran los valores térmicos más elevados, representados por las áreas $\mathrm{f}$ (amarilla), $\mathrm{g}$ (verde) y $\mathrm{h}$ (violeta), que corresponden a temperaturas comprendidas entre $28,5^{\circ} \mathrm{C}$ y $30^{\circ} \mathrm{C}$, siendo las máximas las del área h, (violeta) con $29,5^{\circ}-30^{\circ} \mathrm{C}$, situada en el margen superior del diagrama, con una distribución muy focalizada. En esta misma mitad de la representación se encuentran los registros mínimos $\left(26^{\circ}-27^{\circ} \mathrm{C}\right)$, identificados por las áreas a (salmón) y b (cian). Los más bajos están entre $26^{\circ}-26,5^{\circ} \mathrm{C}$ (área $\mathrm{a}$, salmón), con una ubicación muy cercana a la temperatura máxima. La parte superior del diagrama presenta la mayor variabilidad térmica por zonas, acentuada en el cuadrante superior derecho.

La mitad inferior, el gráfico [figura 7] registra valores térmicos comprendidos entre $27^{\circ} \mathrm{C}$ y $29^{\circ} \mathrm{C}$, con las áreas c (azul celeste), d (azul marino), e (rosa) y f (amarilla). Esta parte es más estable térmicamente.

La focalización de los valores máximos puede obedecer a la irradiación de rayos de iluminación (rayos infrarrojos).

Resumiendo, el gráfico de isotermas del cuadro Albaicín [figura 7], situado en la sala de la segunda (planta segunda) presentó una temperatura de superficie de valores comprendidos entre $26^{\circ} \mathrm{C}$ y 
$30^{\circ} \mathrm{C}$, con un gradiente térmico total de $4^{\circ} \mathrm{C}$. Los valores máximos y mínimos se situaron en la parte superior central y derecha de la superficie pictórica, de forma focalizada, con más incidencia en esta zona de los máximos. La parte inferior de la misma registró mayor estabilidad térmica.

\section{Azul Añil, 1989. Planta 3a}

La imagen [figura 8] muestra la representación gráfica de los valores obtenidos de las mediciones de temperatura de superficie realizadas en la obra de José Guerrero Azul añil (1989), registradas en 2009. Se tomaron un total de 320 mediciones sobre la superficie total del cuadro $(185 \times 145 \mathrm{~cm})$, que estaba expuesto en la sala cuarta el Centro (planta tercera), habiendo medido previamente en ella la temperatura ambiental $\left(\mathrm{T}^{\mathrm{a}}=23,8^{\circ} \mathrm{C}\right)$ y la humedad relativa $(\mathrm{Hr}=34,9 \%)$.

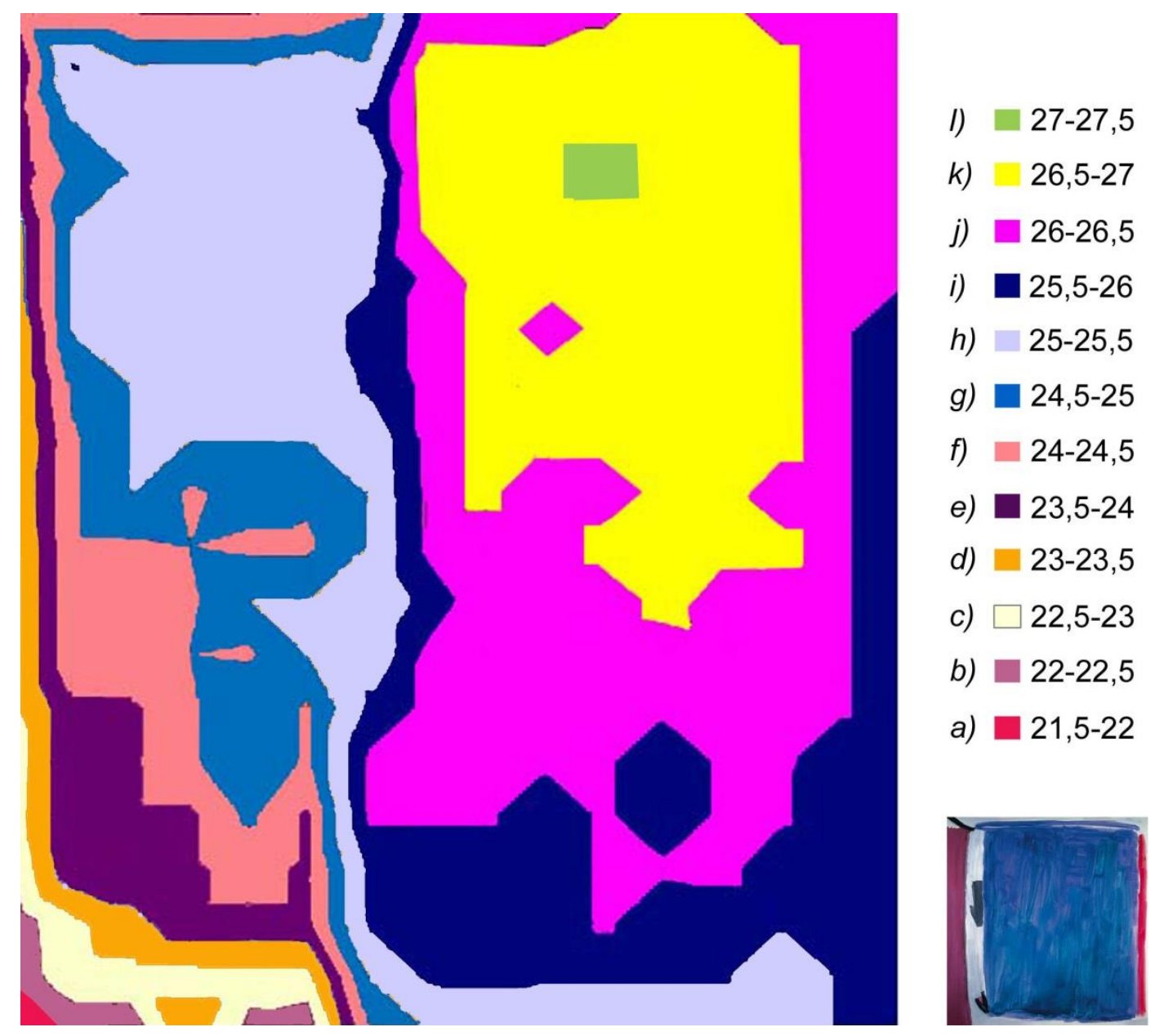

Figura 8: Diagrama de isotermas correspondiente al cuadro Azul Añil, 1989. La escala gráfica (colores y letras) representa variaciones de $0,5^{\circ} \mathrm{C}$. La imagen inferior derecha representa la pintura original. oMaría Carmen Bellido-Márquez.

En el diagrama [figura 8] se observa que el lado izquierdo de la obra registra valores térmicos comprendidos entre $21,5^{\circ} \mathrm{C}$ y $27^{\circ} \mathrm{C}$, definidos por las áreas: a (rojo), b (lila), c (beig), d (naranja), e (violeta), f (salmón), g (cian), h (azul celeste), i (azul marino), j (rosa) y k (amarilla). El valor térmico 
localizado en el ángulo inferior izquierdo corresponde al mínimo total registrado, con temperaturas comprendidas entre $21,5^{\circ}-22^{\circ} \mathrm{C}$ (área a).

El lado derecho del gráfico [figura 8] muestra valores de temperatura que oscilan entre $25^{\circ} \mathrm{C} \mathrm{y}$ $27,5^{\circ} \mathrm{C}$, representados por las áreas: $\mathrm{h}$ (azul celeste), i (azul marino), j (rosa), k (amarillo) y l (verde). Ésta última (área l, verde) muestra las máxima temperaturas registradas, comprendidas entre $27^{\circ}$ $27,5^{\circ} \mathrm{C}$.

Globalmente, el gráfico [figura 8] presenta una variabilidad térmica en la superficie del cuadro de valores inferiores en su lado inferior izquierdo, siendo el cuadrante superior derecho donde están incluidas las máximas. La mayor parte del gráfico presenta valores comprendidos entre $23,5^{\circ} \mathrm{C}$ y $27^{\circ} \mathrm{C}$, representados por las áreas: $\mathrm{d}$ (naranja), e (violeta), $\mathrm{f}$ (salmón), g (cian), h (azul celeste), i (azul marino), j (rosa) y k (amarilla), con un gradiente térmico de $3,5^{\circ} \mathrm{C}$.

En resumen, el diagrama de isotermas del cuadro Azul añil [figura 8], situado en la sala de la tercera del Centro (planta cuarta), presentó valores de temperatura de superficie comprendidos entre $21,5^{\circ} \mathrm{C}$ y $27,5^{\circ} \mathrm{C}$, con un gradiente térmico global de $6^{\circ} \mathrm{C}$, ofreciendo los máximos y mínimos de forma focalizada. La variabilidad térmica fue descendente de derecha a izquierda y de arriba debajo de la obra, siendo particularmente acusada en dirección diagonal descendente, desde el cuadrante superior derecho al cuadrante inferior izquierdo de la misma.

\section{Resumen de resultados}

Con los datos recogidos se ha elaborado la siguiente tabla [tabla 1], que permite estudiar comparativamente las variaciones de temperatura registradas en las obras analizadas y relacionarlas con las temperaturas de las salas en las que estaban expuestas durante el estudio.

Tabla 1. Exposición de datos térmicos de temperatura de superficie (máximos, mínimos, gradiente diferencial), temperatura ambiental en sala y ubicación de las obras en el momento de las mediciones. c María Carmen Bellido-Márquez.

\begin{tabular}{cccccccc}
\hline $\begin{array}{c}\text { N. }{ }^{\circ} \text { de } \\
\text { Catalo- } \\
\text { gación }\end{array}$ & $\begin{array}{c}\text { Título } \\
\text { de las } \\
\text { obras }\end{array}$ & $\begin{array}{c}\mathrm{T}^{\mathrm{a}} \\
\text { mín. de } \\
\text { superficie }\end{array}$ & $\begin{array}{c}\mathrm{T}^{\mathrm{a}} \\
\text { máx. de } \\
\text { superficie }\end{array}$ & $\begin{array}{c}\text { Gradiente } \\
\text { de Ta de } \\
\text { superficie }\end{array}$ & $\begin{array}{c}\text { Ta }^{\mathrm{a}} \text { ambiental } \\
\text { de sala }\end{array}$ & $\begin{array}{c}\text { Diferencia de Ta de } \\
\text { sala/Ta máx. de la } \\
\text { obra }\end{array}$ & $\begin{array}{c}\text { Ubicación de las obras } \\
\text { en el Centro } \\
\text { José Guerrero }\end{array}$ \\
\hline \hline 4 & Autorretrato & $19,5^{\circ} \mathrm{C}$ & $23^{\circ} \mathrm{C}$ & $3,5^{\circ} \mathrm{C}$ & $22,4^{\circ} \mathrm{C}$ & $0,6^{\circ} \mathrm{C}$ & Sala planta baja \\
30 & Lateral & $25,5^{\circ} \mathrm{C}$ & $27,5^{\circ} \mathrm{C}$ & $2^{\circ} \mathrm{C}$ & $24,8^{\circ} \mathrm{C}$ & $2,7^{\circ} \mathrm{C}$ & Sala planta primera \\
12 & Albaicín & $26^{\circ} \mathrm{C}$ & $30^{\circ} \mathrm{C}$ & $4^{\circ} \mathrm{C}$ & $24,4^{\circ} \mathrm{C}$ & $5,7^{\circ} \mathrm{C}$ & Sala planta segunda \\
39 & Azulañil & $21,5^{\circ} \mathrm{C}$ & $27,5^{\circ} \mathrm{C}$ & $6^{\circ} \mathrm{C}$ & $23,8^{\circ} \mathrm{C}$ & $3,7{ }^{\circ} \mathrm{C}$ & Sala planta tercera \\
\hline
\end{tabular}

En el cuadro situado en la sala de la planta baja (Autorretrato) el gradiente diferencial de temperaturas de superficie fue de 3,5 y la diferencia entre la máxima temperatura de superficie registrada y la ambiental fue de $0,6^{\circ} \mathrm{C}$.

El cuadro localizado en la sala de la segunda planta (Lateral) fue el que registró menor gradiente diferencial de temperaturas de superficie, con $2^{\circ} \mathrm{C}$ de diferencia total. También presentó $2,7^{\circ} \mathrm{C}$ de diferencia entre la temperatura máxima de superficie y la ambiental. 
El cuadro situado en la sala de la segunda planta (Albaicín) registró un gradiente diferencial de temperatura de superficie de $4^{\circ} \mathrm{C}$ y una diferencia respecto a la ambiental de $5,7^{\circ} \mathrm{C}$, siendo ésta la mayor registrada.

El cuadro ubicado en la sala de la tercera planta (Azul añil) fue el que presentó un gradiente térmico de $6^{\circ} \mathrm{C}$ y también mostró una diferencia de $2,3^{\circ} \mathrm{C}$ entre la temperatura de superficie y la ambiental.

Todos los cuadros registraron temperaturas de superficie variables a lo largo de su extensión superficial. Los gradientes térmicos presentados entre todas las obras quedaron establecidos entre $2^{\circ} \mathrm{C}$ y $6^{\circ} \mathrm{C}$, registrándose los más altos en la obra Azul añil, expuesta en la sala de la planta tercera.

Las diferencias entre temperatura ambiental de sala y la máxima temperatura de superficie de los cuadros fueron de entre $0,6^{\circ} \mathrm{C}$ (Autorretrato, planta baja) y $5,7^{\circ} \mathrm{C}$ (Albacín, planta segunda).

Las temperaturas registradas en las salas estuvieron comprendidas entre los máximos y los mínimos de las registradas en los cuadros correspondientes a ellas.

Los máximos obtenidos de las temperaturas de superficie fueron superiores a las temperaturas ambiental de las salas en todos los casos y también se detectó, puntualmente en algunas mediciones de superficie, que las temperaturas de los cuadros eran inferiores a los de las salas en las que se exponían; ambos casos se deben a que la temperatura de sala es una medida que ofrece una media de ésta, por lo que en su espacio no todas las zonas y superficies han de estar a la temperatura dada.

Teniendo en cuanta que la medida de temperatura recomendada para pintura de caballete debe registrar entre $18^{\circ} \mathrm{C}$ y $20-22^{\circ} \mathrm{C}$, con $\pm 2^{\circ}$ de oscilación (Guichen, Tapol 1988), se observa que los cuadros situados en la primera, segunda y tercera planta exceden la temperatura recomendada.

De los resultados presentados se deduce que los mayores problemas derivados de los parámetros de temperatura de superficie son la falta de homogeneidad térmica dentro de una misma obra y los niveles elevados de temperatura que han presentado las obras y las salas de exposición, todos ellos son superiores a lo recomendado para la adecuada conservación preventiva de las pinturas de José Guerrero, según recomendaciones de Guichen y Tapol (1998) y Calvo (1997).

\section{Conclusiones}

Según se ha comprobado se determina que las condiciones de temperaturas de superficie de los cuadros estudiados no han presentado homogeneidad en toda su extensión y tampoco hay igualdad térmica de superficie entre unas obras y otras, lo que no es apropiado para su adecuada conservación (Rico, 2011).

Cada pintura presentó una máxima de temperatura de superficie superior a la ambiental de la sala en la que se exhibía, de lo que se deduce que sólo el control de la temperatura de la sala no es un dato fiable para conocer la temperatura real de las obras en exposición y que éste resulta insuficiente como único referente térmico de control climático.

La mayor parte de las obras presentaron temperaturas superiores a las recomendadas por los expertos (Guichen, Tapol 1988), especialmente las aquellas situadas en las salas de las plantas segunda, tercera, primera (en orden de mayor a menor incidencia), siendo el exceso y la 
variabilidad climática de la temperatura de superficie la tónica general que presentaron los cuadros.

Como consecuencia de la variabilidad de la temperatura de superficie de los cuadros se concluye determinado que este efecto es debido al sistema de climatización, que no ha funcionado adecuadamente, acondicionando de forma diferente cada sala, y a la iluminación artificial, que ha influido en el calentamiento diferencial de las obras (Casal, 1982). Además, también ha influido en ello el cromatismo de la policromía de los cuadros, dada la absorción diferencial de energía de ciertos puntos de algunas obras. Todos estos factores, combinados conjuntamente, han sido las causas que han afectado a las temperaturas de exposición que han presentado las obras estudiadas. Pero el sistema de climatización es el agente que principalmente ha provocado estas anomalías.

Dado que la temperatura inadecuada es un factor de riesgo para la conservación de las obras de arte (Michalski, 2009), porque favorece el biodeterioro, aumenta la velocidad de reacción de los compuestos químicos y provoca la reducción de humedad, se ha aconsejado realizar las modificaciones de infraestructura necesarias para mejorar las condiciones ambientales de las salas expositivas del Centro José Guerrero, con una prioridad inmediata, mediante el cambio del sistema de climatización. Se indica que el proyecto de mejora ambiental ya se ha realizado con el cierre del Centro por reformas (julio-2013) y se estima que tras la reapertura del Centro en septiembre de 2013 se habrán minimizado los problemas expuestos tras la remodelación del sistema de control ambiental.

\section{Agradecimientos}

Nuestro agradecimiento al Ministerio de Educación y Ciencia por la Beca FPI concedida (2006-2010); a la Universidad Granada por la Beca FPU concedida (2005-2006); al Grupo de Investigación HUM-450 de la Junta de Andalucía (Universidad de Granada), a la familia de José Guerrero, que en todo momento permitió el estudió y la reproducción de imágenes de las obras; al Centro José Guerrero por la colaboración presada; a la Diputación de Granada; y al Departamento de Conservación-Restauración del MNCARS, por colaborar permitiendo el estudio documental de las obras estudiadas.

\section{Bibliografía}

BAGLIONI, R. y LOSADA, J. M. (2000). "Documento de Vantaa (Finlandia). Hacia una estrategia europea sobre conservación preventiva". En Boletín PH, Boletín del Instituto Andaluz del Patrimonio Histórico, no 33, diciembre, pp.87-91.

BELLIDO MÁRQUEZ, M. C. (2012). "Historial conservacional de la obra Variaciones azules. Una pintura contemporánea con problemas de conservación". En Conservación de arte contemporáneo 13a Jornada, febrero 2011. Museo Nacional Centro de Arte Reina Sofía, Departamento de Conservación-Restauración. Ministerio de Cultura, Museo Nacional Centro de Arte Reina Sofía. Págs.129-140. España: Madrid.

CALVO, A. M. (1997). Conservación y restauración: materiales, técnicas y procedimientos: de la A a la Z. Barcelona: Ediciones del Serbal.

CALVO, A. M. (2002). Conservación y restauración de pintura sobre lienzo. Barcelona: Ediciones del Serbal.

CASAL, J. M. (1982). "Alumbrado de museo: bases de su realización". En Museos. Vol. 1: pp. 47-59. Madrid: Patronato Nacional de Museos. 
CENTRO JOSÉ GUERRERO (2012). "La colección del Centro". En Centro José Guerrero. http://www.centroguerrero.org/index.php/del_Centro/19/0/?\&L=0 [Consulta 10 del 1 de 2013].

GUERRERO, J. (2000). Catálogo de la exposición José Guerrero: La colección del Centro. Granada: Diputación de Granada.

GUICHEN, G. DE y TAPOL, B. DE (1998). Climate in museums:measurement. Rome: ICCROM.

HERRÁEZ, J. A. y. RODRÍGUEZ, M. A. (1989). Manual para el uso de aparatos y toma de datos de las condiciones ambientales en museos. Madrid: Dirección General de Bellas Artes y Archivos, D. L.

HERRÁEZ, J. A. y RODRÍGUEZ, M. A. (1991). Recomendaciones para el control de las condiciones ambientales en exposiciones temporales. Madrid: Instituto de Conservación y Restauración de Bienes Culturales.

LLAMAS, R. (Coord.) (2011). Idea, materia y factores discrepantes en la conservación del arte contemporáneo. Valencia: Universidad Politécnica de Valencia.

MICHALSKI S. (2009). Temperatura incorrecta. Canadian Conservation Institute. (Edición en español). http://www.cci-icc.gc.ca/caringfor-prendresoindes/articles/10agents/chap09-spa.pdf [Consulta $10 \mathrm{del} 1 \mathrm{de}$ 2013].

RICO, J. C. (2011). La investigación teórica: museos, del templo al laboratorio: 1986-2011, 25 años de investigación museográfica, el objeto, el sujeto y el espacio. Madrid: Silex.

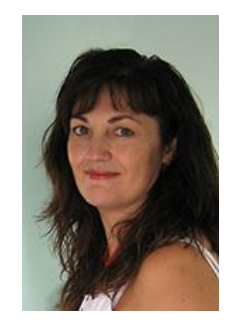

María del Carmen Bellido-Márquez

cbellido@ugr.es

La autora es profesora de Universidad de Granada, adscrita al Departamento de Escultura. Imparte clase en la facultad de Bellas Artes de Granada. Investigador del Grupo de Investigación HUM-951 de la Junta de Andalucía. Posee el Título de Doctorado Europeo en Bellas Artes y Master Propio en Museología por la Universidad de Granada. El tema de su Tesis Doctoral es el estudio de los materiales y la conservación de las obras de arte contemporáneo, centrada en el caso específico de la Colección del Centro José Guerrero (Granada).

Artículo enviado el $31 / 01 / 2013$

Artículo aceptado el 21/09/2013 


\title{
Use of telemetry X-ray techniques in large-size pictorial works
}

\author{
José A. Madrid García
}

\begin{abstract}
In recent years, with the rise of digital technologies and the concurrent demise of related analog instrumentation, researchers in the field of cultural heritage have faced significant new challenges implementing digital solutions.
\end{abstract}

Specifically, this shift has prompted the use of new protocols for the application of radiology in the study of art works. However, due to this change, there has been a return to using older film formats, which is one of the problems that has already been solved using an industrial-type analogical system that allowed largeformat X-ray support, and that was able to adapt to almost any surface.

Therefore, this study attempts to rectify the limits of digital X-ray techniques by using telemetry X-ray techniques. At the Laboratory of Documentation and Registration (IRP, or Institute for the Heritage Restoration), based at the Universitat Politècnica de Valencia (UPV), Spain, mobile telemetry X-ray equipment has been designed and implemented to allows the adaptation of large-size pictorial works.

Keywords: pictorial works, X-ray, radiology, telemetry X-ray techniques, large size paintings.

\section{El uso de radiografía telemétrica en obras pictóricas de gran tamaño}

Resumen: En los últimos años, con el auge de las tecnologías digitales y la desaparición simultánea de la instrumentación analógica, los investigadores en el ámbito del patrimonio cultural se han enfrentado a nuevos e importantes retos en el desarrollo de soluciones digitales.

En concreto, este cambio ha llevado a la utilización de nuevos protocolos para la aplicación de la radiología en el estudio de las obras de arte. Sin embargo, debido a este cambio, ha habido un retorno a la utilización de los antiguos formatos de película, problema que había resuelto utilizando un sistema analógico de tipo industrial que permite el apoyo de rayos $\mathrm{X}$ de gran formato, y que fue capaz para adaptarse a casi cualquier superficie.

Por lo tanto, este estudio trata de rectificar los límites de las técnicas de rayos $\mathrm{X}$ digitales mediante el uso de técnicas de rayos $X$ junto con el empleo de las placas telemétricas. En el Laboratorio de Documentación y Registro (IRP, o Instituto de Restauración del Patrimonio), con sede en la Universitat Politècnica de Valencia (UPV), España, se ha diseñado un equipo de radiografía telemétrica móvil que permite su adaptación a obras pictóricas de gran formato.

Palabra Clave: pintura de caballete, rayos $X$, radiografia telemétrica, gran formato.

\section{A utilização de radiografia telemétrica em obras pictóricas de grande formato}

Resumo: Nos últimos anos, com o aparecimento das tecnologias digitais e o desaparecimento, simultâneo, da instrumentação analógica, os investigadores da área de património cultural têm-se confrontado com novos e importantes desafios para o desenvolvimento de soluções digitais.

Concretamente, esta alteração tem suscitado a utilização de novos procedimentos quanto à aplicação de radiologia no estudo de obras de arte. No entanto, por causa desta alteração, tem havido um regresso aos antigos formatos de película, questão que tinha sido resolvida, utilizando um sistema analógico de tipo industrial que permite um suporte de radiografia de grande formato, capaz de se adaptar a, praticamente, qualquer superfície. 
Deste modo, este estudo tem como objetivo rectificar os limites das técnicas de raios $\mathrm{X}$ digitais, usando técnicas de raios $X$ juntamente com placas telemétricas. No Laboratório de Documentação e Registo (IRP ou Instituto de Restauración del Patrimonio), com sede na Universidade Politécnica de Valência (UPV), em Espanha, foi desenhado um equipamento de radiografia telemétrica portátil que permite a sua adaptação a obras pictóricas de grande formato.

Palavras-chave: pintura de cavalete, raios $\mathrm{X}$, radiografía telemétrica, obras de grande formato.

\section{Introduction}

In the application of X-rays to study internal structure of art works, we have used an adapted the research of Arturo Gilardoni (Gilardoni, 1994).

Commercially available radiographic plates are not commonly adapted to cultural assets. During the past few years, industrial X-rays have allowed us to adapt and obtain X-rays of large-size pictorial works. In the Museo del Prado, Carmen Garrido pioneered work in this area (Garrido, 1984).

In recent years, commercially-available industrial X-ray films supplied in 'daylight packaging' were used to adapt to the surface of all kinds of art works and allowed oversize X-radiographies to be obtained. Initially, to conduct a complete X-ray examination of a large-size pictorial work, assembled X-radiography had to be performed. This approach has the disadvantage of producing $x$-radiographs with different gray scale densities. This introduced a difficulty that affects the understanding of such register. The ability to build a complete surface register for a single radiographic exposure presents the advantage that the gray scale shown in the registration was homogeneous.

In 2000, the X-ray analysis service developed a methodology that sought to optimize all factors involved in obtaining quality $X$-rays and remove some of the subjectivity present in the selection of exposure time. The system was based on the measurement of the radiation dose, which was collected in the same plane of the X-ray and the level of blackening or optical density obtained (Madrid, 2000).

Beyond this, we faced a new challenge of adapting these strategies to new materials and equipment for obtaining radiographic records.

This is the reason why we have been interested in existing possibilities in this field, such as direct radiography or digital radiography plates, with the latter being preferred. There were several reasons that aided us in making this decision, but the most important was the ease of adaptation of this system to the traditional one. The work presented here provides evidence for this (Figure 1).

Since the acquisition of indirect digital radiography equipment (Computed Radiology, CR) by this laboratory, a number of adjustments in relation to the voltage and the exposure time have been carried out to interpolate the integrated dose data and adapt the level of blackening obtained in digital recording. This has improved the possibilities of the digital system, which consists of a dynamic range that allows radiography with a smaller quantity of integrated dose.

Once this question was remedied, the problem of obtaining digital large-format radiographs was tackled. The basis for the improvement and design of a mobile wall telemetric X-ray device system is detailed below. 


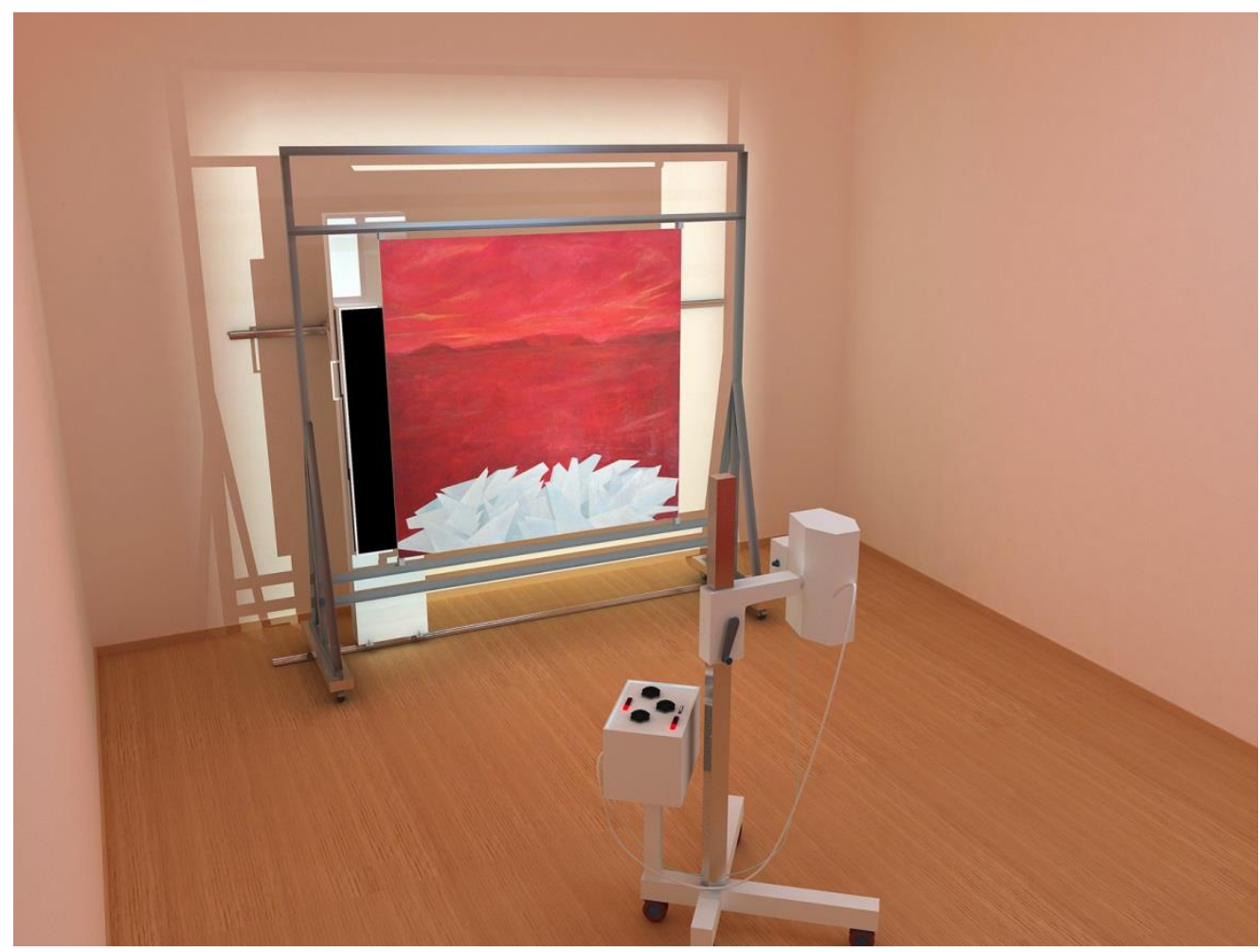

Figure 1: Virtual image of the study.

\section{Laboratory equipment and its adaptation to the telemetric X-ray mobile system}

These studies were performed using TRANXPORTIX $50^{\circledR}$ General Electric Company equipment. This equipment has a $3 \mathrm{kV}$ X-ray tube and a $2.3 \mathrm{~mm}$ focus, with a $2 \mathrm{~mm}$ aluminium filter to control the absorption of the X-ray beam, which allows it to work at very low voltages, from 20 to $110 \mathrm{kV}$. Additionally, the intensity range is also appropriate for this type of study, owing to fixed values of current intensity of 10 and $20 \mathrm{~mA}$. A light collimator centers and locates the beam system of the irradiated area, to which a marker system has been adapted to ensure an effective irradiation area.

The facility also has an indirect radiography CR workstation. Set in concrete, with an AGFA ${ }^{\circ} \mathrm{CR} 30-$ $X$ digitizer, this is one of the most versatile instruments used for this type of work. The CR 30-X combines with the image identification software and quality control AGFA ${ }^{\oplus}$ NX. This station processes the digital images obtained with the indirect digital system through the CR MDT4.OT chassis, also from AGFA ${ }^{\oplus}$, in a format of $35 \times 43 \mathrm{~cm} 2$ and a pixel matrix size of $3480 \times 4248$ pixels 2 .

These chassis are mounted on an installation dedicated to telemetric X-rays, which facilitates an Xray effective area of $126 \times 33 \mathrm{~cm} 2$. The telemetric X-ray system, or the CR Easylift ${ }^{\oplus}$ using its commercial name, from AGFA, permits the superimposition of three chassis in the same plane, and offers an effective area of X-ray. These three plates are mounted in a mobile freight car, which can move in a vertical plane from 0 (e.g. level position) to $230 \mathrm{~cm}$ of the maximum height (Figure 2). 


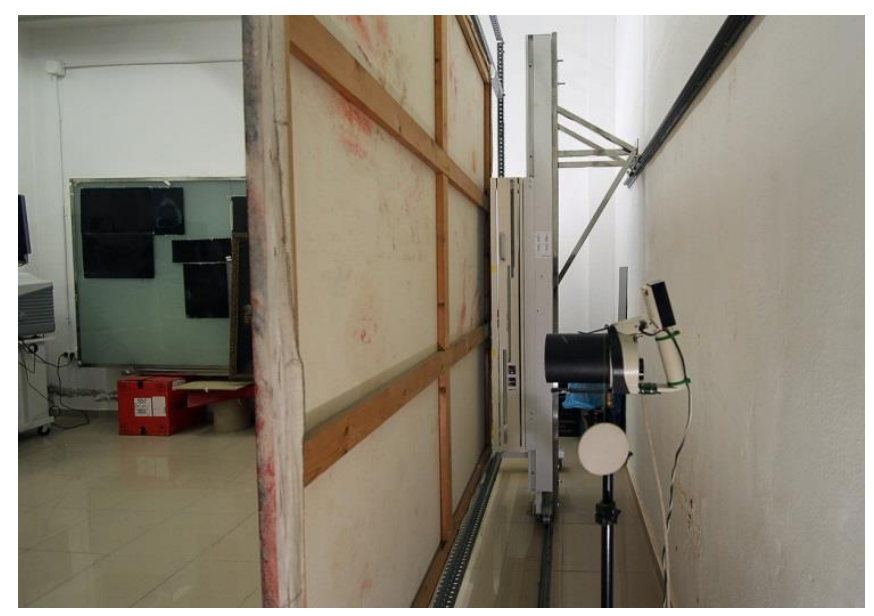

Figure 2: Location of devices.

To make this system more efficient, the IRP Laboratory of Documentation and Registration has built a mobile structure that supports the telemetric X-ray device with two rails. One rail is placed on the wall and the other on the ground. A Teflon-coated roller system ensures smooth displacement movement of the whole system.

The measurements of the rails are $300 \mathrm{~cm}$, which are predefined by the film-to-focus distance that is tangential to the wall. This measurement is the maximum one that the source can be placed at, and we can cover all the area generated by the displacement in the horizontal axis of the mobile system. Including the two movements, one in the horizontal plane of $300 \mathrm{~cm}$ and the second in the vertical plane of $0-230 \mathrm{~cm}$, the plate has an area of approximately $7 \mathrm{~m} 2$. In the rail system, we have adapted some objects that help the positioning of the system along the route followed.

Likewise, the constant need for loading and unloading of the chassis by hand has been taken into account, which is why the structure has been separated by $70 \mathrm{~cm}$ from the vertical rail, to maintain accessibility.

A mobile stretcher has been built to hold the paintings, which anchors the artwork by the upper and lower parts. The material used for holding the artwork is high-density polyurethane foam, which is transparent to radiation.

A radiation monitor completes the equipment. This device, a Ram Ion ${ }^{\circledR}$ (Rotem Company) ionization chamber, has an auto-ranging system. We have used it for dose-integrated measurements.

\section{Current X-radiography protocol}

The work protocol is summarized by the following:

- $\quad$ obtain pre-exposure measurements;

- $\quad$ characterize the points for mural radiography obtained with telemetry X-rays;

- $\quad$ execute the mural radiography;

- $\quad$ edit assembled X-radiography with an image-processing program. 
The first phase, involving obtaining dosimetric measurements, permits the evaluation and adjustment of the exposures. From a sequence of shots, with some fixed exposure time values, the relationship of integrated dose and the slope of its equation relating to time of exposure is determined (Madrid, 2000). In this way, we ensure that the radiography will obtain the best level of optical density (Table 1).

Once fixed, the different parameters of the exposure sequences, such as the voltage, the current, the distances between the focus and the register, and the exposure times, establish a grid of points that mark the different positions of the location of the slide-wagon that carries the chassis. The distribution of these points should ensure a minimum area of overlap between one plate of the telemetric X-rays and another plate.

At this point, each of the wall radiography shots can be taken. These are then downloaded in a sequence of $X$-rays that the computer, through the image identification program and quality control AGFA ${ }^{\oplus} \mathrm{NX}$, presents in a single image. These sequences, or telemetric radiographs, are transferred to an image program capable of reading the Dicom system, where they are later assembled into a full image mosaic in TIFF format (Figure 3).

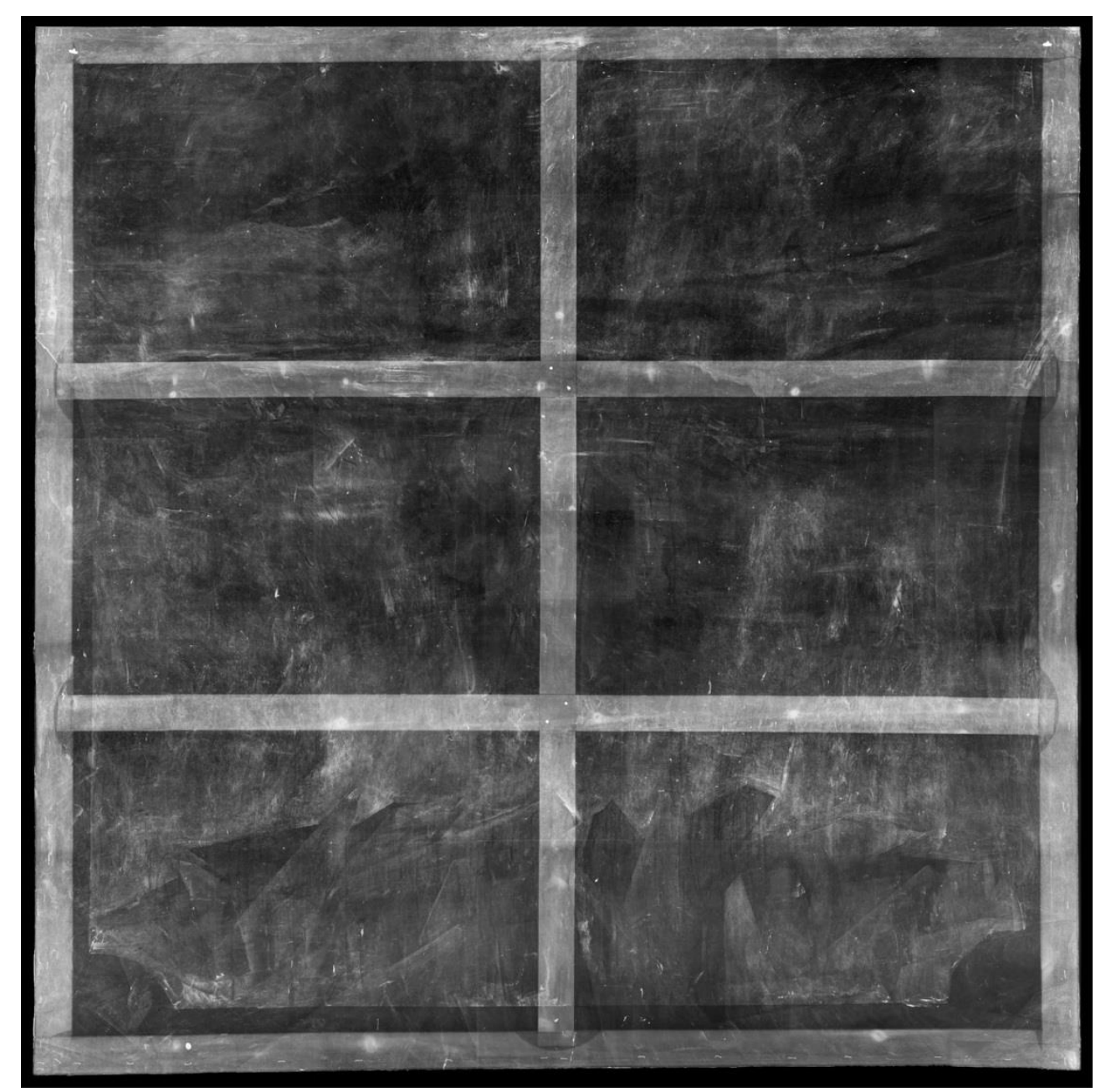

Figure 3: X-rays of the "Equinox" by Rosa Martinez. 
Table 1. Measurements of doses in the telemetric X-ray.

\begin{tabular}{|l|r|}
\hline$N^{\circ}$ Telemetric & Dose (microSv) \\
\hline 1 & 19.50 \\
\hline 2 & 23.10 \\
\hline 3 & 19.00 \\
\hline 4 & 19.00 \\
\hline 5 & 23.00 \\
\hline 6 & 24.00 \\
\hline 7 & 21.00 \\
\hline 8 & 17.00 \\
\hline 9 & 19.00 \\
\hline 10 & 19.00 \\
\hline 11 & 16.00 \\
\hline 12 & 18.00 \\
\hline 13 & 22.68 \\
\hline 14 & 22.10 \\
\hline 15 & 17.40 \\
\hline 16 & 21.50 \\
\hline 17 & 17.00 \\
\hline 18 & 20.00 \\
\hline 19 & 21.00 \\
\hline 20 & 18.00 \\
\hline 21 & 15.00 \\
\hline 22 & 23.00 \\
\hline 23 & 20.00 \\
\hline 24 & 20.00 \\
\hline 25 & 19.00 \\
\hline 26 & 12.00 \\
\hline 27 & 22.00 \\
\hline 28 & 16.00 \\
\hline 29 & 19.00 \\
\hline 30 & 17.00 \\
\hline 31 & 16.00 \\
\hline 32 & 20.00 \\
\hline 33 & 16.00 \\
\hline 34 & 17.00 \\
\hline 35 & 20.00 \\
\hline & \\
\hline 19 &
\end{tabular}




\section{"Equinox" by Rosa Martinez: practical application}

An artwork by Rosa Martinez, which belongs to the Polytechnic University of Valencia Art Heritage Fund, was chosen to test the practical application of this system. The canvas "Equinox", made in acrylic, has dimensions $200 \mathrm{~cm} 2$. This kind of work not only presents a problem for undertaking Xray studies due to its size, but also presents a challenge in optimizing the optical density due to the pictorial technique. Because the constituent materials of this painting have a very high degree of contrast among the different materials is needed so in the radiograph (Figures 4, 5).

To cover the whole $200 \mathrm{~cm} 2$ area, the beam of X-rays had to be displaced by a total of $500 \mathrm{~cm}$. This distance ensured an area of irradiation of over $25 \%$ of this painting. In this type of study, it is important to have a margin in the irradiation zone because the X-ray beam does not radiate the whole perimeter in a uniform manner (Madrid, 2006). The grid that was established to determine the different points of execution of the assembled X-radiography constitutes a mosaic of 35 plates of mural X-rays, composed of 7 columns and 5 rows, ensuring an overlap area of $5 \mathrm{~cm}$ on its horizontal dimension and $10 \mathrm{~cm}$ in its vertical dimension.

The sequence of exposures was performed with the following parameters: $62 \mathrm{kV}$ voltage, $20 \mathrm{~mA}$ current, and $5 \mathrm{~s}$ of exposure, for all exposures. The readings of integrated dose had a mean value of $19.12 \mu \mathrm{Sv}$ and a standard deviation of $2.69 \mu \mathrm{Sv}$.

The 35 wall X-ray plates were processed using commercial digital image processing software, capable of reading Dicom files. By means of a similar point locating system, we have adapted each one of the files until complete registration is obtained.

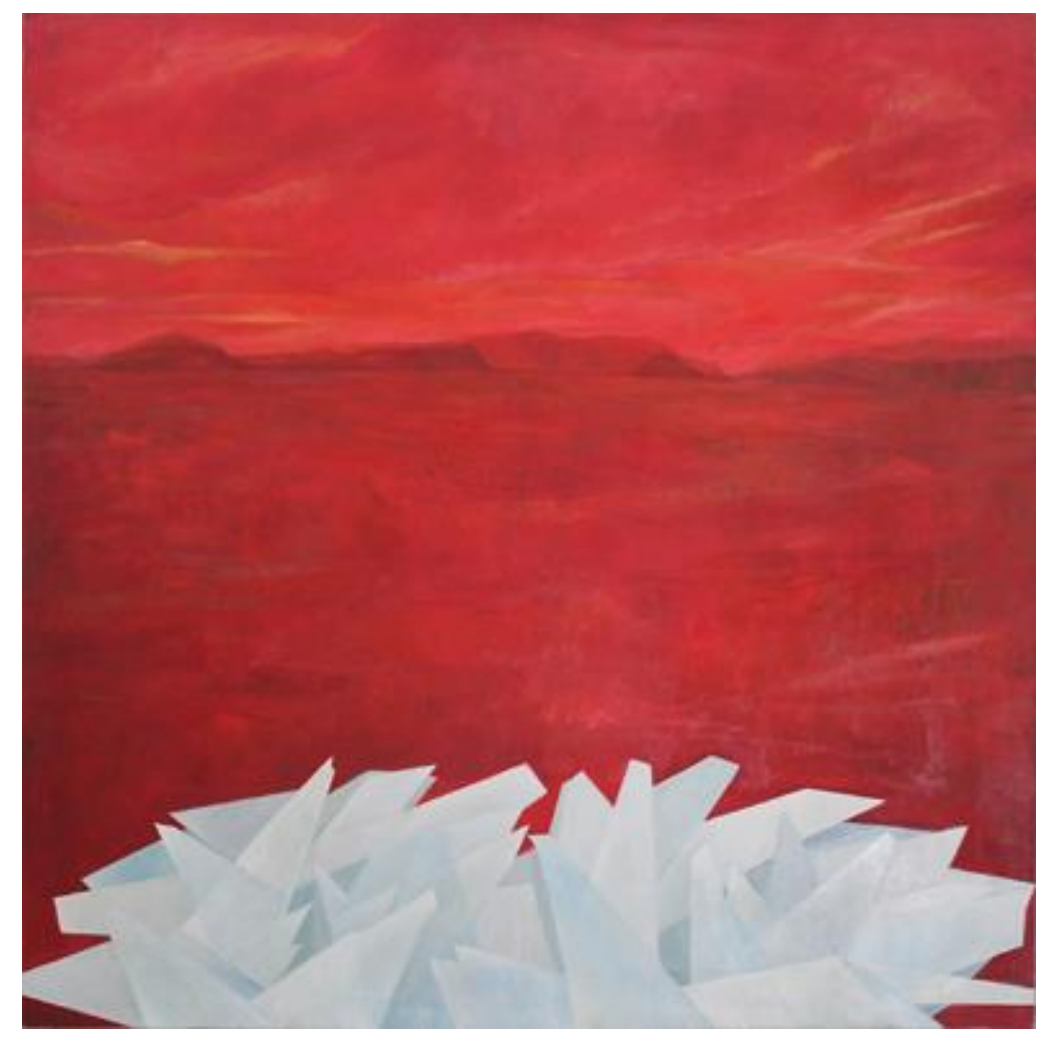

Figure 4: "Equinox" by Rosa Martinez. 


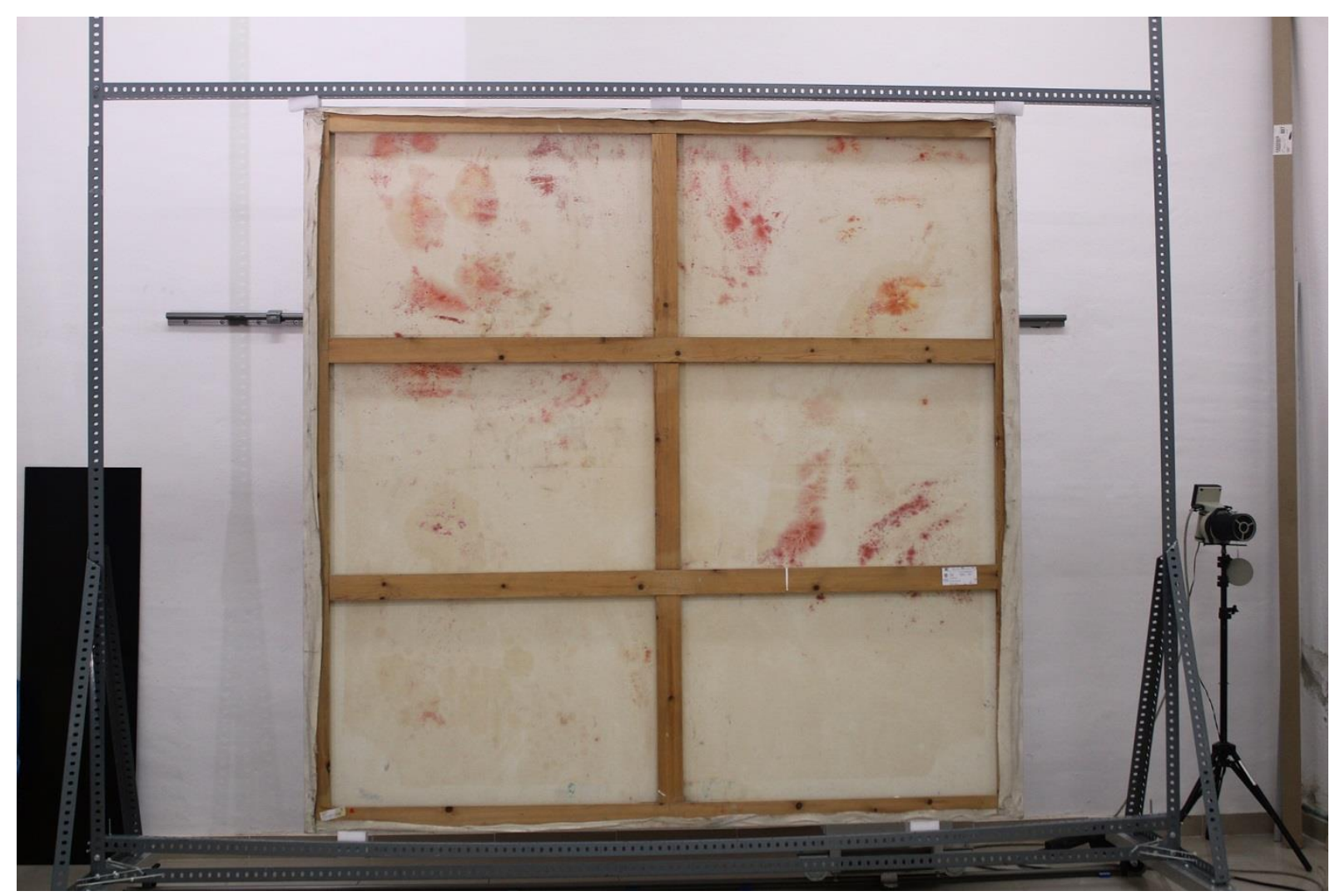

Figure 5: Back of the painting.

\section{Conclusions}

Taking into consideration all the information revealed in our study, we can summarize the most significant conclusions.

Through the practical application of this study, it has been demonstrated that the transition towards a new technology, in this case, the application of digital X-rays, is an opportunity to revise and improve conventional installations.

Digital X-ray analysis has been developed to an optimum quality using plates through a simple work protocol adaptation.

The post-processing control of digital X-ray films improves the likelihood of contrast adjustment improvement. This is a fundamental aspect in work using a low $\mathrm{X}$-ray absorption technique.

The digital system presents advantages due to its versatility in obtaining registration and provides a considerable cost reduction for this type of study.

This study has been able to set up substantial points of improvement for future research. On one hand, the automated movement of the CR Easylift ${ }^{\oplus}$ over the rails allows to maximize radiographed area as well to minimize loss zones between the various plates. On the other hand, the digital data treatment will enhance the adjustment resulting from exposure log mediate $(\mathrm{LgM})$ related to the digitalization process of the plate. 


\section{Bibliography}

BORRELLI, E., and ALONSO, M., (1999). "Obras de arte y técnica de investigación no destructivas: Un binomio imprescindible", En 9० Congreso Nacional de Ensayos no destructivos, Vitoria, 253-259.

GARRIDO, M. C., (1984). "Technique radiographique grand format applicable in situ sur le tableau exposés actuellement au Musée du Prado", In ICOM Committee for Conservation, 7th Triennial Meeting, Copenague, 10 14 September 1984. Paris 1, 7-9.

GILARDONI, A., (1994). X-Ray or art. 2nd. Edn, Lecco (Italy): Gilardoni SpA,.

HOURS-MIEDAN, M., (1964). Les secrets des chefs-d'oeuvre. L'oeuvre d'art est matière avant d'être message. Paris: Ėditions Robert Laffont.

LANG. J, and MIDDLETON. A., (1997). Radiography of Cultural Material. London: Ed. Butterworth Heinemann.

MADRID, J. A., (2000). Metodología para la mejora del contraste en el análisis radiográfico aplicado a la conservación y restauración de obras de arte. Valencia: Ed. Universitat Politècnica de Valencia.

MADRID, J. A., (2006). Aplicación de la técnica radiográfica en la conservación y restauración de bienes culturales. Valencia: Ed. Universitat Politècnica de Valencia.

MADRID, J.A. and RAMíREZ, A., (2011). "Radiografía digital en el estudio de piezas cerámicas. Estudio e interpretación de cerámica medieval procedente del museo Arqueológico de Burriana". En VVAA., La arqueología de la Buriyyana islámica a la Borriana Cristiana. Castellón: Ed. Ayuntamiento de Burriana.

MUCCHI, L. BERTUZZI, A., (1983). Nella profondita'dei dipinti. La radiografia nell 'indagine pittorica. Milan: Ed. Electa.

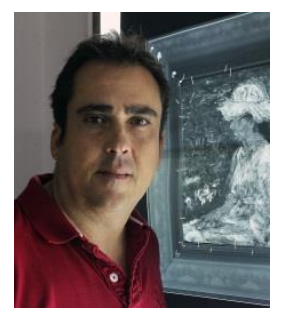

\section{José A. Madrid García}

Dpto. De Conservación y Restauración de Bienes Culturales.

Universitat Politècnica de Valencia (UPV).

C/ Camino de Vera s/n. 46022 Valencia. Spain.

Phone: 0034620923898

jmadrid@crbc.upv.es/jmadrid.webs.upv.es

José A. Madrid García has a doctorate in Conservation and Restoration of Cultural Heritage, and has published various papers and books on the application of X-rays in the study of cultural assets. He is currently a tenured university lecturer in the Department of Conservation and Restoration of Cultural Heritage, a researcher at the Heritage Conservation Institute, and a member of the Documentation and Record Laboratory at the Universitat Politècnica de Valencia (UPV).

Artículo enviado el 20/05/2013

Artículo aceptado el 22/10/2013 


\title{
O sistema das nove cores na reintegração cromática de bens culturais
}

\author{
Ana Bailão
}

\begin{abstract}
Resumo: A seleção das cores mais adequadas para realizar uma reintegração cromática não é normalmente uma questão fácil de resolver. Para utilizar uma paleta restrita, muitos conservadores-restauradores optam por usar as três cores primárias, percebendo a curto prazo que cada fabricante tem as suas cores primárias e que com cada conjunto de três cores-pigmento se obtêm uma gama limitada de tons. Normalmente, segundo a obra, são necessários matizes adicionais para obter tons fora desta gama. O objectivo deste estudo é fazer um levantamento dos conceitos da teoria da cor e propor um sistema alternativo, constituído por nove cores, dois amarelos, dois azuis, dois vermelhos, pelo branco, preto e ainda pela terra de sombra queimada. Nos diversos exercícios demonstrativos recorreu-se às aguarelas Artist's Watercolours da marca inglesa Winsor\&Newton.
\end{abstract}

Palavras-chave: reintegração cromática, cor, nove cores; tendências tonais; aguarelas; Winsor\&Newton.

\section{El sistema de nueve colores en la reintegración cromática de los bienes culturales}

Resumen: La selección de los colores más adecuados para realizar una reintegración cromática generalmente no es un asunto fácil de resolver. Para utilizar una paleta restringida, muchos conservadores optan por usar los tres colores primarios, percibiendo a corto plazo que cada fabricante tiene sus propios colores primarios y con cada conjunto de tres colores-pigmento se puede obtener sólo una gama limitada de tonos. Normalmente, según la obra, es necesario emplear también otros colores adicionales para obtener colores fuera de este rango. El objetivo de este estudio es proponer un sistema alternativo, basado en las normas de la teoría del color, constituido por nueve colores, dos amarillos, dos azules, dos rojos, el blanco, negro y la tierra de sombra quemada. Se recurrió a las acuarelas Artist's Watercolours de Winsor\&Newton.

Palabras-clave: reintegración cromática, color, nueve colores, tendencias tonales, acuarelas, Winsor\&Newton.

\section{The system of nine colours for the retouching of cultural heritage}

Abstract: The selection of the most suitable colours for retouching practice is usually not an easy matter to settle. In order to use a restricted palette, many conservators choose to use the three primary colours, realizing in short term that each paint brand has its own primary colours and that, with each set of three colour-pigments, only a limited range of tones is obtained; additional tints are normally required for tones outside this range. The aims of this study is to undertake a survey of colour theory concepts and to propose an alternative system, based on nine colours: two yellows, two blues, two reds, one white, one black and burnt umber, using the Artist's Watercolours from Winsor \& Newton.

Keywords: retouching, colour, nine colours, colour bias, watercolours, Winsor \& Newton.

\section{Introdução}

A cor, quer sob a forma de luz, quer sob a forma de pigmento, está presente em tudo o que observamos, e constitui um elemento essencial em reintegração cromática, pois desempenha funções múltiplas na visualização dos objectos artísticos. A cor confere continuidade às lacunas e desgastes que podem ocorrer numa dada composição pictórica. Quanto maior for a fidelidade da reprodução da cor a reintegrar com a da superficie cromática original, maior será o realismo e a naturalidade dos resultados observados. 
A cor desempenha também um papel importante na verificação da qualidade de algumas fases das intervenções de restauro, como o caso da aplicação de massas de preenchimento. Não são raras as vezes em que os preenchimentos não ficam correctamente nivelados e que por isso comprometem o resultado final da intervenção. Por exemplo, um mesmo tom verde pode parecer mais escuro em áreas côncavas e mais claro em zonas mais relevadas. Esta variação do matiz na lacuna acentua a percepção do declive e realça um trabalho executado com menor qualidade.

Quando se fala de reintegração cromática surge a questão acerca da escolha das "cores" para realizar a tarefa, isto é, devem usar-se os três tons primários, ou um outro conjunto constituido por seis, doze ou mais matizes? O objetivo deste estudo é sugerir um conjunto de cores para se fazer a reintegração, fundamentando a escolha de matizes na teoria da cor.

\section{A cor}

O processo de percepção de cor pelos seres humanos é algo complexo, contudo pode ser sintetizado em duas etapas fundamentais: captação fisiológica da luz e interpretação cerebral. 0 produto final é a sensação ou estímulo de cor (Kuppers 1975: 24). A justificação destas designações passa por, em sentido estrito, a cor ser um produto sensorial da visão e do funcionamento do cérebro humano, que é subjetivo e não um dado concreto e que começa na retina do olho humano.

O que vulgarmente se chama luz é a radiação electromagnética visível. A organização das radiações electromagnéticas depende do seu comprimento de onda' (González-Cuasante et al. 2005: 26; Tornquist 2008: 29, 30). À totalidade dos comprimentos de onda visíveis pelo olho humano atribuiu-se a denominação de espectro visível (Ball 2001: 25, 38; Hecht 2002: 19-20).

Quando as radiações electromagnéticas visíveis atingem um corpo físico ${ }^{2}$, podem ocorrer um ou mais fenómenos físicos que interferem no processo de percepção da cor. No caso de se tratar de um objecto opaco e colorido, estas radiações visíveis podem ser absorvidas e reflectidas parcialmente. Se o objecto for transparente ou translúcido, estas mesmas radiações são transmitidas, isto é, a luz atravessa o material sem sofrer alterações (Hickethier 1969:6). No entanto, quando a radiação atravessa dois meios distintos, uma parte da energia volta para trás (reflexão), enquanto a restante energia se transmite ao outro meio, acompanhada por uma alteração da direcção de propagação (refração) (Hecht 2002).

Na prática quando a luz é absorvida na sua totalidade vemos preto; quando a luz é reflectida na sua totalidade vemos branco; quando a luz é transmitida o objecto observado é incolor. O estímulo ou sensação de cor que se observa resulta das radiações de energia visíveis não absorvidas pelo objecto ou matéria.

É também importante reter que o modo como os raios luminosos incidem nas superfícies dos objectos altera o modo como são vistos. Se a superfície for plana e lisa há maior reflexão de luz de forma regular ou especular, com o mesmo ângulo incidente e sem alteração de cor, o que corresponde a uma superfície brilhante. Pelo contrário, as superfícies mates, que apresentam ligeiras imperfeições, fazem com que a reflexão se produza de forma irregular ou difusa, podendo haver modificação da cor (González-Cuasante et al. 2005: 34; Saunders 2000: 3-9).

A palavra cor é usada frequentemente com dois sentidos distintos: a que resulta da mistura subtractiva ou a que provem da mistura aditiva. Às substâncias coloridas ou aos materiais que dão 
cor, como as tintas usadas no restauro, associa-se o primeiro fenómeno. Quanto à mistura aditiva, por outro lado, é o resultado da percepção visual de luz que determinados materiais produzem e emanam, como é o caso das fontes de luz ou os dispositivos electrónicos (televisores, écra dos computadores, entre outros). No presente texto será utilizado o termo "cor-pigmento" para a primeira situação, assumindo-se a designação "cor-luz" para o segundo caso.

\section{Léxico}

O léxico da cor utilizado na conservação e restauro é por vezes impreciso. Esta ausência de clareza resulta do facto do estudo científico da cor obrigar à multidisciplinaridade, sendo portanto, um assunto da física, da psicologia, da psicofísica, entre outras. Por este motivo, e consoante os textos, podemos encontrar termos distintos para a mesma qualidade ou atributo.

A explicação das três dimensões ou atributos da cor está definida do ponto de vista físico pela Commission Internationale de l'Eclairage (CIE) (CIE 1987; Fairchild 2005: 85-88). Todavia, a mais corrente e utilizada no campo das artes é a de natureza psicofísica (Urland 1999: 4-5):

- Matiz ou Tom (Hue) define aquilo que associamos usualmente ao conceito de cor (vermelho, verde, amarelo, azul). É a cor-pigmento pura, o comprimento de onda dominante (Fig. 1).

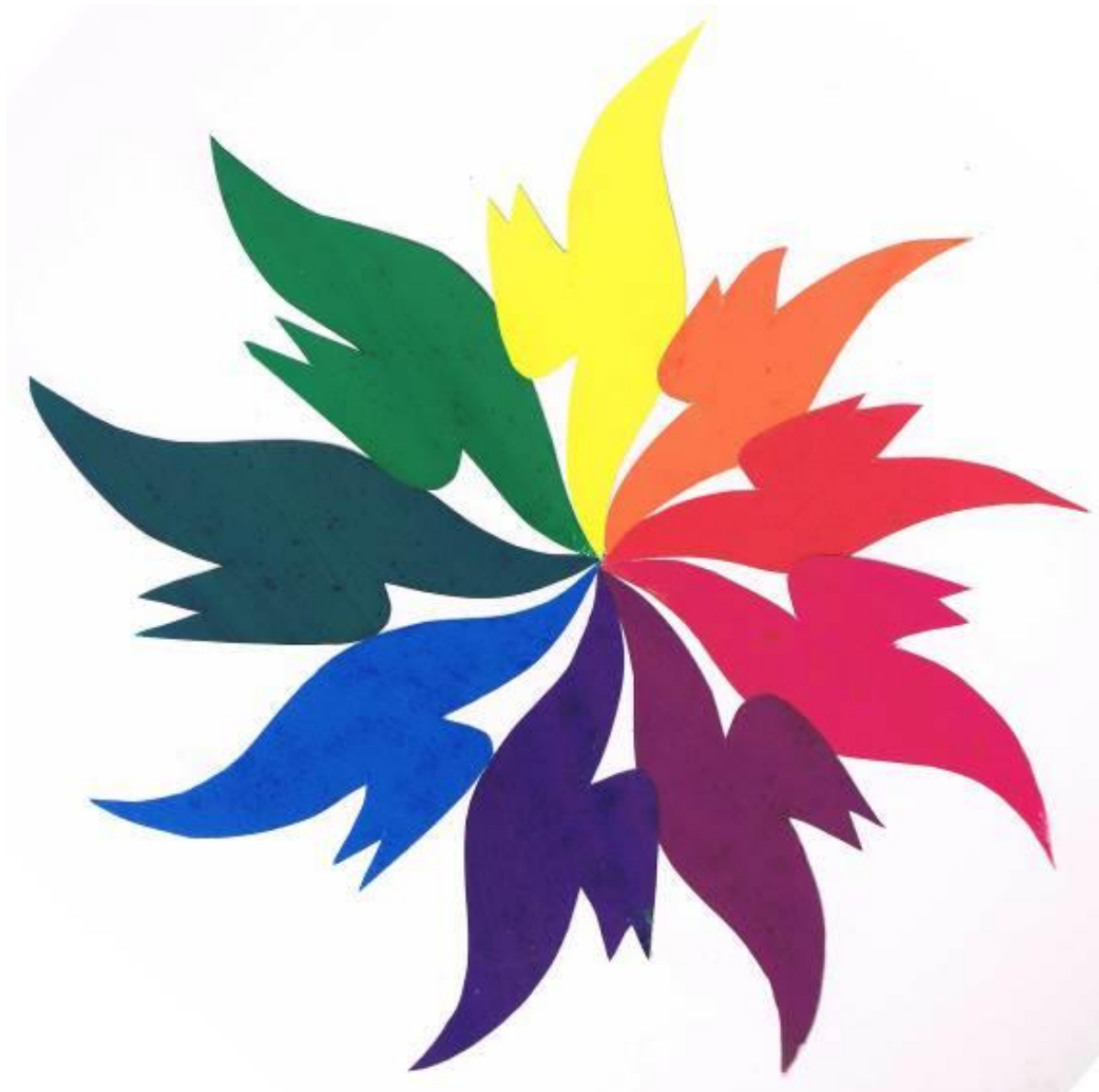

Figura 1: Representação de vários matizes. @Execução técnica e créditos fotográficos de Ana Bailão. 
- Valor ou luminosidade (value) é um atributo que se refere à claridade ou escurecimento que uma cor apresenta quando comparada com a escala de luminosidade do branco e do negro, a escala de cinzentos (Fig. 2 e 3). Esta pode oscilar em níveis sendo a escala acromática de 10 níveis aquela onde se melhor apreciam as diferenças de luminosidade pelo olho humano. A escala é obtida através da adição de branco ou de preto para aclarar ou escurecer uma cor em proporções regulares (Tuan Laka 2013: 58).
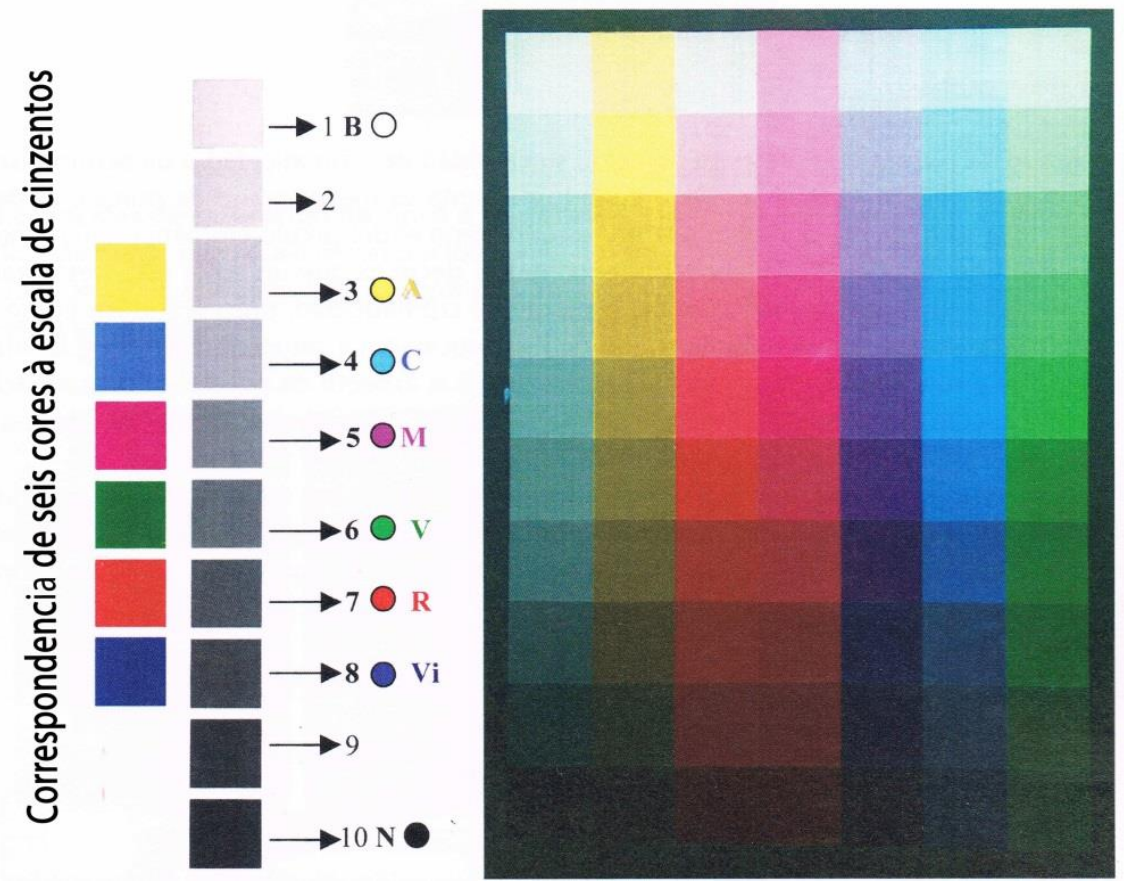

Figura 2: Representação gráfica de seis cores-pigmento segundo a sua luminosidade na escala de cinzas de dez níveis, numerada do branco (1 B) ao negro (10 N): o amarelo é equivalente ao 3 nível, seguido do ciano com 4, o magenta com 5, o verde com 6, o vermelho com 7 e o violeta com 8. llustração de Mercedes Truan Laka (Truan Laka 2013:57).

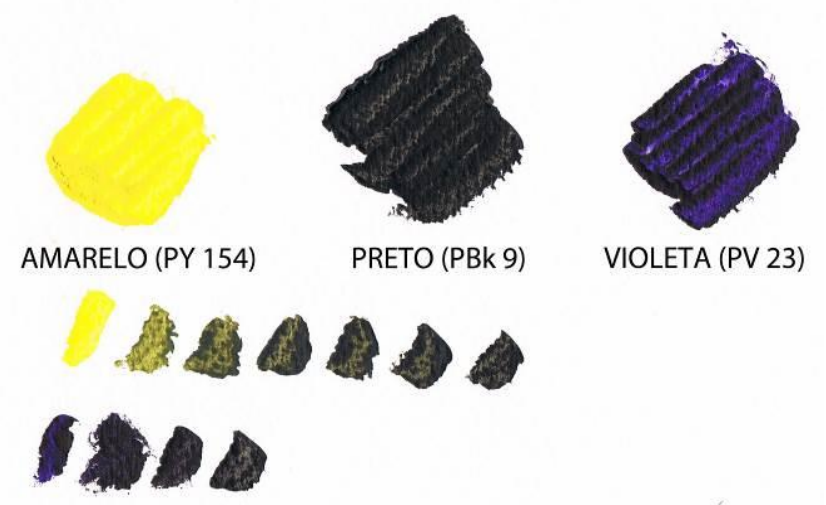

Figura 3: Comparação da luminosidade entre o amarelo (PY 154) e o violeta (PV 23), tendo como referência o preto. O amarelo (PY 154) parece ser mais luminoso porque está mais próximo do branco do que o violeta. Este parece menos luminoso porque está mais próximo do preto. OExecução técnica e créditos fotográficos de Ana Bailão. 
Veja-se o caso da adição das cores-pigmento acromáticas (branco, preto) às três cores primárias (ciano, magenta e amarelo) (Fig. 4). As escalas de cor do amarelo e do vermelho contêm, normalmente, mais gradações facilmente diferenciáveis pelo olho humano do que o azul ou o verde. Isto acontece porque cada escala varia em função do matiz (Loução 1992: 38).

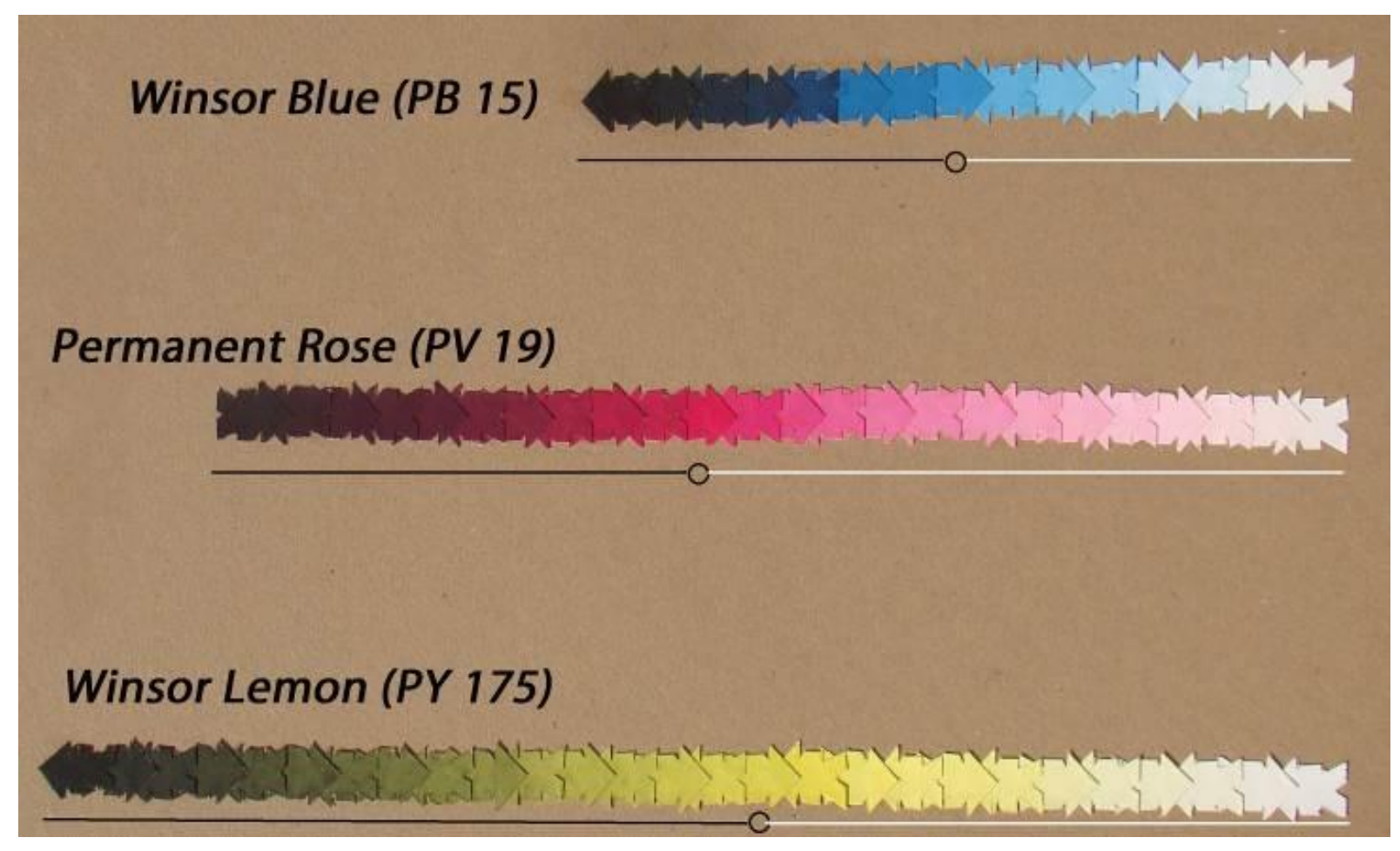

Figura 4: Exemplificação dos resultados obtidos com a adição de Titanium White (PW 6) e de Ivory Black (PBk 9) às três aguarelas primárias da Artist's Watercolours do fabricante Winsor\&Newton (W\&N): Winsor Blue (PB 15), Permanent Rose (PV 19) e Winsor Lemon (PY 175). O pequeno circulo debaixo de cada escala indica a cor retirada diretamente do tubo e a partir da qual se procedeu à gradação através da adição de branco (à direita do circulo) e de preto (à esquerda do círculo). (E) Escalas e créditos fotográficos de Ana Bailão.

- Saturação (Saturation ou chroma) caracteriza o grau de pureza do matiz e descreve a intensidade do tom em relação às cores acromáticas. O nível mais alto de saturação de um matiz é alcançado quando este apresenta uma intensidade de cor similar à do círculo cromático, sem contaminação ou misturas, sobre uma superfície branca (Truan Laka 2013: 58). Um erro comum é pensar que todos os matizes que são aplicados diretamente do tubo são saturados. Todavia, uma terra sombra natural é um amarelo de baixa saturação, um ocre amarelo é um amarelo de média saturação e um amarelo cádmio é um tom de elevada saturação (Fig. 5). O nível mais baixo de saturação caracteriza-se por apresentar um valor cromático baixo, com um matiz próximo do negro, branco ou cinzento. Assim, um matiz perde saturação quando a sua capacidade colorante foi neutralizada. Essa neutralização pode ser realizada de vários modos: pela mistura com branco, com cinzento, com negro ou com a cor complementar (Truan Laka 2013: 58, 59). A cor complementar de um matiz é aquela que mais absorve o seu espectro, como o caso das misturas de vermelho e verde, azul e laranja, amarelo e violeta. 


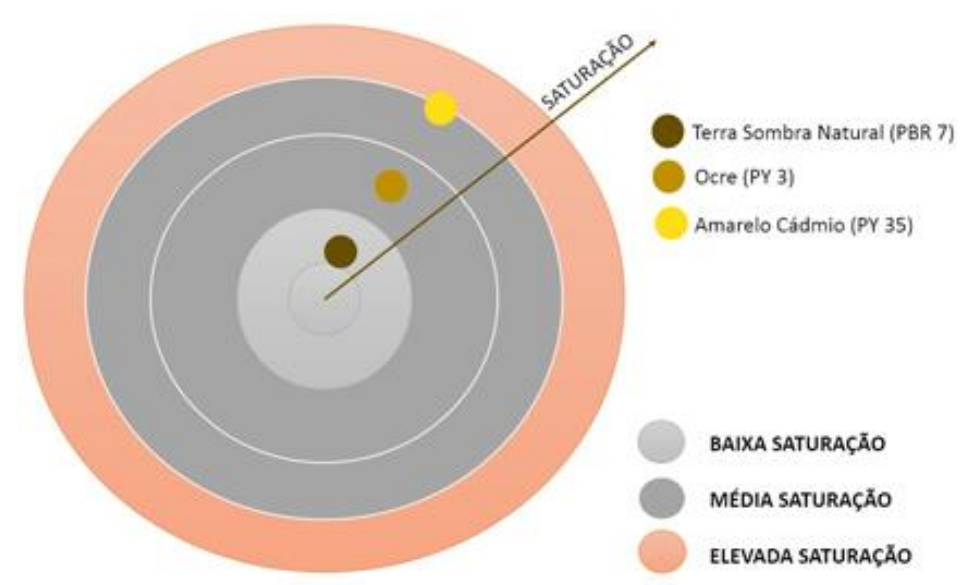

Figura 5: Representação tridimensional dos três níveis de saturação de cor recorrendo a três matizes: terra de sombra natural ( $\mathrm{PBr} 7$ ) de baixa saturação; ocre amarelo de média saturação e amarelo Cádmio (PY 35) de elevada saturação. $\odot$ Esquema de Ana Bailão.

Observando a figura 6 é possível constatar que a luminosidade (Value) e a saturação (Chroma) se relacionam entre si para um determinado matiz (Hue). Esta relação pode gerar alguma confusão, uma vez que é normal os conservadores-restauradores interpretarem uma saturação elevada como uma elevada luminosidade. Como se pode verificar na figura 6 , o vermelho $5 R$ (assinalado com um +) tem uma elevada saturação, /14, mas uma média luminosidade situando-se no valor $5 /$, um valor intermédio na escala de cinzas. Para que este matiz seja mais luminoso é necessário adicionar mais quantidade de branco, o que na prática também significa diminuir a saturação.

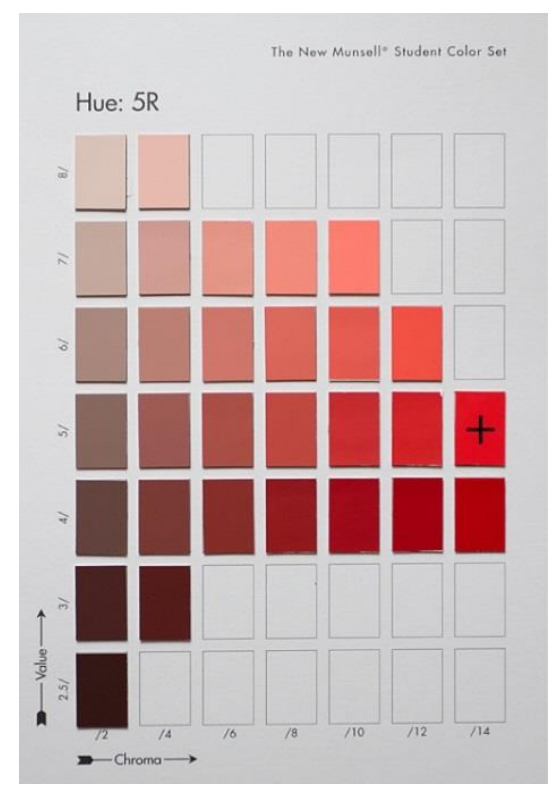

Figura 6: Representação de alguns valores de luminosidade (Value) e de Saturação (Chroma) de um pigmento vermelho na escala de Munsell. $O$ matiz é designado nesta escala por $5 R$ e está assinalado com um símbolo mais (+). A luminosidade é exibida verticalmente (numa escala de 2.5 a 8), enquanto a saturação é indicada horizontalmente (numa escala de 2 a 14). Fotografia de um exercício do conjunto de estudante The New Munsell Student Color Set. @ Créditos fotográficos Ana Bailão. 
O termo Hue, que frequentemente se encontra nos tubos de tinta utilizados em reintegração cromática, é usado para designar todas as tonalidades de cor-pigmento que, permanecendo com determinado matiz, diferem do matiz puro. Por exemplo, Cerulean Blue Hue da Cotman Watercolours da marca Winsor\&Newton $(W \& N)$ significa um tom semelhante ao Cerulean Blue. Nestes casos, os matizes são efectuados a partir de pigmentos alternativos, normalmente menos dispendiosos, mas com semelhanças ao nível dos atributos qualitativos da cor-pigmento (matiz, saturação e luminosidade). Assim, a diferença entre o Cerulean Blue genuíno e o Hue da Cotman está no tipo de pigmento utilizado, bem como na opacidade. O azul cerúleo genuíno é opaco, enquanto a versão Hue é transparente e utiliza o azul de ftalocianina (PB 15). Pelo facto do PB 15 ser transparente, é possível que o produtor tenha adicionado à tinta Cotman uma carga ou um pigmento branco para obter uma opacidade similar ao do Cerulean Blue. O tom Cerulean Blue Hue, apesar de estar próximo do matiz, é parcialmente menos saturado e luminoso que o pigmento puro (Fig. 7). Todavia, são ambos resistentes à luz (Pyle e Pearce 2009: 17; Martel 1855: 9).

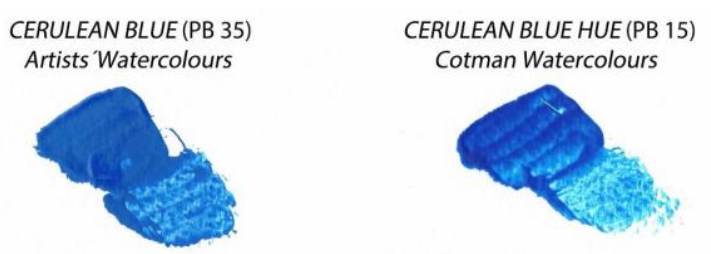

Figura 7: Comparação do pigmento Cerulean Blue da Artists' Watercolours com o Cerulean Blue da Cotman Watercolours, ambos da $W \& N$. Ter em consideração que a fotografia altera os atributos reais dos matizes. () Execução técnica e créditos fotográficos de Ana Bailão.

Importa ainda mencionar que enquanto as cores-pigmento cromáticas são definidas pelo matiz, saturação e luminosidade, isto é, pelos três atributos da cor, as acromáticas (preto, branco e cinza) possuem saturação uniforme em todos os comprimentos de onda e, por isso, são diferenciadas apenas pelo brilho e matiz.

Na terminologia inglesa existem outros conceitos igualmente importantes na caracterização de uma cor-pigmento. Porém, a maioria, não parecem ter tradução directa para português. Por este motivo, no presente texto, os termos serão indicados em inglês, seguindo-se, a sua definição:

- Masstone - termo que se pode traduzir por tom massa, tom geral ou cor geral. É a observação do pigmento concentrado sobre uma superfície, tal como sai do tubo (Fig. 8).

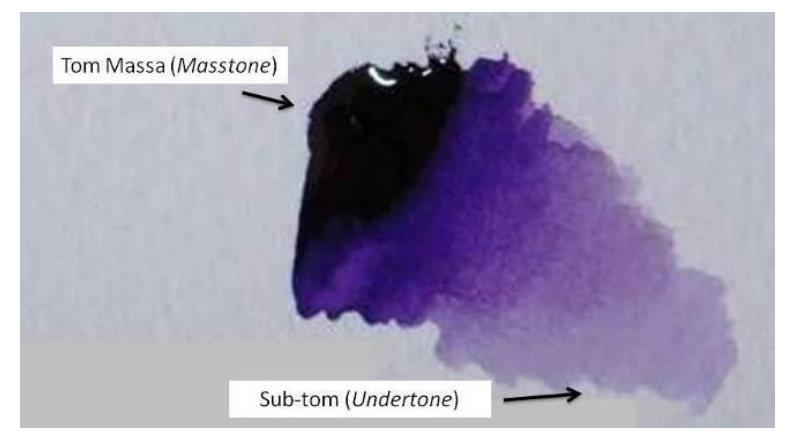

Figura 8: Indicação do tom massa (masstone) e do sub-tom (undertone) com o Permament Mauve (PV 16), Artist's Watercolours, W\&N. @Execução técnica e créditos fotográficos de Ana Bailão. 
- Undertone - termo que poderá traduzir-se por tom diluído ou sub-tom (Fig. 8). É o matiz de um pigmento em fina espessura, que pela sua transparência faz transparecer a cor do suporte. Alguns pigmentos, sobretudo os transparentes, possuem sub-tons distintos dos tons massa, como o Permanent Mauve (PV 16), o verde Viridian (PG 18). Os pigmentos opacos, como o amarelo cádmio (PY 35), apresentam pouca ou nenhuma diferença (Fig. 9).

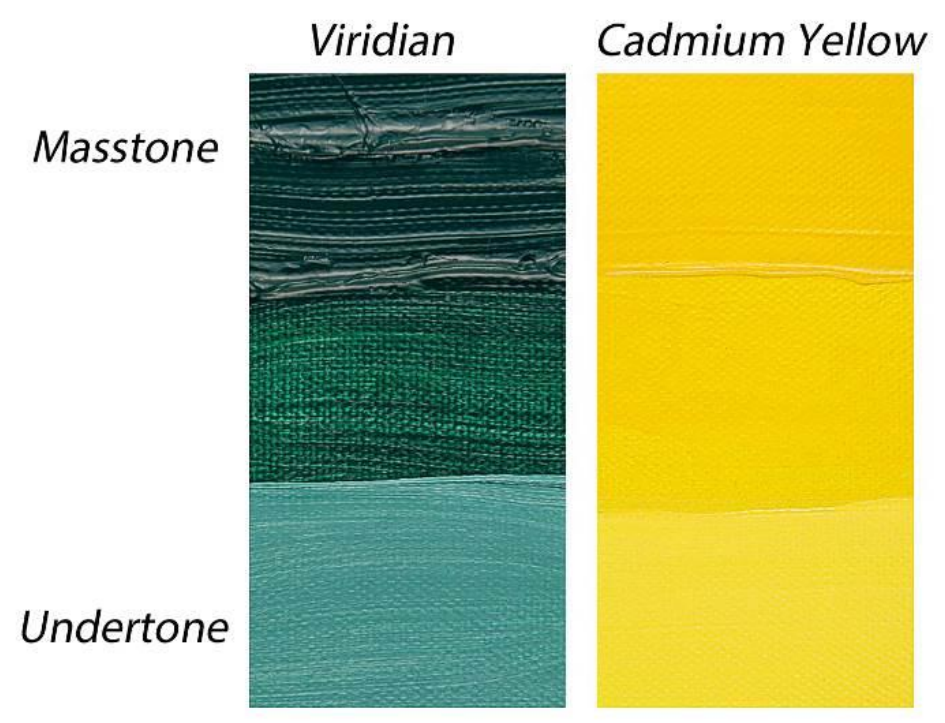

Figura 9: Masstone e undertone do pigmento verde viridian e do cadmium yellow. Como se pode observar a diferença entre a masstone e a undertone é mais evidenciada no pigmento transparente, o viridian.

(c) Execução técnica e créditos fotográficos de Ana Bailão.

Quando se pretende realizar uma reintegração mimética de uma lacuna cujo original tem empaste, o tom massa revela-se muito útil, uma vez que permite a reprodução de áreas opacas e escuras sem a adição de preto, por exemplo. São várias as vezes em que se pode recorrer ao tom massa e ao sub-tom de um matiz numa mesma obra (Fig. 10).

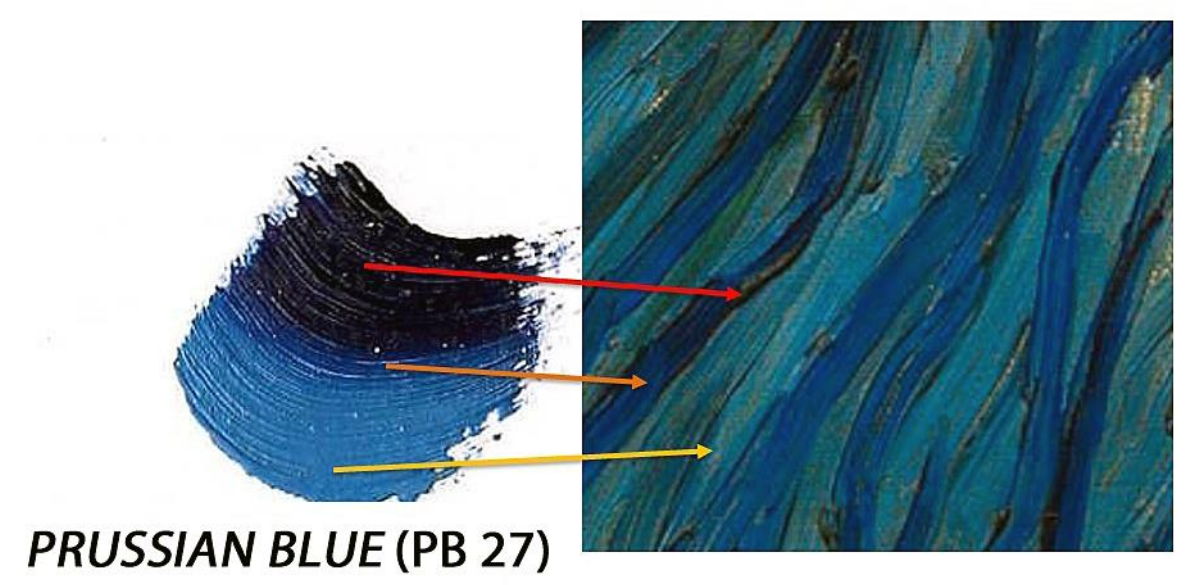

Figura 10: Exemplo da possibilidade de reprodução de vários tons de azul mediante a utilização do masstone, undertone e do tom intermédio do pigmento azul Prussian Blue (PB 27).

○Créditos gráficos de Ana Bailão. 
- Bias (tendência tonal) - Cada cor-pigmento tem uma temperatura de cor: há os tons frios e os tons quentes. Esta característica, também designada de tendência tonal, é facilmente observada quando o matiz é diluído num aglutinante ou misturado com branco. O azul ultramarino (PB 29), por exemplo, é um tom quente quando comparado com outros azuis, como o azul Prússia (PB 27), uma vez que além de azul reflecte vermelho. Por este motivo o PB 29 é designado como um azul com tendência tonal vermelha.

O termo tendência é uma novidade na prática da conservação e restauro, motivo pelo qual pode originar algumas dúvidas, sobretudo relacionadas com o reconhecimento da tendência tonal de um matiz em particular. Para facilitar a identificação o fabricante Winsor\&Newton disponibiliza uma lista de cores quentes e outra de cores frias ${ }^{3}$. As cores quentes podem assumir uma tendência tonal amarela ou vermelha, enquanto as cores frias podem ter uma tendência tonal azul ou verde. Conseguindo fazer esta distinção, a identificação da tendência de cada matiz é mais facilmente perceptível quando é analisada em relação a outro matiz. Por exemplo, o Prussian Blue (PB 27) tem uma tendência tonal esverdeada, quando comparado com o Ultramarine Blue (PB 29) que demonstra ter uma tendência tonal vermelha (Fig. 11). O primeiro é classificado pelo fabricante como um tom frio e o segundo como quente.

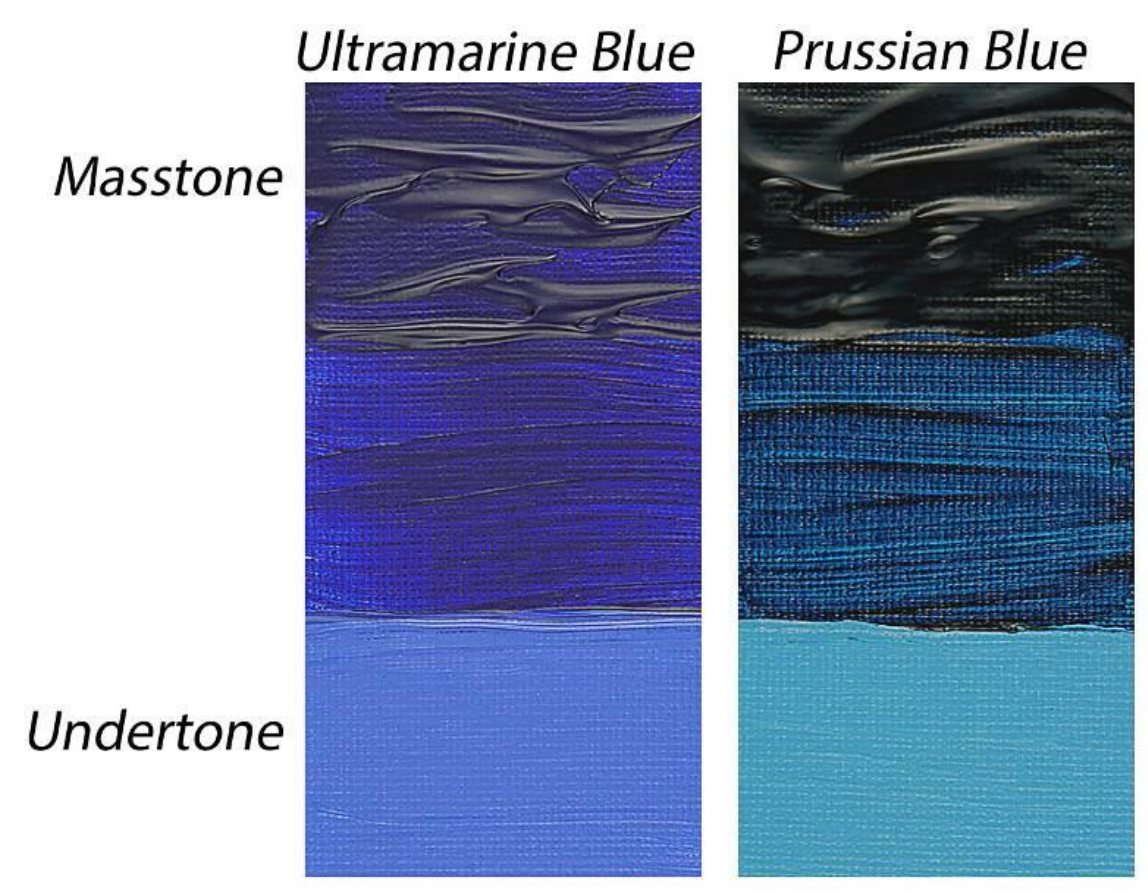

Figura 11: Comparação das tendências tonais entre dois pigmentos: o Ultramarine Blue tem uma tendência tonal mais avermelhada quando comparado com o Prussian Blue, de tendência tonal esverdeada.

○ Execução técnica e créditos fotográficos de Ana Bailão.

Na prática a temperatura de cor de um matiz ajuda a determinar a tendência tonal. Por exemplo, se um vermelho de tendência azul for misturado com azul de tendência verde, como o PB 27, o resultado final será um violeta escuro, um tom menos puro de baixa saturação e luminosidade, pois as tendências tonais são complementares. Para produzir um violeta puro é conveniente misturar um vermelho com tendência azul, como o Permanent rose (PV 19), com um azul de tendência tonal vermelha, como o Ultramarine Blue (PB 29). 


\section{A mistura aditiva, a subtractiva e a óptica}

Além da síntese aditiva e subtractiva, a mistura óptica também desempenha um papel importante na reintegração cromática. A primeira destes sistemas interpreta a cor enquanto resultado da radiação electromagnética (cor-luz), a segunda enquanto consequência da interacção da luz com a matéria e a terceira como uma sensação criada ao nível da retina a partir de dois ou mais elementos coloridos (cor-pigmento).

No processo aditivo são necessárias três fontes de luz para se obter uma ampla diversidade de tons: o vermelho, o verde e o azul. O resultado da mistura das três primárias é branco. A síntese aditiva está presente nos monitores do computador, no telemóvel ou na televisão, entre outros. $\mathrm{Na}$ encriptação de 8 bits dos sistemas computorizados obtêm-se 256 níveis diferentes de intensidade para cada cor-luz primária, que podem ser visualizados e geridos mediante um programa informático de tratamento de imagem, como o caso do conhecido Adobe Photoshop. Através da mescla dos três níveis é possível obter 16.777.216 (256×256×256) tons diferentes. Todavia, no caso dos pigmentos, esta diversidade é menor.

No que diz respeito à síntese subtractiva, tendo como cor base a cor-pigmento elementar acromática branco, consegue-se obter, através da mistura das três cores-pigmento primárias (magenta, amarelo e azul ciano) um matiz próximo do preto (Fig. 12).

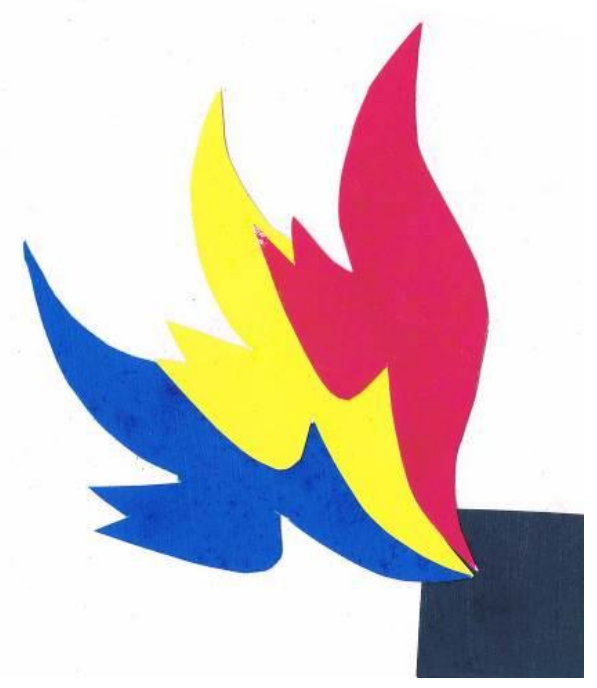

Figura 12: Mistura subtrativa de três cores primárias: Winsor Blue (PB 15), Permanent Rose (PV 19) e Winsor Lemon (PY 175) da W\&N.

A cor-pigmento resultante da síntese é distinta dos matizes iniciais e apresenta uma intensidade luminosa menor que cada um dos tons que formam parte dela (Albers 2007: 40). Assim, por exemplo, a cor-pigmento verde, resultado da subtracção da cor amarelo e ciano, é menos luminosa que os matizes amarelo e ciano no sistema de cor-luz.

No que diz respeito à mistura óptica, esta ocorre quando o nosso sistema visual "origina" uma nova cor através da combinação e fusão de duas ou mais cores-pigmento percecionadas simultaneamente (Tornquist 2008; 54, 55). Trata-se de uma ilusão cromática utilizada frequentemente na reintegração cromática diferenciada, como será explicado mais à frente. 
Para clarificar alguma dúvida acerca da síntese aditiva e óptica, podemos dizer que, enquanto na mistura aditiva há uma combinação de diferentes comprimentos de onda, que se produz antes de chegarem ao olho, na mistura óptica a combinação tem lugar no próprio órgão visual.

\section{As misturas de matizes na reintegração cromática}

Na prática da reintegração cromática os conservadores-restauradores utilizam as tintas de três formas:

a) por mistura das tintas na paleta;

b) por veladuras, sobrepondo camadas transparentes de tinta;

c) intercalando pequenos traços ou pontos/manchas de cor-pigmento que opticamente se misturam, completamente ou parcialmente, consoante a distância de visualização, e que originam as técnicas de reintegração diferenciada.

A mistura na paleta de uma tinta depende da interacção entre aglutinantes e pigmentos. Do mesmo modo que a luz pode ser reflectida da superfície da camada cromática sem interagir com o colorante, contribuindo para uma cor pouco saturada, a luz pode também ser reflectida da superfície das partículas individuais dos pigmentos. A quantidade de luz reflectida depende da diferença entre os índices de refração ${ }^{4}$ do pigmento e do aglutinante envolvente. Este fenómeno de interacção da luz com o meio denomina-se por dispersão e pode ocorrer quando a luz passa através de um meio que não é completamente transparente.

Numa situação em que os grãos dos pigmentos não estão bem aglutinados, como por exemplo no caso dos pastéis secos, a mistura de cores obtida é sobretudo aditiva, e isto acontece porque não se tem um aglutinante a "molhar" ou a envolver todas as partículas do pigmento e a conferir transparência à tinta. Se houver ar nos espaços entre o aglutinante e os grãos, a luz será dispersada, aumentando a luminosidade e reduzindo a saturação de cor (Gottsegen 2006: 154-198; Mayer 2006: 73-43).

O índice de refracção de um pigmento é também importante porque o poder de cobertura dos pigmentos (semi-opacos ou transparentes) é directamente proporcional ao aumento de índice de refracção dos grãos. Quando os pigmentos estão secos, em pó, em contacto com o ar, os grãos reflectem mais luz do que quando estão aglutinados. A diferença entre os índices de refracção dos pigmentos e os dos aglutinantes é também directamente proporcional à reflexão de luz da tinta. Quanto mais elevado é o índice de refracção dos pigmentos e mais baixo é o do aglutinante, maior é a reflexão de luz e, no caso dos pigmentos brancos, maior é o do poder de cobertura e da brancura. Quando o índice de refracção é similar entre pigmentos e aglutinante, os primeiros parecem mais translúcidos, por haver menos reflexão de luz. São, por isso, mais eficazes quando usados para velaturas; mas se os pigmentos tiverem índices de refracção mais elevados do que os aglutinantes, parecerão mais opacos (Gettens e Stout 1966: 147, 148a, 148b, 148c, 148d). É o caso dos pigmentos cádmios que são opacos em goma-arábica, óleo, acrílico, entre outros.

Quando o conservador-restaurador recorre à aplicação de velaturas, seja para minimizar desgastes ou para concluir a reintegração de determinada lacuna, constata que a luz atravessa ambas as camadas, o que resulta na mistura subtractiva, pois há absorção de luz na matéria. Todavia, se a camada superior não for perfeitamente transparente, é possível que alguma da luz que incide sobre ela seja difusa. Isto na prática significa, por exemplo, que o efeito obtido com a sobreposição 
de uma laca vermelha sobre um azul opaco é completamente diferente da sobreposição de um azul opaco sobre uma laca vermelha. O motivo deste efeito está relacionado com o índice de refracção das lacas e corantes que é comparativamente mais baixo que os dos pigmentos (Gettens e Stout 1966: 144, 145).

Nos momentos em que duas ou mais cores são percepcionadas simultaneamente, o nosso sistema visual, através da fusão desses tons, origina uma nova cor. Como mencionado, trata-se de uma ilusão cromática designada por "síntese ou mistura óptica" (Tornquist 2008: 54, 55). Na prática, este efeito ocorre quando o observador contempla, a uma certa distância, a reintegração cromática diferenciada, efectuada com traços ou pontos, dando-se aqui como exemplo as técnicas conhecidas como selezione cromatica e o pontilhismo (Fig. 13).
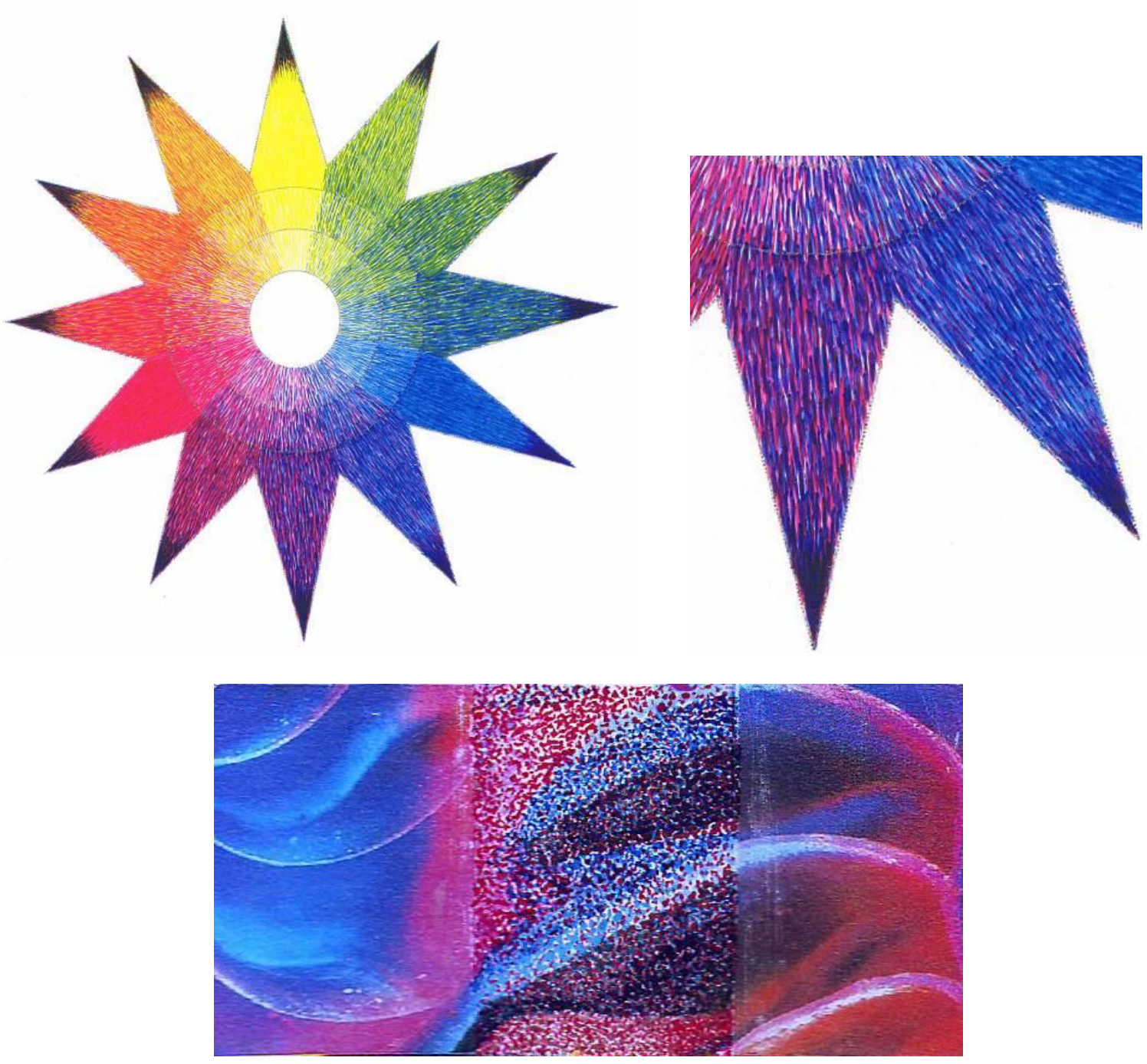

Figura 13: Exemplos de duas técnicas realizadas em dois workshops de reintegração cromática: selezione cromática (em cima) por Mariana Sottomayor na Universidade Católica Portuguesa (UCP) e o pontilhismo (em baixo) por Helena Alexandra no Instituto de Artes e Oficios (IAO) da Fundação Ricardo do Espírito Santo Silva (FRESS). OCréditos fotográficos de Ana Bailão. 
Este fenómeno óptico deve-se ao facto das células receptoras da retina não conseguirem resolver individualmente cada um dos pontos/traços, uma vez que são, na maior parte das vezes, de pequenas dimensões. Quanto menor o tamanho e maior a distância, mais se intensifica o fenómeno. Em vez de misturar na paleta o amarelo e o azul, aplicam-se ambas as cores-pigmento sob a forma de pontos. Esta técnica foi empregue por George Seurat e embora se pense que se conseguiam obter tons mais saturados e luminosos, o resultado final de uma mistura óptica de matizes de elevada saturação são tons pouco saturados (Briggs 2012).

\section{As cores primárias e a mistura de tintas}

No processo subtractivo é vigente a teoria de que existem três cores fundamentais, a partir das quais se pode obter uma ampla gama de tons: o amarelo, o vermelho e o azul. Embora estes três matizes, quando misturados, possam gerar vários tons, não conseguem produzir todas as corespigmento como o violeta ou o verde puro. Como afirma Betty Edwards (Edwards 2006: 21, 22), “(...) as cores utilizadas pelos pintores não são necessariamente verdadeiras cores espectrais". Segunda a autora "(...) os pintores devem complementar os três primários com outros pigmentos cujas estruturas químicas sejam puras na mistura". Para que isso aconteça é necessário utilizar outros dois matizes cujas tendências tonais não sejam complementares. Veja-se o seguinte exemplo: se um vermelho de tendência amarela for misturado com um azul de tendência tonal verde não se consegue obter um tom violeta puro. Para o efeito tem de se recorrer a um matiz menos próximo da cor magenta, com uma tendência tonal para o azul e um azul com uma tendência tonal avermelhada (Fig. 14).

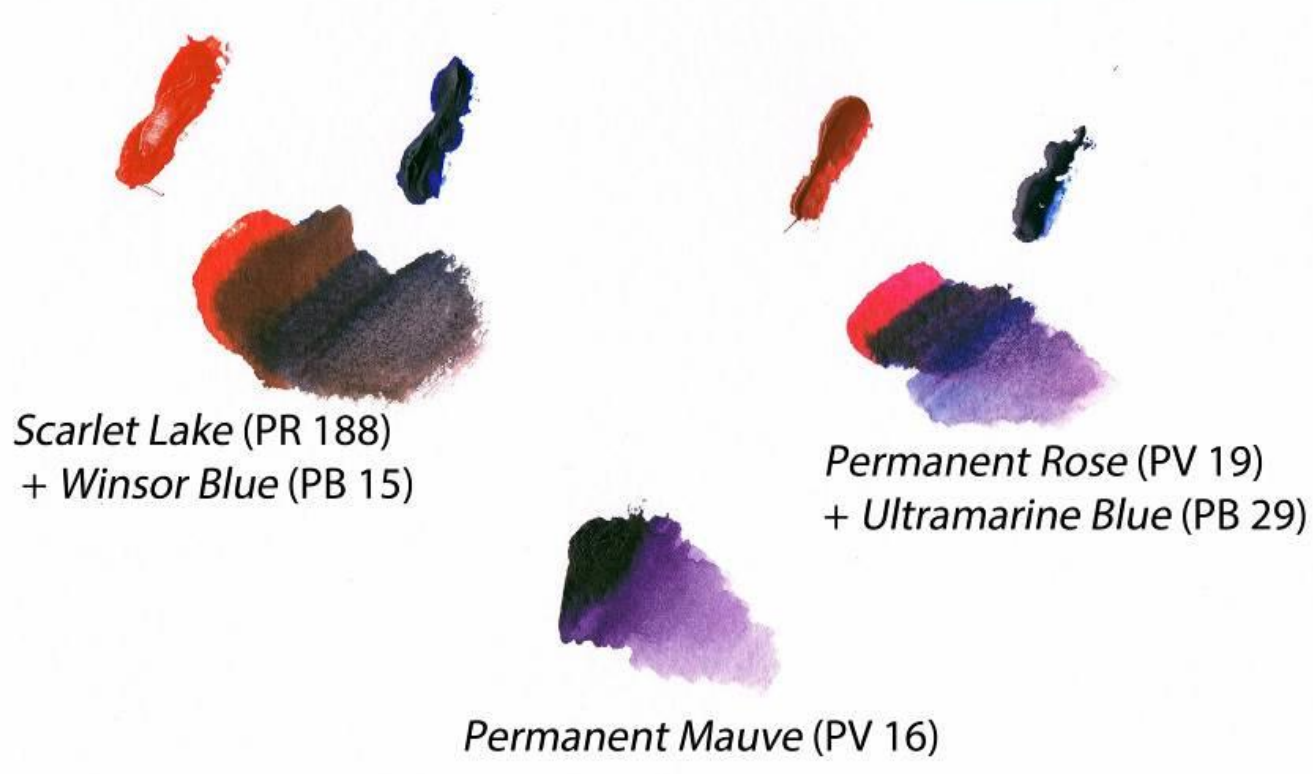

Figura 14: Mistura de tendências tonais: a mistura da esquerda foi realizada com Scarlet Lake (PR 188) (tendência tonal amarela) + Winsor Blue (PB 15) (de tendência tonal verde) e resultou num tom um pouco castanho; a obtenção de um violeta puro, similar ao Permanent Mauve (PV 16), só foi possível com a utilização de um vermelho de tendência tonal azul, como o Permanent Rose (PV 19), e um azul de tendência tonal vermelha, como o Ultramarine Blue (PV 19), como se pode observar na mistura da direita. (C)xecução técnica e créditos fotográficos de Ana Bailão. 
Quando se pretende reproduzir um tom intenso, saturado e luminoso, através de uma mistura de dois matizes, é fundamental ter em conta a tendência tonal. O conservador-restaurador irá obter tons mais puros com uma paleta constituída por um ciano, um amarelo e um magenta, e tons menos puros, de baixa saturação e luminosidade, também designados coloquialmente por "tons quebrados", com um azul, amarelo e vermelho.

Posto isto, é importante anotar que existe uma diferença significativa entre a teoria e a prática da cor, pois os matizes disponibilizados no mercado como cores primárias variam em função do fabricante e do aglutinante utilizado. Embora o ciano, o amarelo e o magenta sejam de facto as três cores primárias, os tons disponíveis afastam-se em vários aspectos importantes das características definidas e consideradas como ideais na teoria da cor para a mistura subtractiva:

a) Cada conjunto de três cores-pigmento pode obter apenas uma gama limitada de tons; matizes adicionais são normalmente necessários para obter tons fora desta gama. Ao contrário do que acontece com o sistema CMYK (cyan, magenta, yellow e black) utilizado pelas impressoras, onde ciano, amarelo e magenta podem gerar hipoteticamente todas as cores RGB, os pigmentos considerados ideais de ciano, amarelo e magenta simplesmente não existem (Briggs 2012).

b) Os pigmentos actualmente disponibilizados no mercado como cores primárias não se aproximam do tom do ciano e do magenta. Os pigmentos amarelos estão disponíveis numa gama de cores diversa, mas o mesmo não acontece com as outras duas primárias. Por exemplo, o tom aproximado do magenta ideal é o Quinacridona Magenta (PV 19), porém este tom, é nitidamente mais vermelho do que o magenta ideal da teoria da cor. Da mesma forma, o tom próximo do ciano ideal é o pigmento azul de ftalocianina green shade (PB 15:3), que é muito mais azul do que o ciano ideal (Briggs 2012, Edwards 2006: 22, 23).

\section{O sistema das seis cores: dois amarelos, dois vermelhos e dois azuis}

Pelo facto das três cores primárias - ciano, amarelo e magenta - reproduzirem uma limitada gama de matizes, há um sistema alternativo, o sistema das seis cores, que se baseia nas três cores primárias, todavia com diferentes tendências tonais (duas para cada primária) com o objetivo de obter uma gama cromática mais alargada. Esta paleta de seis tons varia em função do produtor de tintas mas pode ser uma opção para quem quer fazer reintegração cromática com uma paleta restrita. O sugerido é sempre um vermelho com uma tendência tonal amarela (yellow shade), um vermelho blue shade, um azul green shade, um azul red shade, um amarelo red shade e um amarelo green shade. Por exemplo, pelo facto de se ter dois vermelhos é mais fácil garantir violetas e laranjas mais puros.

Além de multiplicar o número de tons, a diferença entre este sistema e o das três primárias está também nas variáveis em jogo, tais como a opacidade, o poder de tingimento, a granulometria, consoante o tipo de tom utilizado. As seis cores recomendadas pela Winsor \& Newton Artists' Watercolour (Winsor \& Newton 2005: 6) são: Winsor Lemon (PY 175), Winsor Yellow (PY 154), French Ultramarine (PB 29), Winsor Blue (Green Shade) (PB 15), Permanent Rose (PV 19) e Scarlet Lake (PR 188) (Fig. 15). 


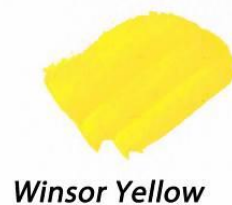
(PY 154)

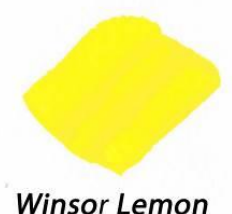

(PY 175)

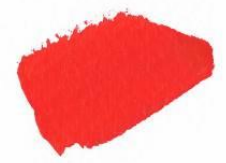

Scarlet Lake (PR 188)

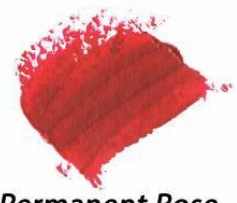

Permanent Rose (PV 19)

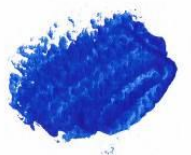

French Ultramarine

(PB 29)

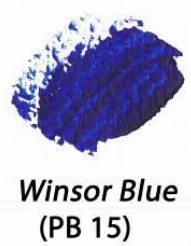

Figura 15: Os seis matizes recomendados pela W\&N Artists' Watercolour. CPreparação de tintas e créditos fotográficos de Ana Bailão.

Como referido, cada fabricante tem os seus matizes, e estes podem variar em função do tipo de tinta/aglutinante (aguarela, guache, acrílicos, óleos, entre outros) e também se forem de qualidade de artista (por exemplo, Artists' Watercolour) ou de estudante (por exemplo, Cotman Watercolour). Se a W\&N recomenda as seis aguarelas de qualidade de artista supracitadas, a Schmincke Horadam ${ }^{\circledR}$ Aquarell sugere Lemon Yellow (PY 3), Cadmium Yellow light (PY 35), Cadmium Red Light (PR 108), Permanent Carmine (PR 83:1), Ultramarine Finest (PB 29) e Prussian blue (PB 27) (Schmincke 2010: 14). O único pigmento em comum é o azul ultramarino (PB 29).

Partindo dos matizes aconselhados é fundamental ter em consideração as propriedades de cada um deles, sendo estas indicadas na tabela seguinte (Tab.1):

Tabela 1: Propriedades dos seis matizes recomendados pela Artists' Watercolour da W\&N (Winsor \& Newton 2005: 12).

\begin{tabular}{|c|c|c|c|c|c|c|}
\hline Nome comum & Série & $\begin{array}{c}\text { C.I. } \\
\text { Name }\end{array}$ & Descrição química & ASTM & $\begin{array}{l}\text { Transparência. } \\
\text { /Opacidade }\end{array}$ & $\begin{array}{c}\text { Poder } \\
\text { tingimento }\end{array}$ \\
\hline Winsor Yellow & 1 & PY 154 & Benzimidazolona & I & Semi-transparente & Baixo \\
\hline Winsor Lemon & 1 & PY 175 & Benzimidazolona & II & Semi-transparente & Baixo \\
\hline $\begin{array}{c}\text { French } \\
\text { Ultramarine }\end{array}$ & 2 & PB 29 & $\begin{array}{l}\text { Aluminossilicato de } \\
\text { sódio e cálcio com } \\
\text { enxofre }\end{array}$ & I & Transparente & Baixo \\
\hline $\begin{array}{l}\text { Winsor Blue } \\
\text { (Green Shade) }\end{array}$ & 1 & PB 15 & Ftalocianina de cobre & II & Transparente & Elevado \\
\hline Permanent Rose & 3 & PV 19 & Quinacridona & I & Transparente & Elevado \\
\hline Scarlet Lake & 2 & PR 188 & Arilamida BON & II & Semi-transparente & Moderado \\
\hline
\end{tabular}


Na primeira coluna tem-se a indicação da Série. Esta está directamente associada ao preço relativo da tinta e é determinada, principalmente, pelo custo do pigmento. A Série 1 é mais económica que a Série 4.

Cada pigmento pode ser universalmente identificado pelo Nome de Índice de Cor [Colour Index Nome (C.I.Name)]. Assim, como se pode observar na segunda coluna, o Winsor Lemon é designando por Pigment Yellow 154, que abreviado fica PY 154.

Na terceira coluna está a descrição química dos pigmentos presentes na tinta e na quarta coluna a estabilidade da cor à luz segundo a norma definida pela American Society for Testing and Materials (ASTM). Na coluna seguinte é anotada a transparência ou opacidade das tintas e na última coluna é indicado o poder de tingimento $(\mathrm{T})$ das cores-pigmento.

Como é possível constatar, três dos matizes são transparentes e três são semi-transparentes. Este dado é muito importante pois impossibilita a reprodução de tons opacos. No caso de ser essencial produzirem-se tons opacos pode-se optar pela versão deste sistema de seis matizes em guache. Os guaches recomendados pela W\&N são: Lemon Yellow (PY 3); Permanent Yellow Deep (PY 65); Phthalo Blue (PG 7 + PB 15); Ultramarine (PB 29); Flame Red (PR 170+PO 72) e Alizarin Crimson (PR 83). Todavia, ao contrário do que acontece com as aguarelas, nestes guaches há mais mistura de pigmentos no mesmo tubo, o que tem, normalmente, implicações na estabilidade das tintas. Existem marcas alternativas, de elevada qualidade, que optam por ter em maioria aguarelas/guaches constituídas por um só pigmento, como são os casos das marcas M.Graham e Schmincke.

Continuando com as aguarelas, a informação referente à estabilidade à luz indica que se tem três tons com uma excelente estabilidade (Winsor Yellow, French Ultramarine, e Permanent Rose) e três com uma estabilidade muito boa (Winsor Lemon, Winsor Blue (Green Shade) e Scarlet Lake).

Esta paleta de seis cores tem dois matizes com elevado poder de tingimento, Winsor Blue $e$ Permanent Rose. Por outras palavras o Winsor Blue (Green Shade) terá um efeito dominante em qualquer mistura, enquanto o French Ultramarine não terá um efeito significativo. Para controlar o poder colorante destas cores-pigmento é necessário adicionar apenas pequenas quantidades de tinta à mistura, repetidas vezes, até que o matiz desejado seja alcançado.

Para misturar os matizes na paleta é importante definir algumas regras:

a) quando se mistura mais de três tons, a mescla deverá ser faseada, isto é, fazer uma mistura A com dois tons e depois outra mistura $B$ com mais dois tons. O matiz pretendido deverá ser a resultado da Mistura A + Mistura B e não a mistura simultânea das quatro corespigmento para evitar uma perda substancial de saturação (Fig. 16). A mistura de diferentes pigmentos resulta numa neutralização cromática entre eles (de la Roja de la Roja 2001; 97) por ocorrer mais absorção de luz. A mistura bipartida permite ajustar os matizes individualmente com maior perceção dos atributos da cor de cada tom, aferindo as proporções sem interferir com a pureza das cores-pigmento.

b) a representação tridimensional dos matizes num circulo cromático facilita a identificação da saturação, das tendências tonais e das cores-pigmento complementares. 

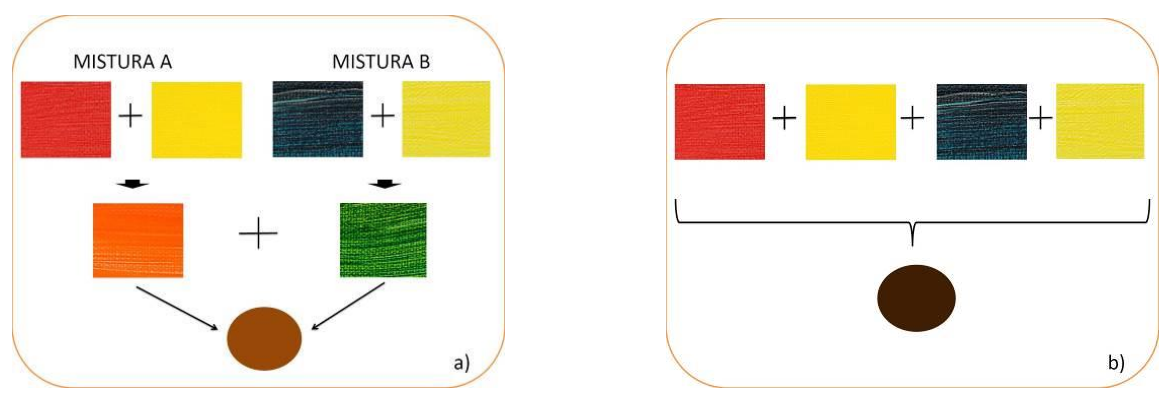

Figura 16: Mistura de tintas: a) Modo mais correcto para efectuar a mistura de quatro matizes; b) modo menos correcto, uma vez que leva a perda de saturação. OEsquema gráfico de Ana Bailão.

Actualmente existem disponíveis na internet diversos círculos cromáticos com a representação colorimétrica de aguarelas, guaches, tintas acrílicas, entre outros. A maioria é produzida por artistas plásticos, como o de Bruce MacEvoy, o de Stephen Quiller e o de Jim Kosvanec, ou pelos fabricantes como o caso da Schmincke. Esta marca de tintas disponibiliza no catálogo das aguarelas Horadam Aquarell a disposição colorimétrica das suas cores (Schmincke 2010: 11). No próximo exercício será utilizado o círculo cromático de Bruce MacEvoy, elaborado em 2009 (Fig. 17). Pretende-se demonstrar a importância do conceito das tendências tonais de cor na mistura das seis cores selecionadas.

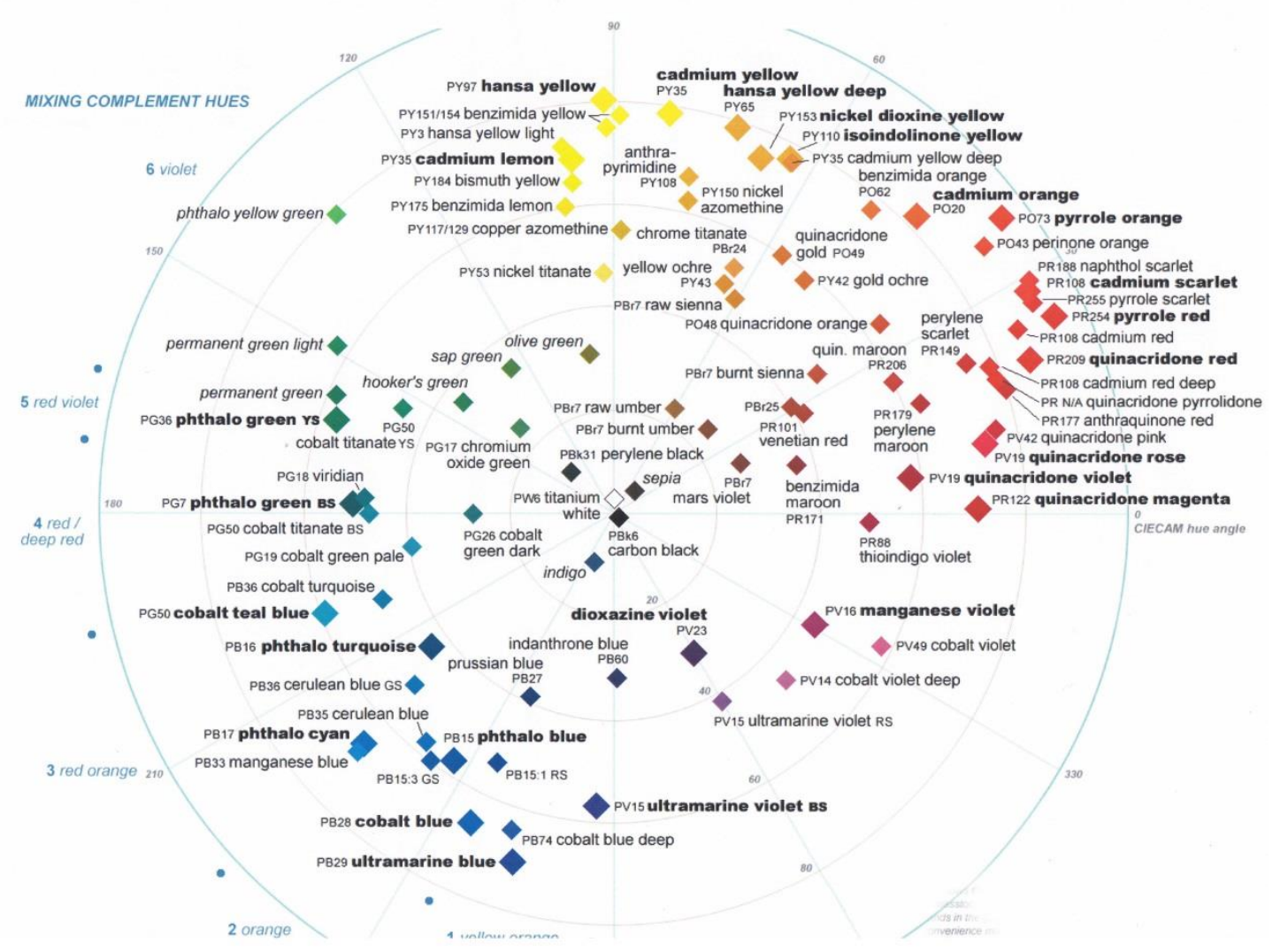

Figura 17: Circulo cromático de Bruce MacEvoy com a representação de aguarelas de várias marcas comerciais, entre as quais a Winsor\&Newton, no modelo CIE 2002 Interim Color Appearance Model (CIECAM02), com observador padrão $10^{\circ}$ e iluminante E. Disponível em http://www.handprint.com/HP/WCL/cwheel06.html. 
Os círculos cromáticos auxiliam no raciocínio acerca da localização dos matizes, da saturação, da tendência tonal e da mistura de tons complementares. Por exemplo, neste caso, os matizes mais saturados localizam-se no exterior do círculo, enquanto os tons mais suaves e neutros (como o branco, preto e cinzento) estão no centro do círculo. À medida que um determinado tom se aproxima do centro, os matizes ficam menos saturados. Todavia, é importante ter em conta que apesar de serem ferramentas de apoio extremamente úteis, tem evidentes margens de erro, uma vez que os pigmentos variam de matiz em função do fabricante e do aglutinante adicionado, e porque não são precisos na determinação do resultado de uma mistura X ou Y. A especificidade das medições também é relevante. Este círculo cromático de Bruce MacEvory será mais útil para uma paleta de aguarelas do que para uma paleta de acrílicos, pelo facto de ter sido executado através da medição colorimétrica de aguarelas.

Para que se perceba a utilidade de um círculo cromático desta tipologia será apresentado de seguida um estudo de caso. Pretende-se reproduzir experimentalmente o tom da terra de sombra queimada da Artist's Watercolour da Winsor\&Newton (W\&N), de tendência amarela, através do uso do sistema das seis cores acima citado.

Para obtenção de um matiz terra de sombra queimada de tendência amarela e de baixa saturação, similar à aguarela da $W \& N$, é necessário que as tintas misturadas sejam complementares (vermelho e verde), mas que tenham tendências tonais similares. Uma vez que o objectivo é produzir a cor tradicional castanha, será utilizado um vermelho com tendência amarela e um verde com tendência amarela para que se mantenha a tendência e não se perca luminosidade.

Na figura 18 estão representadas as tendências tonais das seis cores para comparação. Como podemos constatar, o Permanent Rose (PV 19) tem uma tendência azul quando comparado com o Scarlet Lake (PR 188) que tem uma tendência amarela. Assim, para reproduzir uma sombra queimada com tendência amarela, na eleição do vermelho mais adequado deverá recorrer-se ao Scarlet Lake (PR 188). Na figura 19 estão indicados os matizes obtidos através da mistura das seis cores.
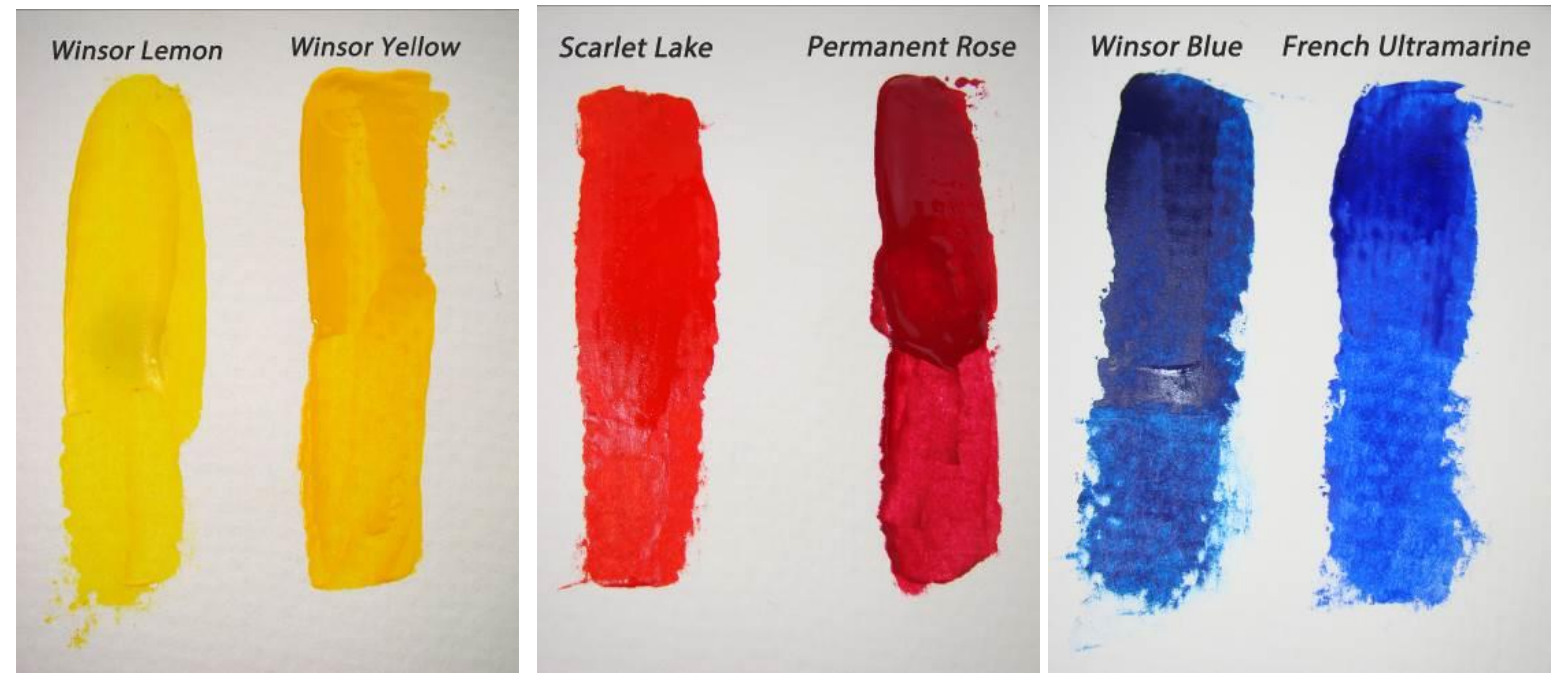

Figura 18: Representação dos seis matizes lado a lado para comparação das tendências tonais. CExecução técnica de Ana Bailão. 


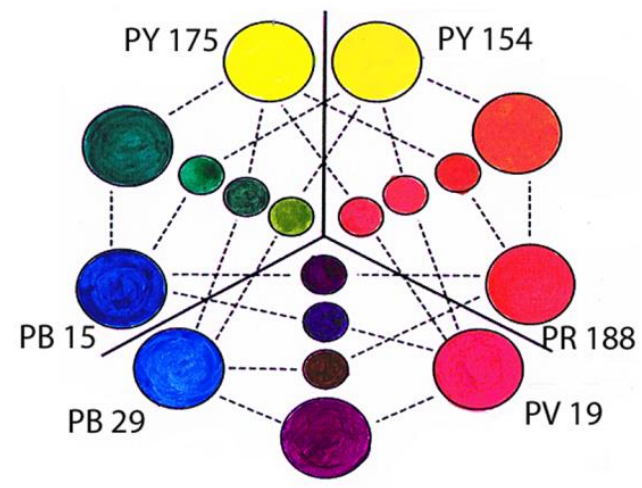

Figura 19: Representação dos matizes obtidos através da mistura de tendências tonais. É importante ter em consideração a alteração de cor proporcionada pela digitalização. O esquema foi adaptado do sítio Foutain Studio Learning to Mix Colors, disponível em http://fountainstudio.com/watercolor\%20tips/tip-mixing_colors.html.

É ainda importante considerar que o Scarlet Lake (PR 188) possa ser demasiado vermelho para o objectivo. Talvez seja necessário adicionar um amarelo para intensificar a tendência amarela de PR 188 e ganhar luminosidade. O amarelo mais adequado é o PY 154, uma vez que o PY 175 tem uma tendência complementar ao vermelho, isto é, verde, favorecendo a obtenção de tons pouco saturados e luminosos. No que diz respeito à escolha do verde, convém ter também uma tendência amarela. As aguarelas mais adequadas são o azul PB 15 e o amarelo PY 175.

Na figura 20 pode-se observar a localização espacial das sete cores: os dois amarelos, os dois vermelhos, os dois azuis e a sombra queimada. Importa referir que a localização geométrica das cores encontra-se redistribuída por 12 secções, através das quais se pode caracterizar o matiz e as tendências tonais. O nível de saturação é determinado em função da distância entre o centro e a periferia do círculo.

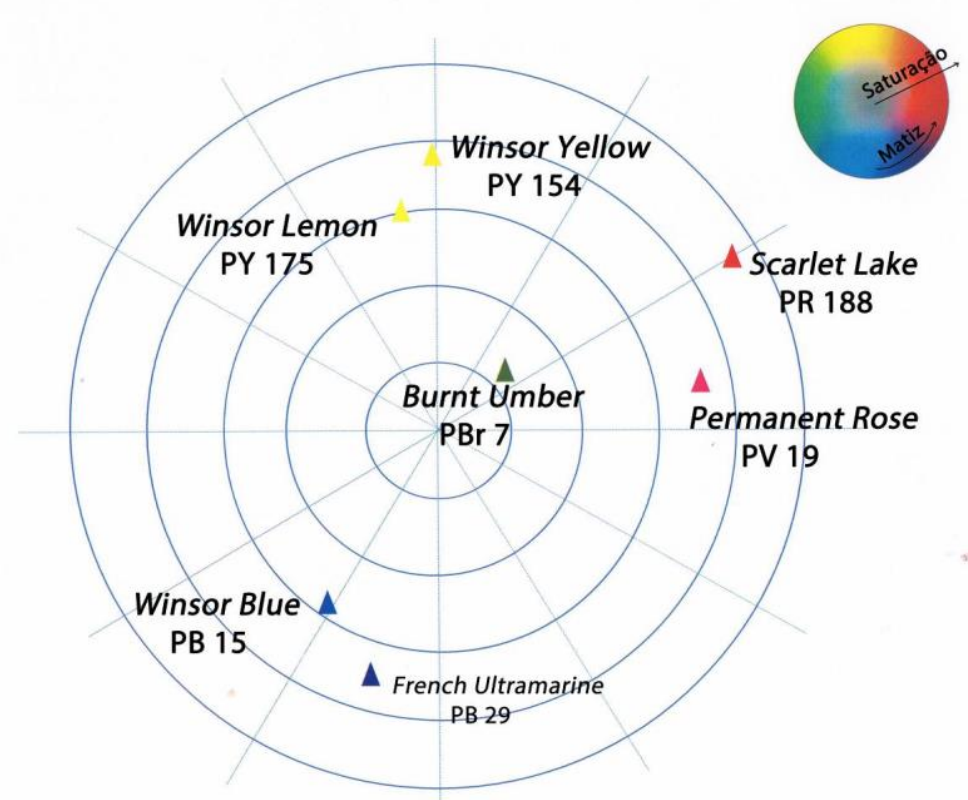

Figura 20: Localização geométrica das sete cores no círculo cromático. A leitura do matiz e das tendências tonais é feito em torno do círculo, enquanto a identificação dos níveis de saturação é feita do centro para a periferia do círculo. @Esquema adaptado por Ana Bailão. 
Fazendo uma análise dos matizes e das tendências tonais do círculo cromático da figura 20, constata-se que entre os vermelhos e os amarelos geometricamente mais próximos de Burnt Umber (PBr 7) são o Scarlet Lake (PR 188) e o Winsor Yellow (PY 154). O PR 188 é uma aguarela bastante vermelha e com tendência amarela, uma vez que está localizada no limite da secção dos vermelhos do círculo cromático. O mesmo acontece com o PY 154 que é um amarelo com uma tendência vermelha. $O$ resultado desta mescla, à qual se atribui o nome de Mistura $A$, resultará num vermelho alaranjado.

Em relação ao verde complementar necessário para reproduzir Burnt Umber é aconselhável que seja obtido através da mistura de um azul e de um amarelo de tendências amarelas (não vermelhas). O produto final da Mistura A [vermelho alaranjado] com um verde avermelhado seria um castanho muito avermelhado, distanciando-se do matiz que se pretende reproduzir. O French Ultramarine (PB 29) é assim excluído da mistura. O azul mais adequado será portanto o Winsor Blue (PB 15) de tendência amarela, ao qual será adicionado o Winsor Lemon (PY 175), devido à proximidade geométrica com o azul mencionado.

A mescla das tintas foi realizada com uma espátula por ser prático no doseamento e manipulação das tintas. A mistura das aguarelas na paleta foi executada em três fases para evitar a perda de saturação:

1a Fase: Mistura A: Scarlet Lake (PR 188) + Winsor Yellow (PY 154) (Fig. 21)

2a Fase: Mistura B: Winsor Lemon (PY 175) + Winsor Blue (PB 15) (Fig. 22)

3a Fase: Mistura A + Mistura B $=\mathrm{PBr} 7$ (Fig. 23)

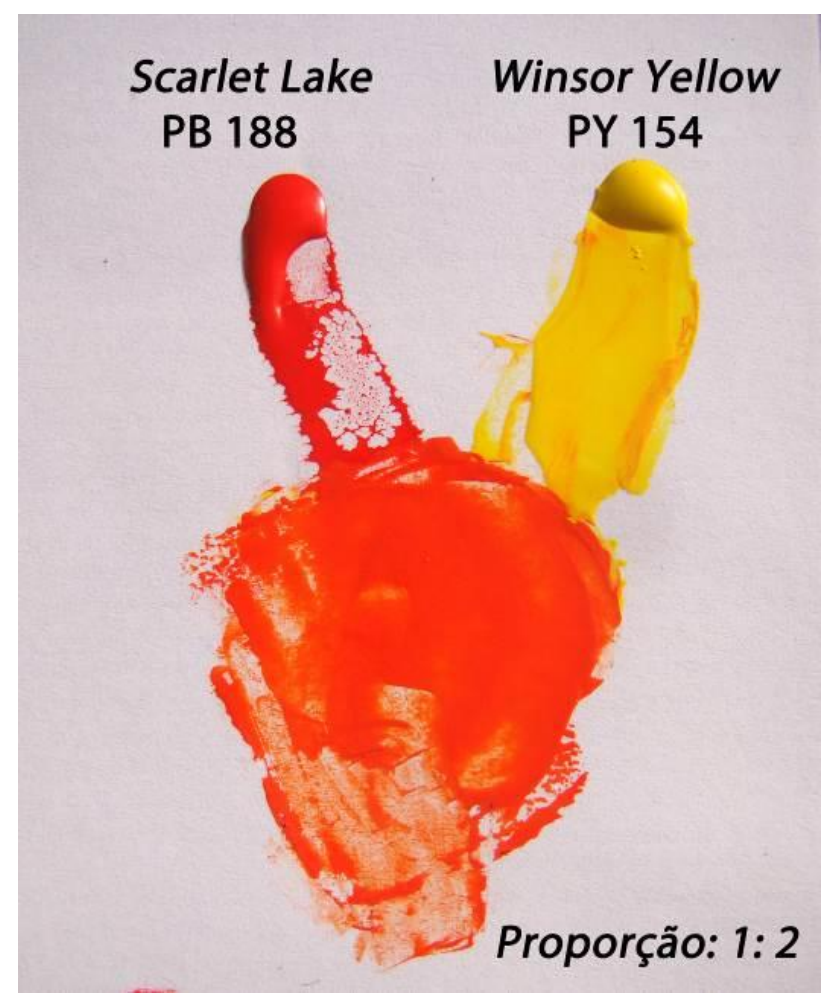

Figura 21: Mistura na paleta das aguarelas Scarlet Lake (PR 188) e Winsor Yellow (PY 154) na proporção 1:2. @Execução técnica e gráfica de Ana Bailão. 
A Mistura A resultou, inicialmente, da adição de partes iguais de Scarlet Lake (PR 188) e Winsor Yellow (PY 154). Todavia, o poder de tingimento de PR 188 é superior ao de PY 154, motivo pelo qual se adicionou mais uma parte de PY 154 para que o matiz obtido tivesse uma tendência tonal amarela (Fig. 21).

A semelhança da Mistura $A$, também na Mistura $B$ houve necessidade de adicionar mais quantidade de Winsor Lemon (PY 175) e menos de Winsor Blue (PB 15) devido ao elevado poder de tingimento deste último. Foram adicionadas 3 partes de PY 175 a uma de PB 15 (Fig.22).

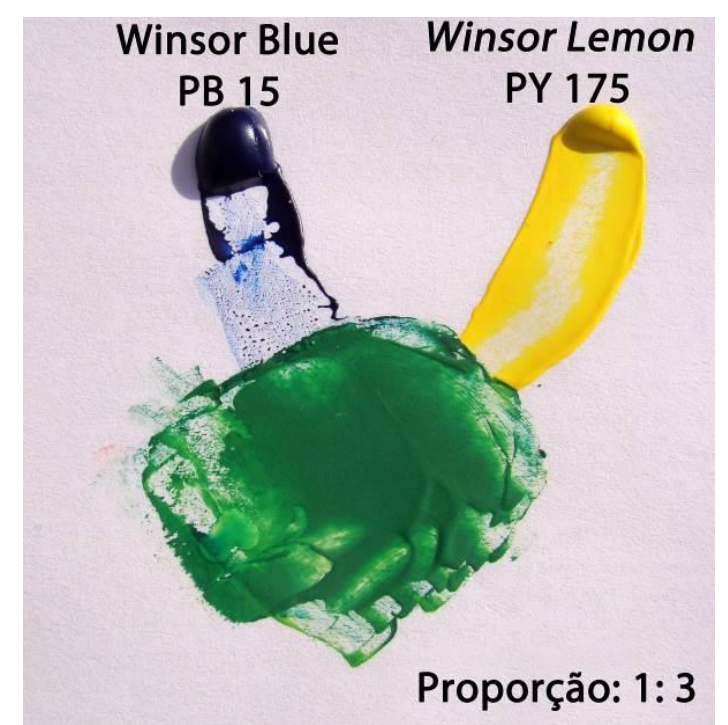

Figura 22: Mistura na paleta das aguarelas Winsor Blue (PB 15) e Winsor Lemon (PY 175) na proporção 1:3. ๑Execução técnica e gráfica de Ana Bailão.

O tom próximo da sombra queimada da W\&N foi obtido com a mescla dos resultados da Mistura $A$ + Mistura B, com maior proporção da Mistura A (2:1) (Fig. 23).

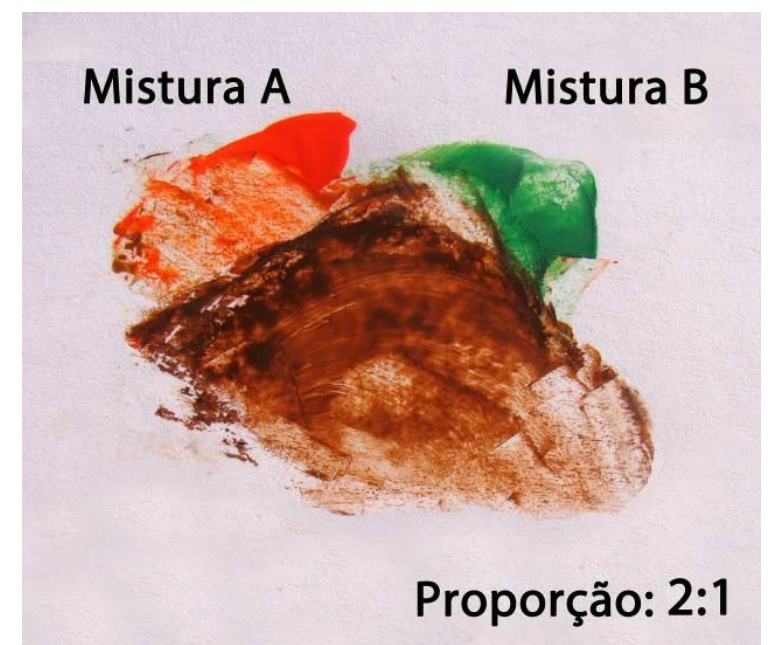

Figura 23: Mistura na paleta das aguarelas resultantes da Mistura A e B. OExecução técnica e gráfica de Ana Bailão. 
Como se pode observar na figura 24 há uma ligeira diferença entre o tom original da aguarela da W\&N e o reproduzido: o primeiro parece um pouco mais amarelo, mais saturado e mais luminoso do que o segundo.

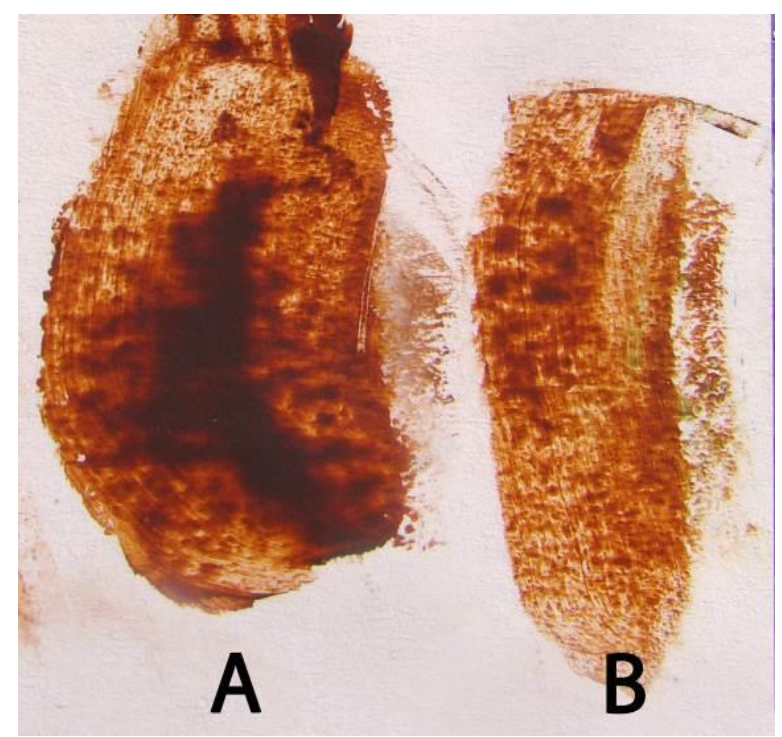

Figura 24: Comparação entre a aguarela Burnt Umber ( $\mathrm{PBr} 7$ ) (imagem $A$ ) e o resultado da Mistura $A+$ Mistura $B$ (imagem $B$ ). Embora a diferença seja ligeira, o matiz da esquerda é um pouco mais saturado e luminoso do que o da direita. @Execução técnica e gráfica de Ana Bailão.

Embora se pudesse aferir o tom final resultante das Misturas A + B com a adição de amarelo PY 154, o matiz obtido teria sempre uma luminosidade inferior ao pigmento $\mathrm{PBr} 7$ puro. Isto significa que, na prática, o matiz resultante da mistura das duas tintas pode parecer um pouco menos saturado e luminoso quando empregue sobre uma camada de tinta que não seja também ela pura. Importa referir que este fenómeno ocorrerá na reprodução de outros matizes.

Na pintura portuguesa, sobretudo na do século XVI, a sombra queimada é muito usada como camada final para a reintegração de lacunas localizadas no chão e nas montanhas. É essencial que tenha o máximo de luminosidade e saturação para que a reintegração realizada se aproxime da camada original. Além disso, as terras naturais e puras são essenciais devido ao seu baixo poder de tingimento. Sugere-se por isso a adição da sombra queimada $(\mathrm{PBr} 7)$ pura à paleta das seis cores já mencionadas ao longo do texto: Winsor Lemon (PY 175), Winsor Yellow (PY 154), Scarlet Lake (PR 188), Permanent Rose (PV 19), Winsor Blue (PB 15) e French Ultramarine (PB 29).

Para além do $\mathrm{PBr} 7$, tons como o negro e o branco, são importantes, sobretudo para uma reintegração mimética. A introdução do negro deve-se ao facto de não se conseguir obter um negro puro através da mistura de três tons, independentemente da tendência tonal dos matizes, e porque é necessário para ajuste na luminosidade e saturação. Quanto ao branco, também é útil para situações de ajustes da luz e de saturação, e para aumentar a opacidade de certos tons. Em relação ao negro, sugere-se o negro de marfim (PBk 9), por ter um tom castanho e um baixo poder de tingimento, e ser mais adequado, por exemplo, para matizar ligeiramente cores de vegetações e panejamentos. Em alternativa, sugere-se também o negro de marte (PBk 11) por ser mais opaco, podendo ser útil para reproduzir áreas onde o negro seja a cor dominante. Para o branco recomenda-se o branco de titânio (PW6) porque permite obter opacidade e poder de cobertura. 


\section{Conclusão}

O sistema dos dois amarelos, dois vermelhos e dois azuis aqui apresentado poderá ser uma alternativa para o conservador-restaurador que utiliza o sistema das três cores primárias ou para um iniciante na realização da reintegração cromática.

O estudo de caso exposto tenta exemplificar o modo como se podem manipular as cores atendendo às sua tendências tonais e recorrendo a um círculo cromático constituído a partir de medições colorimétricas de um conjunto de aguarelas. Este método pode ajudar o conservadorrestaurador a conhecer a priori as cores-pigmento mais indicadas para a reintegração cromática de uma determinada lacuna.

Este processo parece complexo quando os atributos da cor e todo o léxico inerente à teoria da cor não estão interiorizados. As tendências tonais das cores-pigmento são indicadas neste estudo como uma pista importante para reduzir o ensaio e as inúmeras tentativas durante a reprodução de um dado matiz. Esta metodologia pode ser aplicada com aguarelas, com guaches, com pigmento e verniz, entre outros. Para que isso aconteça é necessário que o conservadorrestaurador conheça bem as características individuais das cores-pigmento que utiliza.

A paleta das 9 cores-pigmento aqui sugerida implica a mistura de vários pigmentos para a obtenção de determinado tom, o que a longo prazo pode influenciar a estabilidade das corespigmento, bem como resultar na perda de saturação de cor. Assim, como contributo ao assunto exposto nesta pesquisa, propôs-se a inclusão de alguns pigmentos com o objetivo de serem utilizados puros sempre que possível. São eles: a sombra queimada $(\mathrm{PBr} 7)$, o negro de marfim (PBk 9) ou o negro de marte (PBk 11) e o branco de titânio (PW 6). À exceção do negro de marfim que é semi-transparente, os outros são opacos.

A utilização de uma paleta muito restrita dificulta a reprodução de tons de uma dada pintura, uma vez que existem matizes não reproduzíveis através de determinada gama de cores-pigmento. Convém ter pelo menos dois tons amarelos, dois vermelhos, dois azuis, de forte saturação e luminosidade, o branco e o preto, como cores neutras, e cores de valores mais suaves como as terras, muito úteis na reintegração cromática de pintura antiga.

\section{Agradecimentos}

Este estudo teve o apoio da Fundação para a Ciência e a Tecnologia (FCT) e QREN - POPH, cofinanciado pelo Governo Português e União Europeia através do MCTES. Esta investigação foi financiada pela bolsa se estudo da FCT SFRH/BD/69783/2010. Agradeço as indicações das minhas orientadoras Ana Calvo e Rocío Bruquetas, a ajuda terminológica de Arlindo Silva, as considerações técnicas de Frederico Henriques e as revisões de Lino Bailão.

\section{Notas}

[1] Em física, o comprimento de onda é a distância entre valores repetidos num padrão de onda. É usualmente representado pela letra grega lambda $(\lambda)$. Numa onda senoidal, o comprimento de onda é a distância entre picos (ou máximos) (González Cuasante et al. 2005: 26; Tornquist 2008: 29, 30).

[2] Os corpos físicos podem dividir-se em luminosos e não luminosos. Os corpos luminosos são aqueles que emitem a sua própria luz que os faz visíveis, enquanto os corpos não luminosos só são visíveis 
reflectindo ou devolvendo a luz que recebem de uma fonte luminosa. Este trabalho refere-se a estes últimos.

[3] A lista pode ser consultada no site do fabricante: http://www.winsornewton.com/products/watercolours/artists-water-colour/spectrum-lists/ ou no catálogo disponível em http://www.winsornewton.com/ assets/Leaflets/awcenglish.pdf. As temperaturas de cor dos pigmentos estão também disponibilizadas pela Gamblin Colors aqui: http://www.gamblincolors.com/navigating.color.space/color.temperature.color.html.

[4] $O$ índice de refracção $(\eta)$ é uma relação entre a velocidade da luz num determinado meio e a velocidade da luz no vácuo (c), equivalente a 1 . Em meios com índices de refracção mais baixos (próximos a 1) a velocidade da luz é maior (Gómez 2000: 191; Matteini e Moles 2001: 50; Gettens e Stout 1966: 147, 148a, 148b, 148c, 148d)

\section{Referências}

ALBERS, J. (2007). La interacción del color. Madrid: Alianza Editorial.

BALL, P. (2001). Bright Earth, Art and the invention of color. Chicago: University of Chicago Press.

DE LA ROJA DE LA ROJA, J. M. (2001). "Una nueva metodología en la ejecución del proceso de reintegración cromática". Pátina, n. 10 e 11: 96-101.

EDWARDS, B. (2006). El color. Un método para dominar el arte de combinar los colores. Barcelona: Ediciones Urano.

BRIGGS, D. (2012). The Dimension of colour. http://www.huevaluechroma.com/061.php. [Consulta: 15. 05. $\left.201^{3}\right]$.

CIE (1987). International Lighting Vocabulary. Vienna: CIE Publ. No. 17.4.

FAIRCHILD, M. D. (2005). Color Appearance Models. Second Edition. Chichester, UK: John Wiley \& Sons, Ltd.

FOUTAIN STUDIO. Learning to Mix Colors. http://fountainstudio.com/ watercolor\%20tips/tipmixing_colors.html. [Consulta: 17. 05. 2013].

GETTENS, R. J.; STOUT, G. L. (1966). Painting Materials. A short encyclopedia. New York: Dover Publications

GONZÁLEZ, J. M.; CUEVAS, M. del M.; FERNÁNDEZ, B. (2005). Introducción al color. Madrid: Akal Bellas Artes.

GOTTSEGEN, M. D. (2006). The Painter Handbook. Nova lorque: Watson-Guptill Publications.

GÓMEZ, M. L. (2000). La Restauración. Examen científico aplicado a la conservación de obras de arte. 2.a ed. Madrid: Catedra Cuadernos Arte/Instituto Del Patrimonio Histórico Español.

HECHT, E. (2002) - Óptica. 2. a ed. Lisboa: Fundação Calouste Gulbenkian.

HICKETHIER, A. (1969). Le Cube des Coulers. Paris: Dessain et Tolra.

KUPPERS, H. (1975). La couleur. Origine, methodologie, application. Fibourg: Office du Livre.

LOUÇÃO, M. D. (1992). Cor: natureza, ordem, percepção. Dissertação para Doutoramento em Arquitectura pela Faculdade de Arquitectura da Universidade Técnica de Lisboa.

MARTEL, C. (1855). Principles of colouring in Painting. Londres: Winsor and Newton.

MAYER, R. (2006). Manual do Artista de Técnicas e Materiais. São Paulo: Livraria Martins Fontes Editora.

MATTEINI, M.; MOLES, A. (2001). Ciencia y restauración. Andalucía: Nerea.

PYLE, D.; PEARCE, E. (2009). The Oil Colour Book. A comprehensive resource for painters. Harrow, Inglaterra:

ColArt Fine Art \& Graphics Ltd, p. 17. http://www.winsornewton.com. [Consulta: 19. 05. 2013]. 
SAUNDERS, D. (2000). Retouching: colour vision and optical considerations. In Conference 2000; Retouching Filling. Oxford: Association of British Picture Restorers, pp. 3-9.

SCHMINCKE. (2010). HORADAM AQUARELL Finest artists' water-colours - Series 14. http://www.tempera.fi/Horadam.pdf. [Consulta: 19. 11. 2013].

TORNQUIST, J. (2008). Color y Luz. Teoría y práctica. Barcelona: Editorial Gustavo Gili.

TRUAN LAKA, M. (2013). Introducción a la Pintura a través del color. País Vasco: Universidad del País Vasco.

URLAND, A. (1999). Colour Specification and measurement. Conservation of Architectural Heritage, Historic Structures and Materials. ARC Laboratory Handbook. Rome: ICCROM UNESCO WHC, Vol.5.

WINSOR \& NEWTON. (2005). Artists' Water Colour. Perfecting the Fine Art of Water Colours. http://www.winsornewton.com/assets/Leaflets/awcenglish.pdf. [Consulta: 19. 11. 2013].

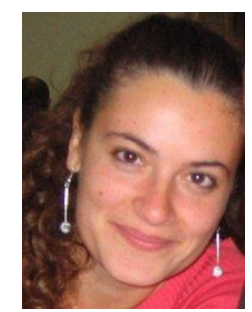

\section{Ana Bailão}

Universidade Católica Portuguesa (UCP)

ana.bailao@gmail.com

Ana Bailão é licenciada (pré-bolonha) em Conservação e Restauro pelo Instituto Politécnico de Tomar (2005) e mestre pela Universidade Católica Portuguesa (2010). O tema de investigação foi sobre as metodologías e as técnicas de reintegração cromática em pintura de cavalete. Atualmente, é doutoranda na mesma instituição, em colaboração com o Centro de Investigação em Ciência e Tecnologia das Artes (CITAR) e o Instituto del Patrimonio Cultural de España (IPCE). O seu tema de doutoramente é sobre os criterios de intervenção e estratégias para a avaliação da qualidade em reintegração cromática de pintura de cavalete.

Artículo enviado el 17/06/2013

Artículo aceptado el 23/11/2013 


\title{
La conservación del patrimonio etnográfico a través de la musealización
}

\author{
Blanca Flor Herrero Morán
}

\begin{abstract}
Resumen: La conservación del patrimonio etnográfico está muy ligada al proceso de musealización que se está llevando a cabo a nivel mundial desde hace varias décadas. El patrimonio etnográfico, antes calificado viejo y considerado como algo inútil, ahora es denominado antiguo, se conserva, colecciona y revaloriza pasando a ser un bien museable. El patrimonio etnográfico es la mejor y más perfecta conjunción entre patrimonio tangible e intangible, y por ello el interés de los museos etnográficos no debe residir sólo en conservar, coleccionar, exhibir y proyectar el objeto (con un carácter únicamente materialista) sino también el no objeto (piezas inmateriales e ideas que contextualizan los bienes) y los sujetos (aludiendo a la comunidad). A su vez, los museos deben custodiar el patrimonio etnográfico teniendo en cuenta las condiciones medioambientales para su óptima conservación.
\end{abstract}

Palabras clave: conservación, patrimonio etnográfico, musealización, museo etnográfico.

\section{Conservação do património etnográfico através de musealização}

Resumo: A conservação do património etnográfico está intimamente ligada ao processo de musealização que se tem vindo a levar a cabo a nível mundial, desde há várias décadas. O património etnográfico, antes qualificado como velho e considerado como algo inútil, é agora denominado de antigo, sendo conservado, coleccionado e revalorizado e passou a ser um bem museológico. O património etnográfico é a melhor e a mais perfeita combinação de património tangível e intangível e, portanto, o interesse dos museus etnográficos não deve residir apenas em conservar, coleccionar, exibir e projetar o objeto (com um carácter, únicamente materialista), mas também o não-objeto (partes imateriais e ideias que contextualizam os bens) e os sujeitos (aludindo à comunidade). Por sua vez, os museus devem guardar o património etnográfico, considerando as condições ambientais para a sua preservação ideal.

Palavras-chave: conservação, património etnográfico, museológico, museu etnográfico.

\section{Ethnographic heritage conservation through musealization}

\begin{abstract}
The conservation of ethnographic heritage is closely linked to the musealization process that is taking place in the world for several decades. The ethnographic heritage, before qualified as old and considered as useless, currently it is called ancient, it is preserved, collected and revalued to become a museum piece. The ethnographic heritage is the best and the most perfect conjunction between tangible and intangible heritage and thus the interest of ethnographic museums must not reside only in the preservation, collection, exhibition and projection of the object (its materialistic character, merely) but also on the non-object (immaterial parts and ideas that contextualize the assets) and the subjects (referring to the community). At the same time, museums must guard the ethnographic heritage taking into account the environmental conditions for its optimal conservation.
\end{abstract}

Key words: conservation, ethnographic heritage, museology, ethnographic museum.

La historia del arte nos muestra, con innumerables ejemplos, el poco aprecio que en determinados momentos se ha tenido por las obras de culturas anteriores que no se han querido y/o podido conservar. Tras la revolución industrial se impone la democratización del acceso a la cultura y se aumenta la conciencia y la conservación patrimonial. Ahora bien, llama la atención que, en ese 
momento, el patrimonio industrial y el patrimonio etnográfico fueran relegados prácticamente al olvido y su conservación quedara en un segundo plano.

La conservación del patrimonio etnográfico está relacionada con el coleccionismo y la musealización. El coleccionismo es un proceso que genera corrientes afectivas hacia las piezas que se adquieren y se basa en los valores que los bienes coleccionados poseen o se les atribuyen. Luego estos valores son heredados por los museos quienes hacen una actualización y revalorización de los mismos. Cuando se colecciona y musealiza el patrimonio etnográfico material e inmaterial se le da una serie de valores sobreañadidos que modifica los valores originales de los bienes gracias a las diferentes funciones y a la conjunción del objeto-no objeto-sujeto que se llevan a cabo dentro de los museos.

\section{Proceso de conservación del patrimonio etnográfico}

En un primer momento la gente poseedora de patrimonio etnográfico mostró recelo y rechazo hacia el progreso y los avances producidos por la industrialización y decidieron conservarlo pero, poco después, se entregaron totalmente al progreso. Es más, apoyados en la idea de un cambio de vida de mayor nivel económico, comenzaron a reformar y cambiar la vivienda y los enseres tradicionales y a desembarazarse de baratijas precarias, anticuadas e innecesarias que les estorbaban y ocupaban espacio. Este cambio de mentalidad favoreció el expolio de piezas etnográficas en el medio rural, un proceso gradual en el que cada vez participaron más personas y más piezas.

Durante un largo periodo hubo una fase de desprecio y reproche hacia los denominados "objetos etnográficos". La máquina (debido a la industrialización) había desplazado a la persona (el artesano). Las piezas dejaban de hacerse a mano y los productos fabricados en la cinta transportadora influían decisivamente en el gusto. La variación continua de los enseres modernos, posibilitada por la proliferación de materiales, formas, decoraciones y técnicas que, unidos a la producción seriada, aceleran el proceso de envejecimiento de los objetos demandados por la sociedad, o impuestos a ella por la publicidad y la técnica industrial, es la esencia de la pérdida de valor de los bienes etnográficos por parte de sus propietarios que empiezan a intercambiarlos, venderlos y malvenderlos. Ya lo dijo Gombrich: "Debemos advertir que cada adelanto o progreso en una dirección entraña una pérdida en otra" (Gombrich 2003: 9).

A la fase de permuta o cambio de objetos nuevos por objetos usados, le sucedió la de compraventa. Los chamarileros empezaron a recorrer diversos pueblos con el fin de recopilar, mayoritariamente a través de la compra, los objetos usados más atractivos o más bellos para luego venderlos en rastros, mercadillos y, a título personal, a anticuarios, a coleccionistas y a museos. Con esta actitud, durante varias décadas, los chatarreros y algunos anticuarios procedentes de la ciudad, arrasaron con el patrimonio etnográfico con fórmulas a menudo poco ortodoxas y fraudulentas y contribuyeron a la dispersión masiva del mismo a través de mercados regionales, nacionales e internacionales. Las consecuencias de esta práctica expoliadora fueron nefastas para la conservación del patrimonio etnográfico. No obstante, aunque en muchas ocasiones no fueran conscientes de ello, con la compra-venta del patrimonio etnográfico también se favoreció su difusión y conservación ya que probablemente numerosos objetos habrían sido destruidos, sin duda por ignorancia. 
En este mismo momento, de forma paulatina, las piezas etnográficas empiezan a llamar la atención a diferentes personas y personalidades que se sensibilizaron y vieron en ellas un valor no sólo estético (forma, función y decoración) sino también histórico y cultural (documentos del pasado, de la tradición y la identidad). Surge entonces el coleccionista de objetos etnográficos que se interesa por estas piezas, toma un contacto cada vez más estrecho con ellas y se convierte en un especialista en la materia. La labor del coleccionista etnográfico centrado en un primer momento en la compra del mayor número de piezas posible evita y/o palia la dispersión atomizada de las piezas por diferentes países (bien en instituciones museísticas bien en domicilios particulares).

Después, gracias a la revalorización del objeto etnográfico surgida en el medio urbano, al coleccionismo etnográfico y a la difusión de los medios de comunicación, los poseedores de objetos etnográficos se dan cuenta de su valor económico y sentimental y deciden no malvender ni desprenderse de todas las piezas haciendo una selección de las mismas para conservarlas y legarlas a sus descendientes.

En las últimas décadas se ha perdido en torno al $90 \%$ del patrimonio etnográfico, desapareciendo así miles de utensilios, enseres y aperos artesanales enterrados bajo los escombros de las casas, olvidados en los desvanes o vendidos a anticuarios a precios de ganga que luego los comercializan a precio de oro.

La situación no es nueva, ya que desde mediados de los sesenta se ha producido, en el ámbito artístico en general y en el de la etnografía en particular, un intercambio desigual basado en el escaso valor otorgado a las piezas, que prácticamente eran regaladas a los anticuarios e intermediarios, porque estorbaban. Este hecho no es aislado, se ha producido en casi todas las partes del mundo. Incluso, en determinadas zonas africanas sigue ocurriendo. Dicha idea ya fue apuntada por Panofsky hace tres décadas:

"Todos nosotros hemos visto con nuestros propios ojos cómo se trasladaban los fetiches y los utensilios de las tribus africanas desde los museos etnológicos a las exposiciones artísticas" (Panofsky 1985: 29).

Señala Eloísa Wattenberg "el patrimonio etnográfico se ve cada vez más indefenso ante su abandono, el alarmante expolio de que es objeto y la degradación que paulatinamente experimenta en lo que de él se mantiene vivo" "Wattenberg 1995: 519). Este mismo aspecto lo recoge José Luis Alonso Ponga incidiendo en la complejidad que conlleva la conservación y puesta en valor del patrimonio etnográfico pues:

"Era muy frecuente que, en las sociedades en proceso de cambio, los objetos etnográficos desaparezcan del grupo que los ha producido y con ellos los procesos de producción y no pocos testimonios de vida. Sin, embargo, en algunos casos en estos estados liminales, la sociedad toma conciencia del valor simbólico de los mismos, lo que mueve al grupo a su salvaguarda, no tanto por el valor de uso que tengan, como porque quedan como testimonio de la propia sociedad que comienza a desaparecer. Se opera aquí un proceso reduccionista mediante el cual, puesto que no se pueden guardar todos los objetos, se decide cuáles se conservan y cuáles se abandonan definitivamente. Es todo un proceso complejo donde la toma de decisiones es muy importante. En este proceso de resemantización se altera el valor de mercado, ya que el objeto pasa de una fase en la que no se le reconoce ningún valor a otra en la se sobrevalora por la escasez de ejemplares" (Ponga 2002: 157). 
En este sentido, teniendo en cuenta la dificultad de valorar y conservar lo cotidiano, Olaia Fontal afirma:

"En nuestras casas hay numerosos objetos con los que crecemos y a los que estamos habituados porque siempre los hemos visto: utensilios, ropa, muebles, fotografías, documentos... Eso no significa necesariamente que lo valoremos. De hecho, casi todos nosotros nos hemos encontrado en algún cajón un objeto cuya forma tal vez identificamos pero del que no sabemos absolutamente nada, salvo que alguien de nuestra familia, por algún motivo desconocido, lo guarda en ese cajón. (...) Sabemos que los objetos existen porque alguien los construye, pero también porque alguien decide conservarlos" (Fontal 2003: 285).

\section{Proceso de musealización del patrimonio etnográfico}

Puesto que el coleccionismo no tiene límites, todo es coleccionable (desde lo más importante a lo intrascendente), y no existen unas normas genéricas; lo primero que hay que valorar es el hecho de que en numerosos países desarrollados, entre los que se incluyen España y Portugal, a partir del último tercio del siglo XX se empiecen a conservar, recopilar y adquirir piezas etnográficas de forma sistemática tanto por parte de instituciones públicas y privadas como por personas a título individual.

La labor de recogida de piezas etnográficas es admirable no sólo por su carácter insustituible sino también por su carácter irrecuperable de tal modo que si no se hubieran empezado a adquirir estas piezas en el momento preciso, hoy, gran parte del patrimonio etnográfico no habría sobrevivido y por lo tanto no lo habríamos conocido.

De esto se deduce que el coleccionista de patrimonio etnográfico (tanto en su variante material como inmaterial) se convierte en un auténtico configurador de patrimonio, del que se hace responsable desde que lo adquiere como medida de protección y conservación ante el inminente peligro de desaparición de muchas de las piezas adquiridas. El coleccionista toma conciencia patrimonial de una serie de piezas que durante demasiado tiempo han sido desechadas del concepto de patrimonio por su carácter funcional y cotidiano, poniendo en valor piezas que son testimonio y documento de una época y una forma de entender la vida. Esta tarea es bastante compleja pues no se trata de adquirir y reunir una serie de piezas sino de delimitar cuándo se trata de una pieza con valor etnográfico y cuándo es un simple objeto en desuso, dos criterios que no siempre se suelen tener claros. De ahí la dificultad de formar una colección que sea verdaderamente una pionera recopilación museística de patrimonio etnográfico.

Las piezas que se exhiben en los museos etnográficos no son patrimonio exclusivo del museo, pues en muchas casas hay piezas similares (aparatos en desuso, objetos del pasado, recuerdos familiares, enseres y artefactos diversos...). El patrimonio etnográfico no fue creado para ser musealizado $y$, sin embargo, el museo se ha convertido en un buen destino para este tipo de bienes que tienen una entidad socio-cultural. Si nos preguntamos por qué el patrimonio etnográfico es merecedor de estar en un museo, la respuesta es sencilla: porque es el reflejo de la cultura que representa, y los bienes etnográficos no dejan de tener un sentido testimonial e ilustrativo de la diversidad cultural, además del sentido utilitarista, por cuanto cada objeto suele tener una función y ha sido construido para realizar una tarea. 
El último tercio del siglo XIX es un periodo esencial desde el punto de vista museológico en general, y de la museología etnográfica en particular, por dos razones: por un lado, se multiplican los museos de todas las disciplinas en Europa y Norteamérica y, por otro, la etnología se convierte en un gran campo de estudio como consecuencia tanto de la expansión colonial europea como de la necesidad de salvaguardar las diferentes culturas tradicionales europeas que la revolución industrial había empezado a destruir. Paulatinamente la etnología y la antropología dejan de ser secciones de los Museos de Historia Natural y conquistan un espacio propio que pasará de ser concebido como gabinete de curiosidades y/o cámara de las maravillas a funcionar como un auténtico museo.

Reflejo de la importancia que se le ha ido otorgando de forma progresiva al patrimonio etnográfico, han proliferado numerosas instituciones museísticas diseminadas por todo el mundo que han facilitado y favorecido su conservación. Por ello, los museos etnográficos cobran ahora una especial atención ante el riesgo de desaparición y conservación del patrimonio etnográfico.

El museo etnográfico, una tipología que parte de la conjunción de la museología de la idea y del objeto, se ha denominado con multitud de apelativos que no tienen por qué ser sinónimos: museo del hombre, museo de las ciencias del hombre, museo de etnología, museo de arte popular, museo del pueblo, museo de artes y oficios tradicionales, museo de costumbres y tradiciones, museo de artes y tradiciones populares, museo de la vida y las costumbres tradicionales, museo del folklore, ecomuseo, museo de la memoria, museo de la civilización, museo étnico, museo etnológico, museo de identidad, museo de antropología, etc.

Dentro de la diversidad de tipologías museísticas existentes, los museos de etnografía tienen una gran complejidad ante la amplitud etnográfica actual. Tal y como afirma Iñaki Díaz Balerdi, "la desbocada fiebre de creación de nuevos museos encuentra su ejemplificación en lo acaecido con el llamado patrimonio etnográfico puesto que, hoy en día, cualquier geografía se ve trufada de un sinfín de museos que recogen las peculiaridades de determinados grupos humanos y de sus formas de vida" (Díaz 2008: 65). Por este motivo, los museos etnográficos resultan polémicos en función del papel que tienen que desempeñar pues algunos de los denominados museos etnográficos son, como dice Concha Casado: "el desván de la abuela". Pero, aunque hay muchos "desvanes de la abuela" (habitaciones, locales y casas donde se colocan y acumulan un montón de objetos) y colecciones etnográficas, son pocos los museos etnográficos verdaderos que cumplen las funciones asignadas por definición de ICOMOS a toda institución museística.

Ahora bien, la importancia no radica sólo en la introducción del patrimonio en el museo con el fin de conservarlo o en la creación de numerosos museos etnográficos sino en la puesta en marcha y funcionamiento de los mismos. Por ejemplo, conviene evitar que los museos etnográficos se conviertan en desvanes de la abuela o en mausoleos llenos de objetos polvorientos, de interés casi exclusivamente para expertos, caros de mantener y difíciles de renovar. Porque no es lo mismo un museo de bienes tradicionales que un museo tradicional o anclado en la museología tradicional.

\section{Museos etnográficos: objeto, no objeto y sujeto}

En esencia se trata de pasar del objeto de museo al objeto del museo. Tener un buen proyecto museológico y una metodología adecuada son las claves para que un museo no sea un simple contenedor o escaparate de objetos sino una institución en la que sus piezas transmitan ideas y trasciendan la condición material de tal manera que sea un museo del objeto, del no objeto y del 
sujeto. La principal tarea de estos museos no es la contextualización del arte sino la contextualización de las ideas culturales y sociales que el patrimonio etnográfico posee ya que coadyuva a explicar costumbres, creencias, pensamientos, tradiciones... Para Gombrich lo material y lo inmaterial están irremediablemente unidos:

"Las costumbres, los oficios y, por supuesto, las leyendas y creencias comunes a la tribu van íntimamente unidos al lenguaje y a las formas del pensamiento de cualquier civilización" (Gombrich 2004: 75).

Se trata de una relación recíproca pues el objeto contribuye a configurar el contexto y, a su vez, el contexto dota de pleno significado al objeto. Por ello, algunos problemas graves en los museos son el ingreso de objetos descontextualizados -de ahí la importancia de la documentación, la catalogación y la investigación-, la pérdida del valor contextual de una pieza al introducirla en un museo, la falta de un discurso lógico que permita un mejor y mayor conocimiento y reconocimiento de los fondos, la ausencia de actividades interdisciplinares...

En los museos etnográficos, la colectividad está por encima de la individualidad de una pieza o un autor como puede ocurrir en los museos de Bellas Artes. Un objeto aislado ofrece una muestra empobrecedora para su valoración cultural corriendo el peligro de caer en el fetichismo, mientras que lo verdaderamente importante es establecer relaciones entre el objeto con otros objetos y entre el objeto y el sujeto. Para ello es necesario observar y analizar críticamente los objetos que forman parte de un conjunto ordenado y un contexto colectivo de recursos materiales y técnicos (sirva de ejemplo las grabaciones sonoras y audiovisuales de las voces de los testigos vivos que utilizaron y convivieron con los objetos etnográficos).

Los museos etnográficos deben hacer algo para explicar no sólo los objetos que albergan sino también la vida y la cultura que hay tras las piezas. En el pasado esa cultura era conservada, transmitida y absorbida en gran medida en casa y en la calle pero ahora hay que conservar la existencia y la esencia del patrimonio etnográfico evitando que los objetos caigan en el desconocimiento y sean objetos desconocidos e intentando que formen parte de nuestra memoria por lo que el museo debe potenciar su conservación, conocimiento y reconocimiento (hay que conservarlos, conocerlos, entenderlos, valorarlos y apreciarlos).

El patrimonio etnográfico, entendido tanto en su variante material (objeto) como inmaterial (no objeto) tiene muy presente al ser humano (sujeto); de tal manera que la musealización del patrimonio etnográfico ha posibilitado la unión objeto-no objeto-sujeto pues los bienes culturales etnográficos constituyen un Patrimonio que debemos conservar, conocer, cuidar, valorar, proteger y difundir. El objeto etnográfico es el que primero se percibe por su carácter material pero sabemos que existe una idea que lo genera que es intangible y una persona o sujeto que lo ideó, creó y utilizó.

Los objetos, las ideas que éstos proporcionan sobre los aspectos intangibles y las personas que los crearon y utilizaron merecen ser igualmente musealizadas pues aportan información valiosa y fiable de la realidad. Son objetos que están humanamente concebidos, que cubren necesidades materiales e inmateriales concretas sin pretensión de convertirse en obras de arte, y que evocan la intrahistoria y la microhistoria de la humanidad.

Lo ideal sería concebir estos centros museísticos aunando la museología del objeto y la museología de la idea que en palabras de Francisca Hernández se diferencian en que "si la museología del objeto viene definida y valorada en relación a los objetos que contiene, cuya exposición suele ir 
acompañada de una pequeña identificación y de una información muy elemental que hace posible su interpretación y el goce de su contemplación, la museología de la idea, por el contrario, hace hincapié en su función divulgativa del patrimonio como una posible oferta cultural frente a otras muchas que se le presentan al visitante" (Hernández 1998: 198).

En general, "Todos sabemos que los museos exponen objetos materiales y que ésta es su característica esencial y peculiar. (...) La cultura material está constituida por los objetos, por cualquier objeto al que suponemos portador de una información en sí mismo. Este hecho le da valor de documento con unas características determinadas. De la materia de que esté hecho, de su forma, de su decoración, podemos deducir el uso que tuvo en su momento ya fuera doméstico o ritual, militar o funerario, etc. Al ser el objeto de respuesta a la necesidad, sea ésta del orden que sea, económica, técnica, social, política, religiosa, estética..., que va a decidir sus características materiales, podemos partir de estas para deducir las necesidades que satisfizo" (García 1988: 7). Partiendo de la dicotomía ¿los objetos son museables porque están en los museos o están en los museos porque son objetos museables?, es interesante la siguiente reflexión:

"Objetos obsoletos que colocados en un determinado contexto nos marcan los hitos de desarrollo humano. ¿Qué otra cosa es un museo? Da igual que los objetos sean elementos de tecnología doméstica o pinturas; ambos nos descubren la esencia de nuestra especie: la evolución del conocimiento" (Santacana y Hernández 2006: 67).

\section{La conservación en los museos}

Teniendo en cuenta las definiciones funcionalistas de los museos, la primera función del museo es coleccionar y conservar objetos, la segunda es la exhibición de las piezas y la tercera es procurar una proyección sociocultural.

Durante demasiados años, los espacios museísticos se han ido creando en función de las tareas a las que estaban destinados, de modo que, hasta ahora, la museología había analizado el museo como un conjunto de funciones que se llevan a cabo en espacios especializados, es decir: la función de conservación se llevaba a cabo en un espacio dedicado a la misma; la de exposición, en la sala de exposiciones; la de investigación, en el espacio de investigación; etc. La zonificación espacial se creaba a través de espacios dedicados a las diferentes funciones que se desarrollan dentro de los museos (exposición, conservación, restauración, investigación, divulgación, educación, ocio, etc.). Sin embargo esta identificación entre espacio museal y función teórica no siempre se corresponde con la realidad.

A partir del siglo XXI, se entiende que el museo se divide en áreas donde se llevan a cabo diversas actividades relacionadas con diferentes funciones; por ello sus características ya no responden a necesidades funcionales, sino a los procesos museológicos concretos que se desarrollan en cada una y a la presencia o no en las mismas de piezas o público. Actualmente, la idea de que a cada función museológica corresponde un espacio funcional concreto ha sido superada. Aunque en la mayoría de las clasificaciones está implícita la idea de que cada función museológica se debe corresponder con un espacio arquitectónico concreto, teóricamente, en la actualidad, las zonas del museo se dividen -según la accesibilidad del público y la presencia o no de las piezas en cada espacio- en cuatro áreas: área de público (sólo público), área semipública (piezas y público), área privada (no público, no piezas) y área de semiprivada (piezas, no público). 
En suma, las áreas espaciales de los museos se suelen dividir en función de dos criterios: los procesos museológicos que tienen lugar en cada una de ellas (espacio funcional-función teórico/práctica) y la presencia de visitantes o de piezas en las mismas (espacio sujeto-objetual). Ambas posturas museológicas no tienen porqué ser contrarias ni contrapuestas. De hecho, la conjunción entre dichos criterios museológicos (espacio-funcional y sujeto-objetual) es posible y factible.

Sin duda, la conservación del patrimonio en los museos se lleva a cabo en todos los espacios sean públicos o privados. Ahora bien, dependiendo de las características de las piezas así como de la existencia y afluencia o no de los visitantes los parámetros de conservación varían para ajustarse a las características propias del espacio en el que se ubican (existen diferencias notables entre las medidas de conservación llevadas a cabo en las salas de exposición, en los almacenes, en las salas de cuarentena...). Es más, dentro de los museos, los espacios con colección requieren unas condiciones técnicas especiales que no tienen que mantenerse en los espacios sin colección.

Dentro de los espacios con colección la conservación del patrimonio etnográfico en los espacios no expositivos, como los almacenes o las salas de cuarentena, es más fácil que en los espacios expositivos por dos razones: en los primeros las visitas son restringidas y/o inexistentes y sólo suele estar el personal del museo y, además, se pueden colocar las piezas por familias y materiales. Este último hecho dificulta la conservación en las salas expositivas ya que los parámetros de iluminación, temperatura y humedad difieren dependiendo del tipo de piezas y de los materiales de las mismas: cerámica, textil, madera, cuero, metal, corcho, etc.

En cuanto al patrimonio etnográfico inmaterial, una de las medidas de conservación llevada a cabo en el ámbito museístico es la digitalización de soportes ya obsoletos realizada con el fin de garantizar la supervivencia de los contenidos y paliar el seguro deterioro de una copia en soporte magnético ante su uso o el paso del tiempo. La digitalización se suele completar almacenando los contenidos en soportes ópticos y conservando las copias en distintos medios como discos duros externos o los servidores de los museos.

Precisamente la principal diferencia que existe entre una colección museográfica y un museo es la funcionalidad, pues la colección museográfica se centra en la recopilación, la conservación y la exhibición, mientras que el museo además de reunir, conservar y exponer se ocupa de tres pilares básicos de la nueva museología: ordenar y clasificar, documentar e investigar, y difundir y enseñar. El museo se concibe como un centro cultural multidisciplinar y multifuncional (conservación, restauración, documentación, catalogación, exhibición, educación, divulgación e investigación).

Dentro de los museos suelen existir diferentes departamentos encargados de cada una de las funciones. Generalmente, la tarea innata del departamento de conservación es la salvaguarda y el control del estado de conservación de las colecciones del museo.

Indudablemente, la prevención es la mejor conservación y lo esencial es lograr un equilibrio entre la conservación de las piezas y su exhibición teniendo en cuenta que el mayor peligro se produce en los diferentes momentos de manipulación de las mismas. Desde mediados del XX existen unos estándares en conservación preventiva que han permitido la unificación de criterios y han favorecido el préstamo de las obras. En relación a la temperatura y la humedad relativa, los valores indicados son: de 19 a $24^{\circ} \mathrm{C}$ de temperatura y alrededor de $55 \%$ de humedad relativa. En cuanto a la iluminación, los niveles de luz en función de las obras deben oscilar entre 50 y 300 lux. 
En el museo se tienen en cuenta una serie de factores que influyen en la conservación como: temperatura, iluminación y humedad. Para una correcta conservación se deben evitar: una humedad relativa demasiado alta, demasiado baja o cambiante y una temperatura demasiado alta o cambiante. Dentro de la iluminación se debe tener en cuenta: la limitación de la iluminancia, la eliminación de la radiación ultravioleta y la limitación del tiempo de exposición. En cuanto a la contaminación los factores fundamentales son: la contaminación exterior, la contaminación interior, los contaminantes intrínsecos a las obras y el polvo.

A esto se suma la elección de los soportes empleados para exponer y almacenar las piezas que deben procurar la conservación óptima de las mismas. Los sistemas expositivos (vitrinas contenedoras, muros expositores, tarimas, peanas...) no sólo articulan los espacios favoreciendo el discurso museológico y la circulación del público, sino que también deben respetar y favorecer la conservación de las diferentes piezas. En el caso de los almacenes, a la hora de diseñar y elegir las unidades de mobiliario y los contenedores de almacenamiento se debe tener en cuenta las características de las piezas tales como medidas, formatos y materiales. Por ejemplo, el uso de estanterías abiertas regulables de metal, de distintas anchuras y alturas, con baldas que se fijan en bastidores de metal perforados es muy útil para una colección etnográfica, compuesta de materiales varios; siempre y cuando el almacén sea hermético, esté climatizado y cuente con sistemas de ventilación artificial filtrada que proteja a las piezas del polvo. Junto a esto, el sistema de almacenaje móvil es muy eficaz, útil y rentable ya que permite multiplicar el espacio en caso de crecimiento y tiene numerosas ventajas como: la necesidad de un solo pasillo para deambular, el aprovechamiento del espacio, el cerramiento compacto y hermético, o la existencia de una amplia gama de posibilidades en el diseño interior de las unidades -estantes, soportes cilíndricos sobre guías deslizantes, cajones de diversas alturas con o sin fondo, e incluso plataformas para grandes formatos-.

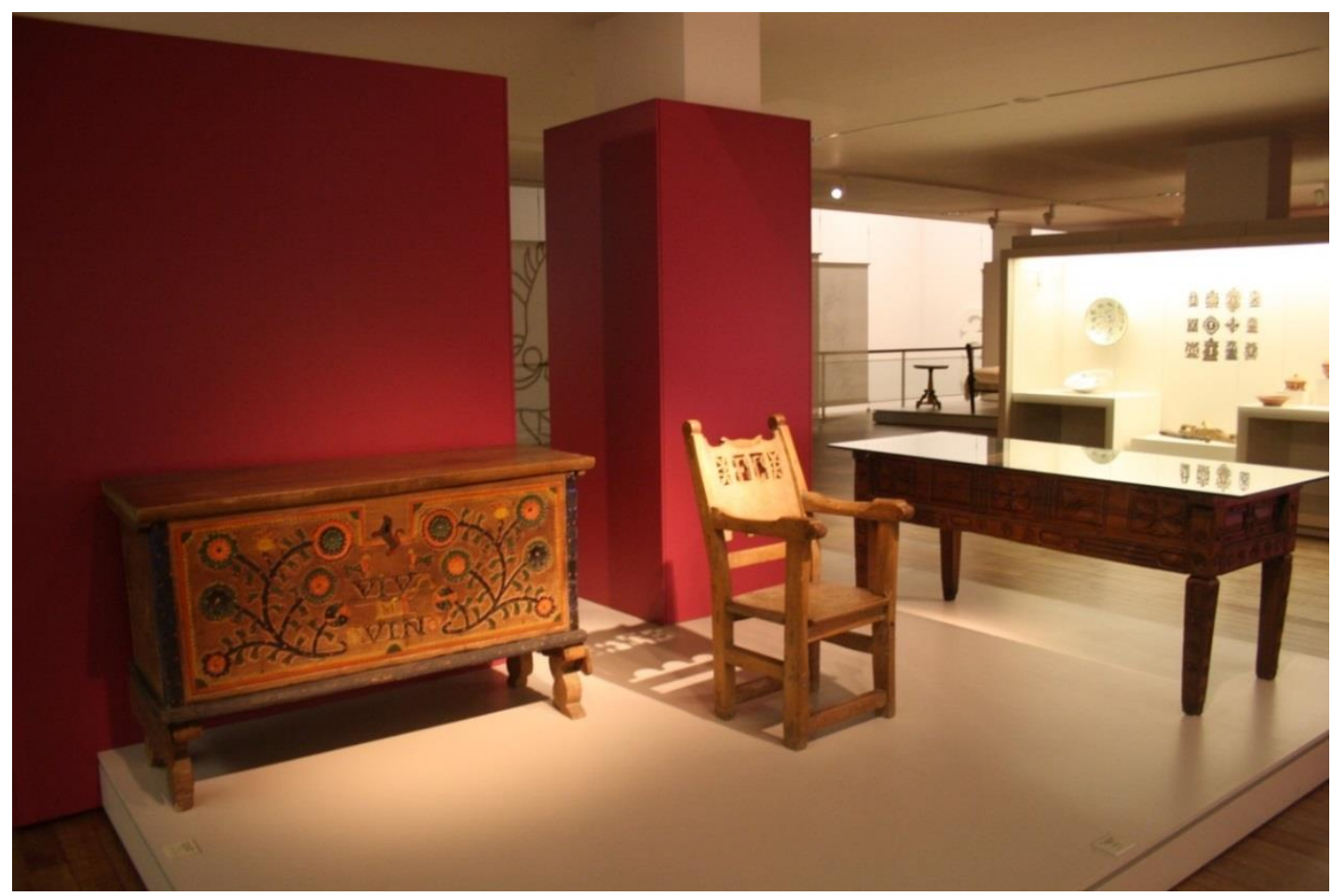

Figura 1: Sala de exposición del Museo Etnográfico de Castilla y León. @Blanca Flor Herrero Morán. 


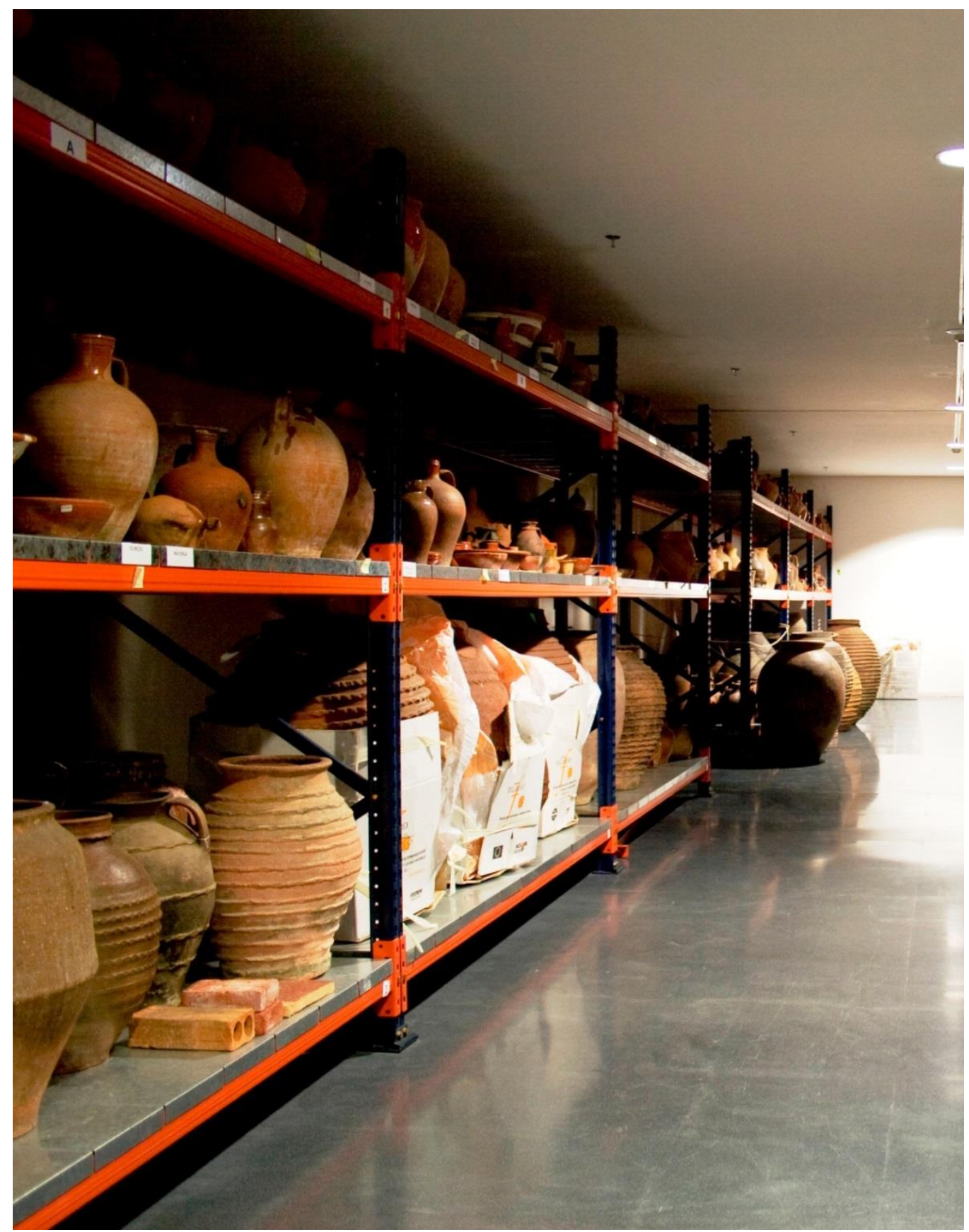

Figura 2: Almacén del Museo Etnográfico de Castilla y León. @Blanca Flor Herrero Morán.

El mantenimiento de cualquier tipo de patrimonio plantea unas dificultades que nacen tanto de su propia naturaleza, como de la falta de su conocimiento y de la inexistencia de instrumentos legales, económicos y sociales que permitan su conservación y rehabilitación. Este hecho se magnifica en el caso del patrimonio etnográfico pues los estudios o inventarios existentes sobre dicho patrimonio son insuficientes y la desaparición de los modos de vida y del patrimonio que testimonia los mismos les hacen especialmente vulnerables. A su vez dado que el patrimonio etnográfico cuenta con bienes materiales e inmateriales su conservación es realmente compleja pues el patrimonio tangible por su carácter material se conserva más fácilmente que el intangible. 
Tabla 1: Esquema: La conservación del patrimonio etnográfico a través de la musealización

\begin{tabular}{|c|c|}
\hline & LA CONSERVACIÓN DEL PATRIMONIO ETNOGRÁFICO A TRAVÉS DE LA MUSEALIZACIÓN \\
\hline \multicolumn{2}{|c|}{ Proceso de conservación del patrimonio etnográfico } \\
\hline \multicolumn{2}{|r|}{ Recelo por el progreso: se conserva el patrimonio etnográfico } \\
\hline \multicolumn{2}{|r|}{ - $\quad$ Admiración por el progreso: se permuta el patrimonio etnográfico por objetos nuevos o por dinero } \\
\hline- & $\begin{array}{l}\text { Valoración del patrimonio etnográfico (estética, histórica y cultural): se conserva, se colecciona y se } \\
\text { musealiza el patrimonio etnográfico }\end{array}$ \\
\hline \multicolumn{2}{|c|}{ Proceso de musealización del patrimonio etnográfico } \\
\hline \multicolumn{2}{|r|}{ - El patrimonio etnográfico se conserva ante el riesgo de desaparición } \\
\hline \multicolumn{2}{|r|}{ - $\quad$ El patrimonio etnográfico es considerado un bien museable } \\
\hline & $\begin{array}{l}\text { La principal dificultad es distinguir las piezas con valor etnográfico que deben ser musealizadas y crear } \\
\text { instituciones que sean auténticos museos }\end{array}$ \\
\hline \multicolumn{2}{|c|}{ Museos etnográficos: objeto, no objeto y sujeto } \\
\hline \multicolumn{2}{|r|}{ - Se pasa del objeto de museo al objeto del museo } \\
\hline \multicolumn{2}{|r|}{ - El patrimonio etnográfico material e inmaterial tiene un valor colectivo que está por encima del individual } \\
\hline- & $\begin{array}{l}\text { Los museos etnográficos deben aunar la museología del objeto y de la idea y conservar el objeto, el no } \\
\text { objeto y el sujeto }\end{array}$ \\
\hline \multicolumn{2}{|c|}{ La conservación en los museos } \\
\hline \multicolumn{2}{|r|}{ - Los criterios museológicos espacio-función y objeto-sujeto son perfectamente compatibles } \\
\hline \multicolumn{2}{|r|}{ - $\quad$ La conservación del patrimonio en los museos se lleva a cabo en todos los espacios } \\
\hline- & $\begin{array}{l}\text { La conservación del patrimonio etnográfico en los museos es compleja por la conjunción existente en } \\
\text { bienes tangibles e intangibles. }\end{array}$ \\
\hline
\end{tabular}


Otra dificultad añadida dentro de la conservación del patrimonio etnográfico son los bienes inmuebles por ser obras que ocupan un determinado espacio y que no pueden ser trasladadas de un lugar a otro, ya sea porque son estructuras (edificaciones), o porque están en inseparable relación con el terreno (sitios arqueológicos). Se trata de bienes que no se pueden introducir en un museo y que debido a la falta de protección y conservación están desapareciendo a un ritmo vertiginoso.

Dado que las piezas etnográficas son bienes heredados y legados de los antepasados debemos potenciar la conservación del patrimonio etnográfico y reflexionar sobre los diferentes modelos que permiten dicha acción entre los que destaca la musealización a través de la puesta en marcha y funcionamiento de los museos etnográficos.

\section{Bibliografía}

ALONSO, J. L. (2002). "Los objetos al servicio del hombre. Enseres". En Catálogo de la Exposición Enseres del Museo Etnográfico de Castilla y León. Zamora: Museo Etnográfico de Castilla y León, 154-159.

DÍAZ, I. (2008). La memoria fragmentada. El museo y sus paradojas. Gijón: Trea.

DÍAZ, J. (1992). La memoria permanente. Reflexiones sobre la tradición. Salamanca: Ámbito.

FERNÁNDEZ, J. (1996). Introducción a la conservación del patrimonio y técnicas artísticas. Barcelona: Ariel.

FONTAL, O. (2003). La educación patrimonial. Teoría y práctica en el aula, el museo e Internet. Gijón: Trea.

GARCíA, Á. (1988). Didáctica del museo: el descubrimiento de los objetos. Madrid: Ediciones de la Torre.

GARCÍA, M. P. (2009). Humilde condición. El patrimonio cultural y la conservación de su autenticidad. Gijón: Trea.

GOMBRICH, E. H. $(2003,1950)$. Historia del arte. Madrid: Random House Mondadori.

-(2004, 1969). Breve Historia de la Cultura. Barcelona: Península.

GONZÁLEZ-VARAS, I. (2006). Conservación de Bienes Culturales. Teoría, Historia, Principios y Normas. Madrid: Cátedra.

HERNÁNDEZ, F. (1998). El museo como espacio de comunicación. Gijón: Trea.

-(2002). El patrimonio cultural: la memoria recuperada. Gijón: Trea.

MACARRÓN, A. M. (2008). Conservación del Patrimonio Cultural. Criterios y normativas. Madrid: Síntesis.

MARCOS, J. (2008). Objetos, sujetos e ideas (Bienes etnológicos y memoria social). Badajoz: Diputación de Badajoz.

PANOFSKY, E. $(1985,1955)$. El significado de las artes visuales. Madrid: Alianza.

RODRÍGUEZ, S. (1992). "Conservación y divulgación del patrimonio etnográfico. El papel de los museos". En Actas do I Congreso Internacional de Cultura Galega, Vigo: Consellería de Cultura e Xuventude. Xunta de Galicia, 313-325.

SANTACANA, J. y HERNÁNDEZ, F. X. (2006). Museología crítica. Gijón: Trea.

WATTENBERG, E. (1995). "Patrimonio Cultural de Castilla y León". En Historia de una cultura. Castilla y León en la Historia de España. Valladolid: Junta de Castilla y León. Consejería de Cultura y Turismo, 479-568. 


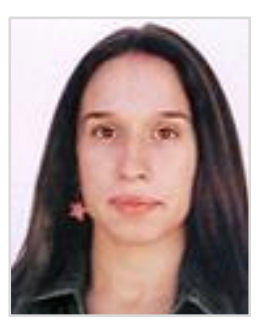

\section{Blanca Flor Herrero Morán}

blancaflorhm@hotmail.com

Doctora en Historia del Arte con la tesis titulada: "El Museo Etnográfico de Castilla y León: patrimonialización y musealización", y Licenciada en Historia del Arte por la Universidad de Salamanca. Actualmente es coordinadora de varios grupos de trabajo sobre el patrimonio etnográfico de Castilla y León en el CFIE de Zamora, y profesora de enseñanza secundaria de la especialidad de geografía e historia en Castilla y León. Ha obtenido la beca del Ministerio de Educación y Ciencia "Recuperación y Utilización Educativa de Pueblos Abandonados" en Granadilla (Cáceres), y la beca de colaboración para Licenciados en Historia del Arte con el Gabinete de Comunicación y Protocolo de la Universidad de Salamanca. Tambien obtuvo una beca de formación del personal investigador (FPI) con la Universidad Salamanca. Junta de Castilla y León, y otra beca de Investigación de la Fundación Villalar de Castilla y León para el trabajo: El Museo Etnográfico de Castilla y León: una seña de identidad".

Artículo enviado el 06/08/2013

Artículo aceptado el 26/11/2013 
Reseñas 


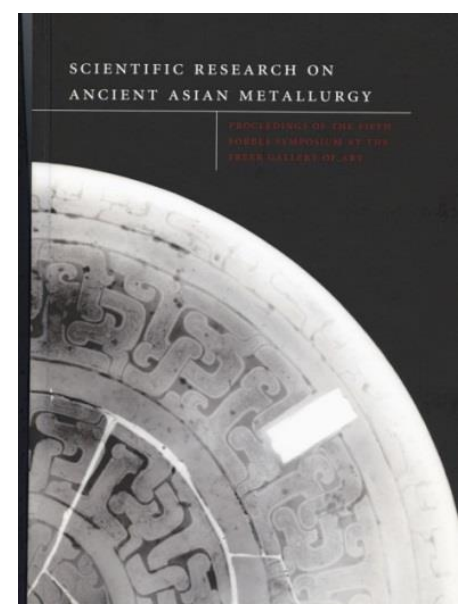

\author{
Scientific Research on Ancient Asian Metallurgy. Proceedings of the \\ Fifth Forbes Symposium at the Freer Gallery of Art \\ Editado por P. Jett, B. McCarty and J. G. Douglas
}

Publicado por Archetype Publications Ltd. and Freer Gallery of Art, Smithsonian Institution. London, Los Angeles, 2012.

268 páginas, $297 \times 210 \mathrm{~mm}$.

ISBN. 9781904982722

El libro editado P. Jett, B. McCarty y J. G. Douglas es un volumen técnico que recopila las ponencias del quinto Simposio organizado en 2009, coincidente con la exposición "Goods of Angkor: Bronzes from the National Museum of Cambodia" de la Sackler Gallery y la apertura de galerías de bronces chinos diseñadas de nuevo en la Freer Collection.

El volumen se divide en cuatro apartados: "Reflexiones de R. J. Gettens y estudio técnico de los bronces chinos", "Los bronces chinos", "Los bronces del sudeste asiático" y "Las aleaciones de cobre en Asia Occidental". El primero supone un homenaje a los antecedentes históricos de los estudios presentes, cuyas ponencias se presentan en las siguientes secciones agrupadas por procedencias y tipologías.

En la revisión histórica se refleja la admiración que suscita la figura de Rutherford John Gettens, que dice de sí mismo qué: "No fue difícil para un químico caer bajo el hechizo de la metalurgia Oriental de la Antigüedad" Desde su ingreso en el laboratorio del Museo Fogg en 1928 se interesó por entender los fenómenos de corrosión de los objetos metálicos patrimoniales publicando numerosos artículos, hasta qué, en 1969, escribiera el libro titulado "The Freer Chinese Bronzes. Vol. 2. Technical Studies". La comprensión del citado volumen incluye una labor de búsqueda en los archivos de la Institución para conocer el equipamiento de que disponía en su trabajo, quienes eran sus colaboradores, las fichas que reflejaban los resultados de los análisis, la documentación fotográfica ilustrativa, etc.

Los objetivos prioritarios del Simposio son: poner de manifiesto la relevancia de los estudios técnicos en la historia del arte, así como la historia de la tecnología, y los avances que se han producido en el transcurso de los últimos años a este respecto.

Una de las ponencias del apartado que estudia los bronces chinos ofrece una revisión crítica de las investigaciones de la metalurgia del bronce en el norte de Asia y cuál era la región que jugó un papel crucial en su desarrollo. Otra, muestra los resultados de análisis recientes de bronces procedentes de excavaciones. Un tercer artículo examina la corrosión de los espejos decorativos chinos, hechos en bronce. Los especialistas del Museo Británico han realizado también estudios técnicos sobre las vasijas Gui del Periodo Zhou, que incluyen radiografía, difracción de rayos X y microscopía electrónica de barrido acoplada a un espectrómetro de rayos $X$. Las transformaciones de las imágenes budistas en bronce se han examinado a través de la radiografía. 
En la parte concerniente a los bronces del sudeste asiático, el primer artículo se ocupa de la evolución de la metalurgia del estaño en el bronce en relación con el intercambio comercial que tuvo lugar en Eurasia en la Edad Odel Bronce. Un segundo artículo analiza la alta proporción de estaño que contienen los bronces en Tailandia. Hay también constancia de un proyecto desarrollado en el sudeste asiático sobre los isótopos de plomo existentes en bronces antiguos de esta región. Por medio de la espectroscopía de emisión atómica por inducción de plasma se ha estudiado un corpus de objetos seleccionados del museo nacional de Camboya. Se evalúan también los componentes de las distintas aleaciones procedentes de los cuatro periodos más relevantes en la edad del bronce en el norte de Vietnam.

La metalurgia de base cobre de Asia Occidental de la última sección refleja importantes innovaciones que tuvieron lugar frente al resto de Eurasia en relación con la difusión de esta tecnología a lo largo de diez milenios. Otro artículo, demuestra que recientes excavaciones en Mesopotamia han supuesto un estudio multidisciplinar que muestra variaciones significativas de cinc en las aleaciones encontradas en las piezas. Un tercero se refiere a como la tecnología de la cerámica y los metales en la antigüedad, debido a la estrecha relación existente entre la porcelana utilizada en los crisoles y la fundición del cobre en Irán. Un estudio se ocupa de los recientes descubrimientos sobre el Calcolítico medio en Azerbaiyán. Las técnicas de las grandes estatuas antiguas de bronce hechas con moldes "a la cera perdida" del sur de Arabia condicionaban la composición de la aleación y el espesor del metal. El último artículo se refiere a las aleaciones de cobre usadas en la cultura islámica medieval.

Este volumen va dirigido a los conservadores-restauradores, arqueólogos y científicos de la conservación especializados en los bienes culturales a los cuales suministra la más reciente y cuantiosa información científico-técnica. Los estudios ofrecen abundantes gráficos y tablas de los resultados experimentales que pueden resultar muy interesantes a los especialistas en estos temas.

\author{
Marisa Gómez González \\ Instituto del Patrimonio Cultural de España
}




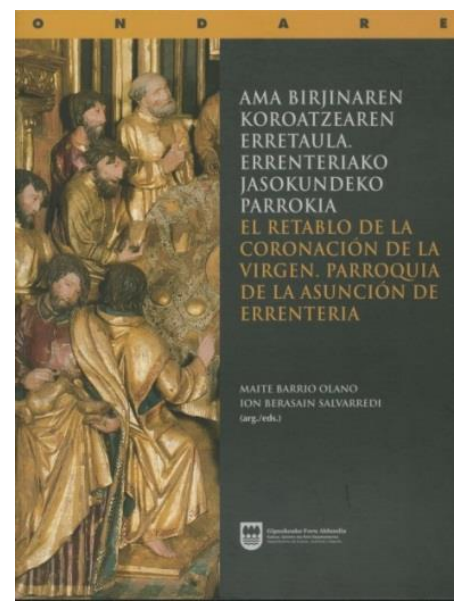

\section{El Retablo de la Coronación de la Virgen. Parroquia de la Asunción de Errentería}

Ama Birjinaren Koroatzearen Erretaula. Errenteiako Jasokundeko

Parrokia.

Colección Ondare. Editado por Diputación Foral de Guipuzkoa.

Andoain, 2013.

208 páginas, $290 \times 230 \mathrm{~mm}$.

ISBN. 9788479076962

El libro constituye una monografía dedicada al Retablo flamenco de la Coronación de la Virgen, situado en la Parroquia de la Asunción de Errentería. Los textos fueron recogidos durante la restauración y el estudio del retablo realizados por la empresa "ALBAYALDE S.L.", en colaboración con especialistas del Instituto real de Patrimonio artístico de Bruselas y la Universidad Libre de Bruselas y han sido publicados por la Diputación Foral de Gipuzkoa, dentro de su colección Ondare.

Los principales interesados en esta monografía sobre el estudio y la restauración del retablo brabanzón de Errentería son los conservadores-restauradores, los historiadores y los científicos dedicados al estudio del Patrimonio Cultural. Sin embargo los distintos especialistas que han intervenido en este volumen han sabido introducir los conceptos esenciales necesarios para facilitar la comprensión de los textos y hacer grata su lectura. Esto hace que resulte una herramientas útil y atractiva para cualquiera de los profesionales mencionados, incluyendo además a estudiantes, estudiosos y aficionados que quieran acrecentar sus conocimientos sobre los Bienes Culturales.

El retablo de La Coronación de la Virgen, es uno de los escasos retablos flamencos importados de Flandes que se encuentran actualmente en buen estado de conservación en la Península Ibérica. Es además una joya del patrimonio retablístico de Guipúzcoa procedente de Bruselas y datado en 1528, declarada Bien Cultural por el Gobierno Vasco en el año 2000.

La restauración, realizada en 2009-2010, permite admirar su belleza y ha sabido recuperar en lo posible el aspecto inicial de la obra, que había sido modificado en múltiples ocasiones.

El libro se estructura en diez capítulos: "Introducciones", "Reseña histórica", "Estudio y ensayo de atribución", "Estudio tecnológico del soporte", "Medidas, proporciones y huellas de herramientas", "El retablo de la Coronación de la Virgen bajo la lupa del dendrocronólogo", "Historia de la investigación de la policromía de esculturas y objetivos de la restauración", "Estudio técnico de la policromía en una perspectiva comparativa", "Las lacas rojas de los siglos XV y XVI: el caso específico del Retablo de la Coronación de la Virgen en Errenteria" e "Intervención de restauración".

La Introducción se subdivide en dos apartados. Cathéline Perier d'leteren Doctora en Historia del Arte y profesora de la Universidad Libre de Bruselas, escribe sobre "Los retablos brabanzones esculpidos de puertas pintadas" encuadrando los aspectos relacionados con su producción a lo largo de los siglos XV y XVI, la fascinación que originaron en las cortes europeas, en las órdenes religiosas y en la burguesía adinerada en Europa. "Los retablos brabanzones y su expansión en 
España" es el segundo apartado abordado por Maite Barrioe lon Berasain, codirectores de ALBAYALDE S.L., Conservadores - restauradores de Bienes Culturales y Licenciados en Historia del Arte. El texto explica como los estrechos vínculos entre la corona de Castilla y los Países Bajos influyeron sobre la importación de estos retablos.

La "Reseña histórica" del retablo de Maite Barrio e Ion Berasain, conocido también con el nombre de "altar de las Ánimas", lo sitúa en la parroquia de la Asunción de la villa de Errentería, describe su ubicación en la iglesia y la ausencia de documentos relacionados con su origen y las menciones sucesivas de historiadores a través de los siglos. Catheline. Périer d'leteren ha tomado como puntos de partida la descripción iconográfica y el análisis estilístico para hacer el "Estudio y ensayo de atribución" del retablo, encuadrándolo en el taller de producción de los Borman originario de Bruselas.

Los estudios del soporte se contemplan desde diferentes perspectivas. Ion Berasaín, examina los aspectos constructivos y las diferentes modificaciones estructurales sufridas. Especialistas belgas, tales como Jean-Albert Glatigny, conservador-restaurador experto en el estudio y tratamiento de los soportes de madera, colaborador del Institut Royal du Patrimoine Artistique (IRPA) y de instituciones y museos nacionales y europeos y norteamericanos, que analiza las medidas y proporciones y las huellas de instrumentos empleados para tallar la madera y ensamblar los elementos constructivos. Pascale Fraiture, Doctora por la Universidad de Lieja, que trabaja en el IRPA en el departamento de dendrocronología y estudio de la madera, muestra la metodología de trabajo usada en la datación del retablo por este procedimiento.

Myriam Serk-Dewaide, Licenciada en Historia del Arte, directora del IRPA (1995-2011) y jefe del departamento de esculturas de la misma institución (1986-1995), hace un resumen histórico de la investigación sobre la policromía en la escultura, centrada en la evolución de la metodología y los criterios de su institución en paralelo con su entorno europeo. Maite Olano contempla los aspectos visuales del retablo de Errentaría que le permiten describir la ejecución de las técnicas decorativas y la combinación de elementos que interviene en los delicados diseños ornamentales de la policromía. Jana Sanyova, doctora en Ciencias Químicas e investigadora del IRPA especializada en técnicas pictóricas y de policromía antiguas, completa el análisis de la policromía y contempla la identificación de los componentes de las veladuras rojas del Retablo de la Coronación de la Virgen en Errentería en relación con las lacas rojas empleadas en Europa en los siglos XV y XVI.

El capítulo final escrito por Maite Barrio e Ion Berasain está dedicado a la "Intervención de restauración" en el retablo de la Coronación de Errentería. En él se examinan los aspectos más relevantes para realizar el diagnóstico previo a la intervención, como son la historia material y el estado de conservación, que determinan los criterios y la metodología del trabajo de restauración que se ha efectuado finalmente.

La monografía titulada "El retablo de la Coronación de la Virgen. Parroquia de la Asunción de Errenteria" se ve enriquecida con fotografías, gráficos, tablas, cuadros e ilustraciones que contribuyen a la buena presentación y mejor comprensión de la lectura de los textos. El estudio riguroso técnico y estilístico y el trabajo coordinado entre los diferentes especialistas han permitido hacer importantes descubrimientos en cuanto a su técnica y procedencia, sustancialmente valiosos para una obra que carece de documentación histórica y sobre la que hasta ahora existían únicamente hipótesis y atribuciones muy generalistas.

El retablo, singular por su iconografía, dimensiones y calidad innegable de su talla y su policromía, a pesar de ser mencionado en algunas publicaciones, permanecía desconocido en un contexto 
científico internacional. Esperemos que esta publicación abra una puerta a futuras investigaciones. La edición francesa preparada por la Universidad Libre de Bruselas (ULB) está disponible igualmente desde finales del presente año.

Marisa Gómez González

Instituto del Patrimonio Cultural de España 


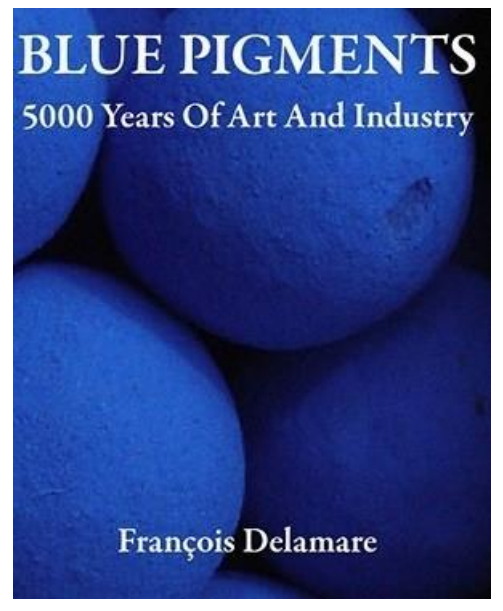

\author{
Blue Pigments. 5000 years of Art and Industry \\ François Delamare \\ Edición original: Bleus en poudres. De l'art à l'Industrie, 5000 ans \\ d'innovations. Ecole des Mines de Paris, 2007. \\ Archetype Publications Ltd., 2013. \\ 442 páginas, $2460 \times 2189 \mathrm{~mm}$.
}

ISBN: 9781904982371

La editorial Archetype amplía su larga lista de publicaciones especializadas en técnicas y materiales artísticos y conservación de bienes culturales con la edición en inglés de la obra de François Delamare, Bleus en poudres. De l'art à l'Industrie, 5000 ans d'innovations, editada en el año 2007 por la Ecole des Mines de Paris. La buena calidad de los títulos seleccionados por esta editorial inglesa constituye una confirmación del interés de esta obra, ya reconocido en la edición original francesa.

La obra de Delamare es un completísimo estudio de los pigmentos azules más importantes de la historia. La búsqueda de pigmentos, naturales o artificiales, que ofrecieran un color azul satisfactorio -en todos los tiempos el azul ha ocupado un lugar particular entre los otros coloresha sido una constante en la historia de la pintura y un permanente reto por la dificultad que siempre ha habido por conseguirlo. Desde las primeras civilizaciones de la Antigüedad se conocían métodos artificiales para su obtención -el azul egipcio, el azul maya, el azul ... de los chinos, así como procedimientos para purificar minerales y extraer la fracción azul -el lapislázuli, la azuritamétodos que irán variando o serán sustituidos por otros según avanzan los siglos, como son los azules de esmalte, las azuritas artificiales, el azul de Prusia, el azul Thenard, el azul Guimet, el ultramar artificial o los ftalocianinos de cobre.

El autor, ingeniero y doctor en Ciencias Físicas, es director de investigación en el Centre en forme des matériaux de l'École des mines en Sophia Antipolis y director del Centre régional d'analyse des matériaux de Alpes-Maritimes. Ya publicó anteriormente un libro sobre pigmentos y colorantes en compañía del ingeniero especialista en colores, Bernard Guineau. En esta obra describe los diferentes procedimientos de fabricación, la historia, la composición de cada pigmento, los usos en cada etapa histórica y su terminología y evolución. Para ello se ha documentado en archivos públicos y bibliotecas, en museos e instituciones, en la industria o mediante encuestas con investigadores especialistas en pigmentos.

De todos ellos aporta importantes datos sobre la historia de su fabricación, su comercio y distribución o sobre su terminología. Delamare se apoya en fuentes literarias muy diversas, desde antiguas recetas extraídas de "libros de secretos" a enciclopedias del siglo XVIII y XIX, así como en documentos de archivo de diversa índole, investigaciones arqueológicas o análisis científicos de materiales, dejándonos un interesante y completísimo estudio, de consulta obligada para conocer la historia de los pigmentos azules.

Rocío Bruquetas Galán Instituto del Patrimonio Cultural de España 


\section{www.revista.ge-ilc.com}

Edición digital del GEIIC 